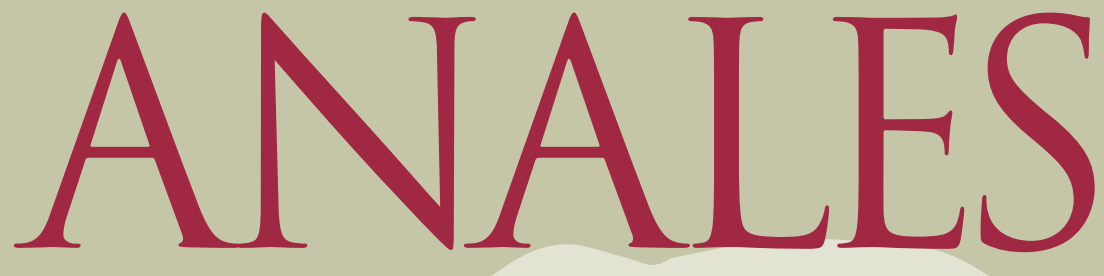

de la Facultad de Derecho

Universidad de La Laguna $38 \quad 2021$ 
Anales de la Facultad de DERECHO 


\section{Anales de la Facultad de DERECHO}

Universidad de La Laguna

DIRECTOR

Andrés Manuel González Sanfiel (ULL)

SUBDIRECTORA

Alicia González Navarro (ULL)

SECRETARIA DE LA REVISTA

Irene Navarro Frías (ULL)

CONSEJO DE REDACCIÓN

Marcel Bonnet Escuela (ULL), Etelvina de las Casas León (ULL), Ulises Hernández Plasencia (ULL), Ruth Martinón Quintero (ULL), Vicente Navarro Marchante (ULL), Margarita I. Ramos Quintana (ULL), María Elena Sánchez Jordán (ULL).

\section{CONSEJO ASESOR}

Andrea Bonomi (Université de Lausanne, Suiza), Martín Diego Farrell (Universidad de Buenos Aires, Argentina), Antonio Fernández de Buján (Universidad Autónoma de Madrid), Tomás López Fragoso (Universidad de La Laguna), María Elvira Méndez Pineda (University of Iceland, Islandia), Manuel Carlos Palomeque López (Universidad de Salamanca), María Ángeles Parra Lucán (Universidad de Zaragoza), Johann-Christian Pielow (Ruhr-Universität Bochum, Alemania), Carlos María Romeo Casabona (Universidad del País Vasco), Esteban Sola Reche (Universidad de La Laguna), Rolando Tamayo Salmarán (Universidad Nacional Autónoma de México), Francisco José Villar Rojas (Universidad de La Laguna), Stefan Vogenauer (Max Planck Institute for Legal History and Legal Theory, Alemania), Katharina Beckemper (Universidad de Leipzig), Juana Pulgar Ezquerra (Universidad Complutense de Madrid).

\section{EDITA}

Servicio de Publicaciones de la Universidad de La Laguna Campus Central. 38200 La Laguna. Santa Cruz de Tenerife Tel.: 34922319198

\section{DISEÑO EDITORIAL}

Jaime H. Vera

Javier Torres/Luis C. Espinosa

\section{MAQUETACIÓN Y PREIMPRESIÓN}

Servicio de Publicaciones

DOI: https://doi.org/10.25145/j.anfade.2021.38

ISSN: 0075-773X (edición impresa) / ISSN: 2530-8319 (edición digital)

Depósito Legal: TF 734/81

Prohibida la reproducción total o parcial de esta obra sin permiso del editor. 


\section{Anales de la Facultad de DERECHO}

38 
ANALES de la Facultad de Derecho de la Universidad de La Laguna. -La Laguna: Universidad, Servicio de Publicaciones, 1991-

Anual

Es continuación de: Anales de la Universidad de La Laguna. Facultad de Derecho.

ISSN: 0075-773X (edición papel); e-2530-8319 (edición digital)

1. Derecho-Publicaciones periódicas I. Universidad de La Laguna. Facultad de Derecho. 34(05)

La correspondencia relativa a la revista debe dirigirse a:

Anales de la Facultad de Derecho

Servicio de Publicaciones

Universidad de La Laguna

Campus Central

38200 La Laguna (Tenerife, España) 


\section{SUMARIO / CONTENTS}

\section{Artículos / Articles}

Reparto territorial, evaluación ambiental e instrumentos excepcionales en la planificación canaria: análisis constitucional (STC 86/2019) / Territorial distribution, environmental assessment and exceptional instruments in Canarian planning: constitutional analysis (STC 86/2019)

$$
\text { Juan Manuel Alegre Ávila. }
$$

Una ley de contratos públicos para tiempos de crisis / A public contracts law for times of crisis

\section{Francisco L. Hernández González.}

La prueba pericial digital y la cadena de custodia / Pericial evidence in crimes committed through computer media and the "chain of custody"

$$
\text { José Miguel González Reyes. }
$$

La situación jurídica de la gestación por sustitución en España / The legal situation of gestation by substitution in Spain

$$
\text { Jagdish Kumar Chulani Raymond... }
$$

La prueba testifical anticipada como instrumento para reducir la victimización secundaria de menores de edad en el proceso penal / The evidence prior to trial as an instrument to avoid the risk of secondary victimation of underage victims in criminal proceedings

\section{Diana Marrero Guanche.}

La responsabilidad de las plataformas de economía colaborativa a la luz de la Ley 34/2002 de Servicios de la Sociedad de la Información / Liability of the collaborative economy platforms in the light of Law 34/2002 on Information Society Services

$$
\text { Nora Rodríguez García... }
$$

La educación cívico-tributaria: una asignatura pendiente y un instrumento necesario contra el fraude fiscal / Civic tax education: a forgotten subject and necessary tool against tax fraud

Sergio Siverio Luis.

\section{CRÓNICA}

Crónica de nuestros maestros y compañeros. Curso 2019-2020 
LAUDATIO

Francisco F. Clavijo Hernández, María del Carmen Sevilla González M. a Victoria Sansón Rodríguez y María Luisa Zamora Rodríguez...

SEMPER SINT IN FLORE

Manuel Morón Palomino y José María Sainz-Ezquerra Foces. 
ARTÍCULOS / ARTICLES 



\title{
REPARTO TERRITORIAL, EVALUACIÓN AMBIENTAL E INSTRUMENTOS EXCEPCIONALES EN LA PLANIFICACIÓN CANARIA: ANÁLISIS CONSTITUCIONAL (STC 86/2019)*
}

\author{
Juan Manuel Alegre Ávila \\ Catedrático de Derecho Administrativo de la Universidad de Cantabria \\ Exletrado del Tribunal Constitucional
}

\section{RESUMEN}

El presente trabajo constituye la ponencia presentada por su autor en la cuarta edición del Máster en Derecho Urbanístico de la Universidad de La Laguna, en la que se da cuenta del pronunciamiento realizado por el Tribunal Constitucional en su sentencia 86/2019 sobre la Ley 4/2017, de 13 de julio, del Suelo y de los Espacios Naturales Protegidos de Canarias. Se analizan algunos de los extremos que fueron objeto de impugnación relacionados con las cuestiones de planificación urbanística y territorial. En particular, de entre los diferentes temas que aborda la sentencia, se expone, desde la adecuación o no a la Constitución, la descentralización operada por la citada Ley en materia de planificación, la regulación de la evaluación ambiental y la introducción de los proyectos de interés autonómico e insulares, como mecanismos excepcionales de ordenación.

Palbras Clave: planificación, evaluación ambiental, mecanismos excepcionales de ordenación.

\section{TERRITORIAL DISTRIBUTION, ENVIRONMENTAL ASSESSMENT AND EXCEPTIONAL INSTRUMENTS IN CANARIAN PLANNING: CONSTITUTIONAL ANALYSIS (STC 86/2019)}

\section{Abstract}

The present work constitutes the paper presented by its author in the fourth edition of the Master in Urban Planning Law of the University of La Laguna about the pronouncement made by the Constitutional Court in its judgment 86/2019 on Law 4/2017, of July 13, on Land and Protected Natural Spaces of the Canary Islands. Some of the extremes that were subject to challenge related to urban and territorial planning matters are analyzed. In particular, among the different issues addressed by the judgment, it is exposed from the adequacy or not to the Constitution, issues such as the decentralization operated by the aforementioned Law in the planning system, the regulation of environmental assessment, and the introduction of projects of regional and insular interest, as exceptional mechanisms of management.

KeYwords: Planning Law, environmental assessment, exceptional mechanisms of management. 


\section{CABILDOS INSULARES Y COMUNIDAD AUTÓNOMA DE CANARIAS: DETERMINACIÓN DEL GRADO DE INTERVENCIÓN EN EL PROCEDIMIENTO DE APROBACIÓN DE LOS INSTRUMENTOS DE PLANIFICACIÓN AMBIENTAL Y DE ORDENACIÓN TERRITORIAL Y URBANÍSTICA}

El fundamento jurídico 9 de la Sentencia del Tribunal Constitucional 86/2019, de 20 de junio [Pleno; ponente: Montoya Melgar; en adelante: Sentencia-suelo canario] examina, en el seno del recurso de inconstitucionalidad número 5049-2017, la impugnación formulada por más de cincuenta diputados del grupo parlamentario Unidos Podemos-En Comú Podem-En Marea en el Congreso de los Diputados contra diversos preceptos del título III de la Ley 4/2017, de 13 de julio, del suelo y de los espacios naturales protegidos de Canarias, en los que se regula «la elaboración y aprobación de los distintos instrumentos de planificación ambiental y de ordenación territorial y urbanística previstos por el legislador canario».

El fundamento de la impugnación se expone así en el primer párrafo del fundamento jurídico 9 de Sentencia-suelo canario:

En esencia, se cuestiona el papel atribuido a los cabildos insulares en la elaboración y aprobación de los instrumentos de planificación ambiental, y la limitación de la intervención autonómica, en relación con todos los instrumentos de planificación ambiental y territorial, a la emisión de un informe, con distinto alcance y contenido. El análisis de la constitucionalidad de los preceptos recurridos se aborda «de forma conjunta [...]: primero, delimitaremos el objeto y el motivo de impugnación de dos grupos de preceptos [A) y B)], para, a continuación, realizar el juicio de constitucionalidad $[\mathrm{C})]$ ».

El primero de los dos grupos de preceptos impugnados aglutina a los artículos 94.3 [«Concepto y objeto-planes insulares de ordenación»] y 102.1 [«Iniciativa-planes insulares de ordenación»] y tiene como hilo conductor la "aprobación por los cabildos insulares de los planes de ordenación de los recursos naturales (planes de ordenación de los recursos naturales)». Las posturas de los recurrentes, de un lado, y del Gobierno y el Parlamento canarios, de otro, se sintetizan así en el último párrafo del apartado A) del fundamento jurídico 9 de Sentencia-suelo canario:

El legislador canario atribuye a los cabildos insulares la competencia para formular, elaborar y aprobar los planes insulares de ordenación, limitando la participación de la comunidad autónoma a la emisión de un informe preceptivo y vinculante. Dado que los planes insulares pueden cumplir la función de planes de ordenación de los recursos naturales, los diputados recurrentes consideran que se vulnera de forma indirecta el artículo 149.1.23. ${ }^{a} \mathrm{CE}$, por infracción de los artículos 17.2 y

* Ponencia presentada en la cuarta edición del Máster en Derecho Urbanístico de la Universidad de La Laguna en el curso 2018-2020. 
22.1 de la Ley 42/2007, de 13 de diciembre, del patrimonio natural y la biodiversidad, que atribuyen la elaboración y aprobación de los planes de ordenación de los recursos naturales a las comunidades autónomas. Las representaciones procesales del Gobierno y del Parlamento canario consideran, con base en las competencias autonómicas de autoorganización, plenamente legítima la decisión del legislador autonómico de atribuir a los cabildos insulares la elaboración y aprobación de los planes de ordenación de los recursos naturales.

El segundo de los dos grupos de preceptos impugnados dice relación con la «limitación de la intervención autonómica en la elaboración y aprobación de los instrumentos de planificación ambiental y de ordenación territorial y urbanística». Un grupo en el que se compendian los apartados o párrafos de los siguientes preceptos: artículo 103.4, párrafos segundo y tercero [«Elaboración y aprobación-planes insulares de ordenación»]; artículo 114.1 [«Aprobación-planes rectores de uso y gestión»]; artículo 122.3, párrafo primero [«Iniciativa y procedimiento de aprobación-planes rectores de uso y gestión»]; artículo $128 \mathrm{~d}$ ), párrafo $2 .^{\circ}$ [«Procedimiento de aprobación-Proyectos de Interés»]; artículo 144.3 párrafos $3 .^{\circ}$ y $4 .^{\circ}$ [«Elaboración y aprobación-planes generales de ordenación»]; artículo 154 [«Ordenanzas provisionales insulares y municipales»]. En síntesis:

En relación con la elaboración y aprobación de estos instrumentos de planificación ambiental y de ordenación territorial se alega una infracción constitucional por limitar la intervención de la comunidad autónoma a la emisión de un informe, en unos casos preceptivo y vinculante sobre cuestiones sectoriales y no de legalidad (planes insulares de ordenación/planes de ordenación de los recursos naturales, planes territoriales de ordenación y planes generales de ordenación), en otros no vinculante (planes rectores de uso y gestión y proyectos de interés), o a la recepción de una simple comunicación (ordenanzas provisionales). En concreto, los recurrentes consideran vulnerados, por omisión o dejación de funciones, los artículos 30.15 [actuales arts. 156, 157 y 158] y 32.12 [actuales arts. 153 y 154] EACan, relativos, respectivamente, a las competencias sobre ordenación del territorio, urbanismo y medio ambiente, en conexión con el artículo 148.1.13. ${ }^{a} \mathrm{CE}$ (penúltimo párrafo del apartado B) del fundamento jurídico 9 de Sentencia-suelo canario).

Frente a este planteamiento, se arguye por el Gobierno y el Parlamento de Canarias, «Los letrados del Gobierno y Parlamento canario niegan la supuesta dejación de funciones por parte de la comunidad autónoma. Entienden que le corresponde a esta establecer el grado de intervención de las entidades locales en la elaboración y aprobación del planeamiento insular y municipal, así como concretar la forma de tutelar los intereses supralocales. Señalan, por último, que, en todo caso, se ha optado por un modelo más respetuoso para la autonomía local, al renunciar a un control autonómico previo o al tradicional procedimiento bifásico de aprobación del planeamiento" (último párrafo del apartado B) del fundamento jurídico 9 de Sentencia-suelo canario).

El apartado C) del fundamento jurídico 9 de Sentencia-suelo canario encara, de acuerdo al método propuesto, el examen de constitucionalidad de los preceptos impugnados. Un examen que aborda los dos motivos de inconstitucionalidad esbo- 
zados, a saber: uno, el reproche de que «la elaboración y aprobación por los cabildos insulares de los planes insulares de ordenación, cuando cumplen las funciones propias de un plan de ordenación de los recursos naturales, vulnera de forma mediata el artículo 149.1.23. ${ }^{2} \mathrm{CE}$, al contradecir los artículos 17.2 y 22.1 de la Ley 42/2007», preceptos formal y materialmente de carácter básico; dos, la minoración, en el entendimiento de los recurrentes, del «rol de la comunidad autónoma en la elaboración y aprobación de los instrumentos de planificación ambiental, territorial y urbanística, vulnerando, por dejación de funciones, sus competencias autonómicas, en conexión con el artículo 148.1.3. ${ }^{a} \mathrm{CE}^{1}$. Examen que se lleva a cabo anteponiendo el del segundo motivo de impugnación sintetizado. Verbalización del encuadramiento de la cuestión atinente al «rol de la comunidad autónoma en la elaboración y aprobación de los instrumentos de planificación ambiental, territorial y urbanística»:

a) Como este Tribunal ya ha tenido ocasión de señalar, «en ámbitos de competencia autonómica, corresponde a las comunidades autónomas especificar las atribuciones de los entes locales ajustándose a esos criterios y ponderando en todo caso el alcance o intensidad de los intereses locales y supralocales implicados [SSTC 61/1997, de 20 de marzo, FJ 25 b); 40/1998, de 10 de febrero, FJ 39; 159/2001, de 5 de julio, FJ 12, y 51/2004, de 13 de abril, FJ 9]. Ello implica que, en relación con los asuntos de competencia autonómica que atañen a los entes locales, la comunidad autónoma puede ejercer en uno u otro sentido su libertad de configuración a la hora de distribuir funciones, pero debe asegurar en todo caso el 'derecho de la comunidad local a participar a través de órganos propios en el gobierno y administración’ (STC 32/1981, FJ 4). Se trata de que el legislador gradúe el alcance o intensidad de la intervención local 'en función de la relación existente entre los intereses locales y supralocales dentro de tales asuntos o materias' (SSTC 32/1981, FJ 4, 170/1989, de 19 de octubre, FJ 9, y 51/2004, FJ 9, entre muchas; en el mismo sentido, últimamente, SSTC 95/2014, de 12 de junio, FJ 5; 57/2015, de 18 de marzo, FJ 6, y 92/2015, de 14 de mayo, FJ 4)» [STC 154/2015, de 9 de julio, FJ 6 A)]².

En atención, pues, a la pertenencia al dominio de las comunidades autónomas, «en ámbitos de la competencia autonómica», de la habilitación para «especificar las atribuciones de los entes locales [...] ponderando en todo caso el alcance o intensidad de los intereses locales y supralocales implicados...», «la comunidad autónoma puede ejercer en uno u otro sentido su libertad de configuración a la hora de distribuir funciones», bien que asegurando en todo caso «el derecho de la comunidad local a participar a través de órganos propios en el gobierno y administración", de acuerdo a «la relación existente entre los intereses locales y supralocales dentro de tales asuntos o materias». En el caso concreto, «... la Comunidad Autónoma de Canarias puede, al amparo de sus competencias en materia de ordenación del territorio y urbanismo, decidir cómo graduar la participación de los entes locales -cabildos insulares y municipios- en los distintos ámbitos del urbanismo (planeamiento,

\footnotetext{
${ }^{1}$ Párrafo primero del apartado C) del fundamento jurídico 9 de Sentencia-suelo canario.
}

2 Primer párrafo del apartado C) a) del fundamento jurídico 9 de Sentencia-suelo canario. 
gestión y disciplina urbanística; STC 159/2001, de 5 de julio, FJ 4), y cómo asegurar la tutela de los intereses supramunicipales, en este caso, por la administración autonómica» ${ }^{3}$. Graduación, por tanto, de «la participación de los entes locales -cabildos y municipios- en los distintos ámbitos del urbanismo [...]» de consuno con el aseguramiento de «la tutela de los intereses supramunicipales, en este caso, por la administración autonómica» ${ }^{4}$. Se apela en el razonamiento a la técnica del informe preceptivo [vinculante y no vinculante] como mecanismo enderezado a «la tutela del interés supramunicipal» por la administración autonómica que engarza con la funcionalidad del referido instrumento en la jurisprudencia constitucional. Se dice así en la última frase del párrafo segundo del apartado C) a) del fundamento jurídico 9 de Sentencia-suelo canario:

En este sentido, hay que recordar que ya nos hemos pronunciado sobre la idoneidad del trámite de informe preceptivo como técnica para asegurar la presencia de los intereses supralocales [SSTC 51/2004, de 13 de abril, FJ 12; 204/2006, de 20 de julio, FJ 13 y 154/2017, FJ 7 c)], y acerca de cómo el carácter vinculante que tiene en algunos casos, convierte la «aprobación final del plan o proyecto en un acto complejo en el que han de concurrir dos voluntades distintas, y esa concurrencia necesaria sólo es constitucionalmente admisible cuando ambas voluntades resuelven sobre asuntos de su propia competencia» [STC 149/1991, de 4 de julio, FJ 7 A) c)].

Es decir, «idoneidad», por tanto, «del trámite de informe preceptivo como técnica para asegurar la presencia de los intereses supralocales», con carácter general; y de manera específica, admisibilidad del "carácter vinculante» del informe cuando, en los casos de "concurrencia [de voluntades] necesaria», "ambas voluntades resuelven sobre asuntos de su propia competencia». Expediente, pues, constitucionalmente justificado en relación con los instrumentos de planificación ambiental y de ordenación territorial y urbanística a que se extiende, en los términos de los preceptos impugnados, la técnica del informe preceptivo [vinculante y no vinculante] por parte de la comunidad autónoma.

Y si el mecanismo o instrumento del informe preceptivo es bastante para enervar la imputación de «dejación de funciones», la intervención [supuesta la opción del legislador canario de «atribuir a los entes locales un papel protagonista en la

3 Última frase del apartado C) a) del fundamento jurídico 9 de Sentencia-suelo canario.

${ }^{4} \mathrm{La}$ justificación de las meritadas "participación" y "aseguramiento» se expresa de la siguiente manera: «El legislador canario ha optado por atribuir a los entes locales un papel protagonista en la elaboración y aprobación definitiva de los instrumentos de planificación ambiental y territorial de ámbito insular y municipal. La tutela del interés supramunicipal, atribuida a la Administración autonómica, se articula insertando en el procedimiento de elaboración un informe preceptivo con distinto alcance y contenido en función del concreto instrumento de planificación: I) vinculante sobre cuestiones sectoriales y no de legalidad (planes insulares de ordenación/planes de ordenación de los recursos naturales [...], planes territoriales de ordenación [...] y planes generales de ordenación [...]); o II) no vinculante (planes rectores de uso y gestión [...] y proyectos de interés [...])»-dos primeras frases del párrafo segundo del apartado C) a) del fundamento jurídico 9 de Sentencia-suelo canario. 
elaboración y aprobación definitiva de los instrumentos de planificación ambiental y territorial de ámbito insular y municipal»] de la comunidad autónoma a propósito de las «ordenanzas provisionales insulares y municipales» es asimismo juzgada suficiente a efectos de descartar, por idéntico motivo, la inconstitucionalidad de la solución patrocinada por el legislador canario a fin de articular la debida «tutela del interés supramunicipal [...] atribuida a la Administración municipal». Con las palabras de las dos primeras frases del párrafo tercero del apartado C) a) del fundamento jurídico 9 de Sentencia-suelo canario:

La administración autonómica está también presente en la adopción de ordenanzas insulares y municipales por razones sobrevenidas de extraordinaria y urgente necesidad pública o interés social, cuya aprobación se hará por el procedimiento previsto en la legislación de régimen local [...]. Aunque la intervención autonómica pudiera parecer limitada a la recepción de una comunicación del acuerdo de aprobación [...], lo cierto es que resulta más amplia: por un lado, puede participar en el trámite de información pública previsto entre la aprobación inicial y la definitiva por el pleno de la corporación local [...]; y, por otro lado, cabe también su participación a posteriori cuando se adopten los instrumentos de ordenación correspondientes.

$\mathrm{Y}$, asimismo en relación con las ordenanzas provisionales insulares y municipales, las tres últimas frases del párrafo tercero del apartado C) a) del fundamento jurídico 9 de Sentencia-suelo canario desmontan la alegada vulneración por los preceptos impugnados de los artículos 3 y 13.1 del Texto Refundido de la Ley de Suelo y Rehabilitación Urbana de 2015, a propósito del cuestionado carácter "excepcional» de las referidas ordenanzas provisionales:

Las otras objeciones formuladas por los recurrentes a estos instrumentos complementarios giran en torno [...] a su eventual contradicción con los artículos 3 y 13.1 TRLSRU, pues su excepcionalidad no se ajusta a lo previsto en los citados preceptos estatales. Pero el carácter excepcional de estas normas provisionales viene avalado por tres elementos: I) su presupuesto (situación extraordinaria y urgente de interés público o social); II) su provisionalidad marcada por su vigencia temporal (plazo máximo de dos años); y III) su limitado contenido (prohibición de reclasificación del suelo y regulación de mínimos) [...].

Consideraciones, en definitiva, que permiten concluir en la no apreciación de "contradicción [alguna] del artículo 154 de la ley controvertida con la legislación básica estatal». Como colofón del análisis del primer motivo de inconstitucionalidad articulado sobre la sedicente «dejación de funciones» por parte del legislador canario en relación con el procedimiento de elaboración y aprobación de los diferentes instrumentos de que se ha dado cuenta, el anteúltimo párrafo del apartado C) a) del fundamento jurídico 9 de Sentencia-suelo canario abunda en la presencia en la regulación impugnada de «otros mecanismos que le aseguran [a la administración autonómica] poder controlar y supervisar los procesos de elaboración de los instrumentos de planificación, garantizando la efectiva tutela de los intereses supralocales y un control de legalidad». En sus propios términos, el Tribunal Constitucional afirma que "por otra parte, como afirman las representaciones procesales del Gobierno y 
Parlamento canario en sus respectivos escritos, la comunidad autónoma dispone de otros mecanismos que le aseguran poder controlar y supervisar los procesos de elaboración de los instrumentos de planificación, garantizando la efectiva tutela de los intereses supralocales y un control de legalidad. Así, el Gobierno canario puede aprobar directrices de ordenación [...], que se erigen en marco de referencia y de obligado acatamiento [sic] por los instrumentos de ordenación insulares y municipales; y también puede sustituir a las islas o municipios en los casos de incumplimiento de sus deberes [...] o suspender motivadamente, por razones de interés público, social o económico relevante, la vigencia de cualquier instrumento de ordenación [...]. En conclusión, ante la falta de la alegada omisión o dejación de funciones por parte de la administración autonómica en el ejercicio de sus competencias estatutarias, se ha de desestimar íntegramente este motivo de impugnación»"

La elucidación de la imputada contradicción con los artículos 17.2 y 22.1 de la Ley 42/2007 de los preceptos rectores del procedimiento de elaboración y aprobación de los diferentes instrumentos de planificación ambiental y de ordenación territorial y urbanística, esto es, el examen del segundo motivo de inconstitucionalidad, se contiene en la letra b) del apartado C) del fundamento jurídico 9 de Sentencia-suelo canario, cuyo primer párrafo encuadra así la cuestión litigiosa: «A continuación, hemos de enjuiciar la eventual infracción de los arts. 17.2 y 22.1 de la Ley 42/2007, de 13 de diciembre, del patrimonio natural y de la biodiversidad, en conexión con el artículo 149.1.23. ${ }^{a} \mathrm{CE}$. En los citados preceptos se atribuye a las comunidades autónomas la elaboración y aprobación de los planes de ordenación de los recursos naturales en sus respectivos ámbitos competenciales. En la legislación canaria, la administración competente son los cabildos insulares, pues suya es la competencia para aprobar con carácter general los planes insulares de ordenación. No obstante, en el procedimiento de elaboración de estos planes insulares -también en su función de planes de ordenación de los recursos naturales- se integra el informe preceptivo y vinculante de la administración autonómica [...]; informe sobre el que ya nos hemos pronunciado en este mismo fundamento jurídico».

Un informe preceptivo y vinculante que, en la economía de la ley canaria, sustituye a la aprobación [definitiva] por la comunidad autónoma de los planes de ordenación de los recursos naturales ex artículos 17.2 y 22.1 de la Ley 42/2007 y que si desde la perspectiva de la imputada «omisión o dejación de funciones» ha sido juzgado mecanismo idóneo a fin de velar por «la tutela del interés supramunicipal [...] atribuida a la administración autonómica», en este momento es examinado a la luz de la organización institucional de la comunidad autónoma canaria a fin de concluir en la no contravención mediata del artículo 149.1.23 del texto constitucional por mor de la [no] conculcación de los correspondientes preceptos básicos estatales. La oportuna respuesta se alberga en el segundo párrafo del apartado C) b) del fundamento jurídico 9 de Sentencia-suelo canario:

5 Último párrafo del apartado C) a) del fundamento jurídico 9 de Sentencia-suelo canario. 
El artículo 2.3 EACan y, en el mismo sentido, los apartados 2 y 3 del artículo 65 atribuyen, simultáneamente, a los cabildos insulares una doble condición: son instituciones de la comunidad autónoma y son órganos [sic] de gobierno de cada isla. Por su parte, el artículo 61.2 EACan contempla la posibilidad de que la Comunidad Autónoma de Canarias ejerza sus funciones «bien por su propia administración, bien, cuando lo justifiquen los principios de subsidiariedad, descentralización y eficiencia, a través de los cabildos insulares»; y en el artículo 70.1 EACan se prevé la posibilidad de delegar o trasferir competencias a los cabildos insulares, atribuyéndoles directamente las funciones ejecutivas en materia de ordenación del territorio y protección del medio ambiente [art. 70.2 b) y n) EACan]. Es desde el ejercicio de las competencias estatutarias que le permiten a la comunidad autónoma decidir si quiere o no descentralizar algunas de sus tareas en materia de ordenación del territorio y protección del medio ambiente, como hemos de interpretar la atribución por los artículos 17.2 y 22.1 de la Ley 42/2007 de la aprobación de los planes de ordenación de los recursos naturales a las comunidades autónomas. El sentido de la legislación básica en relación con estos planes, es que su aprobación en modo alguno corresponde al Estado, sino a las comunidades autónomas, las cuales podrán, en el ejercicio de sus competencias estatutarias, descentralizar dicha tarea de acuerdo con nuestra doctrina constitucional (STC 41/2016, FF JJ 9, 12 y 13). Los eventuales riesgos que pudieran derivarse de este proceso de descentralización, tanto en la elaboración y aprobación de los planes de ordenación de los recursos naturales, como en su aplicación, no pueden servir de fundamento para su anulación, en la medida en que corresponderá a la jurisdicción contencioso-administrativa el control de los posibles excesos que se puedan dar en la aplicación de esta norma.

Así pues, si «es desde el ejercicio de las competencias estatutarias [...] como hemos de interpretar la atribución por los artículos 17.2 y 22.1 de la Ley 42/2007 de la aprobación de los planes de ordenación de los recursos naturales a las comunidades autónomas», ninguna objeción, en términos constitucionales, cabe alzar a la eventualidad de que «las comunidades autónomas [...], en el ejercicio de sus competencias autonómicas, [puedan] descentralizar dicha tarea de acuerdo con nuestra doctrina constitucional [...]», máxime en atención a «la consideración [estatutaria] de los cabildos insulares como institución autonómica [...]». La formulación sintética de la corrección, en términos constitucionales, de tal proceder se verbaliza en el último párrafo del apartado C) b) del fundamento jurídico 9 de Sentencia-suelo canario:

La consideración de los cabildos insulares como institución autonómica, unida a la potestad de autoorganización, reconocida por este Tribunal como inherente a la autonomía (por todas, la STC 34/2013, de 14 de febrero, FJ 16, y las sentencias allí citadas), y la intervención de la administración autonómica, vía informe preceptivo y vinculante, nos llevan a desestimar el motivo de impugnación, al no apreciar contradicción alguna de los artículos 94.3 y 102.1 de la Ley del suelo y de los espacios naturales protegidos de Canarias con los preceptos básicos estatales.

En síntesis, y a modo de valoración, debe enfatizarse la impecable argumentación del fundamento jurídico 9 de Sentencia-suelo canario a la hora de desestimar los dos motivos de impugnación aducidos en relación con el pormenor de la 
elaboración y aprobación de los diferentes instrumentos de planificación ambiental y de ordenación territorial y urbanística previsto en la legislación canaria sometida a enjuiciamiento. Ni hay "omisión o dejación de funciones» por parte del legislador canario, de un lado, ni la atribución de la competencia decisoria a los cabildos insulares por mor de la peculiaridad institucional de la comunidad autónoma canaria, de otro, es merecedora de reproche constitucional. Y, junto con estas consideraciones de índole estrictamente constitucional, cabe ańadir la bondad de la solución patrocinada por la ley canaria al sustituir el «tradicional procedimiento bifásico de aprobación del planeamiento» [último párrafo del apartado B) del fundamento jurídico 9 de Sentencia-suelo canario] por la inserción, en el oportuno procedimiento de elaboración y aprobación, del correspondiente informe autonómico [ya vinculante, ya meramente preceptivo], en cuanto técnica enderezada a velar por «la tutela del interés supramunicipal [...] atribuida a la Administración autonómica» [párrafo segundo del apartado C) a) del fundamento jurídico 9 de Sentencia-suelo canario], que, entre otras virtudes, tiene, y no es la menor, la de deslindar nítidamente los eventuales ámbitos de la responsabilidad de los diferentes poderes públicos implicados en el [complejo, complejísimo] procedimiento de aprobación de los diferentes instrumentos de planificación ambiental y de ordenación territorial y urbanística.

\section{EVALUACIÓN AMBIENTAL ESTRATÉGICA DE PLANES, PROGRAMAS Y PROYECTOS: LEGISLACIÓN ESTATAL Y LEGISLACIÓN AUTONÓMICA}

El apartado 1, letra c) del fallo de la Sentencia del Tribunal Constitucional 86/2019, de 20 de junio [recurso de inconstitucionalidad número 5047-2017, promovido por más de cincuenta diputados del Grupo Parlamentario Unidos Podemos-En Comú Podem-En Marea contra diversos preceptos de la Ley 4/2017, de 13 de julio, del suelo y de los espacios naturales protegidos de Canarias; Pleno; ponente: Montoya Melgar; en adelante, Sentencia-suelo canario] declara la inconstitucionalidad y la nulidad de: «El inciso a tales efectos, se entenderá que no se estima que puedan generarse efectos apreciables en los casos en que, teniendo en cuenta el principio de cautela, quepa excluir, sobre la base de datos objetivos, que dicho proyecto pueda afectar al lugar en cuestión de forma importante, del artículo 174.2».

El régimen jurídico de la evaluación ambiental estratégica de los planes, programas y proyectos que puedan tener efectos significativos sobre el medio ambiente, previstos en los títulos III y IV de la Ley del suelo y de los espacios naturales protegidos de Canarias, es recurrido por diversos motivos que se articulan en varios apartados de la demanda, y que serán objeto de examen conjunto, dada su conexión, en este fundamento jurídico [primer párrafo del fundamento jurídico 11 de Sentencia-suelo canario]. Motivos que, en concreto, son dos y cuyo examen se aborda en los diversos párrafos de las letras A) y B) del fundamento jurídico 11 de Sentencia-suelo canario. El enunciado del primer motivo de impugnación se desglosa del modo que sigue en los cuatro primeros párrafos de la letra A) del fundamento jurídico 11 de Sentencia-suelo canario, en el que se expresa que «El primer motivo alega 
la vulneración indirecta del artículo 149.1.23. ${ }^{a} \mathrm{CE}$, por contravenir los artículos 11.4 y 12.4 de la Ley 21/2013, de 9 de diciembre, de evaluación ambiental (LEA) y el artículo 22.2 LBRL [Ley de Bases de Régimen Local]. La letra c) del artículo 22.2 LBRL atribuye al pleno municipal la aprobación del planeamiento general, por lo que dicho órgano, a efectos medioambientales, es el órgano sustantivo [art. $5.1 \mathrm{~d}$ ) LEA] y el órgano promotor [art. 5.2 a) LEA]». Sin embargo, el artículo 144.6 de la Ley prevé que «en el supuesto de que existan discrepancias sobre el contenido de la evaluación ambiental estratégica, el órgano municipal que tramita el plan trasladará al órgano ambiental un escrito fundado donde manifieste las razones que motivan la discrepancia, en los términos previstos en la legislación estatal básica. Y continúa señalando que recibido el escrito de discrepancias, el órgano ambiental deberá pronunciarse en un plazo máximo de treinta días hábiles. Si el órgano ambiental no se pronunciase en el citado plazo, se entenderá que mantiene su criterio respecto del contenido de la declaración ambiental estratégica. Por último, el precepto señala que de mantenerse la discrepancia, el órgano municipal que tramita el plan elevará la misma, bien al Gobierno de Canarias cuando el órgano ambiental sea autonómico, o bien, en otro caso, al pleno municipal. En tanto no recaiga resolución expresa, se considerará que la declaración ambiental estratégica mantiene su eficacia. A este enunciado al que sigue la verbalización de la controversia» [párrafo quinto de la letra A) del fundamento jurídico 11 de Sentencia-suelo canario]:

De este modo, la Ley del suelo y de los espacios naturales protegidos de Canarias violaría el principio de separación funcional y competencial que establece la LEA, cuando exige que el órgano sustantivo «eleve» la discrepancia (art. 12.4 LEA). Reproche que se hace extensivo a los artículos 102.1 y 103.7 de la Ley para los planes insulares de ordenación, y por el artículo 122.3 para los planes territoriales, parciales y especiales, cuya aprobación corresponde al pleno de los cabildos insulares.

La solución que aporta el Tribunal Constitucional para este extremo es la siguiente: «la impugnación se fundamenta en una vulneración mediata del artículo 149.1.23 ${ }^{a} \mathrm{CE}$, por infringirse dos preceptos básicos de la LEA: I) el artículo 11.4, regulador de las funciones que correspondería asumir al órgano sustantivo cuando, simultáneamente, tiene la condición de órgano promotor, precepto que ha sido derogado tras la reforma por la Ley 9/2018, de 5 de diciembre; iI) el artículo 12.4, que prevé la elevación de la discrepancia por el órgano sustantivo al órgano competente para resolverla; precepto que, según la STC 53/2017, de 11 de mayo, no puede "reputarse legislación básica en materia de medio ambiente, salvo por lo que respecta a la segunda frase del apartado cuarto ('en tanto no se pronuncie el órgano que debe resolver la discrepancia, se considerará que la declaración ambiental estratégica, la declaración de impacto ambiental, o en su caso, el informe ambiental estratégico, o el informe de impacto ambiental mantienen su eficacia'), que tiene carácter básico y es, por consiguiente, conforme con el sistema constitución de distribución de competencias" (FJ 14)».

La conclusión a la que se llega es que, "por tanto, el motivo de impugnación debe decaer debido a que la norma de contraste ha desaparecido en un caso, y en el 
otro ha perdido la condición formal de precepto básico de acuerdo con la doctrina establecida en nuestra STC 53/2017» ${ }^{6}$.

La razón de ser del segundo motivo de impugnación se sintetiza así en el primer párrafo de la letra B) del fundamento jurídico 11 de Sentencia-suelo canario: «El segundo motivo de impugnación se fundamenta, con carácter general, en la vulneración por varios preceptos de la ley canaria del artículo 149.1.23. ${ }^{\mathrm{a}} \mathrm{CE}$, por infracción del artículo 6 LEA, al excluir del procedimiento de evaluación ambiental a determinados planes o proyectos; precepto formal -disposición final octava de la LEAy materialmente básico al fijar una norma mínima de protección medioambiental».

Los instrumentos de planeamiento excluidos del procedimiento de evaluación ambiental son los siguientes: «estudios de detalle» ex artículo 150.4 de la ley canaria [letra B) a) del fundamento jurídico 11 de Sentencia-suelo canario]; «ordenanzas provisionales insulares y municipales» ex artículo 154.1 de la ley canaria ${ }^{7}$; «modificaciones menores de los instrumentos de ordenación del artículo 165.3» de la ley canaria [letra B) c) del fundamento jurídico 11 de Sentencia-suelo canario]; "proyectos que afecten a la red natura 2000" ex artículo 174.2 de la ley canaria ${ }^{8}$.

En relación con los estudios de detalle respecto de los que el artículo 150.4 de la ley canaria estatuye que quedan «excluidos, en todo caso, del procedimiento de evaluación ambiental por su escasa dimensión o intacto», el último párrafo de la letra B) a) del fundamento jurídico 11 de Sentencia-suelo canario señala, a fin de concluir en la no apreciación de «infracción del artículo 6 LEA, al no tener los estudios de detalle efectos significativos sobre el medio ambiente que impliquen un menor nivel de protección». En concreto se indica que «un examen de la regulación contenida en el artículo 150, en su conjunto, revela que los estudios de detalle son instrumentos complementarios, bien del plan general -suelo urbano-, bien del plan parcial -suelo urbanizable-, limitándose su objeto a completar o adaptar la ordenación pormenorizada -alineaciones y rasantes, volúmenes edificables, ocupaciones y retranqueos, accesibilidad y eficiencia energética, características estéticas y compositivas- [...]; no pudiendo, en ningún caso, modificar la clasificación del suelo, incrementar el aprovechamiento urbanístico o incidir negativamente en la funcionalidad de las dotaciones públicas [...]. La escasa entidad de los estudios de detalle, su casi nula capacidad innovadora desde el punto de vista de la ordenación urbanística, y su subordinación a planes que ya han sido objeto de evaluación ambiental, justifican la opción del legislador canario. Se ha de desestimar, por tanto, el motivo de impugnación por no apreciarse infracción del artículo 6 LEA, al no tener los estudios de detalle efectos significativos sobre el medio ambiente que impliquen un menor nivel de protección».

${ }^{6}$ Última frase del último párrafo de la letra A) del fundamento jurídico 11 de Sentencia-suelo canario.

${ }^{7}$ Letra B) b) del fundamento jurídico 11 de Sentencia-suelo canario.

${ }^{8}$ Letra B) d) del fundamento jurídico 11 de Sentencia-suelo canario. 
A propósito de las ordenanzas provisionales insulares y municipales, «cuya constitucionalidad ha sido ya examinada y declarada en el fundamento jurídico 9 C) a), se formula ahora un nuevo reproche que coincide en lo sustancial con el analizado sobre los estudios de detalle: la omisión del procedimiento de evaluación ambiental» [primer párrafo de la letra B) b) del fundamento jurídico 11 de sentencia-suelo canario]. La respuesta que se da a este reproche se contiene en el segundo párrafo de la letra B) b) del fundamento jurídico 11 de Sentencia-suelo canario:

Del contenido del artículo 154.1 no puede deducirse que, en todos los casos, las ordenanzas provisionales no sean sometidas a evaluación ambiental estratégica ordinaria o simplificada ex artículo 6 LEA; máxime cuando el propio precepto prevé que se podrán aprobar «con los mismos efectos que tendrían los instrumentos de planeamiento a los que, transitoriamente, reemplacen» (en términos equivalentes, el art. 24.1 TRLSRU -Texto Refundido de la Ley de Suelo y Rehabilitación Urbana-), por lo que habrá que estar al contenido que dichas ordenanzas asuman en cada caso. La objeción que se apunta por los recurrentes parece pretender declarar la inconstitucionalidad de la norma por lo que en ella «no se regula», y completar lo regulado por la ley, no es función que pueda asumir este Tribunal por corresponder al legislador [STC 26/1987, de 27 de febrero, FJ 14 a)]. Se ha [de] desestimar, pues la impugnación.

La sujeción, pues, de las ordenanzas provisionales insulares y municipales a evaluación ambiental estratégica, ya ordinaria, ya simplificada, se sujeta "al contenido que dichas ordenanzas asuman en cada caso", sin que, por tanto, sea factible una declaración de inconstitucionalidad por causa de lo que en la ley «no se regula» al no ser función del Tribunal Constitucional «completar lo regulado por la ley». Por otra parte, la regulación de las modificaciones menores de los instrumentos de ordenación del artículo 165.3 [...] es objeto de impugnación por vulneración mediata del artículo 149.1.23. ${ }^{a} \mathrm{CE}$, al infringir el artículo $5.2 \mathrm{f}$ ) LEA, que tiene formal y materialmente carácter de básico» [primer párrafo de la letra B) c) del fundamento jurídico 11 de Sentencia-suelo canario]. La regulación que de las modificaciones menores de los instrumentos de ordenación ex artículo 165.3 se somete, a este propósito, a enjuiciamiento es la siguiente:

Las modificaciones menores se someterán al procedimiento simplificado de evaluación ambiental estratégica, a efectos de que por parte del órgano ambiental se determine si tiene efectos significativos sobre el medioambiente.

Cuando el órgano ambiental determine que no es necesaria la evaluación ambiental estratégica, los plazos de información pública y de consulta institucional serán de un mes.

El alegato a que se enfrenta el Tribunal Constitucional se hace descansar por los recurrentes en que «[...] el artículo 165.3 somete al procedimiento simplificado de evaluación ambiental estratégica a las modificaciones menores, definidas en el artículo 164 del mismo texto legal, lo que contradice la legislación estatal básica y, por extensión, la europea (Directiva 2001/42/CE del Parlamento y del Consejo, de 27 de junio de 2001, de evaluación ambiental), por introducir excepciones no 
previstas que disminuyen la protección ambiental» [cuarto párrafo de la letra B) c) del fundamento jurídico 11 de Sentencia-suelo canario]. Alegato que merece la refutación que sigue, como basamento de la inexistencia de «excepción alguna a lo previsto en la legislación estatal». En sus propios términos: «Lo que parecen cuestionar los recurrentes no es tanto el sometimiento de las modificaciones menores al procedimiento simplificado de evaluación ambiental estratégica (art. 165.3), como su propia definición (art. 164). Como señalan los representantes del Gobierno y del Parlamento canario, es necesario hacer una lectura integradora del texto legal para alcanzar una correcta interpretación. Para la LEA las modificaciones menores son los cambios "que no constituyen variaciones fundamentales de las estrategias, directrices y propuestas o de su cronología pero que producen diferencias en los efectos previstos o en la zona de influencia" [art. $5.2 \mathrm{f}$ )], esto es, la clave es la exclusión de los cambios estratégicos o estructurales. El legislador canario define en el mismo sentido las modificaciones menores, pero en oposición a las modificaciones sustanciales, tales como la reconsideración integral el modelo de ordenación o la alteración de elementos estructurales [art. 163.1]. No cabe apreciar, por tanto, contradicción alguna entre la legislación canaria y la legislación básica estatal. Más aún, el artículo 86 de la Ley del suelo y de los espacios naturales protegidos de Canarias regulador de la evaluación ambiental estratégica, afirma que, en el marco de la legislación básica del Estado, serán objeto de evaluación ambiental estratégica simplificada las modificaciones menores de los instrumentos de ordenación [art. $86.2 \mathrm{~b}$ )], por lo que no existe excepción alguna a lo previsto en la legislación estatal. La impugnación se ha de desestimar».

Los proyectos que afecten a la red natura 2000 son, desde la perspectiva de la evaluación ambiental, objeto de la atención de los recurrentes por entender que el artículo 174.2 de la ley canaria vulnera "de forma mediata el artículo 149.1.23. ${ }^{a}$ $\mathrm{CE}$, al reducir el nivel de la protección medioambiental» por «infringir el artículo 46.4 de la Ley 42/2007, de 13 de diciembre, del patrimonio natural y de la biodiversidad, de carácter básico [...]" [párrafo primero de la letra B) d) del fundamento jurídico 11 de Sentencia-suelo canario]. Los términos del debate son los siguientes?: «El artículo 46.4 de la Ley 42/2007 prevé someter a una adecuada evaluación de sus repercusiones en el espacio cualquier plan, programa o proyecto que, sin tener relación directa con la gestión del lugar o sin ser necesario para la misma, "pueda afectar de forma apreciable a las especies o hábitats de los citados espacios" de la red natura 2000. En los mismos términos se expresa el artículo 174.1 de la Ley del suelo y de los espacios naturales de Canarias, el cual no ha sido objeto de impugnación. Como trámite de carácter previo y a los efectos de determinar si un proyecto que afecte a la red natura 2000 debe ser sometido a evaluación de impacto ambiental, el impugnado artículo 174.2 dispone que el órgano ambiental competente deberá:

\footnotetext{
9 Párrafos segundo, tercero y cuarto de la letra B) d) del fundamento jurídico 11 de Sentencia-suelo canario.
} 
Evaluar si la actuación prevista tiene relación directa con la gestión del lugar y/o si es necesaria para la misma, así como si no se prevé que la actuación pueda generar efectos apreciables en el lugar, en cuyo caso podrá eximirse de la correspondiente evaluación. 'A tales efectos, se entenderá que no se estima que puedan generarse efectos apreciables en los casos en que, teniendo en cuenta el principio de cautela, quepa excluir, sobre la base de datos objetivos, que dicho proyecto pueda afectar al lugar en cuestión de forma importante.

Los recurrentes sitúan la infracción de la legislación básica estatal en la sustitución de la afectación «apreciable», prevista por ella para determinar el sometimiento del plan o proyecto a una adecuada evaluación, por la afectación «de forma importante», que establece la legislación canaria, al ser esta exigencia más gravosa o intensa. La letrada del Gobierno canario niega la infracción, pues la regulación del artículo 174.2 se sitúa en una fase intermedia entre las dos que regula el precepto básico estatal. Se trata de una norma adicional de protección que proporciona al órgano ambiental criterios para evaluar las repercusiones y decidir, en su caso, iniciar el procedimiento de evaluación. El letrado del Parlamento canario no ve que se varíe el umbral de protección estatal, rebajándolo, por emplear el término «importante» en vez del de apreciable.

Respuesta, en forma de contrapunto, del Tribunal Constitucional, a fin de concluir en la inconstitucionalidad del inciso del artículo 174.2 de la ley canaria consignado en el párrafo tercero de la letra B) d) del fundamento jurídico 11 de Sentencia-suelo canario, por incurrir en «la definición de lo básico». Los dos últimos párrafos de la letra B) d) del fundamento jurídico 11 de Sentencia-suelo canario dicen así:

El legislador estatal exige someter a evaluación cualquier proyecto que pueda afectar de forma <apreciable> al espacio de la red natura 2000; esta es la única condición prevista en el artículo 46.4 de la Ley 42/2007 y de forma idéntica, tras su reforma, por el artículo 8.5 LEA, también de carácter básico. Sin embargo, el legislador canario, tras reproducir en el artículo 174.1 la legislación básica, introduce criterios para determinar si un proyecto que afecta a la Red Natura 2000 debe ser sometido a evaluación, y lo excluye cuando «no se prevé que la actuación pueda generar efectos apreciables en el lugar». Ninguna contradicción cabe apreciar hasta este momento entre el precepto impugnado y la norma de contraste. No obstante, a continuación se define qué ha de entenderse por "efectos apreciables» en sentido negativo: no lo serán los que «quepa excluir, sobre la base de datos objetivos» por no afectar de "forma importante», conforme al principio de cautela.

Ya hemos tenido ocasión de declarar que «lo básico, como propio de la competencia estatal en la materia de medio ambiente, cumple una función de ordenación mediante mínimos que han de respetarse en todo caso, pero que deben permitir que las Comunidades Autónomas con competencias en la materia establezcan niveles de protección más altos» y lo que «haya de entenderse por básico, en caso necesario será este Tribunal el competente para decidirlo, en su calidad de intérprete supremo de la Constitución» (STC 33/2005, de 17 de febrero, FJ 6). En el presente caso, el reproche constitucional al artículo 174.2 de la Ley del suelo y de los espacios naturales protegidos de Canarias no radica en el empleo del término «importante» frente al de "apreciable», términos que, por lo demás, no son equivalentes, sino en la definición de lo básico, realizada por dicho precepto. Por con- 
siguiente, declaramos la inconstitucionalidad y nulidad del inciso «A tales efectos, se entenderá que no se estima que puedan generarse efectos apreciables en los casos en que, teniendo en cuenta el principio de cautela, quepa excluir, sobre la base de datos objetivos, que dicho proyecto pueda afectar al lugar en cuestión de forma importante» del artículo 174.2 de la ley controvertida».

Una sucinta apostilla a las consideraciones que anteceden en relación con la exclusión de determinados instrumentos de planeamiento de la evaluación ambiental. Salvedad hecha de la razón por la que se declara inconstitucional el inciso del artículo 174.2 consignado en las últimas líneas del apartado inmediatamente anterior, a saber, la extralimitación en que ha incurrido el legislador autonómico por definir lo «básico», importa destacar las aducidas por el Tribunal Constitucional para justificar la meritada exclusión a propósito de los estudios de detalle. Unas razones que dicen relación con el carácter de «instrumento complementario» de la referida figura de planeamiento, cuyo objeto estriba en «completar o adaptar la ordenación pormenorizada", y que en ningún caso puede «modificar la clasificación del suelo, incrementar el aprovechamiento urbanístico o incidir negativamente en la funcionalidad de las dotaciones públicas». Una figura de planeamiento cuya «escasa entidad», «casi nula capacidad innovadora desde el punto de vista de la ordenación urbanística», así como «su subordinación a planes que ya han sido objeto de evaluación ambiental», en definitiva, «justifican la opción del legislador canario» y, por ende, permiten concluir en la no vulneración por aquella opción del artículo 6 de la Ley de Evaluación Ambiental, «al no tener los estudios de detalle efectos significativos sobre el medio ambiente que impliquen un menor nivel de protección $»^{10}$. Confróntense, ahora, las razones esgrimidas por el supremo intérprete de la Constitución para avalar la exclusión de la evaluación ambiental de los estudios de detalle con las aducidas por el orden jurisdiccional contencioso-administrativo para justificar, justamente en sentido contrario, la sujeción de los estudios de detalle a la pertinente evaluación ambiental.

Así, como botón de muestra, por reflejar cumplidamente el estado de la cuestión en su entendimiento jurisdiccional, pueden traerse a colación los fundamentos de derecho tercero y cuarto de la Sentencia de la Sección Primera de la Sala de lo Contencioso-Administrativo del Tribunal Superior de Justicia de Madrid número 52/2019, de 31 de enero [recurso contencioso-administrativo número 439/2018; ponente: González Márquez]. Cabe suponer que a partir de Sentencia-suelo canario, en aquel entendimiento jurisdiccional se operen los oportunos cambios y rectificaciones, aunque, asimismo, no sea de descartar que, por estar implicado el derecho de la Unión Europea, tal y como ha sido interpretado por el Tribunal de Justicia de Luxemburgo, el orden jurisdiccional contencioso-administrativo no se sienta concernido por el pronunciamiento constitucional que aquí nos ha ocupado.

10 Último párrafo de la letra B) a) del fundamento jurídico 11 de Sentencia-suelo canario. 


\section{PROYECTOS SINGULARES DE INTERÉS AUTONÓMICO Y AUTONOMÍA MUNICIPAL}

Otro de los temas tratados en la STC 86/2019 es el que se refiere a los denominados proyectos de interés autonómico e insular. Los preceptos analizados se refieren al objeto y al alcance de las determinaciones ${ }^{11}$.

En relación con los artículos 123 y 126 de la ley canaria se aducen por los recurrentes tres motivos de inconstitucionalidad. El primero, la vulneración mediata del artículo 149.1.23. ${ }^{a}$ de la Constitución por infracción de dos preceptos básicos del Texto Refundido de la Ley de Suelo y Rehabilitación Urbana de 2015, los artículos 20.1 a) y 13.1; el segundo, la vulneración, igualmente mediata, del artículo 149.1.23. ${ }^{a}$ del texto constitucional por conculcación del artículo 19.2 de la Ley 42/2007, de 13 de diciembre, del patrimonio natural y de la biodiversidad, en la medida en que el artículo 126 de la ley canaria otorga a los proyectos de interés insular o autonómico prevalencia «sobre el planeamiento insular y municipal»; el tercero, finalmente, por transgresión por los artículos 123.3 y 4 y 126 del principio de autonomía local ex artículos 137 y 140 de la Constitución y del artículo 149.1.18. ${ }^{a}$ del texto constitucional por infracción de las letras d) y f) del artículo 25 de la Ley de Bases de Régimen Local (en la actualidad, letras a) y b) del artículo 25 , referidas, respectivamente, al urbanismo y al medio ambiente urbano. Los dos primeros motivos de inconstitucionalidad son rechazados, en tanto que el tercero, en lo atinente al inciso del artículo 123.4 arriba consignado, es acogido por el Tribunal Constitucional. La respuesta al primer motivo de inconstitucionalidad se contiene en los dos últimos párrafos de la letra A) del fundamento jurídico 10 de Sentencia-suelo canario. Dicen así:

${ }^{11}$ En particular estos preceptos señalan:-Artículo 123. Objeto. 1. Los proyectos de interés insular o autonómico tienen por objeto ordenar y diseñar, para su inmediata ejecución, o bien ejecutar sistemas generales, dotaciones y equipamientos estructurantes o de actividades industriales, energéticas, turísticas no alojativas [sic], culturales, deportivas, sanitarias o de naturaleza análoga de carácter estratégico, cuando se trate de atender necesidades sobrevenidas o actuaciones urgentes. Estas circunstancias deberán estar justificadas debidamente en el expediente. 2. Los proyectos de interés insular o autonómico pueden aprobarse en ejecución del planeamiento insular, de las directrices o de forma autónoma. En este último caso, el proyecto comprenderá también la determinación y la localización de la infraestructura o actividad de que se trate. 3. El interés insular o autonómico de los proyectos vendrá determinado por el ámbito competencial de la administración actuante en cada caso, debiendo acreditarse su carácter estratégico. 4. Los proyectos de interés insular o autonómico pueden ejecutarse en cualquier clase de suelo, con independencia de su clasificación y calificación urbanística. No obstante, sólo podrán afectar a suelo rústico de protección ambiental cuando no exista alternativa viable y lo exija la funcionalidad de la obra pública de que se trate; y de forma excepcional y únicamente para proyectos de iniciativa pública cuando se trate de suelo rústico de protección agraria. -Artículo 126. Alcance de las determinaciones y condiciones. Las determinaciones contenidas en los proyectos de interés insular o autonómico prevalecerán sobre el planeamiento insular y municipal, que habrá de adaptarse a los mismos con ocasión de la primera modificación que afecte a este suelo. 
Sobre la infracción del artículo 20.1 a) TRLSRU, en cuanto expresión del principio de previa planificación, nos remitimos a lo dicho en el fundamento jurídico 8 A) de esta sentencia. Baste seńalar, en este momento, que en todo caso la propia ley canaria configura los proyectos de interés insular o autonómico como instrumentos de ordenación territorial en su artículo 83. Se ha de desestimar, por tanto, el motivo de impugnación.

La eventual infracción del artículo 13.1 TRLSRU también se ha de rechazar, pues en él se contempla la posibilidad de autorizar, excepcionalmente, "actos y usos específicos que sean de interés público o social». Y si algo define a estos proyectos de interés, a los que es inherente el interés público o social, es su excepcionalidad por varias razones: I) el carácter estratégico de su objeto, ejecución de "sistemas generales, dotaciones y equipamientos estructurantes», o "actividades industriales, energéticas, turísticas no alojativas [sic], culturales, deportivas, sanitarias o de naturaleza análoga»; II) su justificación, pues han de responder a necesidades sobrevenidas o urgentes; III) el carácter público de la iniciativa cuando puedan afectar a suelo rústico de protección ambiental -en el que se exige, además, que no exista alternativa viable- y de protección agraria (art. 123.1 y 4 de la Ley del suelo y de los espacios naturales protegidos de Canarias). Por tanto, no se aprecia vulneración del precepto básico estatal por establecer un menor nivel de protección medioambiental, lo que nos lleva a desestimar el motivo de impugnación.

En síntesis, pues, y a la vista del fundamento jurídico transcrito, puede indicarse que:

- Uno.- con independencia de que los proyectos de interés insular y autonómico son «instrumentos de ordenación territorial», el artículo 20.1 a) de la Ley de suelo estatal de 2015 no impone un «principio de previa planificación».

- Dos.- los proyectos de interés insular y autonómico no vulneran el artículo 13.1 de la Ley de suelo estatal de 2015 por no comportar «un menor nivel de protección medioambiental».

En relación con el segundo motivo de inconstitucionalidad, la letra B) del fundamento jurídico 10 de Sentencia-suelo canario plasma una «interpretación conforme» del artículo 126 de la Ley canaria. La denunciada prevalencia de los proyectos de interés insular o autonómico «sobre el planeamiento insular y municipal» se sustentaba en el que en el artículo 19.2 de la Ley 42/2007 [precepto, formal y materialmente, de carácter básico] «se prevé que las determinaciones de los planes de ordenación de los recursos naturales prevalecerán, en caso de contradicción, sobre aquéllas de los instrumentos de ordenación territorial, urbanística, de recursos naturales y, en general, física, existentes». La respuesta del Tribunal Constitucional, determinante de aquella «interpretación conforme», es la siguiente:

Tal argumentación no puede ser admitida. La Ley del suelo y de los espacios naturales protegidos de Canarias [...] descansa en «la prevalencia de la protección ambiental sobre la ordenación territorial y urbanística», constituyendo uno de sus principios básicos [art. $5.1 \mathrm{~d}$ )]. Prevalencia que se reitera en los artículos 84.2 - «los planes de ordenación de los recursos naturales prevalecerán sobre el resto de ins- 
trumentos de ordenación ambiental, territorial y urbanística previstos en la presente ley»- y 83.3 - «en el caso de contradicción, prevalecerán las determinaciones ambientales sobre las territoriales y las urbanísticas»-. No obstante, no les falta razón a los diputados recurrentes cuando recuerdan que los planes insulares de ordenación son un instrumento de planeamiento insular [art. 84.1 a)] que pueden tener [...] el carácter de planes de ordenación de los recursos naturales (art. 94.3). Siendo esto así, la prevalencia prevista por el artículo 126 de la Ley del suelo y de los espacios naturales protegidos de Canarias de los proyectos de interés insular o autonómico sobre el planeamiento insular no se referirá a aquellos casos en los que el plan insular de ordenación tenga el carácter de plan de ordenación de los recursos naturales, con las determinaciones y el alcance establecidos por la legislación básica estatal. Esta es la interpretación que se deduce del artículo 94.3 de la ley controvertida, al afirmar: "cuando los instrumentos de ordenación ambiental, territorial o urbanística resulten contradictorios con los planes insulares deberán adaptarse a estos; en tanto dicha adaptación no tenga lugar, tales determinaciones de los planes insulares se aplicarán, en todo caso, prevaleciendo sobre dichos instrumentos». Así entendido, nada se opone pues a la plena constitucionalidad del artículo 126 de la Ley; interpretación que será llevada al fallo.

En consecuencia, por tanto: «... la prevalencia [...] de los proyectos de interés insular o autonómico sobre el planeamiento no se referirá a aquellos casos en los que el plan insular de ordenación tenga el carácter de plan de ordenación de los recursos naturales...». Prevalencia, pues, de los planes insulares de ordenación en su función de planes de ordenación de los recursos naturales sobre la expressis verbis dispuesta de los planes de interés insular o autonómico en relación al planeamiento insular, del que aquéllos forman parte. Interpretación que, en suma, permite el ajuste del precepto autonómico al artículo 19.2 de la Ley 42/2007, del patrimonio natural y de la biodiversidad.

El examen del tercer motivo de inconstitucionalidad [letra c) del fundamento jurídico 10 de Sentencia-suelo canario] lleva, in crescendo, a la declaración de inconstitucionalidad del inciso del apartado 4 del artículo 123 de la ley canaria arriba transcrito. La infracción del principio de autonomía local ex artículos 137 y 140 de la Constitución, de consuno con la del artículo 149.1.18. ${ }^{a}$ del texto constitucional, es aducida por los recurrentes al entender que "los preceptos impugnados [los artículos 123.3 y 4 y 126] debilitan la autonomía municipal al priorizar los proyectos de interés singular o autonómico frente al planeamiento municipal, por permitir su ejecución "con independencia de su clasificación y calificación urbanística" (art. 123.4), y exigir "que habrá de adaptarse a los mismos con ocasión de la primera modificación que afecte a este suelo" (art. 126). La indeterminación que caracteriza a los presupuestos - "urgencia" y "carácter sobrevenido"- y al objeto -“carácter estratégico" y "naturaleza análoga”- de los proyectos de interés insular o autonómico permite, igualmente, prescindir de las determinaciones del planeamiento urbanístico municipal».

Una postura frente a la que las representaciones procesales del Gobierno y del Parlamento canarios "coinciden en negar la vulneración del principio de autonomía municipal: por un lado, porque se trata de actuaciones de ordenación del 
territorio que se fundamentan y justifican en la presencia de intereses supralocales; $y$, por otro lado, porque se articula debidamente la participación de las entidades locales a través de los informes preceptivos y la posibilidad de manifestar su disconformidad con los citados proyectos». La Sentencia-suelo canario construye su argumentación sobre dos pilares, a saber: uno, su doctrina a propósito de «los asuntos de competencia autonómica que atañen a los entes locales»; dos, la pertinencia del uso por las normas jurídicas de los llamados "conceptos jurídicos indeterminados»" ${ }^{12}$. Precisadas las exigencias del principio de autonomía local y afirmada la pertinencia de la utilización de los conceptos jurídicos indeterminados en la delimitación del presupuesto de los proyectos de interés insular o autonómica y, aun, en la definición de su objeto, a despecho de su "carácter abierto», el último párrafo de la letra c) del fundamento jurídico 10 de Sentencia-suelo canario marca una cesura radical con la argumentación seguida hasta ese momento para concluir en la censura del cuestionado inciso del artículo 123.4 de la ley canaria ${ }^{13}$.

${ }^{12}$ Los llamados conceptos jurídicos indeterminados -fórmula, en mi opinión, profundamente equívoca y que sería conveniente ir abandonando- han sido, como es de sobra sabido, objeto de profuso tratamiento en la doctrina y en la jurisprudencia. Me remito en este momento, en relación con esta crucial cuestión de la teoría general del derecho, a las impecables consideraciones que la doctora Nuria Ruiz Palazuelos efectúa a este propósito en El control jurisdiccional de la discrecionalidad de los organismos reguladores. Un análisis de casos en los ámbitos de la energía y las telecomunicaciones, prólogo de Luis Martín Rebollo, Thomson Reuters/Aranzadi, Cizur Menor (Navarra), 2018, en particular, 195 y siguientes -que, bajo el rótulo «A modo de recapitulación: sobre el control jurisdiccional de los organismos reguladores en los sectores estudiados», configuran el capítulo III del libro-; y «A vueltas con los conceptos jurídicos indeterminados y su control judicial», Revista Española» de Derecho Administrativo, 196, 2019, 143-166.

${ }^{13}$ El texto de la Sentencia dice así: «Sin embargo, consideración distinta nos merece el artículo 123.4 cuando permite que los proyectos de interés se puedan ejecutar prescindiendo de la clasificación y calificación urbanística. Cuestión sobre la que ya hemos tenido ocasión de pronunciarnos en varias ocasiones. En este sentido, hemos descartado la vulneración del principio de autonomía municipal cuando existe una clara delimitación de las actuaciones integrales estratégicas [las "productivas", en la STC 57/2015, FJ 18 d); las "turísticas" vinculadas a un concreto modelo territorial de desarrollo turístico, en la STC 42/2018, FJ 5 c)], sin que ello supusiera, en ningún caso, descuidar los intereses municipales que deberían ser ponderados en la decisión autonómica. Sin embargo, los proyectos de interés insular o autonómico a que se refiere el artículo 123 de la ley canaria tienen por objeto la transformación física del suelo para conseguir determinadas finalidades consideradas estratégicas, pero que son definidas de forma abierta o indeterminada - "de naturaleza análoga”-. Es por ello por lo que en este caso estamos ante un "debilitamiento del principio de autonomía municipal carente de razón suficiente, lo que representa una quiebra injustificada del principio de autonomía, 'que es uno de los principios estructurales básicos de nuestra Constitución', según dijimos en las SSTC 4/1981, FJ 3; y 214/1989, de 21 de diciembre, FJ 13 c)" [STC 57/2015, FJ 18 a); y en el mismo sentido, la STC 92/2015, de 14 de mayo, FJ 11 a)]. La presencia del interés supralocal en las actuaciones estratégicas abiertamente definidas no es suficiente para poder autorizar su ejecución con independencia de las previsiones urbanísticas del municipio en cuyo territorio se van a asentar. Por ello, debemos estimar el recurso en este punto y declarar la inconstitucionalidad y nulidad del inciso "con independencia de su clasificación y calificación urbanística" del artículo 123.4 de la Ley; desestimando los restantes motivos de impugnación». 
En palabras del Tribunal Constitucional, «la presencia del interés supralocal en las actuaciones estratégicas abiertamente definidas no es suficiente para poder autorizar su ejecución con independencia de las previsiones urbanísticas del municipio en cuyo territorio se van a asentar». La consecución de "determinadas finalidades consideradas estratégicas, pero que son definidas de forma abierta o indeterminada -"de naturaleza análoga"-» se traduce en «un debilitamiento del principio de autonomía municipal carente de razón suficiente, lo que representa una quiebra injustificada del principio de autonomía [...]». Apreciaciones, en suma, que conducen a la anulación del cuestionado inciso del apartado 4 del artículo 123 de la ley canaria. ¿La meritada conclusión es coherente con el razonamiento plasmado en el párrafo anteúltimo de la letra b) del fundamento jurídico 10 de Sentencia-suelo canario a propósito de la utilización de los llamados "conceptos jurídicos indeterminados»? Entiendo que en modo alguno: si el uso de aquéllos, tanto en la delimitación del presupuesto de los proyectos de interés como en la definición de sus objetivos, un uso sujeto a los oportunos controles, incluso de carácter jurisdiccional, es de todo punto procedente, la consecuencia extraída, a saber, ese «debilitamiento del principio de autonomía municipal carente de razón suficiente», supone una "quiebra injustificada» de la lógica argumentativa, sin otra agarradera que la apelación a la «forma abierta o indeterminada" con que se moteja la caracterización de las "finalidades consideradas estratégicas» cuya consecución se pretende con la [excepcional] figura de planeamiento de que se trata. Una "forma abierta o indeterminada» que se anuda a la cláusula ["de naturaleza análoga»] con que se cierra la enumeración [no exhaustiva, por tanto] del apartado primero del artículo 123 de la ley canaria, y que no tiene otro propósito, en consonancia con esa índole extraordinaria o excepcional de la figura "proyectos de interés», que, en consonancia con esos objetivos o "actividades de carácter estratégico", permitir dar respuesta a la consecuencia de finalidades no contempladas, precisamente por razones de «urgencia» o de "carácter sobrevenido», en el planeamiento municipal.

Late, a lo que se me alcanza, en la conclusión extraída un prejuicio, a saber, el urbanismo, esto es, la ordenación del término municipal, como quintaesencia de la autonomía municipal, siendo así que aquél, en cuanto título de intervención, no es sino una más de las competencias de los entes municipales. Prejuicio que conduce ineluctablemente a la resistencia a asumir las consecuencias dimanantes de la admisión de la figura, extraordinaria y excepcional, de los «proyectos de interés insular o autonómico" o, en general, "proyectos singulares de interés autonómico». En tanto que mecanismo extraordinario y excepcional, que pretende dar respuesta a «intereses supramunicipales» por razones sobrevenidas de carácter urgente, la referida figura rompe las determinaciones del planeamiento municipal, justamente en atención a la, por hipótesis, imposible previsión en aquél de las necesidades a cuya cobertura subviene el referido mecanismo. La pretensión de no desvincular absolutamente la "clasificación y calificación urbanística» recogidas en el planeamiento municipal de la concreta ubicación de las actividades de carácter estratégico autorizadas por los «proyectos de interés», y que se cobija en ese altisonante «debilitamiento del principio de autonomía municipal carente de razón suficiente» y, por ende, en «una quiebra injustificada del principio de autonomía [municipal]», conduce en la 
práctica a una dilución de la figura, corolario de la introducción de un inconcuso factor de inseguridad, al deferir a las singulares decisiones jurisdiccionales la determinación casuística de si las concretas localizaciones o ubicaciones dispuestas por los concretos «proyectos de interés» se compadecen o con las exigencias del principio de autonomía municipal.

En definitiva, la figura de los «proyectos singulares de interés autonómi$\mathrm{co}^{114}$ es la «válvula de escape» frente a la praxis dominante entre nosotros a propósito del planeamiento urbanístico. Una praxis, consolidada en un determinado entendimiento, en una ideología del planeamiento urbanístico, que ha conducido, por mor de la elefantiasis que aqueja a la planificación urbanística, a su esclerosis, y que es producto del [pre]juicio de que los planes de urbanismo deben predeterminar de modo exhaustivo y agotador todos los usos y aprovechamientos que el suelo debe albergar. Este «entendimiento» del plan de urbanismo, obediente a una concepción «mítica», por no decir «mixtificada», de aquél, se muestra crecientemente inadecuado e inapropiado para atender a las contingencias de un mundo cabe más flexible y cambiante. Como afortunadamente suele ocurrir, las previsiones «extraordinarias» $\mathrm{y}$ «excepcionales» hacen realidad el debido "principio de realismo» que, a la postre, impide la asfixia a que ineluctablemente abocan los planteamientos cerrados por excesivamente racionalistas.

Recibido: marzo de 2021; ACEPTADO: abril de 2021

${ }^{14}$ Esta figura está contemplada en la mayoría de leyes urbanísticas. 



\title{
UNA LEY DE CONTRATOS PÚBLICOS PARA TIEMPOS DE CRISIS*
}

\author{
Francisco L. Hernández González \\ Profesor titular de Derecho Administrativo \\ Universidad de La Laguna
}

\section{RESUMEN}

El presente trabajo analiza cómo la legislación española de contratación pública ha podido afrontar las situaciones de crisis a lo largo de la historia, destacando las dificultades de la Ley 9/2017 para responder a la situación de crisis sanitaria y económica provocada por la covid-19. Es necesaria una contratación pública estratégica con capacidad para afrontar situaciones futuras de crisis.

Palabras clave: contratos públicos, crisis sanitaria y económica, covid-19, contratación pública estratégica.

\section{A PUBLIC CONTRACTS LAW \\ FOR TIMES OF CRISIS}

\section{Abstract}

This paper analyzes how Spanish public procurement laws has been able to face crisis situations throughout history, highlighting the difficulties of Law 9/2017 to respond to the health and economic crisis situation caused by the covid-19. This requires strategic public procurement with the capacity to respond to future crisis situations.

KEYwords: public contracts; health and economic crisis, covid-19, strategic public procurement. 


\section{PRIMERA ETAPA: DE LA LEY DE CONTRATOS DEL ESTADO DE 1965 A LA LEY DE CONTRATOS DE LAS ADMINISTRACIONES PÚBLICAS DE 1995}

En el año que acaba de finalizar fue el 55 aniversario de la aprobación del Texto Articulado de la Ley de Contratos del Estado de 1965. La que fuera la primera Ley de contratación pública estaba integrada por la entonces nada desdeñable cifra de 125 artículos, 3 disposiciones adicionales y 7 disposiciones finales. Además de consagrar la tesis de la sustantividad del contrato administrativo (en un intento de poner fin a las disputas doctrinales del momento), esta Ley tendría el acierto de agrupar en un único texto las normas de contratación pública aplicables a todos los departamentos ministeriales, superando la diversidad de disposiciones existentes (como años antes había hecho la Ley de procedimiento administrativo de 1958) ${ }^{1}$. De este modo, se imponía un régimen jurídico administrativo que prestaba atención no sólo a la adjudicación de los contratos (como venía sucediendo hasta esa fecha), sino también a su gestación y ejecución ${ }^{2}$. Esta regulación se completó con el Reglamento General de Contratación de 1967, que contaba con 398 artículos, 9 disposiciones finales y una larga disposición derogatoria; dotando de flexibilidad al sistema normativo (por su parte, el reglamento de contratación de 1953 cumplía idéntica función para las entidades locales).

Como se recogía en la exposición de motivos de la Ley de bases de 1963, germen del Texto Articulado de 1965, ya en ese momento la contratación pública se concebía como «un instrumento decisivo para el desenvolvimiento de la acción social», transformándose en "pieza maestra del nuevo estilo de operar administrativo»; al tiempo que se intentaba que el Estado contratase «siempre de la forma más ventajosa y segura».

* Texto de la ponencia impartida en el Seminario sobre El impacto de la crisis en la legislación administrativa, organizado por el Área de Derecho Administrativo de la Universidad de La Laguna, en enero de 2021.

${ }^{1}$ Como señala Ariño (2002, 34-35), la abundante normativa anterior, constituida básicamente por los pliegos de condiciones generales, no constituía propiamente un derecho objetivo de la contratación pública, sino que era más bien una legislación procedimental y rituaria, preocupada exclusivamente por contratar a un precio lo más bajo posible; nos recuerda también este autor que la primera legislación de contratos (Ley de Bases de 1963 y Texto Articulado de 1965) fue obra de dos abogados del Estado, Martínez Esteruelas y Monedero Gil (poco hemos sabido después de la autoría de las leyes que le han sucedido en el tiempo).

${ }^{2}$ La gran virtud de la Ley de Contratos de 1965 fue codificar en un solo texto la regulación del contrato de obras públicas, hasta entonces dispersa y asistemática (VILlar Palasí y Villar Ezcurra, 1983, 47). A pesar de todo fue objeto de una severa crítica, por su «afán excesivamente innovador" y por el uso abusivo de «expresiones pseudotécnicas que oscurecen notablemente su contenido", así como por el «intento de regulación omnicomprensiva de todos los contratos del Estado» (Parada VÁzquez, 1965, 419-420). Vista con la perspectiva del tiempo, qué se podría decir ahora sobre la vigente legislación contractual. 
El legislador se enfrentó al difícil dilema de compatibilizar «agilidad y garantía», compensando las necesarias simplificaciones con un mayor rigor en la actividad de los órganos contratantes.

En esa época, términos como "conflicto de intereses», "fraude», «favoritismo» o «corrupción» no formaban parte del leguaje del legislador. Los problemas eran otros (si se quiere más básicos): de una parte, impedir que la Administración pudiera comprometer sus intereses con un empresario que no dispusiera de medios técnicos y financieros suficientes para cumplir con sus obligaciones, y, de otra, evitar que el contratista pudiera adquirir compromisos desproporcionados que perjudicaran el buen éxito del contrato.

La Ley de Contratos de 1965, con algunas modificaciones (las más importantes en 1973, dando lugar a un nuevo reglamento de contratación en 1975, y en 1986, con motivo de la incorporación a la UE), permitió a la Administración contratar la ejecución de obras, la prestación de servicios y la compra de suministros durante 30 años, hasta su derogación por la Ley de Contratos de las Administraciones Públicas de 1995 (superando situaciones como la crisis del petróleo de 1973 o la generada por la guerra del Golfo de 1990). Entre los objetivos perseguidos hay dos que siguen siendo de actualidad, como son «la necesidad de garantizar plenamente la transparencia de la contratación administrativa como medio para lograr la objetividad de la actividad administrativa y el respeto a los principios de igualdad, no discriminación y libre concurrencia»; y «la simplificación del procedimiento de contratación, suprimiendo algunos trámites que se han considerado menos necesarios y estableciendo preceptos concretos que tienden a lograr la indicada simplificación». Parece que estuviéramos hablando de la reforma de 2017 si no fuera porque el legislador de 1995 apostó entonces por la "potenciación de los contratos menores».

Desde el punto de vista de su contenido, la Ley de contratos de 1995 presentaba una estructura bipolar, que diferenciaba entre una "parte general», aplicable a todos los contratos; $y$ una "parte especial», en la que se recogían las peculiaridades de régimen jurídico de los contratos administrativos típicos. Sus 219 artículos se completaban con 9 disposiciones adicionales, 9 disposiciones transitorias y 4 disposiciones finales. Era una ley sencilla, que se asentaba sobre la distinción entre contratos administrativos y contratos privados, lo que tenía el inconveniente de situar en un ámbito de indefinición el régimen aplicable a los contratos celebrados por las empresas públicas y por otros entes instrumentales de naturaleza privada. Ese intento de eludir la aplicación del régimen de la contratación pública sería la causa de importantes críticas (Baño León las calificó de "piruetas jurídicas» ${ }^{3}$ y, en última instancia, de su posterior derogación (como reconoció la exposición de motivos de la Ley de contratos de 2007). Además, la primera ley de contratos de la democracia inició el proceso de elevar de rango algunos preceptos del Reglamento General de Contratación, introduciendo mayor rigidez en el sistema normativo.

3 Baño León, J.M.a a 2000, 15. 


\section{SEGUNDA ETAPA: DEL TEXTO REFUNDIDO DE 2000 AL TEXTO REFUNDIDO DE 2011}

La historia posterior resulta más conocida. La Ley 13/1995 tuvo una vigencia efímera (la más fugaz de todas) debido a sus numerosas modificaciones, que afectaron a 129 artículos (la más importante en 1999), lo que llevó a su derogación por el Texto Refundido de la Ley de Contratos de las Administraciones Públicas de 2000, que a su vez sería derogado por la Ley de Contratos del Sector Público de 2007 (desarrollada parcialmente por el Real Decreto 817/2009). El cambio de denominación abre paso a una nueva generación de leyes reguladoras de la contratación pública.

La Ley de contratos de 2007, aun teniendo como motivo determinante la trasposición de la Directiva 2004/18/CE, apostó por una reforma global, que se consolidó con la aprobación del Texto Refundido de la Ley de Contratos del Sector Público de 2011. Esta nueva regulación abordaba la actividad contractual pública de acuerdo con una definición funcional más acorde con la normativa europea, extendiendo su aplicación a todos los sujetos del sector público (rompiendo así con la estructura bipolar de la Ley de 1995).

El resultado fue una regulación densa, que dejaba poco espacio para el desarrollo reglamentario (el TR de 2011 constaba de 334 artículos, 36 disposiciones adicionales, 10 disposiciones transitorias, 6 disposiciones finales y 3 anexos), de difícil interpretación y aplicación. Ello motivó duras críticas por parte de la doctrina, sobre la que se llegó a decir que «jamás ha existido una Ley administrativa general tan confusa, tan mal redactada y compleja» (Ramón Parada ${ }^{4}$ ).

Entre sus objetivos, vuelve a aparecer la necesidad de avanzar en la simplificación y racionalización de la compra pública, disminuyendo los costes y cargas para la entidad contratante y para los contratistas. La solución parece pasar por la «plena inserción de los medios electrónicos, informáticos y telemáticos en el ámbito de la contratación pública, a fin de hacer más fluidas y transparentes las relaciones entre los órganos de contratación y los operadores económicos» (lo que conlleva una barrera de acceso para muchas pymes). Estos objetivos se complementan con otras novedades, como la adopción de la terminología comunitaria de la contratación, la incorporación de cláusulas sociales y medioambientales (como criterios de valoración de las ofertas o como condiciones especiales de ejecución) o la regulación del nuevo recurso administrativo especial.

Sin embargo, la Ley de Contratos de 2007 mostró pronto sus debilidades. Esta norma fue una herramienta ineficaz para combatir los efectos de la crisis económico-financiera iniciada en 2007. Adoptada la decisión de combatir los efectos de la crisis mediante la ejecución de obra pública (los conocidos Plan E y Plan.Es Economía Sostenible), el Gobierno se vio obligado a soslayar la aplicación de esa Ley para poder ejecutar en plazo los proyectos aprobados, estableciendo en su lugar un régimen jurídico ad hoc, más flexible, que -entre otras medidas- venía a declarar

\footnotetext{
${ }^{4}$ Parada Vázquez, R., 212, 235.
} 
la urgencia de la tramitación, acortar los plazos de tramitación, suprimir requisitos documentales o eximir de la clasificación del contratista. Los procedimientos ordinarios de contratación dejaron patente su escasa operatividad (según el Tribunal de Cuentas, los dos procedimientos más utilizados fueron el negociado sin publicidad y la contratación menor: en el primer plan los porcentajes fueron superiores al $40 \%$ $y$ al 30\%, respectivamente; $y$ en el segundo plan, a la inversa).

De otra parte, la nueva regulación tampoco evitó los casos de corrupción que salpicaron toda la geografía nacional en esos años. Quedó claro que los problemas de corrupción (que los hay allí donde hay posibilidades de enriquecimiento fácil) no se combaten sólo con nuevas leyes, cada vez más complejas: mayor regulación no es sinónimo de menor corrupción. Con independencia de la posibilidad de introducir algunas medidas concretas (cabe recordar ahora el «Decálogo de reglas para prevenir la corrupción en los contratos públicos» elaborado por Gimeno Feliu'), la mejora de la regulación no es suficiente si -como sostiene Andrés Betancor ${ }^{6}$ - no se actúa sobre los incentivos, tanto los que incitan a la corrupción como aquellos otros que la disuaden (establecimiento de un sistema de denuncia anónima, reforzamiento de los controles internos, trazabilidad y transparencia de la toma de decisiones, mejora de los medios a disposición de los tribunales de justicia, etc.), y si -añadimos nosotros- no se logra una mayor profesionalización de la contratación pública, mejorando la cualificación de los servicios de contratación (como propone el último Informe anual de la Oficina Independiente de Regulación y Supervisión de la Contratación -OIReScon-, de diciembre de 2020, que recomienda crear itinerarios de especialización).

En definitiva, la reforma de 2007 dio lugar a una legislación más prolija en extensión (el TR de 2011 tenía 115 artículos y 27 disposiciones adicionales más que la Ley de 1995) y más compleja en contenido sin que ello se tradujera en una mejor gestión y en una menor corrupción.

\section{TERCERA Y ÚLTIMA ETAPA: LA LEY DE CONTRATOS DEL SECTOR PÚBLICO DE 2017}

Cuando se pensaba que no podía haber textos más largos, la vigente Ley de contratos del sector público de 2017 bate todos los récords, con sus 347 artículos (de los cuales 312 tienen total o parcialmente carácter básico), 59 disposiciones adicionales, 5 disposiciones transitorias, 16 disposiciones finales y 6 anexos. Esta norma pretende ser un verdadero código de contratación pública, con el inconveniente de la rigidez formal que le otorga su carácter legal (también lleva camino de superar el récord de modificaciones parciales, 11 hasta ahora).

\footnotetext{
5 Gimeno Feliu, J.M. ${ }^{a}, 2014,1-8$.

6 Betancor, A., 2014, 1-3.
} 
El motivo de la aprobación de la Ley fue la transposición de las Directivas de contratación pública de 2014. No obstante, el nuevo texto se elaboró en un clima social y político condicionado por numerosos casos de corrupción, algunos muy mediáticos (como son los casos tres por ciento, Innova, Imelsa, Nóos, Púnica, Madeja, Palau, Gürtel, etc.). Se trata, por ello, de una ley que nace inspirada en la desconfianza (hacia los políticos, los funcionarios, los empresarios, los mecanismos de control...). Su redactor parece olvidar las decenas de miles de contratos que las Administraciones Públicas adjudican cada año: según datos del OIReScon, en 2019 se celebraron en nuestro país 129594 licitaciones públicas (28 283, correspondientes al sector público estatal; 34 925, al sector público autonómico; y 66 386, al sector público local). Esta desconfianza alcanza también a las empresas públicas y a los medios instrumentales, pero esto es otra historia que sería larga de contar.

A diferencia de reformas anteriores, los partidos políticos convierten la lucha contra la corrupción en uno de los objetivos de la nueva regulación. Por vez primera se recoge la obligación de los órganos de contratación de adoptar las «medidas adecuadas para luchar contra el fraude, el favoritismo y la corrupción, y prevenir, detectar y solucionar de modo efectivo los conflictos de intereses que puedan surgir en los procedimientos de licitación». También se exige que el informe anual de la OIReScon incorpore toda la información relacionada con la prevención, detección y notificación adecuada de los casos de fraude, corrupción, conflicto de intereses y otras irregularidades graves en la contratación 7 . De igual manera, la Estrategia Nacional de Contratación Pública deberá incorporar medidas que permitan combatir la corrupción. Esto parece una verdadera «declaración legal de culpabilidad ${ }^{8}$.

En esta línea, la medida estrella de la nueva Ley fue la supresión del procedimiento negociado sin publicidad por razón de la cuantía y la restricción de la contratación menor (que había sido el blanco de todas las críticas); así como la creación, como mecanismos alternativos, del procedimiento abierto simplificado y supersimplificado (abreviado o sumario). Medidas que fueron consecuencia de la transacción de las enmiendas n..$^{\circ} 125$ y 583 presentadas por los grupos parlamentarios de la oposición.

Se puede decir, sin temor a equivocarnos, que en este aspecto la reforma no ha cumplido sus objetivos. No sólo porque no ha logrado reducir el número de contratos menores y evitar el fraccionamiento indebido de los contratos (la Administración encontró en los anticipos de caja fija una solución parcial), sino especialmente porque los mismos grupos parlamentarios que promulgaron el cambio, una vez en el

\footnotetext{
${ }^{7}$ Es el módulo IV del informe anual de 2021, que tiene como título «la prevensión y lucha contra la corrupción en la contratación pública».

${ }^{8}$ La nueva Ley refuerza la visión hacendística de la contratación pública que, como apunta Santamaría Pastor, se incorpora ya en los reglamentos de 1967 y 1975, lo que responde al afán de control del Ministerio de Hacienda sobre los departamentos inversores (a los que siempre ha considerado «derrochadores impenitentes y tendencialmente corruptos») y a la desconfianza visceral sobre el contratista tipo, al que ve como «un pirata despachado», sólo atento «a captar fondos públicos para su negocio" $(2013,32)$.
} 
Gobierno, han modificado ambas regulaciones. Por lo que se refiere a la regulación de la contratación menor contenida en el artículo 118 (cuya interpretación provocó la división de las juntas consultivas) ${ }^{9}$, el Real Decreto-ley 3/2020 alteró su redacción, optando por la tesis más flexible a su utilización (de forma provocativa, Julio González ${ }^{10}$ propone la derogación del precepto, al que califica como un "pequeño franquestein») $)^{11}$. De repente, lo que era malo dejó de serlo: ahora, el contrato menor es necesario para dinamizar la compra pública local y para favorecer a las pymes (la realidad es que siempre lo fue). Por otro lado, el procedimiento abierto simplificado ha sido modificado cuatro veces en un solo año (Reales Decretos-leyes 15/20 y 16/2020 y Leyes 3/2020 y 11/2020), lo que evidencia las dificultades de su aplicación.

\section{LAS DIFICULTADES DE LA LEY 9/2017 PARA RESPONDER A LA SITUACIÓN DE CRISIS SANITARIA Y ECONÓMICA PROVOCADA POR LA COVID-19. LA NECESIDAD DE LLEVAR A BUEN PUERTO EL PLAN DE RECUPERACIÓN, TRANSFORMA- CIÓN Y RESILIENCIA DE LA ECONOMÍA ESPAÑOLA}

Como en anteriores ocasiones, la situación de crisis sanitaria y económica provocada por la covid-19 ha vuelto a mostrar las graves deficiencias de la legislación de contratos.

En un primer momento, ante la falta de planificación y la necesidad de dar una respuesta inmediata a la situación de emergencia sanitaria, el Gobierno decidió anteponer el interés público (proteger a las personas) a los principios de la contratación pública. Es así que, frente a la recomendación de la Comisión Europea (que en abril de 2020 propuso utilizar el procedimiento negociado sin publicidad), el Real Decreto-ley 7/2020 (art. 16) permite la tramitación de emergencia de la contratación de los bienes o servicios precisos para hacer frente a la covid-19 (lo que lleva a

${ }^{9}$ La oscura redacción del artículo 118.3 LCSP motivó que, inicialmente, las juntas consultivas de contratación se dividieran en dos grupos: de un lado, las partidarias de una interpretación restrictiva (Informe JCCA de Aragón n. ${ }^{\circ}$ 3/2018, seguido también por las de Madrid y País Vasco); y de otro, más numeroso, aquellas otras que postulaban una interpretación más flexible del precepto (Informe JCCP del Estado n. ${ }^{\circ}$ 41/2017, seguidas también por las de Andalucía, Canarias, Cataluña, Comunidad Valenciana y Galicia). Esta última fue también la posición que adoptó la Instrucción de la OIReSCcon n. ${ }^{\circ} 1 / 2019$, de 28 de febrero (y posterior nota aclaratoria).

${ }^{10}$ González García, J., 2020, 1-3.

${ }_{11}$ Disposición adicional primera del Real Decreto-ley 3/2020, de 4 de febrero (que incorpora la redacción que tenía la D.A. 34 del decaído proyecto ley de Presupuestos Generales del Estado para el año 2019). Previamente, la Disposición final 44.2 de la Ley 6/2018, de 3 de julio, de Presupuestos Generales del Estado para el año 2018, estableció una excepción al régimen general para los contratos celebrados por los agentes públicos del Sistema Español de Ciencia, Tecnología e Innovación, con el fin de elevar el límite de los contratos menores de suministro o de servicios a 50000 euros (añadiendo una nueva Disposición adicional LCSP, la n. ${ }^{\circ} 54$, que sería modificada por la Disposición final 2. ${ }^{a}$ del Real Decreto-ley 3/2019, de 8 de febrero, de medidas urgentes en el ámbito de la Ciencia, la Tecnología, la Innovación y la Universidad). 
la Junta Consultiva de Contratación Pública del Estado y al OIReScon a elaborar sendos documentos interpretativos, recordando las garantías mínimas de publicidad y transparencia). No obstante, esta medida pronto se reveló insuficiente, por lo que - en menos de un mes y siempre por la vía de urgencia- el Gobierno modificó en dos ocasiones dicho precepto con la finalidad de introducir nuevas excepciones a la legislación de contratos (DF 6. ${ }^{a}$ del R.D.-ley 8/2020 y DF $2 .{ }^{a}$ del R.D.-ley 9/2020). En especial, destaca el establecimiento de unas reglas específicas para la contratación de material en el extranjero, que incluye la posibilidad de anticipar el pago a la realización de la prestación (lo que resulta trascendental dada la falta de proveedores en nuestro país y la exigencia de competir con otros países en la adquisición de material). La rúbrica del Capítulo V del Real Decreto-ley 7/2020 es elocuente: «medidas para la gestión eficiente de las Administraciones Públicas». ¿Significa esto un reconocimiento de que los procedimientos ordinarios no son eficientes y que los mecanismos de racionalización de la contratación no funcionan? La respuesta parece haberla dado ya el propio Gobierno (a quien, por cierto, hubo que recordarle que la emergencia no está reñida con la transparencia).

No menos relevante es la falta de coordinación entre las Administraciones Públicas. Tras un momento inicial de tensión entre el Gobierno Central y las Comunidades Autónomas debido a la escasez de material, en agosto de 2020, el Ministerio de Sanidad licitó el mayor acuerdo marco de adquisición centralizada de la historia, con el objeto de adquirir material sanitario y equipos de protección individual por un valor superior a los 2500 millones de euros. Dicho acuerdo vino a sustituir al publicado dos semanas antes, que se decidió no adjudicar para poder atender las peticiones de aquellas Comunidades Autónomas que solicitaron su adhesión con posterioridad al valorar el riesgo de desabastecimiento, lo que provocó un cierto retraso (los últimos 5 lotes se adjudicaron el 30 de noviembre de 2020, 9 meses después del inicio de la pandemia). De esta forma, las administraciones únicamente tendrán que firmar los contratos de suministro con las empresas adjudicatarias, sin necesidad de nueva licitación. A su vez, en julio de 2020, España se adhirió a la compra centralizada de vacunas realizada por la UE, que prevé una compra inicial de 200 millones de dosis a diferentes empresas farmacéuticas, lo que permitirá contrarrestar la posición dominante de los proveedores y garantizar el abastecimiento de todos los Estados miembros.

$\mathrm{Y}$, en un segundo momento, la imperiosa necesidad de comprometer los fondos de recuperación europeos (en especial, los 72200 millones de euros de transferencias del programa Next Generation EU correspondientes al periodo 20212023), ha llevado al Gobierno a excepcionar nuevamente la aplicación de la LCSP, estableciendo un régimen especial que permita ejecutar "de modo ágil y eficaz» los proyectos previstos en el Plan de Recuperación, Transformación y Resiliencia de la Economía española. La regulación contenida en el Capítulo III del Título IV del Real Decreto-ley 36/2020 insiste en la tramitación urgente, eleva los importes de los procedimientos abiertos simplificados (tanto ordinario como abreviado), simplifica el régimen de autorizaciones e informes a recabar, promueve la elaboración de pliegos-tipo, acorta los plazos para la interposición y pronunciamiento del recurso especial, matiza el riesgo operacional de las concesiones y flexibiliza los encargos a 
medios propios (cuya regulación se modifica también en la Ley 11/2020, de Presupuestos Generales del Estado, aprobada el mismo día) ${ }^{12}$.

Dejando a un lado el alcance de las medidas adoptadas (que voces autorizadas como la de Moreno Molina ${ }^{13}$ han calificado de insuficientes), interesa poner el acento en el espíritu de esta regulación y los objetivos que persigue. Según se especifica en la exposición de motivos y se recoge en el propio articulado, el Real Decreto-ley responde a la necesidad acuciante de agilizar los procedimientos, «simplificando sus trámites y eliminando cuellos de botella normativos, de manera que la ejecución del Plan de Recuperación, Transformación y Resiliencia pueda llevarse a cabo de la forma inmediata». A tal fin, «incorpora una serie de instrumentos de carácter general dirigidos a reducir las barreras normativas y administrativas, así como un conjunto de medidas de modernización de las administraciones públicas, que permitan una gestión más ágil y eficiente, para facilitar la absorción de los mencionados fondos»; debiendo la Administración guiar su actuación por los «principios de agilidad, celeridad, simplicidad y claridad en los procedimientos, procesos y ejecución de tareas». Pero ¿no son éstos principios que deben regir toda la actuación de la Administración, no sólo en tiempo de crisis? Al menos, así lo dispone la Ley 40/2015.

\section{REFLEXIÓN FINAL}

En fin, el breve espacio de tiempo transcurrido entre las dos últimas grandes crisis económicas nos hace pensar que estamos ante una tendencia que se reproducirá cada vez con mayor frecuencia. Parece evidente que, en ambas crisis, los procedimientos tradicionales han sucumbido frente al establecimiento de reglas especiales de contratación. Sin embargo, frente a estas soluciones contingentes, de excepcionalidad, la tutela de los bienes jurídicos a los que sirve la contratación pública hace indispensable impulsar una contratación pública estratégica, que al mismo tiempo

${ }_{12}$ Con posterioridad a la elaboración del presente texto, la Junta Consultiva de Contratación Pública del Estado elaboró la Instrucción de 11 de marzo de 2011, sobre la tramitación de urgencia de los procedimientos de licitación de los contratos que se vayan a financiar con fondos procedentes del Plan de Recuperación, Transformación y Resiliencia, en la que se afirma que no cabe efectuar una declaración ex lege de urgencia de todos los procedimientos de licitación de contratos financiados con cargo a los citados fondos, sino que ha de justificarse caso por caso, y que es imprescindible respetar las exigencias de los principios de no discriminación, igualdad de trato y proporcionalidad. Siendo esto así formalmente, en la práctica, la gravedad de la situación económica del país, que cerró el año 2020 con una caída del PIB del 11\% (la peor de la OCDE y la mayor desde la guerra civil, superando a la provocada por la segunda guerra mundial), con 755000 trabajadores en ERTE (expediente de regulación temporal de empleo), con 724000 nuevos desempleados (que sitúa las cifras de paro en más 3,8 millones de personas, a los que hay que sumar otro 1,5 millón de trabajadores en situación de subempleo; con una tasa de paro juvenil superior al $40 \%$, esto es, 20 puntos por encima de la media europea) y 360105 afiliados menos a la Seguridad Social, hace difícil pensar que no sea posible justificar la urgencia de la mayor parte de los contratos que se liciten.

${ }^{13}$ Moreno Molina, J.A., 2021, 1-7. 
sea eficiente y dinamizadora de la actividad económica, lo que exige conciliar adecuadamente los principios de concurrencia y transparencia con procedimientos eficaces, que primen la calidad de la prestación y den respuesta a las necesidades colectivas en plazos razonables.

Las dos crisis económicas vividas en los últimos años han puesto de manifiesto la necesidad de reforzar la proactividad, la coordinación y la transparencia. En este sentido, cabe recordar las palabras de Gimeno Feliu ${ }^{14}$, en el sentido de que «necesitamos una nueva cultura de contratación pública: responsable, abierta, innovadora, cooperativa, profesionalizada, tecnológica y transformadora. Una contratación pública estratégica y proactiva y no meramente reactiva, que ponga en valor la calidad de la prestación». Pero hay que añadir también que, sobre todo, debemos garantizar un régimen de contratación que permita dar respuesta a las apremiantes necesidades públicas y que actúe como dinamizador de un modelo económico más sostenible, inteligente y resiliente que nos prepare mejor para afrontar futuras crisis sanitarias, climáticas, alimentarias, tecnológicas o energéticas.

RECiBIDO: marzo de 2021; ACEPTADO: abril de 2021

${ }^{14}$ Gimeno Feliu, J.M. ${ }^{a}$, 2020, 24; y 2021, 18. 


\section{BIBLIOGRAFÍA CITADA}

Ariño, G., Comentario a la Ley de Contrato de las Administraciones Públicas, Comares, 2002.

Baño León, J.M.a «La influencia del Derecho Comunitario en la interpretación de la Ley de Contratos de las Administraciones Públicas», Revista de Administración Pública, n. ${ }^{\circ}$ 151, 2000, p. 15.

Betancor, A., "Corrupción y contratación pública», Horror Vacui, Blogs Expansión, 3 de noviembre de 2014, disponible en https://www.expansion.com/blogs/horror-vacui.

Gimeno Feliu, J.M. ${ }^{a}$, «Decálogo de Reglas para prevenir la corrupción en los Contratos Públicos», Observatorio de Contratación Pública, 12 de noviembre de 2014, disponible en http:// www.obcp.es/.

Gimeno Feliu, J.M. ${ }^{a}$, «La crisis sanitaria covid-19. Reflexiones sobre su incidencia en la contratación pública y las soluciones adoptadas», Observatorio de Contratación Pública, 22 de abril de 2020, disponible en http://www.obcp.es/.

Gimeno Feliu, J.M.a, «De las ideas a la acción en la gestión de los fondos europeos: reflexiones propositivas para el diseño de una adecuada gobernanza en su ejecución», Observatorio de Contratación Pública, 25 de enero de 2021, disponible en http://www.obcp.es/.

Gimeno Feliu, J.M. ${ }^{a}$, «De las ideas a la acción en la gestión de los fondos europeos: reflexiones propositivas para el diseño de una adecuada gobernanza en su ejecución», Observatorio de la Contratación Pública, 25 de enero de 2021, disponible en http://www.obcp.es/opiniones/ de-las-ideas-la-accion-en-la-gestion-de-los-fondos-europeos-reflexiones-propositivas-para.

Gimeno Feliu, J.M.a «La adquisición masiva de vacunas», El Cronista del Estado Social y Democrático de Derecho, n. ${ }^{\circ}$ 93-94, 2021.

González García, J., "Contratos menores: nuevo cambio legislativo», Global Politics and Law, 5 de febrero de 2020, disponible en https://www.globalpoliticsandlaw.com/.

Moreno Molina, J.A., «Las insuficientes medidas de simplificación y agilización de la contratación pública recogidas en el Real Decreto Ley 36/2020», Observatorio de Contratación Pública, 4 de enero de 2021, disponible en http://www.obcp.es/.

Parada Vázquez, R., «La nueva Ley de Contratos del Estado», Revista de Administración Pública (RAP), n. ${ }^{\circ} 47,1965$.

Parada Vázquez, R., Curso de Derecho Administrativo, t. I, 19. ${ }^{a}$ ed., Marcial Pons, 2012, p. 235.

Santamaría Pastor, J.A., «La constante e interminable reforma reforma de la normativa sobre contratación pública», Revista Española de Derecho Administrativo (REDA), n. ${ }^{\circ}$ 159, 2013 , p. 32.

Villar Palasí, J.L. y Villar Ezcurra, J.L., Principios de Derecho Administrativo, t. III, Contratación administrativa, Universidad Complutense, 1983. 



\title{
LA PRUEBA PERICIAL DIGITAL Y LA CADENA DE CUSTODIA
}

\author{
José Miguel González Reyes \\ Profesor asociado Administrativo de Derecho \\ Universidad de La Laguna
}

\section{RESUMEN}

La irrupción de la denominada revolución digital ha supuesto en todos los órdenes una modificación de los comportamientos sociales planteando a nuestro Derecho nuevos retos que hasta ahora eran desconocidos. El presente trabajo constituye un estudio de los requisitos que han de tener las pruebas derivadas de la comisión de delitos a través de medios informáticos, su licitud y modo de incorporación al proceso penal. En este contexto, viene siendo tradicional en la doctrina y jurisprudencia penal española que para que una prueba se repute lícita, esto es, en última instancia válida, ha de traerse al proceso con una serie de garantías, siendo la más relevante la de poder ser sometida a contradicción, momento en el que la pericia informática, a través de la práctica forense, puede alcanzar un papel en orden a confirmar o denegar la validez de aquéllas para operar como prueba de cargo o descargo en el proceso penal.

Palabras Clave: derecho procesal digital, ciberdelito, indefensión, prueba pericial.

\section{PERICIAL EVIDENCE IN CRIMES COMMITTED THROUGH COMPUTER MEDIA AND THE "CHAIN OF CUSTODY"}

\section{Abstract}

The appearance of the dominant digital revolution has led to a modification of social behaviour in all areas, posing new challenges to the Law that were until now unknown. This work constitutes a study of the requirements for gathering evidence, derived from the commission of crimes through computer media, its legality, and the way in which they are incorporated into criminal proceedings. In this context, it has been traditional in criminal doctrine and jurisprudence that an evidence, to be considered lawful, that is, ultimately valid, it must be brought to the process with a number of procedural guarantees, being the most relevant one the possibility to be subject to contradiction. It is in this light when computer expert, through their forensic practice, can be involved in order to confirm or deny the validity of potential evidence which, in turn, may relate to the charge or discharge of criminal proceedings.

KeYwords: digital procederal law, cybercrime, helplessness, pericial evidence. 


\section{SOBRE LA NATURALEZA DE LA PRUEBA INFORMÁTICA Y EL MODO DE SU INCORPORACIÓN AL PROCESO PENAL}

Lo que se viene entendiendo como prueba informática o evidencia electrónica a día de hoy no ha sido descrito por norma jurídica alguna en España ${ }^{1}$. Si bien, no obstante, sí que se han definido en nuestro ordenamiento interno los conceptos de documento electrónico y firma electrónica ${ }^{2}$.

Como quiera que sea, con mejor precisión, en el ámbito europeo (y del que España forma parte), se ha realizado una mejor aproximación a ese concepto por mor de la Decisión 2002/630/JAI del Consejo, de fecha 22 de julio de 2002, relativa a la creación del programa marco para la cooperación policial y judicial en materia penal (AGIS) ${ }^{3}$. En este instrumento jurídico, se define la prueba electrónica como «la información obtenida a partir de un dispositivo electrónico o medio digital, el cual sirve para adquirir convencimiento de la certeza de un hecho». También define los medios de prueba electrónicos como «los soportes técnicos que recogen la prueba electrónica».

La prueba informática o evidencia digital ${ }^{4}$ implica su necesaria contextualización en el ámbito de las tecnologías de la comunicación e información. La información que generan las operaciones de informática de carácter delictivo resulta producida, almacenada o transmitida mediante dispositivos o instrumentos digitales. De este modo, con carácter general se viene entendiendo por prueba informática

${ }^{1}$ Para una aproximación al concepto de prueba informática vid. Illán Fernández, J.M., La Prueba Electrónica, Eficacia y Valoración en el Proceso Civil, Aranzadi, Navarra, 2009; Hernández Guerrero, F.F.; Álvarez de los Ríos, J.L., «Medios informáticos y proceso penal», en Estudios Jurídicos, Ministerio Fiscal IV, CEJAJ, Madrid, 1999; y Sanchís Crespo, C., "La prueba en soporte electrónico", en Las Tecnologías de la Información y de la Comunicación en la Administración de Justicia. Análisis sistemático de la Ley 18/2011, de 5 de julio (coord. Gamero Casado y Valero Torrijos), Thomson Reuters-Aranzadi, Navarra, 2012.

${ }^{2}$ Se trata de normas extraprocesales que ofrecen definiciones acerca de medios de prueba concretos, como la que hace la Ley 59/2003, de 19 de diciembre, de Firma Electrónica. En el art 3.5 de esta norma se concreta una definición de documento electrónico como «la información de cualquier naturaleza en forma electrónica, archivada en soporte electrónico según un formato determinado y susceptible de identificación y tratamiento diferenciado». Se trata de una definición amplia si bien la firma electrónica en sí no da al documento electrónico carácter de prueba documental en juicio, sino únicamente al documento electrónico firmado electrónicamente. Por su parte, el Reglamento eIDAS 910/2014 lo define como el documento redactado y archivado en soporte electrónico que incorpora datos que están firmados electrónicamente.

3 En el ámbito europeo, no obstante, destaca la Directiva 2006/24/CE sobre la conservación de datos generados o tratados en relación con la prestación de servicios de comunicaciones electrónicas de acceso público o de redes públicas de comunicaciones, así como la Directiva 2013/40/ UE, que establece las normas mínimas a la definición de las infracciones penales y a las sanciones aplicables en el ámbito de los ataques contra los sistemas de la información.

${ }^{4}$ Es importante señalar aquí que el uso en castellano de la palabra «evidencia» como sinónimo de "prueba» o de «indicio» se debe a la influencia de la palabra inglesa evidence, que en este idioma hace referencia a toda prueba (circunstancial, testimonial o material) que se alega en un proceso judicial. 
o evidencia electrónica la referida a la que contiene cualquier tipo de información almacenada o trasmitida a través de dispositivos informáticos que tiene la virtualidad de poder acreditar los hechos sobre los que versa el proceso ${ }^{5}$. Se trataría, en última instancia, de toda aquella información digital que permita constatar la realidad de un hecho afirmado por las partes y que resulta relevante para el objeto del proceso judicial ${ }^{6}$.

En este sentido, las innovaciones tecnológicas en el ámbito delictual se pueden presentar como un medio de prueba autónomo ex art. 299.2 de la $\mathrm{LEC}^{7}$ pudiendo revestir los caracteres de la prueba documental, que será su consideración corriente ${ }^{8}$. Pero también, de prueba pericial; o, incluso, testifical, si se deriva del testimonio de la persona que ha dado noticia del hecho delictivo por inmediación o conocimiento de lo contenido en los elementos informáticos?.

Sobre el carácter documental o no de la prueba electrónica existe una controvertida discusión en la Doctrina. El punto de partida lo constituye el art. 326.1 de la LEC, que viene a conferir al documento privado el valor de prueba plena en el proceso si no es impugnado por la parte a quien perjudica y que resulta, en general, más favorable del aplicable si careciera de esa consideración ${ }^{10}$. Así, por un lado, nos encontramos con una posición que atribuye a la prueba digital un carácter autó-

${ }^{5}$ Por su parte, el dispositivo digital sería todo sistema informático, incluyendo sistemas de almacenamiento y transmisión de la información por medios digitales. Hay que tener en cuenta que todo dispositivo digital es, a su vez, electrónico, pero que no todo dispositivo electrónico es digital.

${ }^{6}$ Cfr., Bueno de Mata, F., Prueba Electrónica y Proceso 2.0, Tiran lo Blanch, Valencia, 2014, p. 130.

7 El art. 299 de la LEC establece como medios de prueba de los que se podrá hacer uso en juicio: (1) Interrogatorio de las parte; (2) Documentos públicos; (3) Documentos privados; (4) Dictamen de peritos; (5) Reconocimiento judicial; (6) Interrogatorio de testigos. No obstante, también se admitirán como se establece en su apartado 2: «los medios de reproducción de la palabra, el sonido y la imagen, así como los instrumentos que permiten archivar y conocer o reproducir palabras, datos, cifras y operaciones matemáticas llevadas a cabo con fines contables o de otra clase, relevantes para el proceso».

${ }^{8}$ Véanse, también, los arts. 384.1 y 382.2.3 y 4 de la LEC.

9 Consciente del impacto de las nuevas tecnologías y sus consecuencias en el mundo jurídico, la STS de 3 de noviembre de 1997, Sala 3. ${ }^{\text {a }}$, describe en su FJ 10 la trascendencia de este nuevo modo de interactuación cuando expresa: «... Estamos asistiendo, en cierto modo, en algunas facetas de la vida, incluso jurídica, al ocaso de la civilización del papel, de la firma manuscrita y del monopolio de la escritura sobre la realidad documental. El documento, como objeto corporal que refleja una realidad fáctica con trascendencia jurídica, no puede identificarse, ya, en exclusiva, con el papel, como soporte, ni con la escritura, como unidad de significación. El ordenador y los ficheros que en él se almacenan constituyen, hoy día, una nueva forma de entender la materialidad de los títulos valores y, en especial, de los documentos mercantiles».

${ }^{10}$ Frente a ese valor de prueba plena como documento, la consideración de la prueba electrónica como simple instrumento de archivo informático, en los términos del art. 384 de la LEC, restringiría la misma a un valor probatorio conforme a las reglas de la sana crítica del juez. 
nomo gozando de naturaleza propia y singular ${ }^{11}$; por otro, a los que de modo análogo entienden que la prueba electrónica equivale a los medios de prueba tradicionales ${ }^{12}$. Más allá de las disquisición doctrinal, el Código Penal da carácter de documento, examinable de oficio por el tribunal (como prevé el art. 726 de la LECrim), a todo soporte material con datos de relevancia jurídica ${ }^{13}$. De aquí, podría intuirse que el documento electrónico surtiría los mismos efectos que el documento en papel a nivel jurisdiccional ${ }^{14}$. Esto es, que habría una equivalencia funcional entre ambas. Idéntico carácter de documento, y, con ello, de prueba admisible en juicio como

11 Vid. esta idea en Montón Redondo, A., «Medios de reproducción de la imagen y el sonido" en La prueba, Cuadernos de Derecho Judicial núm. 7, CGPJ, Madrid, 2000, p. 50 y ss.; y también Álvarez-Cienfuegos SuÁrez, J.M.a , «Las obligaciones concertadas por medios informáticos y la documentación", La Ley. Revista jurídica española de doctrina, jurisprudencia y bibliografía núm. 4, 1992, p. 1013 y ss.

${ }^{12}$ Dicha previsión cuenta con abundante apoyo jurisprudencial. Así, la sentencia de 3 de octubre de 1997 ha señalado: «En torno al concepto de documento como instrumento casacional con eficacia demostrativa del error judicial cuya censura constituye la esencia del Motivo, las Sentencias de éste Tribunal de 23 de diciembre de 1996, entre otras, centran su extensión en los siguientes términos: A Que exista un documento, lo que equivale: a) Que se trate de un documento en sentido estricto, y ha de entenderse por tal el escrito, en sentido tradicional, o aquella otra cosa que, sin serlo, pueda asimilarse al mismo, por ejemplo, un diskette, un documento de ordenador, un vídeo, una película, etc., con un criterio moderno de interacción de las nuevas realidades tecnológicas, en el sentido en que la palabra documento figura en algunos diccionarios como "cualquier cosa que sirve para ilustrar o comprobar algo" (obsérvese que se trata de una interpretación ajustada a la realidad sociológica, puesto que, al no haber sido objeto de interpretación contextual y auténtica, puede el aplicador del derecho tener en cuenta la evolución social), siempre que el llamado "documento" tenga un soporte material, que es lo que sin duda exige la norma penal. (Por todas, SS.TS. 1.114/94, de 3 de junio, 1.763/1994, de 11 de octubre y 711/1996, de 19 de octubre). En la actualidad dicha fórmula jurisprudencial tiene adecuada correspondencia en la norma contenida en el artículo 26 del nuevo Código penal, según el cual "A los efectos de este Código se considera documento todo soporte material que exprese o incorpore datos, hechos o narraciones con eficacia probatoria o cualquier otro tipo de relevancia jurídica"».

13 El documento electrónico ha sido definido por la doctrina como «toda representación en forma electrónica de hechos jurídicamente relevantes, susceptibles de ser representado en forma humanamente comprensible». Vid. Álvarez-Cienfuegos SuÁrez, J.M. a , «Los delitos de falsedad y los documentos generados informáticamente. Concepto procesal y material de documento: nuevas técnicas», en Cuadernos de Derecho judicial, CGPJ, Madrid, 1993, p. 8.

${ }_{14}$ La LEC ha procedido a dar un tratamiento autónomo a los medios de reproducción de la palabra, el sonido y la imagen, diferenciándolos de la prueba documental. Consecuencia de la consideración de la naturaleza autónoma de tales medios probatorios es el tratamiento diferenciado que recibe en la LEC, a saber: (1) El tratamiento independiente que la LEC da a la prueba documental a la que consagra los artículos 317 a 334 y a los medios de reproducción de la palabra, el sonido y la imagen, regulados en los artículos 382 a 384; (2) El artículo 265 LEC al disponer los documentos, escritos u objetos que han de acompañar a la demanda distingue en el apartado $1 .^{\circ}$ "los documentos en que las partes funden su derecho" y en el apartado $2 .{ }^{\circ}$ "los medios e instrumentos a que se refiere el apartado 2 del artículo 299 -medios de reproducción de la palabra, el sonido...- si en ellos se fundaran las pretensiones...»; (3) Los artículos 267 y 268 LEC establecen la forma de presentación de documentos públicos -copia simple y si se impugnara su autenticidad, mediante original, copia o certificación-y de los documentos privados - original o copia autenticada, uniéndose a los autos o dejando testimonio, con devolución de los originales o copias, o designación del archivo, 
documental, otorga el art. 24.2 de la Ley 34/2002, de 11 de julio, de Servicios de la Sociedad de la Información y de Comercio Electrónico al soporte electrónico en que conste un contrato celebrado por vía electrónica ${ }^{15}$.

Como quiera que sea, con carácter general, para el TS las evidencias digitales no tendrían el carácter de prueba documental (salvo en los documentos y contratos firmados electrónicamente, como se ha dicho); si bien, en ciertas ocasiones, se ha mostrado favorable a ese carácter documental de la evidencia electrónica como describe, v.gr., la STS de 12 de junio de $1999^{16}$. Otras veces, como ocurre en el ámbito laboral, se le priva de aquel carácter, como también explica la Sala de lo Social en la STS 6216/2011 ${ }^{17}$.

Debiera, por tanto, acogerse, en cualquier caso, un concepto amplio de documento que abarca tanto los soportes tradicionales (papel) como los nuevos soportes tecnológicos o informáticos (DVD, pendrive, etc.) para que la previsión del art. 26 del Código Penal pueda tener virtualidad respecto a cualquier soporte que, en última

protocolo o registro donde se encuentren-, no resultando de aplicación a los medios de reproducción de la palabra, el sonido y la imagen.

${ }_{15}$ Además, tal posición se encontraría positivamente respaldada por el tratamiento que el art. 3.8 de la Ley 59/2003 de Firma Electrónica da a los soportes de los documentos electrónicos firmados electrónicamente, ya que esta Ley los dota del carácter de prueba documental en juicio. Si además dicha firma es reconocida, la impugnación del documento se resolverá comprobando que dicha firma cumple todos los requisitos prescritos en esta Ley. Si no es firma reconocida, sino avanzada, la impugnación tendrá el mismo tratamiento que el establecido en el art. 326.2 de la LEC para resolver la impugnación de cualquier documento.

${ }_{16}$ Así, expresa, tras reconocer que, aunque tanto sustantivo como procesal (Código Civil y Ley de Enjuiciamiento Civil), dada la antigüedad de su redacción, tales textos no contemplan como posibles medios probatorios los mecanismos o elementos derivados de los importantes avances y descubrimientos técnicos de los tiempos modernos, como son las cintas magnéticas, vídeos y cualquier otro medio de reproducción hablada o representación visual del pensamiento humano que «los mismos aparecen admitidos por la jurisprudencia de esta Sala (Sentencias de 30 de Noviembre de 1992 y 2 de Diciembre de 1996), debiendo ser catalogados, dentro de la enumeración contenida en los artículos 1215 del Código Civil y 578 de la Ley de Enjuiciamiento Civil, como prueba documental asimilable a los documentos privados, por cuanto que, al igual que con estos ocurre, si la parte a quien perjudiquen no los reconoce como legítimos, habrán de ser sometidos a la correspondiente verificación o comprobación, por medio de la prueba pericial o, incluso, de reconocimiento o inspección personal del juez, y siendo ello así, o sea (volvemos a decir), admitida la conceptuación como prueba documental de tales elementos o medios técnicos reproductores de la palabra o de la imagen, ha de regir para ellos la misma norma procesal que para los documentos, en el sentido de que aquellos que sean los fundamentales en que la parte actora base su derecho, han de ser presentados con la demanda (artículo 504 de la Ley de Enjuiciamiento Civil), con la única excepción de los que se hallen en alguno de los supuestos del artículo 506 de la citada Ley».

${ }_{17}$ Sin embargo, tal entendimiento del concepto de prueba documental no resulta de aplicación al proceso laboral porque, en primer lugar, en el mismo opera como supletoria, en todo lo no expresamente previsto en la LEC, en la que se establece la diferenciación entre prueba documental y prueba por instrumentos de reproducción de la palabra, la imagen o el sonido, como anteriormente se ha consignado. En segundo lugar, en el proceso penal se realiza dicha interpretación amplia del concepto de documento a la luz de lo establecido en el artículo 26 del Código Penal. 
instancia, incorpora o expresa datos, hechos o narraciones con la suficiente eficacia probatoria y, en su caso, necesaria relevancia jurídica.

Ahora bien, el hecho de que la LECrim no regule expresamente el régimen jurídico de la incorporación al proceso de la prueba digital ${ }^{18}$ no impide que dicha incorporación al proceso esté exonerada de la observación más elemental de la denominada disciplina de prueba y, muy especialmente, de la posibilidad de contradecir por parte del inculpado las supuestas evidencias digitales que pudieran obrar en su contra.

En este contexto, el peritaje informático de parte se constituye en el garante de uno de los derechos fundamentales más importantes en el orden penal como es el de la presunción de inocencia consagrado en el art. 24 de la $\mathrm{CE}^{19}$.

\section{ANÁLISIS SOBRE LOS REQUISITOS JURÍDICOS Y TÉCNICOS PARA LA VIABILIDAD COMO PRUEBA DE CARGO DE LAS EVIDENCIAS INFORMÁTICAS}

\subsection{Doctrina CONSTITUCIONAL Y JURISPRUDENCIAL RELATIVA A LAS GARANTÍAS EXIGIBLES A LA PRUEBA DE CARGO}

El ordenamiento jurídico español ha establecido un conjunto de reglas procesales en orden a la posibilidad de atribuir un hecho delictivo a una persona y que se concretan en el modo en que se lleva a cabo la actividad probatoria, los medios de prueba en sí y la valoración de aquel resultado.

El derecho a utilizar los medios de prueba no tiene carácter absoluto, ya que la CE se refiere a los medios de prueba pertinentes, de manera que tal derecho de las partes no desapodera al tribunal de su facultad de admitir las pruebas pertinentes rechazando todas las demás -arts. 659 y 785.1 LECrim-, si bien la jurisprudencia

${ }_{18}$ Por tanto, en principio, todos los medios probatorios previstos en la ley son aptos para tal finalidad, pudiendo acceder mediante el documento electrónico, o utilizando soporte papel, o a través de otros medios de prueba tradicionales como el interrogatorio de parte, testifical o pericial.

${ }_{19} \mathrm{El}$ artículo 24.2 CE consagra el derecho a un proceso con todas las garantías y a la presunción de inocencia; y con arreglo a una consabida doctrina constitucional y jurisprudencial se «exige para destruir la presunción de inocencia una actividad probatoria suficiente que se explicite motivadamente, haya podido ser contradicha por el inculpado y que pueda considerarse de cargo" (STC 62/1994, de 28 de febrero, citando las SSTC 311/1981, 13/1982, 36/1983, 9/1984, 37/1985, 169/1986 y 256/1988). Y, todavía con mayor concreción, en la STS 94/2013, de 14 de febrero, se lee: «el control casacional de la presunción de inocencia se extenderá a la constatación de la existencia de una actividad probatoria sobre todos y cada uno de los elementos del tipo penal, con examen de la denominada disciplina de garantía de la prueba, y del proceso de formación de la prueba, por su obtención de acuerdo a los principios de inmediación, oralidad, contradicción efectiva y publicidad». 
ha establecido una serie de requisitos, formales y materiales, para que este motivo pueda prosperar ${ }^{20}$.

Como ha puesto de relieve el supremo intérprete de la CE en la STC 120/1999, de 28 de junio: «La protección del derecho a la presunción de inocencia comporta, en primer lugar, la supervisión de que la actividad probatoria se ha practicado con las garantías necesarias para su adecuada valoración y para la preservación del derecho de defensa. En segundo lugar, comprobar que el órgano de enjuiciamiento expone las razones que le han conducido a constatar el relato de hechos probados a partir de la actividad probatoria practicada. En tercer y último lugar, supervisar externamente la razonabilidad del discurso que une la actividad probatoria y el relato fáctico resultante -STC 189/1998-. Así, sólo cabrá constatar una vulneración del derecho a la presunción de inocencia cuando no haya pruebas de cargo válidas, es decir, cuando los órganos judiciales hayan valorado una actividad probatoria lesiva de otros derechos fundamentales o carente de garantías, o cuando no se motive el resultado de dicha valoración, o, finalmente, cuando por ilógico o insuficiente no sea razonable el iter discursivo que conduce de la prueba al hecho probado -SSTC SS 63/1993 y 68/1998-».

Los requisitos formales de lo que en última instancia viene a ser una modalidad de quebrantamiento de forma son entonces ${ }^{21}$ :

1. ${ }^{\circ}$ Que las pruebas han de estar propuestas en tiempo y forma, de conformidad con las reglas específicas para cada clase de proceso.

2. Que ante la resolución del tribunal, que debe ser fundada, rechazando las pruebas que no considere pertinentes, o denegando la suspensión del juicio ante la imposibilidad de practicar en ese momento las previamente admitidas, quien ha propuesto la prueba debe hacer constar la oportuna protesta ${ }^{22}$.

${ }^{20}$ El derecho a la prueba no es un derecho absoluto o incondicionado, y no se produce vulneración del derecho constitucional cuando la prueba rechazada, aun siendo pertinente, carece su contenido de la capacidad para alterar el resultado de la resolución final, y ello exige por parte de quien alegue tal vulneración una doble acreditación: de una parte que el recurrente ha de concretar la relación de hechos que se quisieron y no se pudieron probar y las pruebas inadmitidas; de otra, el invocante de la vulneración del derecho a los medios de prueba pertinente deberá argumentar de modo convincente que la resolución final del proceso a quo podría haberle sido favorable de haberse aceptado y practicado la prueba objeto de la controversia.

${ }_{21}$ Vid., entre otras, las SSTS 545/2014, de 26 de junio de 2014, y 544/2015, de 25 de septiembre de 2015.

22 En el procedimiento abreviado, el párrafo segundo del art. 785.1 de la LECrim dispone que contra los autos de admisión o inadmisión de pruebas no cabrá recurso alguno, sin perjuicio de que la parte a la que fue denegada pueda reproducir su petición al inicio de las sesiones del juicio oral. Y, en consonancia con ello, el art. 786.2 de la Ley de Enjuiciamiento Criminal expresa que, al inicio del juicio oral, tras la lectura de los escritos de acusación y defensa, el juez o tribunal abrirá un turno de intervenciones para que puedan las partes exponer, entre otras cosas, lo que estimen oportuno sobre el contenido y finalidad de la pruebas propuestas o que se propongan para practicarse en el acto; y resolverá en el mismo acto lo procedente sobre las cuestiones planteadas, sin que, frente a 
3. ${ }^{\circ}$ Que, si se trata de prueba testifical, han de hacerse constar las preguntas que quien la propone pretendía dirigir al testigo, con la finalidad de que, primero el tribunal de enjuiciamiento y después la Sala de casación, en su caso, puedan valorar la trascendencia de la prueba propuesta ${ }^{23}$.

\subsection{ReQuisitos DE ADMISIBILIAD DE LAS EVIDENCIAS DIGITALES: LICITUd Y FIA- BILIDAD}

Tradicionalmente, se vienen considerando como requisitos materiales de la prueba que ésta haya de ser pertinente, esto es, relacionada con el objeto del juicio y con las cuestiones sometidas a debate en el mismo. También, ha de ser relevante, de forma que tenga potencialidad para modificar el sentido del fallo, a cuyo efecto el tribunal puede tener en cuenta el resto de las pruebas de que dispone. Y finalmente, la prueba ha de ser necesaria, es decir, tener utilidad para los intereses de defensa de quien la propone, de modo que su omisión le cause indefensión ${ }^{24}$.

Lo anterior implica un juicio ex ante de licitud y valoración de las pruebas, es decir, saber el tribunal que si desde la obtención de las mismas por los investigadores hasta su incorporación al proceso (y su posible valoración posterior en el plenario) se han cumplido con los estándares legales y jurisprudenciales que permiten garantizar la plenitud, identidad e integridad de las mismas.

La licitud se concreta en la conveniencia inexorable de que de las evidencias digitales se hayan obtenido sin violación o merma de los derechos fundamentales reconocidos en la CE. El juicio de fiabilidad, por su parte, se refiere a la posibilidad de poderse comprobar la autenticidad e integridad de los documentos digitales obtenidos y su no manipulación. Esta fiabilidad se asegura con la denominada cadena

la decisión adoptada, quepa recurso alguno, sin perjuicio de la pertinente protesta y de que la cuestión pueda ser reproducida, en su caso, en el recurso frente a la sentencia.

${ }^{23}$ En cualquier caso, la parte que la propone debe preocuparse de que conste la eventual trascendencia de la prueba respecto del fallo de la Sentencia. La omisión de este requisito no impedirá, sin embargo, la estimación del motivo cuando la pertinencia y necesidad de la prueba se desprenda fácilmente de su propia naturaleza y características.

${ }^{24}$ En este contexto, se trae a colación la STS de 18 de marzo de 2009, que señala: «Es obvio que el doble abordaje del derecho a la prueba -como derecho fundamental o como indebida denegación de la prueba- no altera su esencia: la quiebra se produce cuando la denegada es prueba necesaria, y por tanto es causa de indefensión en los términos del art. 24-1. ${ }^{\circ}$ de la Constitución Española (CE). Por ello es doctrina del Tribunal Constitucional que el derecho a la prueba está delimitado por cuatro consideraciones: a) Que la prueba sea pertinente, pues sólo a ella se refiere el artículo 24.2 CE. b) Que dada su configuración legal, es preciso que la parte la haya propuesto de acuerdo con las previsiones de la ley procesal, es decir en tiempo oportuno y de forma legal. c) Desde la perspectiva del Tribunal sentenciador, que éste la haya desestimado. d) Al tratarse el derecho a la prueba de un derecho medial/procedimental que se acredite que tal denegación ha podido tener una influencia en el fallo de la sentencia, porque podría haberse variado, y es esta aptitud de la prueba denegada en relación al fondo del asunto, lo que da lugar a la indefensión que proscribe la Constitución, indefensión que debe ser material y no simplemente formal». 
de custodia, que se describe en el apartado siguiente, pero también con el adecuado análisis racional, y más extenso, al objeto de que la convicción judicial no adolezca del vicio de inveracidad ${ }^{25}$.

Si no se cumple con los requisitos del art. 11.2 de la LOPJ, la obtención de las supuestas evidencias digitales de cargo quedará fuera del ámbito de valoración del tribunal juzgador por no contar con méritos suficientes para enervar la necesaria presunción de inocencia que obra siempre a favor del acusado.

\subsection{LA CAdENA DE CUSTOdia}

Para que la prueba de cargo (o descargo) obtenida pueda tener relevancia y lograr la convicción favorable a los intereses de parte (y de la que deberá quedar buen reflejo en el informe pericial), se hace necesario garantizar que las evidencias digitales encontradas han sido almacenadas de forma adecuada y sin posibilidad de manipulación; o, como se suele expresar en términos forenses, que se respete la cadena de custodia ${ }^{26}$.

En este contexto, se entiende por cadena de custodia el proceso utilizado para documentar la historia cronológica de una prueba, con el objetivo de convencer al tribunal de que es razonablemente probable que la exposición sea auténtica, así como de que nadie ha alterado la prueba ${ }^{27}$.

Con carácter general, la denominada cadena de custodia se encuentra en íntima relación con las garantías de la prueba de cargo. A este respecto, en la STS 491/2016, de 8 de junio, se señala:

La cadena de custodia es el proceso que transcurre desde que los agentes policiales intervienen un efecto del delito que puede servir como prueba de cargo, hasta

25 Por desgracia, no estamos en un ámbito exento de la posibilidad de que se fabriquen pruebas informáticas manipuladas, montajes ficticios, falsedades o distorsiones fraudulentas del material informático de las supuestas víctimas u obtención con técnicas espurias, incluso por los propios investigadores policiales, como recurrentemente pone de relieve la Doctrina técnica especializada en este campo. Cfr. esta idea en Rubio Alamillo, J., «La Informática en la reforma de la Ley de Enjuiciamiento Criminal», diario La Ley, núm. 8663, 2015, p. 8, donde se expresa explícitamente que los datos informáticos pueden ser manipulados sin que, en ocasiones, ni siquiera pueda detectarse esa manipulación por peritos informáticos.

${ }^{26}$ La cadena de custodia resulta de suma importancia en lo que a pruebas informáticas se refiere, puesto que determinar una posible alteración de la prueba en una evidencia de este tipo es una cuestión matemática y absolutamente dicotómica, esto es, o la prueba no ha sido alterada o la prueba ha sido alterada.

${ }^{27}$ Sobre una descripción amplia de la cadena de custodia en el ámbito de las evidencias digitales puede verse Figueroa Navarro, M.C y Del Amo Rodríguez, A., «La cadena de custodia de las pruebas y los protocolos de actuación de la Policía Científica. Policía Científica: 100 años de ciencia al servicio de la Justicia». Material de las Jornadas. Centenario de la Policía Cientifica Española, Ministerio del Interior, Madrid, 2011. Y, también, Rubio Alamilo, J., "Conservación de la cadena de custodia de una evidencia informática», diario La Ley, núm. 8859, 2016. 
que se procede a su análisis, exposición o examen en la instrucción o en el juicio. Proceso que debe garantizar que el efecto que se ocupó es el mismo que se analiza o expone y que no se han producido alteraciones, manipulaciones o sustituciones, intencionadas o descuidadas. Esta Sala no mantiene una concepción formal, sino material de la cadena de custodia. Así ha establecido que la integridad de la cadena de custodia debe garantizar que desde que se recogen los vestigios relacionados con el delito hasta que llegan a concretarse como pruebas en el momento del juicio, aquello que se ha recogido y aquello sobre lo que recaerá la inmediación, publicidad y contradicción de las partes y, en definitiva, el juicio del Tribunal, es lo mismo. En cuanto a los efectos que genera lo que se conoce como ruptura de la cadena de custodia, esta Sala tiene afirmado que repercute sobre la fiabilidad y autenticidad de las pruebas -STS 1029/2013, de 28 de diciembre-. Y también se ha advertido que la ruptura de la cadena de custodia puede tener una indudable influencia en la vulneración de los derechos a un proceso con todas las garantías y a la presunción de inocencia, pues resulta imprescindible descartar la posibilidad de que la falta de control administrativo o jurisdiccional sobre las piezas de convicción del delito pueda generar un equivoco. Lo contrario podría implicar una mas que visible quiebra de los principios que definen el derecho a un proceso justo -SSTS 884/2012, de 8 de noviembre, y 744/2013, de 14 de octubre. Seguimos sin una regulación legal adecuada y moderna de la cadena de custodia, pese a su relevancia para la fiabilidad de las fuentes de prueba. Aplicando nuestra doctrina jurisprudencial STS 308/2013, de 26 de marzo, entre otras-, a falta de un marco legal, ha de estimarse que una infracción menor de la cadena de custodia solo constituye una irregularidad que no determina la exclusión de la prueba del proceso, por lo que debe igualmente ser valorada como prueba de cargo apta para desvirtuar la presunción de inocencia, sin perjuicio de que el defecto apreciado pueda afectar a su poder de convicción o fiabilidad. Por el contrario una infracción mayor o muy relevante de la cadena de custodia debe determinar la invalidez de la prueba, en la medida que su valoración afectaría al derecho a un proceso con las debidas garantías, al no poderse garantizar la autenticidad de la fuente de prueba.

Es el juicio de fiabilidad lo que nos va a permitir aceptar la viabilidad procesal de la supuesta evidencia digital como auténtica (no manipulable), íntegra (conservación del contenido) y confiable (obtenida sin técnicas espurias) ${ }^{28}$. Ello implica sujetarse a los estándares y requisitos técnicos por parte del juzgador para comprobar si, efectivamente, se ha analizado correctamente y de modo "confiable» el proceso de obtención de las evidencias digitales y su copia clonada, así como la fiabilidad del procedimiento de preservación, análisis del material y correspondencia de lo incautado con el presentado al órgano judicial llamado a decidir ${ }^{29}$.

${ }^{28}$ Si la prueba no ha sido alterada desde su recolección hasta su estudio forense, la cadena de custodia habría sido conservada, mientras que, por el contrario, si la prueba ha sido alterada, la cadena de custodia habría sido destruida

${ }_{29}$ Con poco detalle, el art. 588 de la LECrim ha descrito alguno de estos requisitos técnicos. En este sentido se echa en falta una regulación más prolija o protocolo reglado sobre el modo de 
En otro orden, nuevamente el Tribunal Supremo, a través de su ATS 2197/2012, describe muy gráficamente la importancia del mantenimiento de la cadena de custodia cuando dice que «es a través de la corrección de la cadena de custodia como se satisface la garantía de la mismidad de la prueba», garantizando que aquello sobre lo que recaerá la inmediación, publicidad y contradicción de las partes en el acto del juicio es lo mismo que los vestigios que se recogieron relacionados con el delito ${ }^{30}$.

La cadena de custodia documenta la ubicación e identifica a la persona encargada de su custodia durante todo el ciclo de vida de las evidencias. Como describe la STS 1045/2011, de 14 de octubre, desde que se recogen los vestigios relacionados con el delito hasta que llegan a concretarse como pruebas en el juicio (que es sobre lo que recaerá la inmediación, publicidad y contradicción de las partes) se ha de tener la garantía de que lo incautado y lo analizado en el juicio por el Tribunal es lo mismo. Esto es, que se hace necesario tener la seguridad de que lo que se traslada o analiza es exactamente lo mismo en todo momento desde el momento en que se interviene hasta el final del estudio o análisis ${ }^{31}$.

De lo descrito arriba, se colige la necesidad de preservar la evidencia digital inmediatamente después de ocurrido el delito y de garantizar a partir de ese momento la cadena de custodia, de forma que no puedan existir dudas sobre la «mismidad» de la que habla el Auto del Tribual Supremo anteriormente mencionado ${ }^{32}$.

Lo determinante será que lo hallado debe ser descrito, puesto en depósito y analizado con las debidas garantías, pues, como señala el art. 338 de la LECrim, los instrumentos del delito deben recogerse de tal forma que garanticen su integri-

obtención de las evidencias digitales por parte del CGPJ. Y en este sentido, puede verse Rubio ALAMILLO, J., «La informática en la reforma de la Ley de Enjuiciamiento Criminal», loc. cit., p. 7 y ss.

${ }^{30}$ Así, la sentencia de la Audiencia Provincial de Barcelona 1301/2008, de 29 de enero, describe el proceso de custodia del material informático intervenido durante un registro policial, llevado a cabo por los dos peritos judiciales, concluyendo de ello que «hubo una correcta identificación de elementos incautados y una adecuada custodia judicial», aunque afirmando a continuación de forma sorprendente: "pero es que además considera la Sala acreditado que en este caso no hubo ninguna manipulación", algo que va de suyo si, como se ha dicho, ha existido una adecuada custodia judicial, cosa que en ocasiones no ocurre.

${ }^{31}$ En este sentido, el Tribunal Constitucional en STC 170/2003, de 29 de septiembre, para un supuesto en que los soportes informáticos incautados durante una entrada y registro no fueron correctamente identificados, sellados y precintados, estima que se había «producido una deficiente custodia policial y control de dicho material» y que, por tanto, no podía garantizarse la inexistencia de eventuales manipulaciones o alteraciones del mismo habiéndose producido por la sentencia recurrida la vulneración a un proceso con todas las garantías.

32 Respecto a las evidencias digitales, la importancia de la misma y la ruptura de la cadena de custodia resulta extraordinariamente relevante. Baste de ejemplo el auto de la Audiencia Provincial de Madrid 18559/2011 al desestimar la validez de una prueba pericial informática sobre un disco duro por haberse interrumpido la cadena de custodia al haber permanecido durante un año en poder del denunciante, previamente a la realización del informe pericial. Es de resaltar que este tipo de eventualidades se pueden solventar con un proceso de contextualización de la evidencia digital, evitando así que se invaliden todas las circunstancias probatorias obtenibles de un hecho que se descubra tiempo después de haber ocurrido. 
dad y reenvío al organismo adecuado para su depósito. Y así, en interpretación de la STC 170/2003 de 29 de septiembre (FJ 3), se establece ${ }^{33}$ :

La legislación procesal penal pone un especial cuidado en regular el modo en que ha de procederse en la recogida de las piezas de convicción y su custodia. A esos efectos el art. 338 LECrim establece que los instrumentos, armas y efectos que puedan tener relación con el delito se sellarán, si fuera posible, y se acordará su retención, conservación o envío al organismo adecuado para su depósito, con la finalidad evidente de que, siendo elementos probatorios, se evite cualquier alteración en los mismos. En este caso, queda acreditado y así es reconocido en vía judicial por la Sentencia de instancia, sin que fuera negado por la de apelación, que los soportes informáticos no sólo no fueron identificados para determinar el domicilio en el que fueron intervenidos, sino que tampoco se procedió a su correcto sellado y precintando. A ello debe unirse el hecho objetivo, también destacado en vía judicial, de la existencia de una significativa discordancia numérica entre los CD-Rom intervenidos. Ello acredita que se ha producido una deficiente custodia policial y control judicial de dicho material, que no estaba debidamente precintado y a salvo de eventuales manipulaciones externas tanto de carácter cuantitativo (número de las piezas de convicción halladas en los registros) como cualitativo (contenido de aquellos soportes que admitieran una manipulación por su carácter regrabable o simplemente por su naturaleza virgen en el momento de su incautación, e incluso su sustitución por otros), lo que impide que pueda afirmarse que la incorporación al proceso penal de los soportes informáticos se diera con el cumplimiento de las exigencias necesarias para garantizar una identidad plena e integridad en su contenido con lo intervenido y, consecuentemente, que los resultados de las pruebas periciales se realizaran sobre los mismos soportes intervenidos o que éstos no hubieran podido ser manipulados en cuanto a su contenido.

De este modo, la ausencia de control judicial de las evidencias electrónicas lesiona y vicia la pertinencia de la prueba. Si la prueba informática es traída al proceso sin las debidas garantías de custodia policial y control judicial sobre su identidad e integridad, pudiera lesionar el derecho a un proceso con todas las garantías. No estamos ante una garantía meramente legal, sino ante una que afecta a la validez constitucional de la prueba.

El modo de conseguir el mantenimiento de la cadena de custodia y, por tanto, la virtualidad de la prueba (cargo o descargo) consiste en la realización de un

33 Pues bien, en relación con el cumplimiento de las garantías procesales en la incorporación al procedimiento penal de los soportes informáticos incautados y los informes periciales realizados sobre ellos, los recurrentes parten de un doble presupuesto fáctico. El primero, reconocido como hecho probado en ambas Sentencias, es que los soportes informáticos incautados no fueron clasificados ni relacionados por la Guardia Civil en función de los que habían sido ocupados en cada uno de los domicilios registrados. El segundo, explicitado en la Sentencia de instancia y obviado cualquier consideración o razonamiento sobre ello en la de apelación, es que, por un lado, se examinaron pericialmente un número de CD-Rom superior al que consta que se ocuparon en las diligencias de entrada y registro y, por otro, que el primer perito recibió los soportes informáticos intervenidos en cajas rotas y sin etiquetar. 
clonado o copia de los dispositivos y la obtención de la denominada función hash o huella digital, cuya complejidad técnica y valor jurídico detallaremos en las páginas siguientes, únicas garantías básicas de inalterabilidad de los dispositivos aprehendidos.

\section{ACTUACIÓN FORENSE Y PERICIA INFORMÁTICA}

\subsection{LA PREVIA HABILITACIÓN JUDICIAL}

En los supuestos de análisis de evidencias digitales, cual es el objeto del presente estudio, el acceso a la información contenida en estos instrumentos queda sometido a la extensión previa y vinculante de una autorización judicial específica ${ }^{34}$.

De este modo, ante una previsible intervención de las Fuerzas y Cuerpos de Seguridad del Estado donde se cree la posible incautación de evidencias digitales, no bastará con la motivación genérica de la resolución judicial que habilite el registro domiciliario, sino que será precisa una autorización y motivación específica en el auto habilitante -del investigado que pudieran tener relación con los hechos investigados- para poder acceder a su contenido.

${ }^{34}$ La STC 173/2011, 7 de noviembre, recuerda la importancia de dispensar protección constitucional al cúmulo de información personal derivada del uso de los instrumentos tecnológicos de nueva generación. Allí puede leerse el siguiente razonamiento: «si no hay duda de que los datos personales relativos a una persona individualmente considerados, a que se ha hecho referencia anteriormente, están dentro del ámbito de la intimidad constitucionalmente protegido, menos aún pueda haberla de que el cúmulo de la información que se almacena por su titular en un ordenador personal, entre otros datos sobre su vida privada y profesional (en forma de documentos, carpetas, fotografías, vídeos, etc.) - por lo que sus funciones podrían equipararse a los de una agenda electrónica-, no sólo forma parte de este mismo ámbito, sino que además a través de su observación por los demás pueden descubrirse aspectos de la esfera más íntima del ser humano. Es evidente que cuando su titular navega por Internet, participa en foros de conversación o redes sociales, descarga archivos o documentos, realiza operaciones de comercio electrónico, forma parte de grupos de noticias, entre otras posibilidades, está revelando datos acerca de su personalidad, que pueden afectar al núcleo más profundo de su intimidad por referirse a ideologías, creencias religiosas, aficiones personales, información sobre la salud, orientaciones sexuales, etc. Quizás, estos datos que se reflejan en un ordenador personal puedan tacharse de irrelevantes o livianos si se consideran aisladamente, pero si se analizan en su conjunto, una vez convenientemente entremezclados, no cabe duda que configuran todos ellos un perfil altamente descriptivo de la personalidad de su titular, que es preciso proteger frente a la intromisión de terceros o de los poderes públicos, por cuanto atañen, en definitiva, a la misma peculiaridad o individualidad de la persona. A esto debe añadirse que el ordenador es un instrumento útil para la emisión o recepción de correos electrónicos, pudiendo quedar afectado en tal caso, no sólo el derecho al secreto de las comunicaciones del art. 18.3 CE (por cuanto es indudable que la utilización de este procedimiento supone un acto de comunicación), sino también el derecho a la intimidad personal (art. 18.1 CE), en la medida en que estos correos o email, escritos o ya leídos por su destinatario, quedan almacenados en la memoria del terminal informático utilizado. Por ello deviene necesario establecer una serie de garantías frente a los riesgos que existen para los derechos y libertades públicas, en particular la intimidad personal, a causa del uso indebido de la informática así como de las nuevas tecnologías de la información». 
Esta resolución ha de dispensar una protección al imputado frente al acto de injerencia de los poderes públicos. Son muchos los espacios de exclusión que han de ser garantizados. No todos ellos gozan del mismo nivel de salvaguarda desde la perspectiva constitucional. De ahí la importancia de que la garantía de aquellos derechos se haga efectiva siempre y en todo caso, con carácter anticipado, actuando como verdadero presupuesto habilitante de naturaleza formal ${ }^{35}$.

El acceso deberá realizarse conforme a las condiciones establecidas en la resolución judicial para asegurar la integridad de los datos y las garantías de su preservación. En este sentido, el art. 588 sexies c de la LECrim da cobertura legal a la necesidad de que se fijen judicialmente las condiciones y el alcance del registro sobre tales dispositivos y la realización de copias, debiendo fijarse las condiciones necesarias para asegurar la integridad de los datos y las garantías de su preservación haciendo posible, en su caso, la práctica de un dictamen pericial ${ }^{36}$.

Sea como fuere, lo cierto es que tanto desde la perspectiva del derecho de exclusión del propio entorno virtual como de las garantías constitucionales exigidas para el sacrificio de los derechos a la inviolabilidad de las comunicaciones y a la intimidad, la intervención de un ordenador o dispositivo electrónico para acceder a su contenido exige un acto jurisdiccional habilitante. Y esa autorización, en principio, no está incluida en la resolución judicial previa para acceder al domicilio en el que aquellos dispositivos se encuentran instalados. De ahí que, ya sea en la misma resolución, ya en otra formalmente diferenciada, el órgano jurisdiccional ha de exteriorizar en su razonamiento que ha tomado en consideración la necesidad de sacrificar, además del domicilio como sede física en la que se ejercen los derechos individuales más elementales, aquellos otros derechos que convergen en el momento de la utilización de las nuevas tecnologías ${ }^{37}$.

El art. 588 series c de la LECrim establece que el juez fijará las condiciones para asegurar la integridad de los datos y las garantías de su preservación, pero en ningún momento especifica en qué modo se debe proceder al acceso de la información para preservar los datos contenidos en los dispositivos intervenidos. Adivina

${ }^{35}$ La posible lesión al derecho fundamental a la intimidad es patente como también describe la STC 121/1998, de 15 de junio, en su FJ 3.

36 Se hace necesario documentar la elación detallada y exacta (por parte de la fuerza actuante que se hará cargo de los dispositivos electrónicos que constituyen la fuente de prueba) de quién, cuándo y durante cuánto tiempo ha tenido acceso a los dispositivos electrónicos intervenidos, antes de devolverlos al juzgado instructor, que será el custodio definitivo -en realidad el servicio común- de los mismos como efectos del delito.

${ }^{37}$ La doctrina del TC es firme al señalar que el contenido de un ordenador personal forma parte de la intimidad de su propietario y no se puede acceder al mismo sin autorización del titular o de un juez. Referido al caso, el Constitucional desautoriza al Tribunal Supremo y afirma que el llevar un aparato a reparar o el utilizar un programa de intercambio de archivos no puede ser entendido como una autorización para que la policía entre a mirar el contenido de un ordenador. Detrás de esta decisión está una postura muy frecuente en nuestro Tribunal Constitucional: proclamar con fuerza los derechos fundamentales recordando su valor extraordinario como protección a los ciudadanos frente al poder, pero no aplicar esa teoría en los casos que le llegan. 
ya el lector que una mala praxis puede dar al traste con todo el juicio de fiabilidad ya descrito ${ }^{38}$.

En última instancia habrá que asegurar las garantías que permiten preservar la cadena de custodia de modo que se desvanezca cualquier tipo de duda acerca de la identidad e integridad plena de los dispositivos intervenidos y de las copias que se efectúen. Se ha de posibilitar, por tanto, que se realicen las periciales oportunas que acrediten la imposibilidad de cualquier manipulación no autorizada judicialmente ${ }^{39}$. Lo que se conoce vulgarmente como volcado comprende en realidad dos operaciones, el clonado o copia y la obtención de la correspondiente firma o código hash.

${ }^{38}$ En este contexto, la STS 342/2903, de 17 de abril, (FJ 8) establece que: «El acceso de los poderes públicos al contenido del ordenador de un imputado, no queda legitimado a través de un acto unilateral de las fuerzas y cuerpos de seguridad del Estado. El ordenador y, con carácter general, los dispositivos de almacenamiento masivo, son algo más que una pieza de convicción que, una vez aprehendida, queda expuesta en su integridad al control de los investigadores. El contenido de esta clase de dispositivos no puede degradarse a la simple condición de instrumento recipiendario de una serie de datos con mayor o menor relación con el derecho a la intimidad de su usuario. En el ordenador coexisten, es cierto, datos técnicos y datos personales susceptibles de protección constitucional en el ámbito del derecho a la intimidad y la protección de datos (art. 18.4 de la CE) [...]. Pero su contenido también puede albergar - de hecho, normalmente albergará- información esencialmente ligada al derecho a la inviolabilidad de las comunicaciones. El correo electrónico y los programas de gestión de mensajería instantánea no son sino instrumentos tecnológicos para hacer realidad, en formato telemático, el derecho a la libre comunicación entre dos o más personas. Es opinión generalizada que los mensajes de correo electrónico, una vez descargados desde el servidor, leídos por su destinatario y almacenados en alguna de las bandejas del programa de gestión, dejan de integrarse en el ámbito que sería propio de la inviolabilidad de las comunicaciones. La comunicación ha visto ya culminado su ciclo y la información contenida en el mensaje es, a partir de entonces, susceptible de protección por su relación con el ámbito reservado al derecho a la intimidad, cuya tutela constitucional es evidente, aunque de una intensidad distinta a la reservada para el derecho a la inviolabilidad de las comunicaciones [...]. La ponderación judicial de las razones que justifican, en el marco de una investigación penal, el sacrificio de los derechos de los que es titular el usuario del ordenador, ha de hacerse sin perder de vista la multifuncionalidad de los datos que se almacenan en aquel dispositivo. Incluso su tratamiento jurídico puede llegar a ser más adecuado si los mensajes, las imágenes, los documentos y, en general, todos los datos reveladores del perfil personal, reservado o íntimo de cualquier encausado, se contemplan de forma unitaria. Y es que, más allá del tratamiento constitucional fragmentado de todos y cada uno de los derechos que convergen en el momento del sacrificio, existe un derecho al propio entorno virtual. En él se integraría, sin perder su genuina sustantividad como manifestación de derechos constitucionales de nomen iuris propio, toda la información en formato electrónico que, a través del uso de las nuevas tecnologías, ya sea de forma consciente o inconsciente, con voluntariedad o sin ella, va generando el usuario, hasta el punto de dejar un rastro susceptible de seguimiento por los poderes públicos. Surge entonces la necesidad de dispensar una protección jurisdiccional frente a la necesidad del Estado de invadir, en las tareas de investigación y castigo de los delitos, ese entorno digital».

39 Sobre este aspecto puede verse Martínez Guerrero, A., «Las diligencias de entrada y registro en el procedimiento penal español», Revista Actualidad Judicial núm. 3, enero-junio, 2019, p. 45 y ss. 


\subsection{El CLONADO}

Sobre cómo se realiza tal clonado o copia debe quedar claro que, conforme a la jurisprudencia consolidada del Tribunal Supremo, los volcados constituyen un procedimiento informático y técnico que, en algunas ocasiones, puede ser muy lento, pero siempre ajeno a la ciencia jurídica ${ }^{40}$.

El análisis y pericia del material informático no se llevará a cabo sobre los soportes originales, sino sobre las copias que de los mismos se realicen. Para la obtención de la evidencia digital como primera operación se realiza el denominado clonado de datos, consistente en la realización de una copia espejo, bit a bit, de la información digital original ${ }^{41}$.

Desde el punto de vista jurídico, el clonado constituye una garantía del juicio de fiabilidad en el registro y análisis de los dispositivos y que permite acreditar la mismidad de lo aprehendido, esto es, que lo que se copia es imagen fiel de lo ocupado o intervenido. De este modo, se preserva la fuente original al tiempo que se facilita a los investigadores o peritos trabajar a partir de las copias, ya sin el riesgo de una alteración imprudente o malintencionada. Quedará así garantizada la mismidad del dispositivo intervenido y, ante cualquier duda que pueda plantearse en el proceso sobre alteración de la prueba, se podrán llevar a cabo las operaciones de contraste necesarias entre la copia y el original ${ }^{42}$.

Tales copias o clonados se materializarán -en casi todos los supuestos- en los laboratorios informáticos policiales dada la complejidad técnica de estas operaciones y, de ser posible, bajo la custodia o vigilancia del servicio común ${ }^{43}$. Por ello, deberá determinarse en el acta de registro (con fe pública judicial) la identificación y precinto de los dispositivos, así como cuantos datos permitan identificar a su posible titular, claves si las hubiera y demás elementos que aseguren el material probatorio, así como en poder de quién quedan los dispositivos intervenidos.

40 Vid. la STS de 26 de septiembre de 2005.

${ }^{41}$ Se trata de obtener la evidencia clara, manifiesta y tan perceptible de una cosa, que nadie puede dudar de ella.

42 Nuevamente, la STS 3 de noviembre de 1997 expresa: «... al igual que en el caso de los documentos comunes, puede haber documentos electrónicos sin firma, el documento electrónico (y, en especial, el documento electrónico con función de giro mercantil) es firmable, en el sentido de que el requisito de la firma autógrafa o equivalente puede ser sustituida, por el lado de la criptografía, por medio de cifras, signos, códigos, barras, claves u otros atributos alfa-numéricos que permitan asegurar la procedencia y veracidad de su autoría y la autenticidad de su contenido. Por lo tanto, si se dan todas las circunstancias necesarias para acreditar la autenticidad de los ficheros electrónicos o del contenido de los discos de los ordenadores o procesadores y se garantiza, con las pruebas periciales en su caso necesarias, la veracidad de lo documentado y la autoría de la firma electrónica utilizada, el documento mercantil en soporte».

43 Solo de manera excepcional se podrán realizar in situ, pues se trata de una actuación que exige de unos medios técnicos y de amplio lapso que lo hacen incompatible con la agilidad del registro y con el mandato recogido en el artículo 552 de la LECrim. 
El clonado forense de discos duros se realiza a fin de certificar y mantener la cadena de custodia de las evidencias digitales contenidas en el dispositivo ${ }^{44}$. Ello es fundamental en cualquier proceso judicial ya que, de no hacerse correctamente, los elementos probatorios quedarían invalidados. Es deber del perito informático certificar la cadena de custodia, esto es, que las evidencias aprehendidas permanecen inalteradas desde el momento en que son intervenidas, pudiendo certificar su originalidad en cualquier momento posterior a la intervención.

La copia del dispositivo incautado se realizará en otro dispositivo de almacenamiento o fichero de imagen obteniendo la firma hash de los bits leídos durante el proceso. Con ello, se obtiene una copia exacta de todo el contenido del disco duro, además de certificar la correspondencia de su contenido con el original mediante la coincidencia de las firmas con hash ${ }^{45}$.

Los investigadores o, en su caso, el perito informático de parte ${ }^{46}$ deberá documentar exhaustivamente el proceso de clonado forense del disco duro o dispositivos de que se trate, incluyendo la situación y tipología del dispositivo original intervenido, así como las características del dispositivo donde se va a volcar la información clonada. Para ello, como primera medida resulta determinante-como se ha dicho en el epígrafe anterior- la identificación detallada, con número de serie del dispositivo que se trate y características del mismo, realizada por el letrado de la Administración de Justicia en el acta de la entrada y registro, y de la que deberá darse cuenta en el informe respecto del cual se pretende el clonado.

Todo ello deberá incorporarse en el informe de peritaje informático, de forma detallada e inteligible, a fin de asegurar la cadena de custodia de las evidencias digitales aprehendidas (físicas y lógicas) antes de proceder al estudio de las mismas.

En relación con el procedimiento de obtención de la evidencia digital, el Tribunal Supremo exonera al secretario judicial (actual letrado de la Administra-

${ }^{44}$ Entre las herramientas para el tratamiento técnico pericial de memorias destaca Volatility, conjunto de herramientas desarrolladas en Python. Permite hacer volcados de memoria de máquinas con sistemas operativos Windows, Linux, Mac OSX e incluso Android trabajando con versiones tanto de 32 como de 64 bits. A partir de los datos se pueden extraer, por ejemplo, tipo de sistema, fecha y hora, puertos abiertos, ficheros cargados por procesos, así como DLL, módulos del kernel, direccionamiento de memoria por procesos, claves de registro utilizadas en los procesos, etc. Otros ingenios periciales informáticos lo constituyen las herramientas Memoryze y RedLine.

${ }_{45}$ Entre las técnicas más utilizadas que se conocen de tratamiento de discos destaca $D c d d 3$, que permite trabajar sobre el disco del equipo que se quiere analizar realizando copias a bajo nivel para proteger el original. Por su parte, se suele preferir para realizar la copia bit a bit o réplicas de imagen de disco la herramienta Guymager.

${ }^{46}$ La clonación forense de discos duros o el peritaje de parte puede requerir de un laboratorio de informática forense móvil compuesto por dispositivos electrónicos específicos, así como de software concreto para realizar el clonado forense, bit a bit, de los dispositivos a intervenir para el clonado forense de discos duros, pudiendo realizar intervenciones in situ, e incluso en dependencias judiciales ante el letrado de la Administración de Justicia. 
ción de Justicia) de permanecer durante un proceso de clonado de dispositivos realizado por la policía judicial ${ }^{47}$.

\subsection{LA OBTENCIÓN DEL HASH O HUELLA DIGITAL ${ }^{48}$}

Las evidencias electrónicas deben seguir un tratamiento específico para preservar y mantener la cadena de custodia, conservación de las evidencias y seguir un proceso de contextualización adecuado para que, en caso de surgir alguna conclusión cuestionable o controvertida, ésta pueda ser analizada de nuevo por los mismos intervinientes u otros distintos, con las garantías de que la evidencia sigue intacta. Esto es, que se permita la contradicción de la prueba a través de su repetibilidad ${ }^{49}$.

En cuanto se ha realizado el volcado de los datos, se procede a obtener la firma hash de los ficheros electrónicos aprehendidos. Dicha firma hash es una función basada en un algoritmo resumen de los bits que componen el fichero, cuya aplicación práctica es la de afirmar que dicho fichero no ha sido alterado con posterioridad ${ }^{50}$. Al cambiar un solo bit del fichero digital, la firma hash cambia. Si la firma de dos ficheros coincide, significa que ambos son plenamente coincidentes ${ }^{51}$.

La integridad del contenido se obtiene comparando las firmas hash obtenidas de la información aprehendida y de la formación original, debiendo ser ambas coincidentes. Al firmarse la imagen digitalmente mediante una función hash que permite identificar unívocamente el contenido de la imagen forense se posibilita saber, en todo momento, que la información contenida en la copia es idéntica a la original.

47 Así, la STS 256/2008, de 14 de mayo, señala que dicha presencia es inútil e innecesaria dado que el letrado de la Administración de Justicia no es experto técnico en dicha materia, y por ello no se requiere su presencia durante la práctica de la pericial informática. En el mismo sentido resuelve la STS 1599/1999, de 15 de noviembre, cuando dispone que «lo que no se puede pretender es que el fedatario público esté presente durante todo el proceso, extremadamente complejo e incomprensible para un profano, que supone el análisis y desentrańamiento de los datos incorporados a un sistema informático. Ninguna garantía podría añadirse con la presencia del funcionario judicial al que no se le puede exigir que permanezca inmovilizado durante la extracción y ordenación de los datos, identificando su origen y procedencia».

${ }^{48}$ El término hash proviene, aparentemente, de la analogía con el significado en inglés, esto es, picar y mezclar.

49 Para poder ser calificada de evidencia digital una prueba se requiere la cumplimentación de los siguientes elementos en materia forense: identificación, preservación, recuperación, análisis y presentación de los hechos.

${ }^{50}$ Una función hash es una función computable mediante un algoritmo tal que: $\mathrm{H}: \mathrm{U} \rightarrow$ $\mathrm{M} ; \mathrm{x} \rightarrow \mathrm{h}(\mathrm{x})$. Tiene como entrada un conjunto de elementos, que suelen ser cadenas, $\mathrm{y}$ los convierte en un rango de salida finito, normalmente cadenas de longitud fija. Es decir, la función actúa como una proyección del conjunto $\mathrm{U}$ sobre el conjunto M. También se denominan funciones resumen.

${ }^{51}$ Marques Arpa, T. y Serra Ruiz, J., "Cadena de Custodia en el Análisis Forense», en Actas de la XIII Reunión Española sobre Criptología y Seguridad de la Información. Alicante, 2-5 de septiembre de 2014. Universidad de Alicante, Alicante, 2014, p. 167. 
En todo informe técnico pericial debe hacerse constar el denominado formulario de adquisición de evidencias, en el que deben quedar recogidas tanto la cadena de custodia como las autorizaciones de acceso a la información. Estos códigos hash permitirían, según lo exigido en derecho procesal penal para las evidencias digitales, repetir las pruebas, tantas veces como se considere necesario para eliminar las dudas, y permitir el análisis a la parte contraria con el fin de no incurrir la indefensión de la otra parte ${ }^{52}$.

Es fundamental que el informe pericial que lleven a cabo los investigadores de las Fuerzas y Cuerpos de Seguridad del Estado (o en su caso el perito de parte) establezca, además de la metodología técnica usada en el volcado, las huellas digitales o códigos de cada uno de los ficheros informáticos obtenidos del dispositivo electrónico clonado, así como de la fecha del cálculo de la misma.

La función hash permite además que terceros distintos de quienes hayan obtenido la copia digital puedan someterla a contraste. Lo contrario impediría la eficacia de la prueba por ser de imposible contradicción ${ }^{53}$.

52 La Sentencia de la Audiencia Provincial de Málaga 1/2011 es una buena fuente de detalles acerca de procedimientos de custodia de las evidencias digitales y uso en sede judicial de tan singular concepto técnico en orden a fundamentar la convicción del tribunal juzgador. Así, se señala que declaraciones de los agentes policiales, tales como «se extrajeron los discos de cuatro ordenadores, se sellaron y se precintaron -por ello no se hizo huella digital-» o que «los CDs empleados eran de una sola escritura y como las copias de los discos se sellaron, no hizo falta hacer el Hash o huella digital».

53 Así, la célebre Sentencia del Caso Anonymus dictada por el Juzgado de lo Penal núm. 3 de Gijón, de 6 de julio de 2016 (FJ 5. a), y que condujo a la absolución de los acusados estableció que «... Pese a que el TS tiene declarado -entre otras en sentencias de 7 de julio de 2010 y 26 de abril de 2016 - no basta la mera sospecha sino la evidencia de la ruptura de la cadena de custodia, en el presente supuesto la confusión y contradicción apreciadas acerca de la adopción de garantías suficientes para preservar la identidad e integridad de los efectos incautados a los tres acusados y sobre la posible manipulación o contaminación de los mismos, exceden como se decía anteriormente de la mera sospecha y vienen a evidenciar la ruptura de la cadena de custodia y asimismo exceden de la mera irregularidad o infracción menor a que se refiere la jurisprudencia más reciente y valorados los datos relativos a los efectos incautados y las medidas adoptadas respecto de los mismos en relación con los datos relacionados acerca de los volcados de datos, las manifestaciones efectuadas por el secretario judicial con ocasión del primer volcado en clara contradicción con las de los testigos y peritos que elaboraron los informes de errores y solicitaron y practicaron un nuevo volcado, los defectos de forma apreciados con ocasión de la citación de los investigados, las contradicciones acerca de los efectos examinados en relación con el anterior volcado incluso relativas al número de efectos examinados, y las afirmaciones relativas a que no se examinan determinados dispositivos por carecer de interés, etc que no fueron debidamente aclarados en el plenario por los testigos y peritos, se considera que debe acogerse la cuestión invocada por las defensas por estimar que se produjo la vulneración del derecho a un proceso con las debidas garantías y en consecuencia del derecho de defensa y el derecho a la tutela judicial efectiva consagrada en el art. 24 de la C.E. en contra de lo que sostiene el Ministerio Fiscal y en consecuencia prescindir de la prueba relativa a los efectos incautados a los acusados y la prueba de análisis de los mismos que de ella trae causa». 
Fruto de la combinación de los dos procedimientos anteriores, resulta de vital importancia la obtención de la imagen como instrumento de acreditación de la obtención de las evidencias digitales.

El término informático «imagen» se refiere al contenido de la información de un dispositivo electrónico, a su vez, contenido, como copia, en otro. Es decir, que cuando se emplea en los informes periciales la expresión «imagen de un dispositivo electrónico» (v.gr., disco duro o USB) se está indicando que se ha creado un archivo que contiene la estructura y los contenidos del dispositivo original ${ }^{54}$. El original y la copia serán idénticos en el momento justo en que se hace la imagen. En resumen, las imágenes forenses son una copia exacta y no manipulable de los datos contenidos en los equipos informáticos originales ${ }^{55}$.

De esta forma, obteniendo una imagen forense podemos garantizar la integridad de la información que se presenta, constituyendo la forma más eficaz y fiable de preservar y presentar la información digital.

\section{EL INFORME PERICIAL}

\subsection{Doctrina general SObre la Utilización de este medio de prueba. Su NECESARIO CARÁCTER DE PRUEBA ANTICIPADA EN EL ÁMBITO DIGITAL}

La LEC en su artículo 335.1 define el dictamen pericial como «una actividad procesal mediante la que una persona o institución especialmente cualificada suministra al Juez argumentos o razones para la formación de su convencimiento acerca de ciertos datos controvertidos, cuya percepción o comprensión escapa a las aptitudes comunes judiciales». Por su parte, en el orden penal, la LECrim regula lo relativo al informe pericial en el Capítulo VII del Título V, dentro del Libro II correspondiente al Sumario (artículos 456 a 485), y en la Sección 3. a del Capítulo III, dentro del Título $3 .^{\circ}$ del Libro III referente al Juicio Oral (artículos 723 a 725).

54 Un archivo es un conjunto de bits que son almacenados en un dispositivo. La imagen forense constituye, entonces, una copia íntegra de todos los sectores que componen un volumen físico o soporte digital (copia byte a byte) de toda la información contenida en un soporte digital. De esta forma, obteniendo una imagen forense podemos garantizar que tenemos una copia con el $100 \%$ de la información original.

55 Como herramienta suele utilizarse ForLEx, que constituye distribución Linux orientada a aplicaciones de informática forense. Incluye FTK Imager, que permite crear imágenes de los sistemas para su posterior análisis forense. Permite agregar más herramientas a las que ya presenta por defecto. Por su parte, Autopsy es un conjunto de aplicaciones muy útiles para el análisis forense que permite un análisis de la línea de tiempo para ayudar a identificar la actividad. Permite búsquedas de palabras sobre todo el equipo, analiza el registro del sistema operativo Windows y extrae datos EXIF de las imágenes. 
La buena práctica judicial, y como extensión del juicio de fiabilidad, haría que la autoridad judicial dicte auto ordenando realizar la pericial informática correspondiente a los grupos especializados de información de los investigadores judiciales o a designar perito o experto de confianza. Por otra parte, en los supuestos de que la parte acusada ${ }^{56}$ (o el propio tribunal a la luz de los informes presentados por los investigadores o acusador particular) albergue dudas de la fiabilidad del material probatorio, podrá acordarse la práctica de la pericial informática para descartar éstas y determinar si los archivos informáticos han sido alterados y manipulados o no ${ }^{57}$.

La constitucionalización del derecho a la prueba digital comporta la exigencia de efectuar una lectura de las normas procesales tendente a permitir la máxima actividad probatoria por mor del principio favor probatione ${ }^{58}$. Dada la complejidad técnica de los tratamientos arriba descritos, lo normal será que la pericia informática sobre la evidencia digital no pueda practicarse en el día señalado para la vista oral concurriendo a la defensa del informe correspondiente. Ahora bien, al no ser reproducible en el juicio oral, debería estar presente el letrado de la Administración de Justicia para que la misma tenga plena validez probatoria ex arts. 476 y 477 de la LECrim quedando configurada, por tanto, como prueba anticipada.

${ }^{56}$ No cabe, como señala la STS 587/2003, de 16 de abril, imponer a la defensa carga alguna en el sentido de justificar su impugnación del análisis efectuado.

57 De la importancia del informe pericial informático da buena cuenta la STS 2047/2015 de 19 de mayo de 2015, cuando estableció la necesidad de llevar a cabo un informe pericial informático que acredite la identidad de los interlocutores, así como la integridad de la conversación mantenida a través de una red social, para que dicha conversación sea aceptada como prueba válida en un procedimiento judicial y establece: «la prueba de una comunicación bidireccional mediante cualquiera de los múltiples sistemas de mensajería instantánea debe ser abordada con todas las cautelas» y basa esta preocupación en la facilidad de manipulación de los archivos digitales mediante los que se materializa ese «intercambio de ideas», amparándose en el anonimato y en la facilidad de creación de cuentas con identidades fingidas que habitualmente permiten las plataformas de redes sociales, haciendo posible de esta manera «aparentar una comunicación en la que un único usuario se relaciona consigo mismo». Por ello, en caso de impugnación, se desplaza la carga de la prueba hacia quien pretende aprovechar la idoneidad probatoria de dichas conversaciones cuando éstas son aportadas al proceso mediante archivos de impresión. La sentencia concluye estableciendo de forma terminante que «será indispensable en tal caso la práctica de una prueba pericial que identifique el verdadero origen de esa comunicación, la identidad de los interlocutores y, en fin, la integridad de su contenido».

${ }^{58}$ En estos términos se pronuncia la STC 10/2009, de 12 de enero, que considera que la legislación procesal criminal debe ser interpretada «sin desconocimiento ni obstáculos» al derecho fundamental a la prueba; y la STC 1/1992, de 13 de enero, al afirmar que «la garantía del art. 24.2 del derecho a la defensa, consiste en que las pruebas pertinentes propuestas sean admitidas y practicadas por el Juez o Tribunal y al haber sido constitucionalizado impone una nueva perspectiva y una sensibilidad mayor en relación con las normas procesales atinentes a ello, de suerte que deban los Tribunales de justicia proveer a la satisfacción de tal derecho, sin desconocerlo ni obstaculizarlo». 


\subsection{El PERITAJE FORENSE INFORMÁTICO}

Para lograr que la prueba electrónica tenga una mayor fuerza de convicción sobre el tribunal, resulta necesario presentar la evidencia digital que se va a utilizar como medio de prueba dentro del contexto en el que se ha generado e introducido en el proceso con las garantías ya descritas. Así, el art. 384.2 de la LEC prevé la conveniencia de que la parte que quiera proponer este tipo de medios de prueba aporte un dictamen pericial, así como cualquier medio de prueba instrumental que considere conveniente para incrementar el poder de convicción de dicha prueba sobre el tribunal ${ }^{59}$.

En cualquier caso, la prueba pericial informática será indispensable para los supuestos en que se impugne la veracidad de la prueba digital aportada -tal y como dispone la STS 224/2017, de 8 de marzo-, así como cuando se requiera el acceso a la información contenida en un dispositivo y la misma haya sido encriptada o eliminada o, simplemente, cuando el acceso a dicha información sea difícil y se requiera por ello conocimientos técnicos.

Aunque en principio la prueba pericial informática pudiera parecer una prueba pericial más, dado que no tiene un tratamiento procesal diferenciado con respecto a las otras, lo cierto es que ostenta un carácter especial ${ }^{60}$. Tal singularidad deriva de las características particulares de las fuentes de prueba digitales, especialmente su volatilidad y su facilidad de replicación y alteración, que las distingue del resto de fuentes de prueba utilizadas en otro tipo de pericias y, en particular, de las fuentes de prueba documentales. La prueba pericial alcanza, entonces, por sí, caracteres, extremadamente relevantes, que se tornan decisivos cuando se refiere a aspectos técnicos y especialmente complejos como es el ámbito informático ${ }^{61}$.

Para obtener tales razones y argumentos, el perito informático usa una rama de la informática denominada informática forense, definida en la literatura anglosajona (Computer Forensics) como «la colección de técnicas y herramientas para encontrar evidencias en un ordenador ${ }^{62}$.

59 En este contexto, Bueno de Mata, F., Prueba Electrónica y Proceso 2.0, op. cit., p. 130, define a las mismas como «cualquier prueba presentada informáticamente y que estaría compuesta por dos elementos: uno material que depende de un hardware, la parte física y visible de la prueba para cualquier usuario de a pie, por ejemplo la carcasa de un Smartphone o una memoria USB; y por otro lado un elemento intangible que es representado por un software consistente en los metadatos y archivos electrónicos modulados a través de unas interfaces informáticas».

${ }^{60}$ Todas las vicisitudes derivadas del momento y la forma de aportación del dictamen pericial al proceso, su valoración por el juez, las obligaciones y las condiciones del perito, su posible tacha o recusación se rigen por las mismas reglas que el resto peritajes. Sobre esta cuestión véase ampliamente Figueroa Navarro, M., Dolz Lago, M.J. y Valmaña Ochaita, S., «La prueba pericial científica», en Coleccion de Ciencias Jurídicas y Forenses, Madrid, 2012.

${ }^{61}$ Gimeno Sendra, V., Derecho procesal civil. El proceso de declaración. Parte General, Colex, Madrid, 2010, p. 473.

${ }^{62} \mathrm{La}$ informática forense es una ciencia, de reciente aparición, que se encarga de asegurar, identificar, preservar, analizar y presentar un conjunto de datos que pueden constituir pruebas digi- 
En el ámbito de la informática forense, campo propio de actuación del peritaje de las nuevas tecnologías, se especifican una serie de procedimientos de cara a garantizar que la evidencia electrónica se adquiere, se conserva y se trata de manera que se cumplan los preceptos de inalterabilidad, conservación y posibilidad de repetición de los resultados ${ }^{63}$.

De este modo, para que la prueba o evidencia digital pueda alcanzar relevancia en sede judicial, se requiere cumplir las siguientes características: verificable (se debe poder comprobar la veracidad de las conclusiones extraídas a partir de la realización del análisis); reproducible (se deben poder reproducir en todo momento las pruebas realizadas durante el proceso); documentada (de manera comprensible y detallada); independiente (las conclusiones obtenidas deben ser las mismas, independientemente de la persona que realice el proceso y de la metodología utilizada); auténtica (debe ser verídica y no haber sufrido manipulación alguna, garantizando y asegurando para ello su total integridad); completa (debe representar la prueba desde un punto de vista objetivo y técnico, sin valoraciones personales, ni prejuicios); creíble (debe ser comprensible por los órganos judiciales profanos en la materia); y, finalmente, confiable (las técnicas utilizadas para su obtención no deben generar ninguna duda sobre su veracidad y autenticidad).

\subsection{OBJETO DE LA PERICIA INFORMÁtICA}

Con independencia de las diversas clases de peritaje informático existentes, en este estudio vamos a centrarnos en el denominado peritaje forense informático, cuya virtualidad consiste en obtener evidencias de la información digital encontrada en los dispositivos informáticos y confeccionar los medios de prueba correspondientes.

En cuanto al objeto de la pericia informática, ésta viene a concentrarse en el análisis de los equipos intervenidos o dispositivos de almacenamiento en el marco de un procedimiento judicial penal por delito. Una veces para concretar el tipo penal que se persigue (análisis de archivos, enlaces, historiales de búsqueda, malware insta-

tales, de tal modo que éstas puedan llegar a ser aceptadas en un proceso judicial. En este contexto, tradicionalmente, se distingue la informática forense (Computer Forensics) de lo que se vienen conociendo en este entorno como electrónica digital forense (Digital Forensics), y en íntima relación con el concepto de seguridad informática, y que se refiere al uso de métodos científicamente derivados y comprobados para la preservación, adquisición, validación, identificación, análisis, interpretación, documentación y presentación de evidencias digitales derivadas también de fuentes digitales con el propósito de facilitar o promover la reconstrucción de eventos de carácter criminal o de ayudar a anticiparse a acciones no autorizadas que puedan perturbar operaciones planificadas. Para una aproximación al estudio de la ciencia forense vid., ampliamente, Caloyannides, M.A., Computer Forensics and Privacy, Artech House, London, 2001.

${ }^{63}$ Es decir, que se puedan repetir los resultados obtenidos el número de veces que sea necesario, para eliminar cualquier duda respecto a ellos o a los procedimientos empleados para obtenerlos. 
lados y ocultos...) ${ }^{64}$. Otras, se pretende conocer la autoría del delito (grado de conocimientos informáticos, nicks, procedencia del interlocutor, etc.).

Lo determinante será que las distintas operaciones periciales queden plasmadas en el informe pericial y que necesariamente deberá comprender la descripción del objeto junto con la relación detallada de las operaciones practicadas; y, muy especialmente, las conclusiones de los peritos según las reglas de la ciencia y arte informática o conclusiones ${ }^{65}$.

En este contexto, la pericia de autenticidad implica la facultad de tener a disposición tanto el hard como el soft como patrón de materias de comparación (indubitable), y que permite el contraste o análisis comparativo determinante (o no) de la autenticidad e integridad del elemento cuestionado. Así, las fases y elementos básicos que componen todo análisis forense digital son las siguientes:

1. Identificación del hecho tratado y su entorno.

2. Recopilación de evidencias.

3. Preservación de la evidencia.

4. Análisis de la evidencia.

5. Contextualización de la evidencia.

6. Documentación y presentación de los resultados.

Con toda esta información, el perito informático forense elaborará un informe pericial que se presentará ante el tribunal.

\subsection{NORMAS Y ESTÁNDARES PARA LA ELABORACIÓN DE LOS INFORMES PERICIALES INFORMÁTICOS}

Nada dice la LECrim o la LEC sobre las especificaciones o metodología técnica usada en el volcado y demás técnicas usadas para obtener las huellas digitales o códigos hash de los ficheros obtenidos en el dispositivo clonado (ya descritas en apartados anteriores) y de las que también se deberá tomar razón, en orden a una

${ }^{64}$ La STS 1102/2007, de 21 de diciembre, ha puesto de manifiesto la importancia de exponer debidamente los principios, leyes científicas y técnicas empleadas por constituir, en realidad, el fundamento necesario del consecuente dictamen pericial, y así expresa: «la necesidad de tomar en consideración, entre otros extremos, la dificultad de la materia sobre la que verse el dictamen, la preparación técnica de los peritos, su especialización, el origen de la elección del perito, su buena fe, las características técnicas del dictamen, la firmeza de los principios y leyes científicas aplicados, los antecedentes del informe (reconocimientos, períodos de observación, pruebas técnicas realizadas, número y calidad de los dictámenes obrantes en los autos, concordancia o disconformidad entre ellos, resultado de la valoración de las otras pruebas practicadas, las propias observaciones del Tribunal, etc.); debiendo éste, finalmente, exponer en su sentencia las razones que le han impulsado a aceptar o no las conclusiones de la pericia».

65 Vid. art. 478 LECrim. 
buena práctica procesal y profesional de acuerdo con la normativa de calidad profesional del sector.

Así, para la realización del análisis forense existen una serie de estándares nacionales e internacionales que recogen unas guías de buenas prácticas que tratan de garantizar, mediante su seguimiento y correcta aplicación, la validez como medios de prueba de las evidencias recogidas en un posterior proceso judicial ${ }^{66}$.

En cualquier caso, en el ámbito forense merece destacarse la familia ISO 27000, que contiene una serie de normas estándares de seguridad publicadas por la Organización Internacional para la Estandarización (ISO) y la Comisión Electrotécnica Internacional (IEC). En concreto, la ISO 27037 proporciona directrices para la identificación, recolección, adquisición y preservación de la prueba digital ${ }^{67}$. Por su parte, las normas UNE 71505 y 71506 tienen como finalidad dar una metodología para la preservación, adquisición, análisis y presentación de pruebas digitales ${ }^{68}$.

Otra norma de extraordinaria importancia es la RFC 3227. Este documento, publicado por la Internet Engineering Task Force (IETF), recoge directrices para recopilar y almacenar evidencias sin ponerlas en riesgo ${ }^{69}$. En el mismo, se describen, en primer lugar, unos principios directores a tener en cuenta durante la recopilación de evidencias (y que divide en cuatro apartados) ${ }^{70}$; en segundo lugar, describe las recomendaciones para el procedimiento de recopilación, que debe ser lo más detallado posible, sin ambigüedades y minimizando la toma de decisiones durante la recogida de evidencias ${ }^{71}$; $y$, finalmente, en relación con el procedimiento

${ }_{66}$ Tales criterios, no obstante, no tienen un carácter unánime en la doctrina forense y la normativa de referencia en ausencia de criterio vinculante para a ser una guía de buena práctica profesional.

${ }^{67}$ Esta norma ofrece orientación para tratar situaciones frecuentes durante todo el proceso de tratamiento de las pruebas digitales. Además, define dos roles especialistas: DEFR (Digital Evidence First Responders, expertos en primera intervención de evidencias electrónicas) y DES (Digital Evidence Specialists, expertos en gestión de evidencias electrónicas).

${ }_{68}$ Otras guías similares son UNE 71506 (Metodología para el análisis forense de las evidencias electrónicas); Guidelines for the best practices in the forensic examination of digital technology; Electronic Crime Scene Investigation: A Guide for First Responders; o Forensic Examination of Digital Evidence: A Guide for Law Enforcement.

${ }^{69}$ En las mismas, se contienen principios para la recolección de evidencias donde destacan básicamente tres: el orden de volatilidad de los datos, las acciones que deben evitarse y las consideraciones sobre la privacidad.

${ }^{70}$ Orden de volatilidad de las evidencias digitales, debiendo recopilarse en orden de mayor a menor volatilidad. En un sistema típico, se empezaría por los registros o la memoria caché del sistema y se finalizaría por los dispositivos de almacenamiento (CD, DVD, etc.). Se debe evitar para impedir la fácil destrucción de evidencias, como no apagar el equipo hasta terminar la recopilación de evidencias, utilizar programas residentes en dispositivos conocidos y que no modifiquen la fecha de los ficheros o recopilar la información de red previamente a su desconexión.

${ }^{71}$ Se trata de obtener consideraciones legales respecto de las evidencias, que deben ser admisibles en juicio, auténticas, completas, fiables y creíbles para el juez. En relación con las herramientas informáticas a utilizar en la recopilación, y ya en términos más técnicos, se recomienda disponer previamente de un conjunto de herramientas para cada sistema operativo en soportes de solo lectura, incluyendo un programa para el examen de los procesos del sistema $(p s)$; programas para examinar el estado del sistema (como showrev, ifconfig, netstat o arp); un programa para hacer copias a nivel de 
de archivo, se indica el modo en que cada evidencia debe asegurarse, así como la documentación de su cadena de custodia ${ }^{72}$.

Por su parte, en nuestro ámbito nacional nos encontramos con la UNE 197001, que tiene por objeto el establecimiento de los requisitos formales que deben tener los informes y dictámenes periciales, facilitando la lectura y comprensión de los análisis y conclusiones desarrollados por el perito para personal no especializado, incluyendo, por supuesto, el de los organismos judiciales y policiales. La citada norma contiene unas sencillas recomendaciones acerca de que todo informe o dictamen pericial debe disponer de un título que identifique claramente su objeto y debe constar de una estructura básica compuesta por identificación, índice, cuerpo del informe $y$, cuando corresponda, documentos anexos, así como que, en cada página del dictamen, debe figurar su referencia identificativa, el número de la página y el total de éstas ${ }^{73}$.

Del cuerpo del informe pericial, no han de faltar la precisión objeto, alcance, antecedentes, consideraciones preliminares, documentos de referencia, análisis y conclusiones $^{74}$.

\subsection{SOBRE LA CONSIDERACIÓN DE PERITO INFORMÁTICO}

Los peritos informáticos son los profesionales que se encargan de dar soporte a la hora de presentar pruebas tecnológicas ante un tribunal. Ellos son quienes se encargan de analizar la veracidad de dichos pruebas y de exponerlas de forma clara y sencilla para que puedan ser comprendidas por un juez ${ }^{75}$. La LEC, en su artículo

bit (como dd o SafeBack); programas para generar huellas digitales y firmas (como SafeBack, shalsum o $p g p$ ); y programas para generar y examinar imágenes del núcleo del sistema (como gcore o $g d b$ ).

72 Responde a las preguntas de "Cómo se encontró y fue tratada la evidencia; Dónde, cuándo y quién la descubrió y recogió, Dónde, cuándo y quién la trató o examinó; Quién, durante qué periodo y cómo la ha custodiado y, en caso de cambio de custodia, cuándo y cómo se ha llevado a cabo».

${ }^{73}$ La información de identificación del dictamen debe incluir título del informe y su código o referencia de identificación; nombre del Organismo al que se dirige el informe pericial y, en su caso, número de expediente o procedimiento; nombre y apellidos del perito, titulación o destreza específica y, en su caso, colegio o entidad a la que pertenece, DNI, domicilio profesional, teléfono, fax, correo electrónico y cualquier otro dato profesional que pudiera existir, salvo que no sea legalmente procedente; nombre, apellidos y DNI del solicitante del informe pericial, si es en nombre propio o en representación de tercero, con sus datos, y cualquier otro identificador legalmente procedente.

${ }^{74}$ Todo ello, sin perjuicio de la declaración del perito acerca de posibles vicisitudes sobre tachas y juramento.

75 En este sentido, indica la STS de 26 de septiembre de 2005 que no parece discutible que el perito es un auxiliar experto que suministra al juez conocimientos especializados de carácter científico o técnico, de los que él no dispone, y que son necesarios para formar criterio sobre el thema probandum; así, en el proceso, es pericia la que se emite a partir de saberes que no son jurídicos y que tampoco corresponden al bagaje cultural del ciudadano medio no especialista; consecuentemente, no pueden darse por supuestos y deben ser aportados al juicio, para que su pertinencia al caso y su concreta relevancia para la decisión sean valoradas contradictoriamente. 
340.1, especifica que «los peritos deberán poseer el título oficial que corresponda a la materia objeto del dictamen y a la naturaleza de éste. Si se tratare de materias que no estén comprendidas en títulos profesionales oficiales, habrán de ser nombrados entre personas entendidas en aquellas materias» ${ }^{76}$.

En el ámbito de las tecnologías informáticas y digitales, esta exigencia legal se concreta en que el perito ostente la condición de ingeniero o ingeniero técnico en informática, existiendo colegios profesionales de ingenieros o ingenieros técnicos en informática para mayor garantía de los dictámenes emitidos ${ }^{77}$.

Con independencia de las consideraciones legales, los ingenieros e ingenieros técnicos en informática serían a nivel técnico los únicos profesionales cualificados para la realización de peritajes informáticos dado que el estudio de la ingeniería informática cubre todas y cada una de las áreas de esa disciplina incluyendo, por supuesto, la ciencia forense.

En este contexto, se hace necesario llamar la atención sobre el escaso nivel de conocimientos informáticos que, en ocasiones, ponen de manifiesto los agentes actuantes en las intervenciones policiales por no contar con personal cualificado sobre esta compleja materia. $\mathrm{O}$, en peor escenario, cuando, aun contando con personal y e infraestructura adecuada, los primeros agentes intervinientes no han sabido preservar o recolectar las evidencias digitales de forma conveniente para su correcto análisis posterior en los laboratorios tecnológicos forenses. Los cursos de formación sobre peritaje informático no suponen una titulación oficial ni permiten, por tanto, ostentar la cualidad de perito informático titulado u oficial, no debiéndose admitir como prueba pericial válida por nuestros tribunales ${ }^{78}$.

Prevé también la LEC, en su artículo 340.2, que «podrá asimismo solicitarse dictamen de Academias e instituciones culturales y científicas que se ocupen del estudio de las materias correspondientes al objeto de la pericia. También podrán emitir dictamen sobre cuestiones específicas las personas jurídicas legalmente habilitadas para ello».

${ }^{76}$ Con respecto a la identificación del perito informático, ésta, de ser necesario que se produzca, será siempre mediante la presentación del carné o certificado expedido por su colegio profesional, en el que constarán su nombre y sus apellidos, su número de DNI y su número de colegiado, sin ser necesarias chapas, placas u otro tipo de certificaciones.

77 El colegio es el único órgano profesional que puede garantizar, según el ordenamiento jurídico español, que el perito está en el ejercicio de sus plenas facultades profesionales y que por tanto no ha sido inhabilitado debido a mala praxis por su colegio profesional.

${ }^{78}$ Entre esos cursos pueden mencionarse por su amplia difusión en el campo policial los siguientes: Perito Judicial Informático en la UNIR; Curso de Ciberseguridad y Peritaje Informático Forense de Euroinnova; o el Curso de Peritaje Informático de Emagister. Estos «pseudoperitos» pueden realizar análisis e investigaciones, pero no podrán presentar los informes ante un juez con tal carácter de perito. 


\section{LA VALORACIÓN DE LA PRUEBA INFORMÁTICA A LA LUZ DE LA JURISPRUDENCIA DEL TRIBUNAL SUPREMO Y EL CONSITUCIONAL}

\subsection{Sistema DE LibRE VALORACiÓN DE LAS EVIDENCIAS DigitaleS}

A la prueba electrónica, con carácter general, le serán aplicables las reglas procesales generales sobre actividad probatoria, medios de prueba y resultado probatorio. De este modo la evidencia se inserta en el procedimiento posibilitando el necesario debate contradictorio una vez superado el juicio de fiabilidad descrito en páginas anteriores ${ }^{79}$.

La prueba o evidencia digital se incorporará al proceso a petición de las partes, bien solicitando la unión a los autos del propio dispositivo, bien mediante su solicitud al juez para que reclame la remisión de una prueba o documento electrónico ${ }^{80}$. En torno a la valoración de las pruebas en el ámbito procesal, se distinguen, tradicionalmente, dos sistemas: la libre valoración y la prueba legal o tasada.

El sistema de libre valoración de la prueba tiene como característica permitir maximizar la función decisoria del juez al encomendarle a éste la determinación del resultado probatorio específico y conjunto de los medios de prueba aportado a un proceso concreto. Por su parte, la prueba tasada reduce al mínimo esta posibilidad al imponerle al juez ex ante una forma determinada de establecer el resultado probatorio de uno o diversos medios de prueba. En cualquier caso, la valoración de la prueba no podrá ser arbitraria, sino que deberá ser siempre motivada y fundamentada ex arts. $120.3 \mathrm{CE}$ y $247 \mathrm{LOPJ}^{81}$.

Como quiera que sea, en la valoración de la prueba informática rige la previsión del art. 741 de la LECrim referente a la «íntima convicción o apreciación en con-

79 La admisibilidad de la prueba es el resultado de un juicio hecho por el juez sobre las condiciones del medio o actividad probatoria propuestos para su admisión en el proceso. Deberá determinarse si tal material probatorio cumple los requisitos de pertinencia, utilidad y legalidad. La prueba que pretenda ser incluida en el proceso ha de reunir necesariamente dichos requisitos, pues su incumplimiento será motivo de inadmisión de la misma. El juez decidirá por medio de auto sobre la admisión o inadmisión de la prueba. En caso de inadmisión, ésta deberá estar motivada. En relación con el recurso a interponer frente al auto de admisión o inadmisión de la prueba, en función del procedimiento en que nos encontremos, existen una serie de precisiones. Así, en el procedimiento ordinario, conforme al art. 659 LECrim, contra el auto que declare la admisión de las pruebas no cabe recurso, y contra el auto que declare la inadmisión cabrá protesta en aras de interponer en su debido tiempo el recurso de casación contra la Sentencia por quebrantamiento de forma y garantías procesales, al haberse propuesto en tiempo y forma una diligencia que se considera pertinente.

${ }^{80}$ La prueba electrónica no es diferente, en esencia, a la prueba tradicional. Ambas pueden probar tanto la ocurrencia de hechos físicos como de hechos electrónicos. La única diferencia que pudiera es que la prueba electrónica se expresa mediante un soporte electrónico creado por las tecnologías de la información y comunicación, motivo por el cual reviste un carácter efímero y manipulable mayor que el de las otras pruebas

81 Vid. Urbano Castrillo, E., La valoración de la prueba electrónica, op. cit., p. 55 y ss. 
ciencia» del juzgador respecto a la relevancia de la evidencia digital ${ }^{82}$. Y en relación con ello, el art. 726 del mismo texto legal concreta que «El Tribunal examinará por sí mismo los libros, documentos, papeles y demás piezas de convicción que puedan contribuir al esclarecimiento de los hechos o a la más segura investigación de la verdad», términos extensivos predicables de cualquier clase de soporte o evidencia digital ${ }^{83}$.

Se impone, entonces, el sistema de libre valoración de la prueba bajo las reglas de la sana crítica. El sistema de prueba legal se aplicará -solo y exclusivamente- en los casos que la Ley así lo disponga de modo expreso, como puede suceder, v.gr., cuando la prueba electrónica se basa en un documento público con firma electrónica avan$\mathrm{zada}^{84}$, sin perjuicio de que en dicho caso el juez pueda realizar una valoración del instrumento conforme a las reglas de la sana crítica, cuando éste haya sido impugnado ${ }^{85}$.

Lo relevante es, en última instancia, que la prueba informática no conforma prueba plena. No obstante, el peso de las pericias informáticas resulta indudablemente potente para los órganos jurisdiccionales por su valor de convicción, dada la complejidad técnica o científica sobre la que versa, haciendo que, en última instancia, su desprecio o ignorancia por parte del tribunal juzgador ponga en riesgo la ecuanimidad de la resolución adoptada y, en consecuencia, la salvaguarda a un proceso con todas las garantías para el acusado.

\subsection{INADMISIÓN DE LA PRUEBA PERICIAL INFORMÁTICA LEGALMENTE SOLICITADA}

La doctrina sobre el derecho a la prueba, que inspira la jurisprudencia del Tribunal Constitucional acerca de esta materia, se halla recogida, entre otros numerosos precedentes, en la STC 121/2009, 18 de mayo.

82 Señala el art. 741 de la LECrim que «El Tribunal, apreciando, según su conciencia las pruebas practicadas en el juicio, las razones expuestas por la acusación y la defensa y lo manifestado por los mismos procesados, dictará sentencia dentro del término fijado en esta Ley». Por Real Decreto Ley de 8 septiembre 1928 se introdujo un segundo párrafo a esta previsión señalando que «Siempre que el Tribunal haga uso del libre arbitrio que para la calificación del delito o para la imposición de la pena le otorga el Código Penal, deberá consignar si ha tomado en consideración los elementos de juicio que el precepto aplicable de aquél obligue a tener en cuenta».

${ }^{83}$ La legislación procesal espańola recoge el sistema de la libre valoración de la prueba basado en las reglas de la sana crítica, entendida esta última como la combinación de criterios lógicos y de experiencia que debe aplicar el juez (arts. 316.2, 326.2, 334.1, 348, 376, 382.3 y 384.3 LEC). No obstante, existen algunos vestigios de prueba legal, como sucede, por ejemplo, con el art. 319.1 LEC cuando establece que «los documentos públicos comprendidos en los números 1 a 6 del art. 317 harán prueba plena del hecho, acto o estado de cosas que documenten».

${ }^{84}$ Vid. el 319.1 LEC.

${ }^{85}$ Según el art. 3.6 de la Ley 59/2003, de 19 de diciembre, de firma electrónica: «El documento electrónico será soporte de: a) Documentos públicos, por estar firmados electrónicamente por funcionarios que tengan legalmente atribuida la facultad de dar fe pública, judicial, notarial o administrativa, siempre que actúen en el ámbito de sus competencias con los requisitos exigidos por la ley en cada caso. b) Documentos expedidos y firmados electrónicamente por funcionarios o empleados públicos en el ejercicio de sus funciones públicas, conforme a su legislación específica. c) Documentos privados». 
De este modo, recuerda el Tribunal Constitucional que el derecho a la utilización de los medios de prueba pertinentes para la defensa es un derecho fundamental de configuración legal en cuya vulneración, para que tenga relevancia constitucional, han de concurrir varias circunstancias: en primer lugar, el recurrente ha de haber respetado las reglas procesales de tiempo, lugar y forma de su proposición $^{86}$; en segundo término, se ha establecido que la denegación o inejecución han de ser imputables al órgano judicial ${ }^{87}$; finalmente, ha de acreditarse que la ausencia del medio de prueba en cuestión se ha traducido en una indefensión material para la parte, lo que significa que la prueba denegada era decisiva en términos de defensa ${ }^{88}$.

En el concreto ámbito de las periciales informáticas y su denegación, la STS 160/2016, de 1 de marzo, ha establecido que la denegación indebida de la pericial de parte solicitada inexorablemente conduce, en aplicación de una amplia jurisprudencia consolidada, a la anulación de la sentencia recurrida y la consiguiente necesidad de celebración de un nuevo juicio oral, que haga posible la práctica de la prueba pericial tecnológica. Y así, razona el TS:

La Audiencia da por probado el acceso al sistema informático - para lo que ha considerado decisivo el informe pericial- y atribuye la autoría del delito de daños informáticos del art. 264.2 del CP al acusado [...]. Pese a la negativa del acusado, los Jueces de instancia le atribuyen el acceso inconsentido a la vista de la utilización de un nombre de usuario Zapatones identificable con la primera inicial y el apellido del recurrente y de la coincidencia temporal entre esa intrusión y el día en que se produjo el despido. Además, porque resultaría absurdo pensar que lo efectuara el propio denunciante causándose perjuicios a sí mismo y como venganza frente al acusado [...] no se trata de restar valor probatorio a una prueba pericial informática por el simple hecho de que haya sido aportada por la acusación particular. Sobre todo cuando, como expresa la sentencia recurrida, la defensa tuvo cumplida oportunidad en el plenario de someter a contradicción los extremos del dictamen. Sin embargo, sea ese dictamen de carácter oficial o tenga su origen en expertos informáticos no adscritos a un centro de esa naturaleza, lo cierto es que la autoría de una intromisión en los sistemas informáticos ajenos exigirá, en buena parte de los casos, algo más que el conocimiento de una dirección IP y un nickname de usuario. Si a ello se añade que el desconocimiento de los términos del acceso al correo corporativo y al programa de edición de vídeos estuvo originado por no haber sido cursada la correspondiente solicitud judicial, los argumentos que respaldan la reivindicación de la defensa adquieren pleno significado.

${ }^{86}$ No podrá considerarse menoscabado este derecho cuando la inadmisión de una prueba se haya producido debidamente en aplicación estricta de normas legales cuya legitimidad constitucional no pueda ponerse en duda.

${ }^{87}$ Por haberse inadmitido, por ejemplo, pruebas relevantes para la resolución final del asunto litigioso sin motivación alguna o mediante una interpretación de la legalidad manifiestamente arbitraria o irrazonable de tal manera que la prueba denegada o impracticada ha de ser decisiva en términos de defensa.

${ }^{88}$ Esto es, que hubiera podido tener una influencia decisiva en la resolución del pleito, potencialmente trascendental para el sentido de la resolución 
Las razones de la pertinencia del dictamen pericial que se solicite por las partes, y que pudiera ser rechazado por el tribunal, pueden llegar a comprometer en mucho los derechos fundamentales del acusado. De este modo, si la pericia informática resulta inadmitida o no practicada, y era decisiva en términos de defensa, resultará ya evidente $a b$ initio, que ha existido una lesión al ámbito material protegido por el derecho fundamental a utilizar los medios de prueba pertinentes, especialmente, en los casos en que no exista pericial en contra o se contradiga ésta (si existiera) por alguna de parte ${ }^{89}$.

\subsection{OBLIGACIÓN DEL TRIBUNAL DE NO IGNORAR LA PERICIA INFORMÁTICA ADMITIDA Y PRACTICADA}

Pues bien, como se ha puesto de relieve en las páginas precedentes, las supuestas evidencias digitales, si no han sido traídas a las actuaciones con las debidas garantías que permitan comprobar tanto la realidad del origen de aquéllas como que las mismas coinciden efectivamente con las contenidas en los elementos ocupados, podrían quedar viciadas en el juicio de fiabilidad ${ }^{90}$.

Por otra parte, no resulta infrecuente una actuación culposa de los agentes policiales investigadores que han manipulado las evidencias digitales con inobservancia de las cautelas establecidas para la preservación de la cadena de custodia no pudiendo excluirse, tampoco, como por desgracia se ha constatado, que exista una alteración dolosa de éstos con fines de atribuir la autoría de un hecho a persona en quien, en realidad, no concurrían méritos para ello. Ignorar en tal contexto la contrapericial o pericial solicitada por la parte solo puede conducir a resultados proscritos en el ordenamiento jurídico ${ }^{91}$.

Precisamente, uno de los aspectos de la doctrina constitucional y jurisprudencial relativa a la presunción de inocencia es la necesidad de valorar la prueba de

${ }^{89}$ Así, la STS 160/2016, 1 de marzo, establecía que, más allá de la consistencia del juicio inferencial proclamado por la Audiencia, siendo que el dictamen pericial de parte (y que constituyó la clave probatoria de la condena del acusado) aconsejaba el complemento de otro informe de experto que permitiera concluir, entre otras cuestiones, si la autoría del acceso a un sistema informático puede decidirse en atención a la utilización de un nickname coincidente con el apellido del sospechoso. Que resolviera, en fin, si no puede existir otra alternativa razonable.

${ }_{90}$ La STC 123/2006, de 24 de abril , recuerda en cuanto al derecho de presunción de inocencia consagrado en el art. 24.2 CE que «se configura en tanto que regla de juicio y desde la perspectiva constitucional, como el derecho a no ser condenado sin pruebas de cargo válidas, lo que implica que exista una mínima actividad probatoria, realizada con las garantías necesarias, referida a todos los elementos esenciales del delito y que de la misma quepa inferir razonablemente los hechos y la participación del acusado en ellos».

${ }_{91}$ El delito de estafa procesal está regulado en el art. 250.1.7. del Código Penal. El citado precepto dispone que «incurren en la misma los que, en un procedimiento judicial de cualquier clase, manipularen las pruebas en que pretendieran fundar sus alegaciones o emplearen otro fraude procesal análogo, provocando error en el juez o tribunal y llevándole a dictar una resolución que perjudique los intereses económicos de la otra parte o de un tercero». 
descargo, y de cuyo control no escapa el juicio sobre la pericia informática ${ }^{92}$. En este sentido, la STC 55/2015, de 16 de marzo, dice: «ciertamente, este Tribunal tiene fijada doctrina a tenor de la cual el principio de libre valoración de la prueba, reconocido en el artículo 741 de la Ley de Enjuiciamiento Criminal, exige para que pueda considerársele ajustado a la Constitución, que se ponderen los distintos elementos que constituyen la actividad probatoria, sin que de esa ponderación pueda excluirse la prueba de descargo realizada en el juicio oral, ya que ello supone desconocer los derechos del inculpado consagrados en el artículo 24.2 de la Norma fundamental».

En esa argumentación, la doctrina del supremo intérprete de la Carta Magna es clara y contundente. Así, la STC 148/2009, de 15 de junio (citando la STC 186/2006, de 19 de junio), explicita con acierto que «... dentro del control que le corresponde realizar a este Tribunal sobre la eventual vulneración de este derecho (derecho fundamental a la presunción de inocencia) se encuentra verificar si se ha dejado de someter a valoración la versión o la prueba de descargo aportada, concretándose que se exige solamente ponderar los distintos elementos probatorios, pero sin que ello implique que esa ponderación se realice de modo pormenorizado, ni que la ponderación se lleve a cabo del modo pretendido por el recurrente, sino solamente que se ofrezca una explicación para su rechazo»" ${ }^{93}$.

En este contexto, y en el ámbito de las evidencias tecnológicas, la transcendental STS 987/2012, de 3 de diciembre, absuelve al acusado por ignorar la prueba pericial solicitada por vulnerar la garantía constitucional de presunción de inocencia del recurrente, llegando a dictar nueva Sentencia absolutoria, y de la que merece la pena reproducir la siguiente fundamentación jurídica:

... Alega el recurrente que el Tribunal de instancia no ha dispuesto de una «mínima actividad probatoria» que desvirtúe aquélla. Y ello en relación al dato esencial de la autoría de los hechos que se le imputa [...]. En definitiva, Reprocha a la sentencia el desprecio de la prueba pericial que acreditaría que, pese a la identificación

${ }_{92}$ No obstante, la Sala Segunda del TS solo excepcionalmente ha admitido la virtualidad de la prueba pericial como fundamentación de la pretensión de modificación del apartado fáctico de una sentencia, impugnada en casación. El primero, cuando existiendo un solo dictamen o varios absolutamente coincidentes y no disponiendo la Audiencia de otras pruebas sobre los mismos elementos fácticos, el tribunal haya estimado el dictamen o dictámenes coincidentes como base única de los hechos declarados probados, pero incorporándolos a dicha declaración de un modo incompleto, fragmentario, mutilado o contradictorio, de forma que se altere relevantemente su sentido originario. El segundo, cuando contando solamente con dicho dictamen o dictámenes coincidentes y no concurriendo otras pruebas sobre el mismo punto fáctico, el tribunal de instancia haya llegado a conclusiones divergentes con las de los citados informes, sin expresar las razones que lo justifiquen o sin una explicación razonable (vid. SSTS. 182/2000 de 8 de febrero y 1224/2000 de 8 de julio). En el primer caso se demuestra un error porque asumiendo su informe al incorporar a los hechos las conclusiones del único informe pericial sin explicación que lo justifique se hace de un modo que desvirtúa su contenido probatorio, y en el segundo se evidencia un razonamiento abiertamente contrario a la exigencia de racionalidad del proceso valorativo (STS 2144/2002, de 19 de diciembre).

${ }_{93} \mathrm{Y}$, en este mismo sentido, cabe citar las SSTC 242/2005, de 10 de octubre, 187/2006, de 19 de junio, 148/2009, de 15 de junio, y 172/2011, de 19 de julio. 
de la IP desde la que se desplegó la actividad defraudadora, el indicio que permite inferir que fue el acusado el autor resulta poco concluyente y equívoco [...]. Desde luego el informe pericial no acredita por sí solo el error que se denuncia y es objeto de consideración, siquiera insuficiente, en la sentencia. Eso le inhabilita como documento a los efectos del cauce casacional en que es invocado [...]. Para justificar tales conclusiones la sentencia parte del informe policial, confeccionado a partir de la denuncia de quien luego fue coacusado, y que acredita que la orden telemática dirigida a la entidad bancaria se emitió utilizando una IP que había sido adjudicada a un equipo terminal que usaba una línea telefónica de la que era titular el recurrente [...]. La sentencia enfatiza la validez de la indagación policial. Y concluye: el acusado era el usuario del ordenador usado en dicha comunicación. $\mathrm{Y}$, a partir de tal dato básico infiere que él fue el que impartió la orden. En cuanto al informe pericial aportado por la defensa no hace otra consideración que la de recordar que el perito y la policía «en ningún momento examinaron el ordenador del acusado» [...]. Son las afirmaciones inferidas a partir de ahí las refutadas y ello por ilógicas y en exceso abierta. Todo ello a partir de la ostensible insuficiencia del trato retórico dado a la prueba pericial aportada. La sentencia omite todo análisis crítico de tal informe y lo desautoriza partiendo de un dato, tampoco discutido, que, sin embargo, hace poco razonable tal rechazo [...]. En efecto el propio informe advierte que su objetivo y alcance se reduce a poner en evidencia que la inferencia que vincula ser usuario de un ordenador y línea telefónica no lleva necesariamente a la conclusión de que ese usuario sea el autor de toda utilización telemática de esa infraestructura informática [...]. El informe avala sus conclusiones con experiencias que relata y advierte de que ni siquiera tal posibilidad exige una muy cualificada formación en el invasor que incluso dispone de herramientas de ayuda en la misma red. Al respecto facilita un amplio elenco de links en que se puede obtener tutoriales paso a paso para hacerse con el control de otro ordenador.

De este modo, en el ámbito de las evidencias digitales, la no valoración de las periciales informáticas tiene una transcedencia definitiva y a la que no puede dejar de serle aplicada la doctrina general instaurada ya en nuestra jurisprudencia, pues, como recuerda la STS 258/2010, de 12 de marzo: «La ponderación de la prueba de descargo representa un presupuesto sine qua non para la racionalidad del desenlace valorativo». Por tanto, su toma en consideración por el tribunal llamado a resolver es indispensable para que el juicio de autoría pueda formularse con la apoyatura requerida por nuestro sistema constitucional ${ }^{94}$.

94 Vid. SSTC 148/2009, de 15 de junio, y 187/2006, de 19 de junio. Y, en el mismo sentido, la STS 252/2008, de 21 de mayo, recuerda que «La STS de 16 de febrero de 2005 absuelve de una condena en la instancia porque la motivación, al no contemplar referencia alguna a la prueba de descargo, no satisfizo de forma adecuada el estándar de justificación que le era exigible». 


\subsection{CONSECUENCIAS DE LA INOBSERVANCIA DE LAS GARANTÍAS PREVISTAS PARA LAS EVIDENCIA DIGITALES}

Como dispone el tenor literal del art. 11.1 de la LOPJ, en los procedimientos se respetarán las reglas de la buena fe y «no surtirán efecto las pruebas obtenidas, directa o indirectamente, violentando los derechos o libertades fundamentales». La prueba obtenida produciendo la vulneración de derechos fundamentales es ilícita. De este modo, cualquier medio de prueba que no haya sido obtenido respetando los derechos y las libertades fundamentales consagradas en la CE y los tratados internacionales ratificados por Espańa está contaminado de ilegalidad y, por lo tanto, no podrá ser utilizado en los tribunales de justicia como medio de prueba válido y eficaz ${ }^{95}$.

Cualquier duda sobre la fiabilidad del material probatorio debiera determinar su inadmisibilidad como medio de prueba denegando virtualidad o efectos probatorios a los datos informáticos que compongan la prueba. De este modo, partiendo de la premisa del art. 11.1 LOPJ, y de conformidad con la STS 320/2011, es imprescindible distinguir entre las pruebas originales nulas, las pruebas derivadas de éstas (directa o indirectamente) y las pruebas independientes y autónomas de la prueba nula. Estas últimas «deben estimarse independientes jurídicamente por proceder de fuentes no contaminadas, como serían aquellas pruebas obtenidas fruto de otras vías de investigación tendentes a establecer el hecho en que se produjo la prueba prohibida».

En este contexto, el Tribunal Constitucional, en su Sentencia 66/2009, de 9 de marzo, ha precisado que la valoración en juicio de pruebas que pudieran estar conectadas con otras obtenidas con vulneración de derechos fundamentales sustantivos requiere un análisis a dos niveles: en primer lugar, ha de analizarse si existe o no conexión causal entre ambas pruebas, conexión que constituye el presupuesto para poder hablar de una prueba derivada. Solo si existiera dicha conexión procedería el análisis de la conexión de antijuridicidad (cuya inexistencia legitimaría la posibilidad de valoración de la prueba derivada). De no darse siquiera la conexión causal no sería necesario ni procedente analizar la conexión de antijuridicidad, y ninguna prohibición de valoración de juicio recaería sobre la prueba en cuestión. En definitiva, se considera lícita la valoración de pruebas causalmente conectadas con la vulneración de derechos fundamentales, pero jurídicamente independientes, esto es, las pruebas derivadas o reflejas ${ }^{96}$.

Por lo anterior, para que tan nocivos efectos se produzcan es siempre necesario que la admisión a valoración de una prueba conculque también, de alguna forma, la vigencia y efectividad del derecho constitucional infringido por la origi-

95 Se trae a colación ahora la Doctrina de TS, mantenida, entre otras, en la Sentencia $416 / 2005$, de 31 de marzo, al examinar cuál es la trascendencia mediata a los efectos inhabilitantes de la prueba obtenida con violación del derecho fundamental, en el sentido de superar las diversas interpretaciones y la integración, en los más justos términos, de lo que el mandato legal contiene como severa proscripción del uso de prácticas constitucionalmente reprobables.

96 Vid. la STC. 81/98 de 2 de abril. 
naria que, de este modo, le transmite una antijuridicidad que la obligación de tutela de aquel derecho está llamada a proscribir. De no ser así, aunque la segunda prueba haya sido obtenida a causa de la constitucionalmente inaceptable, conservará su valor acreditativo, pues esa vinculación causal se ha producido en virtud de unos resultados fácticos que no pueden excluirse de la realidad y no existen razones de protección del derecho vulnerado que justifiquen unas consecuencias más allá de la inutilización del propio producto de esa vulneración. Y, lo que puede ser todavía más contundente, cualquier prueba que se obtenga, posteriormente, a partir la prueba contaminada tampoco debería poder ser admitida en un proceso judicial.

De este modo, la prueba electrónica, proveniente de un árbol envenenado, pretende erradicar en juicio la utilización de una prueba secundaria que se obtuvo a partir de una prueba primaria, ilegalmente obtenida, por vulnerar derechos fundamentales.

\section{CONCLUSIONES Y PROPUESTAS DE LEGE FERENDA}

I. Lo que se viene entendiendo por evidencia o prueba electrónica no ha sido descrito por norma jurídica alguna. Ante la ausencia de una definición legal se hace necesario modernizar la legislación procesal para que defina, de forma homogénea y coherente, el tratamiento a dar a dicha prueba.

II. Con carácter general se viene entendiendo por prueba informática o evidencia electrónica la que contiene cualquier tipo de información almacenada o trasmitida a través de dispositivos informáticos que tiene la virtualidad de poder acreditar los hechos sobre los que versa el proceso.

III. En su naturaleza, la prueba informática participa de las características de los medios de prueba comunes con las especialidades propias de tan singular disciplina. De este modo, la evidencia electrónica constituye una información obtenida a partir de un dispositivo electrónico o medio digital (soporte técnico), el cual sirve para adquirir convencimiento de la certeza de un hecho en orden a la destrucción o mantenimiento de la necesaria presunción de inocencia que siempre obra a favor del acusado.

IV. La admisibilidad de la prueba electrónica debe cumplir los requisitos exigidos a cualquier otro medio de prueba: pertinencia, utilidad y licitud. Respecto de esta última, la prueba lícita será aquélla que se obtiene sin violar derechos y libertades fundamentales.

V. Se evidencia una controvertida discusión en la Doctrina sobre el carácter de documento electrónico de las evidencias digitales. Debiera, por tanto, acogerse, en una oportuna reforma legislativa, un concepto amplio de documento para que la previsión del art. 26 del Código Penal pueda tener virtualidad respecto a cualquier soporte que, en última instancia, incorpora o expresa datos, hechos o narraciones con la suficiente eficacia probatoria y, en su caso, necesaria relevancia jurídica.

VI. No existe una homogeneidad legislativa en el tratamiento de la prueba electrónica como documento, lo que da lugar a un posicionamiento jurispru- 
dencial restrictivo por los tribunales que no se corresponde con la realidad digital del mundo actual y con el impulso al desarrollo de la sociedad de la información.

VII. En la valoración de la prueba informática serán de aplicación las referidas a los llamados medios probatorios análogos, es decir, los medios de reproducción de la palabra, el sonido y la imagen, así como los instrumentos que permiten archivar y conocer o reproducir palabras, datos, cifras y operaciones matemáticas llevadas a cabo con fines contables o de otra clase, relevantes para el proceso.

VIII. El modo de preservación y conservación de la prueba electrónica dentro del proceso judicial no está, tampoco, regulado debidamente en la normativa procesal donde genéricamente se contemplan medidas de conservación. Debiera protocolizarse y normativizarse la actuación judicial tendente a la obtención y preservación de las evidencias digitales o pruebas informáticas.

IX. El Juez siempre puede y debe, dada la complejidad de la materia, contar con el auxilio de un perito informático que le ayude a esclarecer si ha habido o no manipulación de un medio de prueba electrónico contando, en su caso, con el apoyo de un prestador de servicios de certificación que le ayude a determinar la integridad de los datos y la corrección del origen de los mismos.

$\mathrm{X}$. La cadena de custodia en el ámbito de las evidencias informáticas constituye un proceso transcendental utilizado para documentar la historia cronológica de tales pruebas con el objetivo de convencer al tribunal de que es razonablemente probable que la exposición sea auténtica, así como de que nadie ha alterado la misma. Una metodología de cadena de custodia con lagunas graves puede destruir la certidumbre sobre la prueba que deba servir de soporte probatorio a la demostración de un delito informático o de un ilícito de cualquier tipo.

XI. Se constata la carencia de una metodología con suficiente rigor y que permita garantizar que las evidencias digitales no se han alterado en absoluto desde su recogida hasta su contrastación en el juicio oral. Sería conveniente que por vía normativa o, al menos, jurisprudencial, se recogiera un modelo de referencia con capacidad para responder a las cuatro preguntas, qué, quién, cuándo y dónde, acerca de cada cambio de la evidencia digital a lo largo de la cadena de custodia, desde su recogida hasta su presentación ante el tribunal.

XII. El tiempo establecido para la proposición y aportación de la prueba electrónica debería ser el más temprano posible a fin de asegurar la cadena de custodia garantizando así, en última instancia, la autenticidad, inalterabilidad e indemnidad de las mismas.

XIII. El modo de conseguir el mantenimiento de la cadena de custodia y, por tanto, la virtualidad de la prueba (cargo o descargo) consiste en la realización de un clonado o copia de los dispositivos y la obtención de la denominada función hash o huella digital, únicas garantías técnicas que permiten la 
inalterabilidad de los dispositivos aprehendidos asegurando el debate contradictorio sobre las pruebas.

XIV. La prueba electrónica aportada debe analizarse, como cualquier medio probatorio ordinario o convencional, bajo los principios de oralidad, contradicción, concentración, publicidad e inmediación.

XV. El sistema de valoración aplicable a la prueba electrónica, como regla general, es el de la libre valoración de la prueba bajo las reglas de la sana crítica. Aunque el carácter técnico-informático de la prueba electrónica no justifica la aplicación automática de un sistema de valoración de prueba tasada, resulta, sin embargo, de extraordinaria relevancia la intervención de un perito informático para elaborar el correspondiente dictamen pericial determinante, sin duda, de la ulterior convicción del tribunal, dada la complejidad de la materia.

XVI. El sistema de prueba legal se aplicará -solo y exclusivamente- en los casos que la Ley así lo disponga de modo expreso, como sucede cuando la prueba electrónica se basa en un documento público con firma electrónica avanzada sin perjuicio de que en dicho caso el juez pueda realizar una valoración del instrumento conforme a las reglas de la sana crítica, cuando éste haya sido impugnado.

XVII. Finalmente, si la prueba informática es traída al proceso sin las debidas garantías de custodia policial y control judicial sobre su identidad e integridad, pudiera lesionar el derecho a un proceso con todas las garantías. No estamos ante una garantía meramente legal, sino ante una que afecta a la validez constitucional de la prueba. Por tanto, la ausencia de control judicial de las evidencias electrónica lesiona y vicia la pertinencia de la prueba 



\title{
LA SITUACIÓN JURÍDICA DE LA GESTACIÓN POR SUSTITUCIÓN EN ESPAÑA
}

\author{
Jagdish Kumar Chulani Raymond* \\ Profesor asociado de Derecho Civil \\ Universidad de La Laguna
}

\section{Resumen}

El presente trabajo trata de realizar una aproximación inicial al fenómeno de la gestación subrogada en nuestro país. El artículo 10 de la Ley 14/2006, de 26 de mayo, sobre Técnicas de Reproducción Humana Asistida dispone de forma expresa que (a) Será nulo de pleno derecho el contrato de gestación subrogada; (b) La filiación de los hijos nacidos por gestación de sustitución será determinada por el parto. Sin embargo, y pese a la claridad del precepto, actualmente se puede inscribir en nuestro Registro Civil a los hijos de españoles nacidos en el extranjero mediante esta técnica de reproducción, siempre que se cumpla con los requisitos formales que se establecen en la Instrucción de 5 de octubre de 2010, de la Dirección General de los Registros y del Notariado, sobre régimen registral de la filiación de los nacidos mediante gestación por subrogación.

Palabras clave: gestación subrogada, padres comitentes, filiación, orden público internacional, interés superior del menor.

\author{
THE LEGAL SITUATION OF GESTATION \\ BY SUBSTITUTION IN SPAIN
}

\section{Abstract}

This paper attempts to make an initial assessment of the phenomenon of surrogate pregnancy in our country. Article 10 of the Spanish Law 14/2006 of 26th May on Assisted Human Reproduction Techniques expressly provides that: (a) The surrogate gestation contract shall be null and void; (b) The filiation of children born by substitute pregnancy shall be determined by childbirth. However, despite the clarity of the precept, Spanish children born abroad can now be registered in the Civil Registry by means of this reproduction technique, provided that the formal requirements laid down in the Instruction of 5th October 2010 of the Directorate-General for Registers and Notaries on filiation registration of children born through surrogate pregnancy are met.

KEYWORDS: surrogate pregnancy, intended parents, filiation, international public policy, interests of the child. 


\section{PLANTEAMIENTO}

La moralidad de una generación cambia con respecto a otra debido a que la sociedad se encuentra en continua transformación. Así, los avances de la ciencia médica han contribuido a que no sólo el modelo de familia tradicional ${ }^{1}$ se transforme, sino también las formas de concebir a los descendientes. De este modo, surge la gestación por sustitución ${ }^{2}$, con sus distintas modalidades, como la subrogación tradicional (traditional surrogacy) o total, en donde la mujer gestante es inseminada artificialmente, aportando su propio óvulo, y en consecuencia heredando el nasciturus su información genética; y la subrogación gestacional (gestational surrogacy) o parcial, en donde la embarazada no tiene ningún vínculo ${ }^{3}$ genético con el concebido, pues es la cedente del óvulo la que transmite sus genes ${ }^{4}$.

Desde un punto de vista religioso, confesiones como judaísmo ${ }^{5}$ o el islam no prohíben la maternidad subrogada. De hecho, en los países de credo musulmán un hombre puede contraer nupcias con una segunda mujer ${ }^{6}$, y ésta someterse luego a un proceso de inseminación con el óvulo de la primera esposa ${ }^{7}$.

En el plano jurídico internacional distinguimos tres opciones:

* Profesor asociado del Departamento de Disciplinas Jurídicas Básicas de la Universidad de La Laguna, jchulani@ull.edu.es.

${ }_{1}$ El Código civil español en su redacción originaria de 1989, siguiendo los criterios del Code civil napoleónico de 1804, adoptó el sistema de la concepción formalista, adaptándose así al modelo social imperante en la época, basado en la llamada familia tradicional. Díaz Fraile, J.M., «La gestación por sustitución ante el Registro Civil espańol. Evolución de la doctrina de la DGRN y de la jurisprudencia española y europea», Revista de Derecho Civil, vol. vi, núm. 1 (enero-marzo), 2019, p. 59.

2 La llamada gestación por sustitución consiste en un contrato, oneroso o gratuito, a través del cual una mujer consiente en llevar a cabo la gestación, mediante técnicas de reproducción asistida, aportando o no también su óvulo, con el compromiso de entregar el nacido a los padres comitentes (intended parents), que pueden ser una persona o una pareja, casada entre sí o no, que a su vez pueden aportar o no sus gametos. Vid. F.J. 1. ${ }^{\circ}$ de la Sentencia de la Audiencia Provincial de Valencia, número 949/2011, de 23 de noviembre de 2011.

${ }^{3}$ Nótese que incluso en estos casos existe relación entre la mujer gestante y el bebé (vínculo gestacional). Véase el Informe sobre aspectos éticos y jurídicos de la maternidad subrogada, elaborado por el Comité de Bioética de España en 2017, pp. 12-16. Disponible en https://eprints.ucm. es/id/eprint/42816/ (último acceso: 10/1/2021).

${ }^{4}$ Ver mi artículo periodístico «Ser padres a través de una madre de alquiler», Revista Canaria de la Salud, núm. 24 (abril), 2014, pp. 90-91.

5 El judaísmo apoya la gestación por sustitución con ciertas condiciones, como por ejemplo que la mujer gestante sea de religión judía.

${ }^{6}$ Sura IV, aleya 3, Libro Sagrado Corán: «Si teméis no ser equitativos con los huérfanos, entonces, casaos con las mujeres que os gusten: dos, tres o cuatro. Pero si teméis no obrar con justicia, entonces con una sola».

7 No obstante, el hecho de que un hombre musulmán se case con una segunda esposa y tenga un hijo con ella mediante esta técnica de reproducción humana asistida no impide que luego se pueda divorciar de ella. 
- Países que la prohíben, como por ejemplo Francia o el nuestro, en donde el contrato de gestación por subrogación es nulo de pleno derecho.

- Estados que la permiten, siempre que no medie precio y se realice de forma altruista, como por ejemplo Bélgica ${ }^{8}$.

- Y otros que la promocionan, como por ejemplo algunos estados de EE. UU.?

En el presente artículo hemos querido abordar el estudio de la maternidad subrogada desde la perspectiva española. Una cuestión polémica no sólo en nuestro ámbito jurídico interno, sino también en el marco internacional ${ }^{10}$. Un fenómeno propio de la época en la que nos ha tocado vivir, sin precedentes en la historia, fruto del avance de la ciencia ${ }^{11}$, y que en cualquier caso puede suponer la quiebra del principio formulado por el jurista romano Paulo mater semper certa est ${ }^{12}$. Lo que nos lleva a plantearnos preguntas de difícil respuesta, tales como si son todas las formas de concepción válidas para nuestro sistema de valores occidenta ${ }^{13}$; o cuáles son los efectos de un contrato nulo cuyo objeto sea el alumbramiento de un hijo ${ }^{14}$. Todas estas controversias surgen cuando nos aproximamos a esta materia desde una perspectiva tanto moral como jurídica, cuya consideración permitirá al lector esgrimir argumentos a favor y en contra de este novedoso contrato, siendo complicado, a nuestro modo de ver, encontrar una solución colmada de virtudes a priori.

La posibilidad de que otra mujer distinta a la madre intencional geste un embrión ha sido una posibilidad con la que durante siglos ha soñado el ser humano. De hecho, podemos encontrar precedentes que guardan relación con este contrato

${ }^{8}$ Como consecuencia de una admisión indirecta a través de una situación de práctica tolerancia.

${ }^{9}$ De los cincuenta estados que conforman EE. UU., esta técnica se permite sólo en algunos, como por ejemplo California, Connecticut, Florida, Idaho, Illinois, Nevada o Utah.

${ }^{10}$ En la siguiente página web se puede consultar la situación de la gestación subrogada en distintos países de la comunidad internacional: https://babygest.com/es/tag/maternidad-subrogada/ (último acceso: 2/1/2021).

${ }^{11}$ Que, por ejemplo, permite que los matrimonios homosexuales de varones puedan superar la impotencia generandi a través de esta técnica de reproducción humana asistida.

${ }_{12}$ Digesto de Justiniano, tomo I, libro 2, título 4, apartado 5. La mayoría de las legislaciones reconoce la maternidad legal de la mujer que dio a luz al hijo alegando este antiguo axioma romano. A diferencia de la paternidad, que se funda en presunciones que parten de la existencia de matrimonio - pater est quem nuptiae demonstrant-y de los deberes de cohabitación y fidelidad de los cónyuges entre sí dentro del propio matrimonio, el vínculo de filiación respecto de la madre resulta siempre de dos hechos susceptibles de prueba directa. El primero es el parto de la madre y el segundo la identidad del descendiente, esto es, la determinación de que el hijo o la hija es realmente el que la mujer dio a luz. Vela Sánchez, A.J., La maternidad subrogada: estudio ante un reto normativo, Comares, Granada, 2012, p. 31.

${ }_{13}$ Desde luego este tipo de gestación nos lleva a replantearnos el concepto jurídico y ético de la maternidad. En este sentido ver Quicios Molina, S., "Regulación por el ordenamiento espanól de la gestación por sustitución: dónde estamos y hasta dónde podemos llegar», Revista de Derecho Privado, núm. 1, enero-febrero, Reus, 2019, pp. 6-8.

${ }_{14}$ ¿No estamos ante una res extra commercium? 
en pasajes bíblicos ${ }^{15}$. Pero no nos vamos a centrar en estas páginas en cuestiones relacionadas con fuentes historiográficas, o en regulaciones de otros ordenamientos jurídicos, al no ser éste un estudio de derecho comparado.

Lo que pretendemos es realizar un somero análisis de la situación jurídica actual en España de los menores nacidos mediante gestación por sustitución, pues muchos son los ríos de tinta que han corrido sobre este controvertido tema, no sólo en los distintos medios de comunicación, sino también en la literatura especializada en derecho privado ${ }^{16}$. Para ello, hemos hecho una recopilación de las distintas fuentes normativas relacionadas con este fenómeno; las resoluciones e instrucciones de la Dirección General de los Registros y del Notariado (en adelante, DGRN ${ }^{17}$ ); las sentencias de nuestros tribunales de justicia, todo ello complementado por los imprescindibles comentarios de la doctrina científica; hasta los intentos por regular mediante ley esta nueva forma de concepción de la descendencia ${ }^{18}$.

Con el objetivo de poder realizar un estudio coherente, todas las fuentes utilizadas se irán citando por orden cronológico. El lector podrá así observar la evolución jurídica en España de la situación de estos menores, que en muchas ocasiones parecen encontrarse en una especie de limbo jurídico.

Aunque estamos ante un estudio de derecho civil, no podemos ignorar el necesario elemento de extranjería que está presente en estos negocios jurídicos, pues sin la cobertura de otros ordenamientos jurídicos sería imposible conseguir el resultado perseguido por las partes contratantes, ya que incluso podría ser constitutivo de sanción penal, tal y como prevén los artículos 220 a 222 del Código Penal (RCL $1995(3170)^{19}$.

15 Génesis: 16:1 Sarai mujer de Abram no le daba hijos; y ella tenía una sierva egipcia, que se llamaba Agar. 16:2 Dijo entonces Sarai a Abram: Ya ves que Jehová me ha hecho estéril; te ruego, pues, que te llegues a mi sierva; quizá tendré hijos de ella. Y atendió Abram al ruego de Sarai. 16:3 Y Sarai mujer de Abram tomó a Agar su sierva egipcia, al cabo de diez años que había habitado Abram en la tierra de Canaán, y la dio por mujer a Abram su marido. 16:4 Y él se llegó a Agar, la cual concibió; y cuando vio que había concebido, miraba con desprecio a su señora. Génesis: 30:1 Viendo Raquel que no daba hijos a Jacob, tuvo envidia de su hermana, y decía a Jacob: Dame hijos, o si no, me muero. 30:2 Y Jacob se enojó contra Raquel, y dijo: ¿Soy yo acaso Dios, que te impidió el fruto de tu vientre? 30:3 Y ella dijo: He aquí mi sierva Bilha; llégate a ella, y dará a luz sobre mis rodillas, y yo también tendré hijos de ella. 30:4 Así le dio a Bilha su sierva por mujer; y Jacob se llegó a ella. 30:5 Y concibió Bilha, y dio a luz un hijo a Jacob.

16 Sobre todo, civilista e internacional-privatista.

17 El Real Decreto 139/2020, de 28 de enero, por el que se establece la estructura orgánica básica de los departamentos ministeriales, ha cambiado la denominación de la DGRN por Dirección General de Seguridad Jurídica y Fe Pública. No obstante, en este estudio continuaremos refiriéndonos a ella como DGRN.

${ }_{18}$ Pese al considerable descenso de la tasa de natalidad en nuestro país. En la página web del Instituto Nacional de Estadística se puede consultar la tasa de natalidad por comunidades autónomas, según nacionalidad (española/extranjera) de la madre. Disponible en https://www.ine.es/ jaxiT3/Tabla.htm?t=1433 (último acceso: 4/01/2021).

${ }^{19}$ Delitos relativos a la suposición de parto y de la alteración de la paternidad, estado o condición del menor. A fecha de realización del presente trabajo no se han encontrado sentencias condenatorias relacionadas con las conductas típicas, antijurídicas, culpables y punibles mencionadas. 
Por último, sólo esperamos que el lector se sumerja a través de este sucinto artículo, en el que, sin duda, será uno de los grandes hitos de la humanidad para unos, y la cosificación de la mujer para otros. Como todo en la vida, la gestación por subrogación tiene sus luces y sus sombras.

\section{LA GESTACIÓN POR SUBROGACIÓN: MODALIDADES Y REFERENCIA A LAS TÉCNICAS DE REPRODUCCIÓN HUMANA ASISTIDA}

Sin entrar a profundizar en su delimitación conceptual, la gestación subrogada consiste en el supuesto por el que una pareja comitente, o una persona sola, realiza un contrato ${ }^{20}$ con una madre subrogada (también denominada sustituta, portadora o de alquiler) con el objetivo de que, previa inseminación o transferencia de un embrión fecundado in vitro, dé a luz al niño deseado, siendo éste considerado como hijo de la pareja o persona comitente.

Pese a la rotunda prohibición contenida en el artículo $10.1^{21}$ de la Ley 14/2006, de 26 de mayo, de Técnicas de Reproducción Humana Asistida (RCL 2006\1071, en lo sucesivo LTRHA), que establece la nulidad del contrato de gestación ${ }^{22}$, en la práctica nos encontramos con una abundante casuística de familias tanto heteroparentales como homoparentales o incluso monoparentales ${ }^{23}$ que están

${ }^{20}$ En el que podría afirmarse que la obligación básica que asume la madre gestante es una obligación de resultado. SÁNCHEz JoRdán, M.E., «La necesaria doble aproximación a la gestación subrogada. En particular, de los olvidados contratos de gestación por sustitución», InDret Privado, Revista para el Análisis del Derecho, n. ${ }^{\circ}$ 4, 2020, p. 124.

${ }_{21}$ Dispone el artículo 10.1 LTRHA que «Será nulo de pleno derecho el contrato por el que se convenga la gestación, con o sin precio, a cargo de una mujer que renuncia a la filiación materna a favor del contratante o de un tercero". Destaca que el contenido de este artículo sea exactamente igual al de su correlativo en la ya derogada Ley 35/1988, de 22 de noviembre, sobre Técnicas de Reproducción Asistida (RCL 1988\2332). La última modificación de esta Ley fue la introducida por la Ley 19/2015, de 13 de julio, de medidas de reforma administrativa en el ámbito de la Administración de Justicia y del Registro Civil (RCL 2015\1082). Esta prohibición de la gestación por sustitución en nuestro ordenamiento jurídico tiene su origen en el informe de la Comisión especial de la fecundación in vitro y la inseminación artificial humanas, bajo la Presidencia de D. Marcelo Palacios Alonso, aprobado por el Congreso de los Diputados el 10 de abril de 1986.

22 Podríamos decir que el contrato es nulo no sólo por lo dispuesto en el artículo 10 LTRHA, sino en base a otros artículos del Código Civil (LEG 1889\27), como el 1255, el 1271 o el 1275.

${ }^{23}$ Como por ejemplo el matrimonio estadounidense formado por el actor Matthew John Broderick y la actriz Sarah Jessica Parker; el matrimonio formado por el cantante británico Elton John y el cineasta canadiense David Furnish; el futbolista portugués Cristiano Ronaldo o la coleccionista de arte Carmen Cervera, nacida en España, y viuda del barón alemán Hans Heinrich von Thyssen-Bornemisza. Vid. la noticia en el periódico El Pais, 20-06-2018, disponible en https://smoda. elpais.com/celebrities/estos-famosos-han-recurrido-a-los-vientres-de-alquiler-para-ser-padres/ (último acceso: 5-01-2021). 
acudiendo a países en los que tal contrato ${ }^{24}$ no está prohibido, con el fin de obtener descendencia. Se trata de una vía ${ }^{25}$ para burlar la prohibición legal del artículo 10.1 LTRHA.

Estas técnicas de reproducción engloban un conjunto de procedimientos que implican la intervención médica en al menos alguna de las fases de la procreación $^{26}$, las cuales podemos clasificar de la siguiente forma:

- Inseminación artificial. Consiste en la introducción del esperma en la vagina o útero de una mujer por cualquier medio distinto de la relación sexual. Puede ser homóloga ${ }^{27}$ o heteróloga ${ }^{28}$. Gregorio MARAÑón afirma en su obra Ensayo biológico sobre Enrique IV de Castilla y su tiempo que fue en España y en la persona de la reina, Dña. Juana de Portugal, a quien primero se le aplicó una inseminación artificial homóloga ${ }^{29}$.

- Fecundación in vitro. En este supuesto la fecundación del óvulo se realiza en un laboratorio, ante la imposibilidad de que el semen se fertilice en el tercio externo de las trompas de Falopio. Puede ser también homóloga ${ }^{30}$ o heteró$\operatorname{loga}^{31}$. La primera niña que nació como consecuencia de este tipo de fecundación fue Louise Brown, en el año 1978, en Londres ${ }^{32}$.

- Transferencia intratubárica de gametos. Consiste en colocar en cada una de las trompas de Falopio dos óvulos y espermatozoides para que los fecunden en las mismas trompas.

- Gestación por sustitución. Como hemos dicho con anterioridad, esta técnica consiste en que una mujer lleva en su cuerpo implantado un embrión hasta el

${ }^{24}$ Cuyas posibles partes intervinientes son los comitentes, la agencia intermediaria (como por ejemplo Surrobaby, Gestlife o la Agencia Española de Gestación Subrogada [AEGES]), la mujer gestante y los donantes del material genético. No obstante, en los últimos años ha entrado en escena un nuevo elemento, que permite alterar la aproximación habitual a ese fenómeno y centrar la atención en el análisis del contrato en virtud del cual se acuerda encargar a una mujer la gestación de un bebé a cuya filiación renuncia por anticipado. SANCHEZ Jordán, M.E., op. cit., p. 120. Ver también la Sentencia de la Audiencia Provincial de Barcelona, número 10/2019, del 15 de enero de 2019 (JUR 2019\25547); y la Sentencia de la Audiencia Provincial de Zaragoza número 38/2019, de 15 de febrero de 2019 (JUR 2019\185867).

${ }^{25}$ Que ha derivado en lo que ha llegado a denominarse «turismo reproductivo, procreativo o de fertilidad».

${ }^{26}$ Leonsegui Guillot, R.A., "La maternidad portadora, sustituta, subrogada o de encargo", Boletín de la Facultad de Derecho de la UNED, segunda época, número 7, invierno 1994, p. 318 .

27 En aquellos casos en los que la mujer es inseminada con el semen del marido.

${ }^{28}$ En aquellos supuestos en los que la mujer es inseminada con el semen de un tercero ajeno a la relación.

29 Díaz-Ambrona Bardají, M.D., Ponencia "Genética y filiación», XIII Congreso Internacional de Derecho de Familia, Sevilla, 2004, p. 10.

${ }^{30}$ Los gametos provienen de los cónyuges o parejas convivientes.

${ }^{31}$ Los gametos han sido donados por terceras personas previamente.

32 Díaz-Ambrona Bardají, M.D, op. cit., p. 11. 
nacimiento, para el beneficio de otra pareja o persona. No obstante, podemos distinguir las siguientes cuatro modalidades de gestación por sustitución ${ }^{33}$ :

1) Aportación por la pareja comitente únicamente del semen de un varón, mientras que la mujer sustituta aporta su óvulo y llevará acabo la gestación. Se trata de la denominada maternidad subrogada tradicional (traditional surrogacy), plena o total, realizada normalmente a través de inseminación artificial. De esta manera, la mujer sustituta será madre biológica del nacido, además de ser quien le dará a luz, y un varón de la pareja comitente su padre biológico ${ }^{34}$.

2) Aportación por la pareja comitente de la totalidad del material genético, de modo que la mujer sustituta únicamente llevará acabo la gestación. Por tanto, los progenitores biológicos del nacido serán los miembros de la pareja comitente ${ }^{35}$.

3) Aportación por la pareja comitente solamente de los gametos de uno de ellos (sólo el semen o sólo el óvulo), que se combinarán con los gametos de una cuarta persona, que será el donante de ovocitos o semen respectivamente. Nuevamente, la mujer sustituta únicamente llevará a cabo la gestación, sin aportar material genético alguno, siendo padres biológicos el miembro de la pareja comitente que aportó sus gametos y el donante ${ }^{36}$.

4) No aportación de gametos por la pareja comitente, obteniéndolos de donantes de semen y ovocitos. Al igual que en la situación anterior, la mujer sustituta únicamente llevará a cabo la gestación, sin aportar material genético alguno, pero ahora serán padres biológicos del nacido los correspondientes donantes ${ }^{37}$.

Estos tres últimos supuestos serían variantes de la denominada maternidad subrogada gestacional (gestational surrogacy) o parcial, caracterizada por el hecho de que la gestante no aporta material genético propio, disociándose la maternidad genética y la gestación ${ }^{38}$. De hecho, el caso más sencillo se produce cuando los titulares de las células germinales coindicen totalmente con los miembros de la pareja comitente, quienes aportan tanto el semen como el óvulo, produciéndose así una

${ }^{3}$ Jiménez MuÑoz, F.J., La reproducción asistida y su régimen jurídico, Reus, Colección Jurídica General, Madrid, 2012, p. 105.

34 Jiménez Muñoz, F.J., op. cit., p. 106.

35 Jiménez Muñoz, F.J., op. cit., p. 107.

36 Jiménez Muñoz, F.J., op. cit., p. 107.

37 Jiménez Muñoz, F.J., op. cit., p. 107.

38 Jiménez Muñoz, F.J., op. cit., p. 107. La posibilidad que ofrecen las técnicas de reproducción de disociar la maternidad en tres elementos (genético, gestacional y volitivo), que pueden no coincidir en la misma mujer, ha aportado complejidad a una cuestión en principio pacífica y ha planteado nuevos retos al legislador. FArnós Amorós, E., $A D C$, tomo LXVIII, fascículo I, 2015, p. 9. 
fecundación in vitro homóloga para luego implantar el cigoto en el útero de la mujer que llevará acabo el embarazo. Todas estas combinaciones dan lugar al fenómeno de la maternidad subrogada, que irremediablemente producirá una contraposición de intereses entre la pareja comitente, que aportó el huevo fecundado, y la portadora, que es la madre, en cuanto que gesta y alumbra al nacido ${ }^{39}$.

Por último, aparece unánimemente descartado del fenómeno de la maternidad subrogada la utilización animal, como los rumores de querer convertir a una simia en portadora de un embrión humano ${ }^{40}$.

\section{POSTURA DE LA DIRECCIÓN GENERAL DE LOS REGISTROS Y DEL NOTARIADO SOBRE LA GESTACIÓN SUBROGADA}

Pese a la prohibición contenida en el artículo 10.1 LTRHA, numerosos ciudadanos españoles han salido de nuestras fronteras en busca de países que admitan los contratos de gestación por sustitución con la intención de poder acceder a la paternidad. Ante esta situación, la DGRN trató de dar una solución administrativa, en contra de lo dispuesto en la referida LTRHA, fundamentada en el Reglamento del Registro Civil aprobado por el Decreto de 14 de noviembre de 1958 (RCL 1958\1957, en adelante $\mathrm{RRC}$ ), $y$, por tanto, en detrimento del principio de jerarquía normativa.

\subsection{Resolución de la Dirección General de los Registros y del Notariado, DE 18 DE FEBRERO DE 2009}

La primera vez que este centro directivo tuvo que pronunciarse sobre esta materia fue con la Resolución de la Dirección General de los Registros y del Notariado, de 18 de febrero de 2009 (RJ 2009\1735, en adelante RDGRN), por la que se admitió la pretensión de un matrimonio, formado por dos varones ${ }^{41}$, de nacionalidad española y residentes en España, de inscribir a dos menores, nacidos en San

39 Leonsegui Guillot, R.A.: op. cit., p. 323.

40 Higuera, G., «Biogenética y Derecho», Revista Española de Derecho Canónico, 44, Madrid, 1987, p. 13.

${ }_{41}$ Casados en octubre de 2005, pocos meses después de la entrada en vigor de la Ley 13/2005, de 1 de julio, por la que se modifica el Código Civil en materia de derecho a contraer matrimonio (RCL 2005\1407). Ver también Sentencia del Tribunal Constitucional, número 198/2012, de 6 noviembre de 2012 (RTC 2012\198), por la que se desestima el recurso de inconstitucionalidad interpuesto por el Grupo Popular del Congreso contra la citada Ley 13/2005, de 1 de julio. 
Diego el 24 de octubre de 2008, como hijos ${ }^{42}$ suyos, aportando los certificados de nacimiento ${ }^{43}$, expedidos por las autoridades californianas ${ }^{44}$.

Dicha RDGRN trae causa de la denegación por parte del canciller encargado del Registro Civil Consular de España en Los Ángeles-California (EE. UU.), en su Auto de 10 de noviembre de 2008, de la inscripción solicitada por parte del referido matrimonio homosexual, con base en el artículo 10 LTRHA y en la prohibición de la celebración, en nuestro ordenamiento jurídico, del contrato de gestación subrogada. Este auto se recurrió por parte del matrimonio ante DGRN, quien estimó la pretensión de los recurrentes en su RDGRN, y en consecuencia autorizó la inscripción en el Registro Civil del nacimiento de los menores y su respectiva filiación a favor del matrimonio ${ }^{45}$.

Los principales fundamentos de derecho en los que se sustenta la RDGRN son los siguientes:

En primer lugar, el artículo 81 del RRC establece que «El documento auténtico, sea original o testimonio, sea judicial, administrativo o notarial, es título para inscribir el hecho de que da fe. También lo es el documento auténtico extranjero, con fuerza en España con arreglo a las leyes o a los Tratados internacionales». En virtud de ello, entiende la DGRN que la misión del encargado del Registro Civil se tiene que limitar a realizar un control formal de legalidad de la decisión registral extranjera. La aplicación del artículo $81 \mathrm{RRC}$ excluye, por tanto, la utilización de las normas españolas de conflicto de leyes y, en concreto, la del artículo 9.4 CC. Por tanto, también excluye la aplicación de la Ley sustantiva a la que tales normas de conflicto españolas pudieran conducir, como la LTRHA. Las normas de conflicto españolas y las normas sustantivas designadas por tales normas de conflicto son sólo aplicables a los supuestos que surgen ante las autoridades españolas sin que haya sido dictada una decisión por la autoridad pública extranjera. Por consiguiente, son aplicables en el presente caso las normas jurídicas españolas que regulan el acceso al Registro Civil español de las certificaciones regístrales extranjeras, esto es, el artículo 81 RRC y no las normas de conflicto españolas y tampoco las normas sustantivas españolas que determinan la filiación ${ }^{46}$.

${ }^{42}$ Biológicos de ambos, ya que lo que pretendían era obtener la doble filiación paterna, evitando así, los padres de intención, el tener que recurrir a otras instituciones como la adopción o el acogimiento familiar.

${ }^{43}$ En los que se constataba la paternidad a favor de los recurrentes de dos niños mellizos nacidos de una madre subrogada en California a partir de material genético de uno de los recurrentes y de óvulos de donante anónima. Heredia Cervantes, I., «La Dirección General de los Registros y del Notariado ante la gestación por sustitución», $A D C$, tomo LXVI, fascículo II, 2013, p. 695.

${ }^{44}$ Estas certificaciones registrales extranjeras fueron emitidas por la autoridad administrativa del Registro de California (The California Office of Vital Records).

${ }^{45}$ Jiménez Martínez, M.V., «La inscripción de la filiación derivada de la gestación por sustitución. Problemas actuales», Anuario de la Facultad de Derecho de la Universidad de Alcalá, núm. 5, 2012, p. 371.

46 Vid. F.D.2. de la RDGRN de 18 de febrero de 2009. 
En segundo lugar, el interés superior del menor aconseja proceder a la inscripción en el Registro Civil español de la filiación que figura en el Registro extranjero y en la certificación registral extranjera, ya que, en el caso de rechazar la inscripción de la filiación en el Registro Civil español, podría resultar que los hijos, de nacionalidad española, quedarían privados de una filiación inscrita en el Registro Civil. Ello vulnera el artículo 3 de la Convención sobre los Derechos del Niño hecha en Nueva York el 20 noviembre 1989 (BOE número 313 de 31 diciembre 1990 [RCL 1990\2712]), en vigor para España desde el 5 de enero de $1991^{47}$.

Y, en tercer lugar, en el derecho español, la filiación natural no se determina necesariamente por el hecho de la vinculación genética entre los sujetos implicados, como se deduce del artículo 7.3 LTRHA ${ }^{48}$, precepto que permite que la filiación natural de un hijo conste en el Registro Civil a favor de dos mujeres. Por ello, no existen obstáculos jurídicos a la inscripción en el Registro Civil español de una certificación registral extranjera que establezca la filiación en favor de dos varones españoles ${ }^{49}$.

Sin embargo, esta RDGRN fue recurrida en sede judicial por el Ministerio Fiscal, el 28 de enero de 2010, al presentarse en el Decanato de los Juzgados de Valencia demanda contra la RDGRN, que recayó en el Juzgado de Primera Instancia número 15, cuyo titular, mediante Sentencia de 15 de septiembre de 2010 (AC 2010\1707), estimó íntegramente la demanda interpuesta por el Ministerio Fiscal contra la RDGRN, dejando sin efecto la inscripción de nacimiento de los menores, realizada en el Registro Civil Consular de Los Ángeles, y, en consecuencia, procediéndose a la cancelación del asiento de inscripción.

\subsection{InSTRUCCIÓN DE 5 DE OCTUbRe De 2010, SObRe RÉGIMEN REGISTRAL DE LA FILIACIÓN DE LOS NACIDOS MEDIANTE GESTACIÓN POR SUSTITUCIÓN}

En el año 2010, la DGRN dio un paso más en la regulación de las condiciones de acceso al Registro Civil de los niños nacidos en el extranjero de madres gestantes que, en virtud del recurso a un contrato de gestación subrogada, han renunciado con carácter anticipado a su filiación materna. Para ello, el centro directivo dictó la Instrucción de 5 de octubre de 2010, sobre régimen registral de la filiación de los nacidos mediante gestación por sustitución (RLC 2010〈2624), que establece

$47 \mathrm{Vid}$. F.D.5. ${ }^{\circ}$ de la RDGRN de 18 de febrero de 2009.

48 Cuando la mujer estuviere casada, y no separada legalmente o de hecho, con otra mujer, esta última podrá manifestar, conforme con lo dispuesto en la Ley del Registro Civil, que consiente en que se determine a su favor la filiación respecto al hijo nacido de su cónyuge (artículo incorporado por la Ley 3/2007, de 15 de marzo, reguladora de la rectificación registral de la mención relativa al sexo de las personas [RCL 2007\524]). No obstante, este artículo establece la imposición legal de contraer matrimonio a las parejas de mujeres, antes del alumbramiento del hijo, siendo ésta hasta ahora la única forma de poder determinar la filiación del menor a favor de la madre no gestante, a menos que, una vez nacido el menor, inicie los trámites de adopción.

${ }^{49}$ Vid. F.D.5. ${ }^{\circ}$ cit. de la RDGRN. 
unos criterios para el acceso al Registro Civil español de los menores nacidos en el extranjero mediante esta técnica de reproducción humana asistida. No obstante, el objetivo esencial ${ }^{50}$ de la Instrucción, contemplado desde una perspectiva global, fue establecer:

1. ${ }^{\circ}$ Los instrumentos necesarios para que la filiación tenga acceso al Registro Civil español cuando uno de los progenitores sea de nacionalidad española, como vía de reconocimiento a efectos registrales de su nacimiento.

2. ${ }^{\circ}$ Que la inscripción registral en ningún caso puede permitir que con la misma se dote de apariencia de legalidad supuestos de tráfico internacional de menores.

3. ${ }^{\circ}$ La exigencia de que no se haya vulnerado el derecho del menor a conocer su origen biológico ${ }^{51}$.

Sin embargo, lo más novedoso de la Instrucción fue que, en ejercicio de las competencias que le vienen atribuidas por el artículo 9 de la Ley del Registro Civil, de 8 de junio 1957 (RCL 1957\777, en adelante, LRC), 41 RRC y 7 del Real Decreto $1125 / 2008$, de 4 de julio, por el que se desarrolla la estructura orgánica básica del Ministerio de Justicia y se modifica el Real Decreto 438/2008, de 14 de abril, por el que se aprueba la estructura orgánica básica de los departamentos ministeriales, acordó establecer y hacer públicas las siguientes directrices:

1. La inscripción de nacimiento de un menor, nacido en el extranjero como consecuencia de técnicas de gestación por sustitución, sólo podrá realizarse presentando, junto a la solicitud de inscripción, la resolución judicial dictada por el tribunal competente en la que se determine la filiación del nacido ${ }^{52}$.

2. Salvo que resultase aplicable un convenio internacional, la resolución judicial extranjera deberá ser objeto de exequatur según el procedimiento contemplado en la Ley de Enjuiciamiento Civil de 1881 (LEG 1881\1) ${ }^{53}$. Para prolimbo jurídico.

50 Además de evitar que la determinación de la filiación de estos menores quedase en un

${ }^{51}$ Según se expresa en el artículo 7, número 1, de la Convención sobre los Derechos del Nińo de 20 de noviembre de 1989, en el artículo 12 de la Ley 54/2007, de 28 de diciembre, de Adopción Internacional (RCL 2007\2383), así como en la Sentencia del Tribunal Supremo de 21 de septiembre de 1999 (RJ 1999\6944).

52 En los casos en los que se solicite la inscripción del nacido en el extranjero mediante gestación por sustitución sin que se presente una resolución que determine la filiación, reconocible incidentalmente o por exequatur, el encargado del Registro Civil denegará la inscripción. Ello no impedirá que el solicitante pueda intentar dicha inscripción por los medios ordinarios regulados en el artículo 10.3 LTRHA y en los artículos 764 y siguientes de la Ley 1/2000, de 7 de enero, de Enjuiciamiento Civil (RCL 2000\34).

53 En los artículos 951 a 958 ya derogados por el número 1 de la disposición derogatoria única de la Ley 29/2015, de 30 de junio, de cooperación jurídica internacional en materia civil (RCL 2015\1200, en adelante, LCJIMC), y ahora regulado por los artículos 52 a 55 de la LCJIMC. No obstante, es causa de denegación del reconocimiento de resoluciones judiciales extranjeras firmes el ser contraria al orden público, conforme con lo dispuesto en el artículo 46.1 a) LCJIMC. Sin 
ceder a la inscripción de nacimiento, deberá presentarse ante el Registro Civil español la solicitud de la inscripción y el auto judicial que ponga fin al mencionado procedimiento de exequatur.

3. No obstante, en el caso de que la resolución judicial extranjera tuviera su origen en un procedimiento análogo a uno español de jurisdicción voluntaria, el encargado del Registro Civil controlará incidentalmente, como requisito previo a su inscripción, si tal resolución judicial puede ser reconocida en España. En dicho control incidental deberá constatar:

a. La regularidad y autenticidad formal de la resolución judicial extranjera y de cualesquiera otros documentos que se hubieran presentado.

b. Que el tribunal de origen hubiera basado su competencia judicial internacional en criterios equivalentes a los contemplados en la legislación española.

c. Que se hubiesen garantizado los derechos procesales de las partes, en particular, de la madre gestante.

d. Que no se ha producido una vulneración del interés superior del menor y de los derechos de la madre gestante. En especial, deberá verificar que el consentimiento de esta última se ha obtenido de forma libre y voluntaria, sin incurrir en error, dolo o violencia y que tiene capacidad natural suficiente.

e. Que la resolución judicial es firme y que los consentimientos prestados son irrevocables, o bien, si estuvieran sujetos a un plazo de revocabilidad conforme a la legislación extranjera aplicable, que éste hubiera transcurrido, sin que quien tenga reconocida facultad de revocación la hubiera ejercitado.

Además de todo lo anterior, dispone también la Instrucción que en ningún caso se admitirá como título apto para la inscripción del nacimiento y filiación del nacido una certificación registral extranjera o la simple declaración, acompañada de certificación médica relativa al nacimiento del menor en la que no conste la identidad de la madre gestante.

Hasta este momento, con la solución ofrecida por la Instrucción de la DGRN, el conflicto había obtenido una pseudorrespuesta, en tanto en cuanto no se produzca la derogación del artículo 10 LTRHA.

embargo, entre los presupuestos a los que se refiere la Instrucción de la DGRN no se encuentra la conformidad con el orden público español internacional, requisito que sí se exige en el artículo 96.2 d) de la Ley 20/2011, de 21 de julio, del Registro Civil (RCL 2011\1432, en lo sucesivo, LRC 2011, cuya entrada en vigor está prevista para el 30 de abril de 2021, conforme con lo dispuesto en la disposición final quinta de la Ley $3 / 2020$, de 18 de septiembre, de medidas procesales y organizativas para hacer frente al COVID-19 en el ámbito de la Administración de Justicia [RCL 202011497]) y en la disposición adicional tercera de la Ley 15/2015, de 2 de julio, de la Jurisdicción Voluntaria (RCL 2015\1016, en adelante, LJV). 
De esta forma se vuelve a dar validez en España a un evidente fraude de ley, ahora no sólo frente al claro tenor literal del artículo 10 LTRHA, sino frente a las sentencias que a continuación comentaremos, con el único apoyo jurídico de la Instrucción de la DGRN, cuyo valor normativo es ciertamente endeble ${ }^{54}$. Sin embargo, como veremos, el problema parece tener todavía un largo camino por recorrer.

\section{LA GESTACIÓN POR SUSTITUCIÓN ANTE LOS TRIBUNALES ESPAÑOLES}

Tal y como observaremos a continuación con la exposición del iter judicial de este fenómeno, tan analizado por la doctrina científica, la solución ofrecida por parte de los tribunales de justicia no ha sido la misma que la que ha establecido la DGRN.

\subsection{Sentencia del Juzgado de Primera Instancia número 15 de Valencia, DE 15 DE SEPTIEMBRE DE 2010}

La RDGRN, como hemos dicho anteriormente, fue recurrida por la Fiscalía y el Juzgado de Primera Instancia número 15 de Valencia dictó la Sentencia de 15 de septiembre de 2010, por la cual se revocó la citada RDGRN en aplicación del principio de jerarquía normativa reconocido en el artículo 9.3 de la Constitución (RCL 1978\2836), al considerar, el juzgador, preferente la aplicación del artículo 23 LRC, frente al artículo 81 RRC, ya que dicho Reglamento desarrolla y completa la ley citada.

Según reza el artículo 23 LRC: «Las inscripciones se practican en virtud de documento auténtico o, en los casos señalados en la Ley, por declaración en la forma que ella prescribe. También podrán practicarse, sin necesidad de previo expediente, por certificación de asientos extendidos en registros extranjeros, siempre que no haya duda de la realidad del hecho inscrito y de su legalidad conforme a la Ley española». Vemos por tanto que el mencionado artículo 23 LRC sí obliga al registrador a realizar un control de fondo del contenido de la certificación extranjera, puesto que se tiene que asegurar de que no incurra en contradicción con la Ley española, lo cual ocurría en este caso, al contradecir el contenido del artículo 10.1 LTRHA. Aparte, esta sentencia despejó cualquier duda respecto del principio de no discriminación. La DGRN consideró que, si se permite la inscripción de la filiación a favor de dos mujeres casadas, también se tendría que permitir la filiación a favor de dos varo-

${ }^{54}$ Martínez de Aguirre Aldaz, C., «Acciones de filiación. Filiación derivada de técnicas de reproducción asistida", en Martínez de Aguirre Aldaz, C. (coord.), Curso de Derecho Civil (IV) Derecho de Familia, Edisofer, 5. ${ }^{a}$ edición, Madrid, 2016, p. 375. 
nes casados ${ }^{55}$. A este respecto, considera el juzgador de instancia que la nulidad del contrato se deriva de las consecuencias que se producen tras el alumbramiento, con independencia del sexo de las personas, distintas de la madre gestante, que pretenden ostentar la filiación del nacido, por la existencia de un contrato de maternidad por sustitución ${ }^{56}$.

La Sentencia también determinó que el fin no justifica los medios, ya que el ordenamiento jurídico español tiene medios e instrumentos suficientes para conseguir esta concordancia y que los hijos consten a nombre de sus padres, pero la consecución de ese fin no legitima actuaciones contrarias a ese propio ordenamiento jurídico, sino que el resultado debe conseguirse a través de las vías que el derecho español establece ${ }^{57}$.

Algunos supuestos, con cierto parecido al tratado, son los referidos en el fundamento jurídico quinto de la Sentencia:

El primero de ellos es el acceso al Registro Civil de los matrimonios entre personas del mismo sexo contraídos en el extranjero con anterioridad a la Ley 13/2005, los cuales hasta la modificación del Código Civil tenían vedado el acceso al Registro Civil. Sin embargo, tras la entrada en vigor de la Ley 13/2005, se dictó la Resolución-Circular de 29 de julio de 2005 de la DGRN por la que se resuelve el reconocimiento en España de los matrimonios celebrados en el extranjero entre españoles, o entre españoles y extranjeros del mismo sexo, antes de la entrada en vigor de la citada Ley 13/2005, de 1 de julio. Tal vez sea éste el supuesto, de entre los que menciona el juzgador de primera instancia, que más similitudes presenta con respecto al fenómeno de la gestación subrogada, ya que, hasta la entrada en vigor de la Ley por la que se modifica el Código Civil en materia de derecho a contraer matrimonio, muchos espańoles recurrían a países en donde el contrato matrimonial entre personas del mismo sexo sí estaba regulado, con el objetivo de contraer nupcias.

El segundo supuesto que expone la Sentencia es el caso de matrimonios celebrados entre una menor y un español en el extranjero. Así, en países como Colombia, en donde la edad mínima exigida a una mujer para contraer matrimonio es de 12 años, el matrimonio allí celebrado entre una menor y un español no tendría acceso al Registro Civil español ${ }^{58}$.

El tercer caso al que hace referencia la Sentencia es el de los matrimonios poligámicos, legales en otros países, pero no inscribibles en el Registro Civil español. En nuestra opinión, consideramos que el tratar de relacionar los matrimonios polígamos con la maternidad por subrogación era del todo innecesario, más aún cuando en España, si bien es cierto que dichos matrimonios no son susceptibles de

55 Vid. F.D. 4. ${ }^{\circ}$ de la Sentencia del Juzgado de Primera Instancia número 15 de Valencia, de 15 de septiembre de 2010. De hecho, el artículo 7.3 LTRHA permite inscribir la filiación natural respecto de dos mujeres y sería discriminatorio por razón de sexo no permitirlo a dos varones.

56 Jiménez Martínez, M.V., op. cit., pp. 374-375.

57 Vid. F.D. $4 .^{\circ}$. cit. de la SJPI.

58 Conforme con lo dispuesto en el artículo 46 CC: «No pueden contraer matrimonio: $1 .^{\circ}$ Los menores de edad no emancipados». 
reconocimiento, el ordenamiento jurídico español sí que les ha venido atribuyendo efectos, como por ejemplo ocurre con el reparto de la pensión de viudedad entre las esposas legítimas del causante.

\subsection{Sentencia de la Sección Décima de la Audiencia Provincial de Valen- CIA, DE 23 DE NOVIEMBRE DE 2011}

Los padres comitentes, en su anhelo de conseguir el reconocimiento de la filiación de los menores y, por ende, de la prevalencia del principio de la autonomía de la voluntad de las partes, sobre la legalidad vigente del Estado español, interpusieron recurso de apelación frente a la Sentencia de 15 de septiembre de 2010, del Juzgado de Primera Instancia número 15 de Valencia, por la que se estimó totalmente el recurso contra la RDGRN, dejando sin efecto la inscripción de nacimiento y, en consecuencia, procediéndose a la cancelación del asiento de inscripción.

Sin embargo, la Sentencia dictada por la Sección Décima de la Audiencia Provincial de Valencia, de 23 de noviembre de 2011 (AC 2011\1561), desestimó también el recurso interpuesto por los apelantes, pronunciándose sobre las siguientes cuestiones: (a) Las consecuencias de la inscripción de la certificación registral extranjera; (b) La Instrucción de 5 de octubre de 2010 de la DGRN; (c) La huida de los demandantes de la aplicación de la norma imperativa española; (d) La no discriminación por razón del sexo; (e) La defensa del interés superior del menor; (f) El derecho a una identidad única.

La Sentencia de la Audiencia da preferencia, al igual que la de instancia, a la aplicación del artículo 23 LRC frente al $81 \mathrm{RRC}$, al encontrar en el texto de la Ley un impedimento para la inscripción de la filiación certificada por los funcionarios estadounidenses, que consiste en su contrariedad a la legalidad española, y en concreto al artículo 10 LTRHA, que, como se ha dicho, declara la nulidad del contrato de gestación por sustitución ${ }^{59}$.

En relación con los presupuestos que establece la Instrucción de 5 de octubre de 2010 de la DGRN, antes comentados, la Sentencia de la Audiencia determina que, aunque se dice en la demanda que la certificación californiana ha sido expedida por orden de una previa decisión judicial, lo cierto es que dicha resolución judicial no constaba en el procedimiento, ni tampoco la identidad de la madre gestante, por lo que no es posible aseverar, como hacen los apelantes (padres comitentes), que, conforme a la Instrucción de la DGRN, la filiación californiana de los menores se podría inscribir en el Registro Civil español. Igualmente, considera la Audiencia Provincial que no puede hablarse de fraude por parte del matrimonio, aunque hay indicios para pensar que han huido de la aplicación de una norma imperativa espańola, poniendo la determinación de la filiación en manos de las autorida-

59 Vid. F.J. 2. ${ }^{\circ}$ de la Sentencia de la Audiencia Provincial de Valencia, número 949/2011, de 23 de noviembre de 2011. 
des californianas mediante el desplazamiento a aquel estado y la suscripción allí de un contrato permitido según la Ley de California, que tiene por objeto además una materia, como es la filiación y el estado civil, caracterizada por la indisponibilidad ${ }^{60}$.

Señala la Audiencia Provincial, también, que no puede decirse que la Sentencia recurrida implique una infracción del principio de igualdad y de la prohibición de la discriminación por razón de sexo, de acuerdo con el artículo 14 de la Constitución, en tanto en cuanto el artículo 7.3 LTRHA permite la inscripción en el Registro Civil de la filiación a favor de dos mujeres, mientras que no se permite la inscripción a favor de dos hombres, pues las parejas de dos mujeres no necesitan acudir a otra mujer a la que encomendar la gestación. De modo que no puede considerarse discriminatorio el tratar desigualmente lo que es desigual, ya que, en el supuesto de que una pareja de mujeres acudiera a la gestación por sustitución también le sería aplicable la prohibición ${ }^{61}$.

Respecto a la vulneración del principio del superior interés del menor tanto por aplicación de la Convención sobre los Derechos del Nińo de 20 de noviembre de 1989 , que proclama este principio en su artículo 3, como por aplicación del artículo 39 de nuestra Norma Suprema o de las disposiciones de la Ley Orgánica 1/1996, de 15 de enero, de Protección Jurídica del Menor (RCL 1996\145), así como de las normas concordantes del Código Civil, la satisfacción de dicho interés no puede conseguirse infringiendo la Ley, máxime cuando la Ley española ofrece cauces para la inscripción de la filiación de los menores a favor de los demandados ${ }^{62}$.

Por último, tal y como alegó el Ministerio Fiscal en su escrito de oposición al recurso de apelación, la Sentencia recurrida no atenta contra el derecho a la identidad única de los menores, pues éstos tienen la que resulta de la certificación californiana, que será la que publique el Registro Civil español si acceden a él de acuerdo con la Ley ${ }^{63}$.

\subsection{Sentencia de la Sala de lo Civil del Tribunal Supremo, de 6 de febrero DE 2014}

Como era de esperar, el matrimonio interpuso recurso de casación contra la Sentencia de la Audiencia Provincial de Valencia. Recurso que fue desestimado por el pleno del Tribunal Supremo, confirmándose nuevamente la cancelación de la inscripción de nacimiento de los menores, a través de la Sentencia del Tribunal Supremo, número 835/2013, de 6 de febrero de 2014 (MP: Sarazá Jimena; RJ

${ }^{60} \mathrm{Vid}$. F.J. 3. ${ }^{\circ}$ de la Sentencia de la Audiencia Provincial de Valencia, número 949/2011, de 23 de noviembre de 2011.

${ }_{61}$ Vid. F.J. $4 .^{\circ}$ de la Sentencia de la Audiencia Provincial de Valencia, número 949/2011, de 23 de noviembre de 2011.

62 Vid. F.J. 5. ${ }^{\circ}$ de la Sentencia de la Audiencia Provincial de Valencia, número 949/2011, de 23 de noviembre de 2011.

63 Vid. F.J. 5. ${ }^{\circ}$ cit. de la SAP. 
20141833). Los recurrentes basaron la interposición del recurso en un único motivo, que fue la infracción del artículo 14 de la Constitución, por vulneración del principio de igualdad, en relación con el derecho a la identidad única de los menores y al interés superior de los menores consagrados en la Convención de Derechos del Niño ${ }^{64}$.

Los principales argumentos que sustentan la Sentencia pueden resumirse en los tres siguientes:

En primer lugar, entiende el Tribunal Supremo que la certificación registral aportada por los recurrentes no puede acceder a nuestro Registro Civil porque vulnera el orden público internacional español al disponer en el último párrafo del fundamento de derecho tercero de la Sentencia que la filiación cuyo acceso al Registro Civil se pretende es frontalmente contraria al artículo 10 LTRHA y, como tal, incompatible con el orden público, lo que impide el reconocimiento de la decisión registral extranjera en lo que respecta a la filiación que en ella se determina. Además, según la Sentencia, en nuestro ordenamiento jurídico y en el de la mayoría de los países con ordenamientos basados en similares principios y valores, no se acepta que la generalización de la adopción, incluso internacional, y los avances en las técnicas de reproducción humana asistida vulneren la dignidad de la mujer gestante y del niño, mercantilizando la gestación y la filiación, cosificando a la mujer gestante y al nińo, permitiendo a determinados intermediarios realizar negocio con ellos, posibilitando la explotación del estado de necesidad en que se encuentran mujeres jóvenes en situación de pobreza y creando una especie de ciudadanía censitaria en la que sólo quienes disponen de elevados recursos económicos pueden establecer relaciones paternofiliales vedadas a la mayoría de la población ${ }^{65}$.

En segundo lugar, rechaza la existencia de discriminación por razón de sexo u orientación sexual ${ }^{66}$, y reitera que la causa de denegación de la inscripción de la filiación no es que ambos solicitantes sean varones, sino que la filiación pretendida trae causa de un contrato de gestación subrogada, a lo que ańade que la solución habría de ser la misma si los contratantes formaran un matrimonio homosexual de mujeres, un matrimonio heterosexual, una pareja de hecho o una sola persona, hombre o mujer ${ }^{67}$.

Y, en tercer lugar, consideró el Tribunal Supremo que el interés superior del menor es un concepto jurídico indeterminado, esto es, una cláusula general susceptible de concreción, que el legislador introduce de forma consciente para ampliar los márgenes de la ponderación judicial, que debe ser aplicada al caso concreto ${ }^{68}$.

64 Vid. F.D. 2.1 de la Sentencia del Tribunal Supremo, número 835/2013, de 6 de febrero de 2014.

65 Vid. F.D. 3.6 de la Sentencia del Tribunal Supremo, número 835/2013, de 6 de febrero de 2014 .

${ }^{66}$ Vid. F.D. 4.1 de la Sentencia del Tribunal Supremo, número 835/2013, de 6 de febrero de 2014 . de 2014 .

${ }^{67}$ Vid. F.D. 4.2 cit. de la STS.

68 Vid. F.D. 5.3 de la Sentencia del Tribunal Supremo, número 835/2013, de 6 de febrero 
Asimismo, el Alto Tribunal instó al Ministerio Público para que ejercitase las acciones pertinentes para determinar, en la medida de lo posible, la correcta filiación de los menores, tomando en consideración, en su caso, su efectiva integración en el núcleo familiar de facto ${ }^{69}$.

Para minorar los efectos negativos que produce sobre los menores la falta de reconocimiento en España de la filiación de los mismos, acreditada por la certificación registral extranjera, el Tribunal Supremo sugiere dos soluciones compatibles entre sí: (a) Que el progenitor biológico de los menores reclame judicialmente la filiación; (b) Que los comitentes soliciten ex novo, en España, su adopción o su acogimiento familiar (STS 6 febrero 2014, F.D. 5.11) ${ }^{70}$.

Pese a la desestimación del recurso de casación (aunque la Sentencia cuenta con un voto particular ${ }^{71}$ ), los padres comitentes interpusieron un recurso extraordinario de nulidad de actuaciones por vulneración de derechos fundamentales, que concluyó con el Auto del Tribunal Supremo de 2 de febrero de 2015 (MP: Sarazá Jimena; JUR 2015\47648, en adelante, ATS) ${ }^{72}$, con idéntico sentido desestimatorio, contando también este ATS con un voto particular ${ }^{73}$, en los que no profundizare-

69 Vid. fallo de la Sentencia del Tribunal Supremo, de 6 de febrero de 2014.

70 Calvo Caravaca, A.L., «Gestación por Sustitución y Derecho Internacional Privado. Más allá del Tribunal Supremo y del Tribunal Europeo de Derechos Humanos», Cuadernos de Derecho Transnacional, (octubre 2015), vol. 7, n. ${ }^{\circ} .^{\circ}$, pp. 92-93.

${ }^{71}$ Que lo formula el magistrado D. José Antonio Seijas Quintana, y al que se adhieren los magistrados D. José Ramón Ferrándiz Gabriel, D. Francisco Javier Arroyo Fiestas y D. Sebastián Sastre Papiol. Entienden los magistrados que no debe aplicarse el artículo 10 LTRHA al tratarse del reconocimiento de una decisión extranjera en la que ya se ha determinado la filiación y que no hay vulneración del orden público. VAquero Pinto, M.J., «¿Debe admitirse y regularse la gestación por sustitución?», en Barber Cárcamo, R., Quicios Molina, S. y Verdera Server, R. (coords.), Retos actuales de la Filiación, Asociación de Profesores de Derecho Civil, Tecnos, Madrid, 2018, p. 242.

72 Este ATS fue resuelto después de que el Tribunal Europeo de Derechos Humanos (en lo sucesivo, TEDH) dictara las sentencias de los casos Labasse (asunto 65941/11) contra Francia y Mennesson (asunto 65192/11) contra Francia. En dichos procedimientos se dilucidó la vulneración del artículo 8 del Convenio para la Protección de los Derechos Humanos y de las Libertades Fundamentales, hecho en Roma el 4 de noviembre de 1950 (RCL 1979\2421, en adelante, CEDH), en relación con el derecho al respeto a la vida privada y familiar, dado que Francia había denegado la inscripción de los descendientes de ambos matrimonios en el Registro Civil por vulneración del orden público internacional francés. Ambos casos fueron resueltos mediante las Sentencias de 26 de junio de 2014 (caso Labasse JUR 2014\176905; caso Mennesson JUR 2014\176908). El TEDH apreció la violación del citado artículo $8 \mathrm{CEDH}$, por considerar que se había producido la infracción del derecho a la vida privada de los recién nacidos, en base al argumento de que el derecho a la identidad forma parte integral de la noción de vida privada. El ATS realiza la comparación de los casos franceses y el español para constatar que el TEDH no considera como violación del derecho a la vida privada cualquier decisión que afecte a la filiación. VAquero Pinto, M.J., op. cit., p. 244.

73 Por el que se apartan del criterio mayoritario los magistrados D. José Ramón Ferrándiz Gabriel, D. José Antonio Seijas Quintana Francisco, D. Javier Arroyo Fiestas y D. Sebastián Sastre Papiol, al discrepar en lo que se refiere a la trascendencia que, en el caso objeto de este incidente, han tenido las sentencias dictadas por el TEDH en los casos Labassee contra Francia y Mennesson contra Francia; y en el caso Paradiso y Campanelli (asunto 25358/12) contra Italia-Sentencia 27 de enero de 2015 (TEDH 2015\17)-. Vid. párrafo primero del voto particular del ATS. En relación con el 
mos por motivos de tiempo y espacio, quedando de este modo firme la Sentencia del Juzgado de Primera Instancia número 15 de Valencia, de 15 de septiembre de 2010, tras el largo iter judicial $^{74}$.

\section{POSTURA DE LA DGRN TRAS EL FALLO DEL TRIBUNAL SUPREMO}

La STS de 6 de febrero de 2014 mantuvo una posición contraria a lo dispuesto por la DGRN. Pese a ello, el centro directivo emitió una Circular, con fecha 11 de julio de 2014, ordenando la inscripción de las filiaciones derivadas de los contratos de gestación por sustitución conforme con la Instrucción de 5 de octubre de 2010, por considerar que dicha sentencia no afectaba a su aplicación, ya que se refería a un supuesto en el que lo que se pretendía era la simple transcripción de una certificación registral ${ }^{75}$. De tal modo que nos encontramos ante un conflicto con dos extremos opuestos. Por un lado, se encuentra la postura de la DGRN, que permite el acceso al Registro Civil de la filiación de los hijos de españoles nacidos en el extranjero mediante esta técnica de reproducción humana asistida, siempre y cuando se cumplan los requisitos establecidos en la citada instrucción; y, por otro lado, tenemos la postura de nuestro Alto Tribunal, que rechaza su acceso al Registro Civil. Sin embargo, tras la STS de 6 de febrero de 2014, se podía haber producido un cambio de paradigma, dado que se hubiera podido plantear la cuestión de si la STS no sólo anulaba la RDGRN, sino si afectaba también a los criterios de la Instrucción de 5 de octubre de 2010, y por tanto a la vigencia de esta última. Cuestión que fue resuelta tras la Circular de 11 de julio de 2014 de la DGRN, que mantuvo la vigencia de la Instrucción, frente al criterio mayoritario del TS en relación con la RDGRN, reflejado en el iter judicial tanto en la STS de 6 de febrero de 2014 como posteriormente en el ATS de 2 de febrero de $2015^{76}$.

caso Paradiso y Campanelli ver también la Sentencia de la Gran Sala, de 24 de enero de 2017 (JUR 2017\25806). Igualmente, los magistrados consideran que la solución alcanzada por la mayoría no ha realizado una adecuada ponderación de los bienes jurídicos en conflicto, que toma en consideración primordial no sólo el interés superior de los menores, sino la incertidumbre jurídica que la situación genera y seguirá generando en tanto no se dé respuesta a su solicitud de inscripción. Vid. último párrafo del voto particular del ATS.

${ }^{74}$ No obstante, los recurrentes, una vez agotada la jurisdicción ordinaria, interpusieron recurso de amparo ante el Tribunal Constitucional contra la STS de 6 de febrero de 2014 y el ATS de 2015, que fue inadmitido a trámite. González Carrasco, M.C., "Gestación por sustitución: regular o prohibir», Revista CESCO de Derecho de Consumo, núm. 22, 2017, p. 120.

75 Vaquero Pinto, M.J., op. cit., p. 240.

${ }^{76}$ Llama la atención que, pese a la negativa de la Sala Primera de lo Civil del Tribunal Supremo, y su postura encontrada con la de la DGRN, la Sala Cuarta de lo Social del Alto Tribunal haya mantenido una postura favorable a la concesión de la prestación de maternidad. En este sentido se pronuncia la Sentencia del Tribunal Supremo, de la Sala de lo Social, número 881/2016, de 25 octubre de 2016 (RJ 201616167). Este posicionamiento de la Sala de lo Social, que ha obviado lo dispuesto por el artículo 10.1 LTRHA y ha colocado el interés superior del menor por encima de 
Cabe destacar también la sorpresa que supuso la Instrucción de 14 de febrero de 2019 de la $\mathrm{DGRN}^{77}$, sobre actualización del régimen registral de la filiación de los nacidos mediante gestación por sustitución, en lo que sin duda pretendía ser un cambio evolutivo respecto a la Instrucción de 2010. Sin embargo, a los dos días se publicó por parte del Gobierno de España una nota de prensa en la que se comunicaba que se dejaba sin efecto la citada instrucción enviada a los registros consulares sobre gestación subrogada en el extranjero ${ }^{78}$. Publicándose, días después, la Instrucción de 18 de febrero 2019 de la DGRN, sobre actualización del régimen registral de la filiación de los nacidos mediante gestación por sustitución (RCL 2019\268), por la que se dejaba sin efecto la Instrucción de 14 de febrero de 2019, quedando así nuevamente vigente la Instrucción de 5 de octubre de 2010 de la DGRN.

\section{HACIA UNA LEY DE GESTACIÓN SUBROGADA}

No podemos finalizar este artículo sin hacer referencia a los intentos por legalizar esta controvertida cuestión desde el ámbito político. Así, podemos decir que ante el crecimiento del número de españoles que están recurriendo a esta técnica de reproducción humana asistida ${ }^{79}$, reservada en la actualidad únicamente a aquellas personas con una elevada solvencia económica, el Grupo Parlamentario Ciudadanos presentó, por primera vez en el Congreso de los Diputados, la Proposición de Ley reguladora del derecho a la gestación por subrogación, que se publicó en el Boletin Oficial de las Cortes Generales el 8 de septiembre de $2017(122 / 000117)^{80}$, a la cual se opusieron el resto de formaciones. Pese a ello, el partido político volvió a intentar introducir, por segunda vez, en el debate parlamentario la regulación legal de esta técnica de reproducción humana asistida, mediante la Proposición de Ley reguladora del derecho a la gestación por sustitución, publicada en el Boletín Oficial de las Cortes Generales el 16 de julio de $2019(122 / 000015)^{81}$.

cualquier otra consideración, puede interpretarse como un apoyo a la doctrina de la DGRN, frente a lo sostenido por la Sala de lo Civil del TS. Quicios Molina, op. cit., p. 25.

77 Que no fue publicada en el $B O E$, aunque se puede encontrar en el siguiente enlace: https:// www.elindependiente.com/wp-content/uploads/2019/07/instrucci\%C3\%B3n-14-febrero-2019.pdf (último acceso: 2/01/2021).

${ }^{78}$ Dicha nota de prensa está disponible en el siguiente enlace: https://www.lamoncloa.gob. es/serviciosdeprensa/notasprensa/justicia/Paginas/2019/160219gestacion-subrogada.aspx (último acceso: 3/01/2021).

79 El derecho es un instrumento dinámico que debe dar respuesta a las demandas sociales, y en España existe una demanda real en este sentido. FARnós Amorós, E., «¿Debe permitirse la gestación por sustitución en Espańa?», en CASADO, M. (coord.), De la solidaridad al mercado: el cuerpo humano y el comercio biotecnológico, Fontamara, México, 2016, p. 224.

${ }^{80}$ XII Legislatura. Serie B: Proposiciones de Ley. Disponible en http://www.congreso.es/ public_oficiales/L12/CONG/BOCG/B/BOCG-12-B-145-1.PDF\#page=1 (último acceso: 5/01/2021).

${ }^{81}$ XIII Legislatura. Serie B: Proposiciones de Ley. Disponible en http://www.congreso.es/ public_oficiales/L13/CONG/BOCG/B/BOCG-13-B-46-1.PDF (último acceso: 7/01/2021). 
En ambas ocasiones se ha generado un encendido debate, no sólo entre nuestros representantes, sino también entre la propia ciudadanía.

La estructura de la Proposición de Ley de $2019^{82}$ no difiere en demasía de su antecesora, cuyo articulado sigue distribuyéndose en 7 capítulos $^{83}$, que apenas revisten cambios respecto de la Proposición de Ley de 2017. Sí llama la atención el cambio de su nomenclatura, pues en este último caso han preferido optar por el término de sustitución frente al de subrogación, si bien es cierto que en el desarrollo de la misma continúan utilizándolo indistintamente en diferentes artículos ${ }^{84}$.

El primero de los capítulos recoge las disposiciones generales, en concreto el objeto y los principios rectores, las definiciones necesarias, los requisitos de la gestación por sustitución y la naturaleza altruista de la misma ${ }^{85}$. Es en este capítulo en donde encontramos las principales novedades respecto de la Proposición de Ley de 2017, puesto que es en la actual en la que se establece que no existirá impedimento para la existencia de vínculo de consanguineidad entre la mujer gestante y los progenitores subrogantes ${ }^{86}$.

Sorprende, sin embargo, que, pese a que se contempla ahora la posibilidad de existencia de un vínculo de consanguinidad entre los comitentes y la mujer gestante, se continúa manteniendo la compensación resarcitoria, sobre todo en lo que respecta al lucro cesante inherente al proceso de gestación, que podrá recibir la mujer gestante, la cual, desde nuestro punto de vista, puede encubrir una auténtica retribución, que fuera en contra de la naturaleza altruista de este contrato ${ }^{87}$.

El segundo capítulo regula los derechos de los cuales son titulares, y los requisitos que deben cumplir, los sujetos ${ }^{88}$ intervinientes en el procedimiento de nes finales.

${ }^{82}$ Actualmente admitida a trámite parlamentario.

${ }^{83}$ Con un total de 27 artículos, una disposición derogatoria única y cuatro disposicio-

${ }^{84}$ Véase por ejemplo en la extensa exposición de motivos o en los artículos 13 o 24.2 c) $9 .^{\circ}$. Entendemos que este indiferente uso trata de evitar la reiteración del mismo término.

85 «Aunque la ausencia de precio no puede asegurar que la gestación por sustitución no acabe convirtiéndose en un negocio de mercantilización de los cuerpos de las mujeres [...] la prohibición de precio no resuelve esta cuestión, ni puede garantizar que no existirán intereses económicos». González Carrasco, M.C., op. cit., p.119.

${ }^{86}$ En el artículo 4.3 de la Proposición de Ley de 2017 (su correlativo en la actual) se establecía que «La mujer gestante por subrogación no podrá tener vínculo de consanguineidad con el o los progenitores subrogantes». Esto hubiera supuesto una dificultad ańadida para los comitentes a la hora de encontrar a una mujer gestante en España, dada la naturaleza gratuita de este contrato.

${ }^{87}$ Ver artículo 5.1 y 5.2 de la Proposición de Ley de 2019.

${ }_{88}$ Conforme con el artículo 7.1 de la Proposición de Ley de 2019, la mujer gestante deberá cumplir los siguientes requisitos generales: a) Ser mayor de 25 (no basta con la capacidad de obrar general, sino que se requiere tener capacidad especial, al igual que ocurre con la adopción [ver artículo 175 del Código Civil]. No puede, por tanto, tener modificada judicialmente su capacidad de obrar, sino que debe tener capacidad de obrar plena en el momento de celebrar el contrato y recibir la información previa necesaria para formar válidamente su voluntad y prestar así su consentimiento. Quicios Molina, S., op. cit., pp. 40-41) y menor de la edad que reglamentariamente se fije en función de las condiciones psicofísicas que se consideren adecuadas para la gestación con éxito. b) Estar en posesión de plena capacidad de obrar (en el nuevo texto no se hace referencia a la capacidad jurí- 
gestación por sustitución, así como el contenido ${ }^{89}$ del contrato de gestación y la forma en que debe formalizarse. De este capítulo resulta de interés resaltar que la mujer gestante tiene derecho a gestar, sin aportar material genético propio ${ }^{90}$, al hijo o hijos del progenitor o progenitores subrogantes. Además, de no modificarse ni suspenderse ni derogarse los derechos que a la mujer le reconoce la legislación general, en particular, la Ley Orgánica 2/2010, de 3 de marzo, de salud sexual y reproductiva y de la interrupción voluntaria del embarazo (RCL 20101534), en cuya virtud la mujer gestante podrá interrumpir el proceso, dentro de los supuestos reconocidos por la legislación general, en pleno ejercicio de su autonomía y sin consecuencia negativa alguna para ella.

Destaca también el cambio de operador jurídico respecto al control de legalidad del contrato de gestación. Así, en la Proposición de 2019 se ha optado por realizar la propuesta del contrato de gestación por sustitución ante la autoridad judicial competente, y no ante notario, con carácter previo a cualquier aplicación de una técnica de reproducción humana asistida, redactada de forma accesible y comprensible tanto para la mujer gestante ${ }^{91}$ como para los progenitores subrogantes. Ade-

dica). c) Tener buen estado de salud psicofísica, conforme a lo dispuesto en el artículo 5.6 LTRHA, respecto de las exigencias fijadas a los donantes. d) Tener buen estado de salud mental y, en particular, no haber sufrido episodios de depresión o desórdenes psíquicos. e) Haber gestado, al menos, un hijo con anterioridad. f) Disponer de una situación socioeconómica, así como familiar, adecuadas para afrontar la gestación en condiciones óptimas de salud, bienestar y seguridad. g) Poseer la nacionalidad española o residencia legal en España. h) No tener antecedentes penales. i) No tener antecedentes de abuso de drogas o alcohol. j) No haber sido mujer gestante en más de una ocasión con anterioridad. Respecto al progenitor subrogante, el artículo 8.2 de la Proposición de Ley de 2019 establece que deberá cumplir los siguientes requisitos: a) Ser mayor de 25 años (se requiere también capacidad especial) y menor de 45 ańos. b) Estar en posesión de plena capacidad de obrar (tampoco aquí se hace referencia con la nueva redacción a la capacidad jurídica). c) Tener la nacionalidad espańola o residencia legal en España. d) Acreditar, mediante certificado de idoneidad, que cuenta con la capacidad, aptitud y motivación adecuadas para ejercer la responsabilidad parental asociada a la familia que pretende constituir. En el caso de parejas, deberán estar unidas por el vínculo matrimonial, o una relación equivalente reconocida por la Ley.

${ }^{89}$ Conforme con lo dispuesto en el artículo 9.2 de la Proposición de Ley de 2019, el contrato de gestación por sustitución contendrá, como mínimo, las siguientes determinaciones: a) Identidad de las partes intervinientes. b) Consentimiento informado, libre, expreso e irrevocable de las partes intervinientes. c) Los conceptos por los cuales la mujer podrá percibir una compensación económica, conforme a lo establecido en el artículo 5.2 de la presente Ley, y forma y modo de percepción de la misma. d) Técnicas de reproducción humana asistida que se emplearán. e) Información sobre el seguro al que hace referencia el artículo 5.5 de la presente Ley. f) Forma, modo y responsables médicos del seguimiento del proceso de gestación. g) Previsión del lugar del parto y de las circunstancias en las que el o los progenitores subrogantes se harán cargo del hijo o hijos. h) Designación de tutor, de acuerdo con lo previsto en el artículo 223 del Código Civil.

90 Esto significa que no se contempla la subrogación tradicional (traditional surrogacy) o total (en donde la mujer gestante es inseminada artificialmente aportando su propio óvulo), sino la subrogación gestacional (gestational surrogacy) o parcial.

91 Conforme con el artículo 9.7 de la Proposición de Ley de 2019, la mujer gestante deberá recibir asesoría legal que garantice la compresión de todo el proceso y sus implicaciones. Esta asesoría será independiente de la del progenitor o progenitores subrogantes. 
más, dicha propuesta de contrato tiene que ser objeto de tramitación conforme al procedimiento que a tal efecto se contemple en la LJV.

El tercer capítulo aborda el proceso de la fecundación y posterior parto, así como la relación de filiación entre el progenitor o progenitores subrogantes y el menor ${ }^{92}$, incluyendo los casos de premoriencia de uno de los dos progenitores subrogantes o el fallecimiento de los progenitores subrogantes durante la gestación.

El cuarto capítulo está reservado a la creación del Registro Nacional de Gestación por Sustitución, adscrito al Registro Nacional de Donantes, así como la inscripción en el mismo de las mujeres que libremente deseen participar en la gestación por sustitución.

El quinto capítulo regula las condiciones de funcionamiento que deben reunir los centros y servicios sanitarios para llevar a cabo la gestación por sustitución, incluyendo la obtención de la calificación y autorización necesarias y su inscripción en los registros de centros y actividades.

El sexto capítulo aborda el asesoramiento y orientación de la utilización de la gestación por sustitución, que son competencia de la Comisión Nacional de Reproducción Humana Asistida.

El séptimo capítulo se refiere al régimen sancionador, en el que se tipifican las infracciones y sanciones de aquellas conductas contrarias a la legalidad ${ }^{93}$.

Por último, y como no podría ser de otra manera, la Proposición de Ley cuenta con una disposición derogatoria única, por la que se derogan todas las disposiciones normativas que se le opongan a la Ley y, en particular, el reiterado artículo 10 LTRHA, que tanto debate ha suscitado.

92 Conforme con lo dispuesto en el artículo 11 de la Proposición de Ley de 2019, en ningún momento se establecerá vínculo de filiación entre la mujer gestante y el niño o niños que pudieran nacer; ni tampoco la inscripción en el Registro Civil reflejará datos de los que se pueda inferir el carácter de la generación. En caso de parejas, el progenitor subrogante que no hubiese aportado material genético a la gestación por sustitución podrá manifestar, conforme a la LRC 2011, que consiente en que se determine a su favor la filiación respecto del hijo o hijos del progenitor subrogante que sí lo hubiese aportado. Nótese siguiendo a Gete Alonso y Calera que a lo largo de todo el iter legislativo de modificación y reformulación de la LRC 2011, operada por la Ley 19/2015, de 13 de julio, se ha mantenido el criterio de prohibición de la maternidad subrogada, aunque lo que realmente se prohíbe no es esta maternidad, sino que se mantiene la declaración de nulidad del contrato en el que se conviene conforme con lo establecido en el artículo 10.1 LTRHA. Ver Gete Alonso y Calera, M.C., "La Inscripción de Nacimiento en la Ley 20/2011. Entre el derecho a la identidad de la personal y la reserva de la maternidad», Revista de Derecho Civil, vol. v, núm. 1 (enero-marzo), 2018, pp. $18-32$ y p. 53.

93 Como consecuencia de lo dispuesto en el artículo 4.3 de la Proposición de 2019, ya no se contempla como infracción muy grave la regulada en el artículo 24 c) 7. e la Proposición de 2017 , relativa a la realización del proceso de gestación por subrogación cuando la mujer gestante tenga vínculo de consanguineidad con el o los progenitores subrogantes. 


\section{REFLEXIONES FINALES}

A la vista de todo lo anterior, y tras haber realizado este somero estudio sobre un tema tan controvertido, no podemos sino mostrarnos totalmente a favor de una profunda revisión normativa de este "anárquico rompecabezas", tal y como refiere Álvarez GonzÁlez ${ }^{94}$, que vaya más allá de la mera prohibición o nulidad del contrato de gestación por subrogación.

Consideramos que la gestación por sustitución no es más que un método de reproducción humana, que encierra un profundo debate moral que debe ser superado. Mirar hacia otro lado de la realidad, o simplemente aumentar la penalidad por realizar este tipo de praxis, no evitará que esta técnica se siga practicando. Y menos aún cuando países de nuestro entorno cultural más inmediato la han regulado ya.

Los tiempos cambian, y con ellos los esquemas de valores de las sociedades deben ir transformándose junto con las nuevas realidades sociales y familiares, ya que el instinto reproductivo está presente en la mayoría de los seres humanos. Por ello, resulta más que razonable que cada familia quiera tener descendencia, con independencia de su orientación sexual.

La situación legislativa no está acorde con los tiempos actuales. No es lógico que, en una sociedad democrática como la nuestra, sean sólo las personas más pudientes las que tengan la posibilidad de acceder a la paternidad por esta vía, al contar con los recursos económicos suficientes para poder desplazarse a otros países en donde sí está regulada y admitida esta técnica. Además de tener que conjugar, obligatoriamente, no sólo el necesario elemento de extranjería para poder llevar a cabo estos negocios jurídicos, sino el sinfín de obstáculos a los que se tienen que enfrentar fuera de nuestras fronteras, e incluso dentro de ellas, a la hora de inscribir a sus hijos en el Registro Civil español.

Por último, esperamos que se llegue a un consenso parlamentario que permita la pronta regulación de este fenómeno que tanta polémica y sentimientos encontrados está generando. Por eso, consideramos acertada para concluir estas breves páginas la cita del escritor inglés William SHAKeSPEARE: «No existe nada bueno ni malo, es el pensamiento humano el que lo hace aparecer así».

Recibido: julio de 2020; ACEPTAdo: febrero de 2021

94 Álvarez GonZÁLeZ, S., «Nuevas y viejas reflexiones sobre la gestación por sustitución», en García Rubio, M.P. (directora), Mujer, maternidad y Derecho. V Congreso sobre la feminización del Derecho Privado. Carmona V, Tirant lo Blanch, Valencia, p. 647. 


\title{
LA PRUEBA TESTIFICAL ANTICIPADA COMO INSTRUMENTO PARA REDUCIR LA VICTIMIZACIÓN SECUNDARIA DE MENORES DE EDAD EN EL PROCESO PENAL
}

\author{
Diana Marrero Guanche* \\ Contratada predoctoral FPI \\ Universidad de La Laguna
}

\section{RESUMEN}

En este artículo se estudia la creciente importancia del riesgo de victimización secundaria tanto en la normativa nacional como en la supranacional. Asimismo, se examina cómo esta preocupación ha provocado la regulación de especialidades en las declaraciones sumariales de las víctimas menores de edad, por ejemplo, a través de la Ley 4/2015, de 27 de abril, del Estatuto de la víctima del delito o, más recientemente, la Ley 8/2021, de 4 de junio, de protección integral a la infancia y la adolescencia frente a la violencia. Finalmente, se analiza en qué medida las modificaciones efectuadas para evitar la victimización secundaria han afectado al principio de contradicción y al derecho a la presunción de inocencia.

Palabras Clave: victimización secundaria, principio de contradicción, prueba anticipada, declaración sumarial, víctimas de delitos.

\section{THE EVIDENCE PRIOR TO TRIAL AS AN INSTRUMENT \\ TO AVOID THE RISK OF SECONDARY VICTIMATION \\ OF UNDERAGE VICTIMS IN CRIMINAL PROCEEDINGS}

\section{Abstract}

This article studies the growing importance of the risk of secondary victimization in both national and supranational legislation. It also examines how this concern has led to the regulation of specialties in the statements of underage victims at the pre-trial stage, for example, through Law 4/2015, of April 27, on the Statute of the victim of crime or, more recently, Law 8/2021, of June 4, on the comprehensive protection of children and adolescents against violence. Finally, it is analyzed to what extent the modifications made to avoid secondary victimization have affected the principle of contradiction and the right to the presumption of innocence.

KEYWORDS: secondary victimization, adversarial principle, evidence prior to trial, statements at the pre-trial stage, victims of crimes. 


\section{INTRODUCCIÓN}

En España preocupa el número de delitos contra la libertad e indemnidad sexuales y, sobre todo, los casos en los que las víctimas de estos delitos son menores de edad, pues, según el informe sobre delitos contra la libertad e indemnidad sexual emitido por el Ministerio del Interior del Gobierno de España, en el año 2019 el $46,2 \%$ de este tipo de delitos se cometió contra una víctima menor de edad ${ }^{1}$.

La ejecución de este tipo de delitos causa a las víctimas -especialmente a los menores de edad-daños tanto físicos como psicológicos ${ }^{2}$. A estos perjuicios provocados por la comisión del hecho delictivo se suman también los efectos negativos que sufre la víctima como consecuencia de sus relaciones con los agentes de la policía o la administración de justicia; en definitiva, la denominada victimización secundaria.

La pregunta que se plantea en relación con la victimización secundaria es la siguiente: ¿`cómo pueden reducirse los daños que sufren los menores en sus relaciones con la administración de justicia?

En esta ocasión, a pesar de la importancia que el uso de la inteligencia artificial ha alcanzado en la solución de los problemas que plantea el proceso penal ${ }^{3}$, la respuesta no la encontramos en el uso de ninguna tecnología revolucionaria. Aunque es cierto que, como se analizará en líneas posteriores de este trabajo, los medios de grabación de sonido e imagen tienen un papel importante en la protección de los menores, pero más allá de estos medios tecnológicos parece que debe prestarse especial atención al factor humano.

La respuesta a la anterior pregunta podemos encontrarla en la práctica de la prueba testifical anticipada como instrumento para reducir la victimización secundaria. Como es sabido, en la LECrim se permite anticipar la realización de la prueba cuando se presuma que los testigos o peritos no podrán estar presentes en el acto del juicio oral ${ }^{4}$. Pues bien, la preocupación por reducir la victimización secundaria

* Trabajo realizado en el ámbito de un contrato predoctoral de formación del personal investigador concedido por la Consejería de Economía, Conocimiento y Empleo del Gobierno de Canarias, cofinanciado por el Fondo Social Europeo.

${ }^{1}$ El 15,9\% de las víctimas de este tipo de delitos tienen entre 0 y 13 años, mientras que el 17,5\% tiene entre 14 y 17 años. Puede consultarse en https://bit.ly/3sqHZgj (último acceso: $11 \mathrm{de}$ marzo de 2021).

${ }^{2}$ Para hacer referencia a estos daños se utiliza la expresión victimización primaria.

3 Bueno de Mata, F., «Macrodatos, inteligencia artificial y proceso: luces y sombras», en Revista General de Derecho Procesal, n. ${ }^{\circ}$ 51, 2020; BARona Vilar, A., "Cuarta revolución industrial (4.0) o ciberindustria en el proceso penal: revolución digital, inteligencia artificial y el camino hacia la robotización de la justicia», en revista jurídica digital UANDES, n. ${ }^{\circ} 1,2019$. El Ministerio de Justicia español ha valorado contratar un deep learning -o sistema de inteligencia artificial de caja negra- denominado Prometea. Véase el artículo periodístico «La justicia artificial se asoma a la justicia pero despierta dudas éticas» en la revista Retina del periódico El País. Puede consultarse en el siguiente enlace: https://bit.ly/3tbwoSs (último acceso: 25 de marzo de 2021).

${ }^{4}$ Artículo 448 párrafo $1 .^{\circ}$ LECrim: «Si el testigo manifestare, al hacerle la prevención referida en el artículo 446, la imposibilidad de concurrir por haber de ausentarse del territorio nacional, y también en el caso en que hubiere motivo racionalmente bastante para temer su muerte o inca- 
de los menores ha provocado que también pueda procederse a la anticipación de las declaraciones de los menores, a pesar de que, como se analizará en este trabajo, en rigor, no estemos ante un hecho irrepetible .

Por todo ello, resulta de especial interés el estudio de la prueba testifical anticipada como instrumento para reducir el riesgo de victimización secundaria de los menores, así como su regulación en el Anteproyecto de Ley de Enjuiciamiento Criminal aprobado por el Consejo de Ministros el 24 de noviembre de 2020 (en adelante APLECrim 2020). Asimismo, recientemente ha entrado en vigor la Ley Orgánica 8/2021, de 4 de junio, de protección integral a la infancia y la adolescencia frente a la violencia (en lo sucesivo LOPIIA), que ha modificado la regulación de la prueba testifical anticipada y ha establecido como excepcional la declaración en juicio de los menores de catorce años o personas con discapacidad necesitadas de especial protección ${ }^{6}$.

\section{LA VICTIMIZACIÓN SECUNDARIA}

La Real Academia Española define el término victimización como la «acción de victimizar" y el verbo victimizar como "convertir en víctimas a personas o animales». La victimización, desde un punto de vista jurídico, hace referencia no sólo al

pacidad física o intelectual antes de la apertura del juicio oral, el Juez instructor mandará practicar inmediatamente la declaración, asegurando en todo caso la posibilidad de contradicción de las partes. Para ello, el Secretario judicial hará saber al reo que nombre abogado en el término de veinticuatro horas, si aún no lo tuviere, o de lo contrario, que se le nombrará de oficio, para que le aconseje en el acto de recibir la declaración del testigo. Transcurrido dicho término, el Juez recibirá juramento y volverá a examinar a éste, a presencia del procesado y de su abogado defensor y a presencia, asimismo, del Fiscal y del querellante, si quisieren asistir al acto, permitiendo a éstos hacerle cuantas repreguntas tengan por conveniente, excepto las que el Juez desestime como manifiestamente impertinentes».

5 Todo lo más podríamos decir que nos encontramos ante una imposibilidad objetiva impuesta por el legislador para salvaguardar el interés del menor. Véase Serrano Masip, M., «La incorporación al proceso penal español de la normativa UE sobre el interrogatorio o la exploración de la víctima menor de edad", en Delitos contra la libertad e indemnidad sexual de los menores, Aranzadi, Navarra, 2015, p. 540.

${ }^{6}$ Párrafos 39 y 40 del apartado II del Preámbulo de la LOPIIA: «En relación con la prueba preconstituida es un instrumento adecuado para evitar la victimización secundaria, particularmente eficaz cuando las víctimas son personas menores de edad o personas con discapacidad necesitadas de especial protección. Atendiendo a su especial vulnerabilidad se establece su obligatoriedad cuando el testigo sea una persona menor de catorce años o una persona con discapacidad necesitada de especial protección. En estos supuestos la autoridad judicial, practicada la prueba preconstituida, solo podrá acordar motivadamente su declaración en el acto del juicio oral, cuando, interesada por una de las partes, se considere necesario. Por tanto, «se convierte en excepcional la declaración en juicio de los menores de catorce ańos o de las personas con discapacidad necesitadas de especial protección", estableciéndose como norma general la práctica de la prueba preconstituida en fase de instrucción y su reproducción en el acto del juicio evitando que el lapso temporal entre la primera declaración y la fecha de juicio oral afecten a la calidad del relato, así como la victimización secundaria de víctimas especialmente vulnerables». 
acto de convertir a una persona en víctima, sino también a las consecuencias negativas que la persona sufre como consecuencia de este proceso.

Gómez Colomer distingue hasta cuatro tipos de victimización, aunque señala que sólo son verdaderamente importantes tres: victimización primaria, secundaria y terciaria ${ }^{7}$. La victimización primaria es la que sufre el sujeto pasivo del delito de forma directa por la ejecución del hecho delictivo: por ejemplo, las lesiones psíquicas que parece se derivan de los delitos de carácter sexual ${ }^{8}$. La victimización secundaria, que será estudiada con más detalle en el epígrafe siguiente, se define como las consecuencias negativas adicionales que puede sufrir la víctima durante la tramitación del proceso penal, desde la investigación policial hasta la sentencia firme. Finalmente, la victimización terciaria estaría constituida por los efectos que padece la sociedad, por ejemplo, el miedo social o la desconfianza hacia la justicia penal'.

\subsection{Concepto}

La Directiva 2012/29/UE ${ }^{10}$ no contiene un concepto de victimización secundaria, a pesar de las referencias que se realizan en la citada norma al riesgo de victimización reiterada que padecen las víctimas y a las medidas que deben adoptar los gobiernos nacionales para evitarlo. Asimismo, la Ley 4/2015, de 27 de abril, del Estatuto de la víctima del delito (en adelante LEVD), que transpone la anterior directiva al ordenamiento jurídico español, tampoco ofrece una definición.

La victimización secundaria se ha definido por la doctrina como aquel proceso por el que, paradójicamente, la persona que ha sufrido el hecho delictivo se

7 Gómez Colomer, J.L., Estatuto Jurídico de la Victima del delito. La posición jurídica de la víctima de delito ante la justicia penal. Un análisis basado en el Derecho comparado y en las grandes reformas españolas que se avecinan, Aranzadi, Navarra, 2014, p. 230.

${ }^{8}$ Sentencia de la Sala Segunda del TS, de 17 de octubre de 2019: «Respecto a las consecuencias de tales actos sufridos por la menor, señalar que la doctrina apunta las dos vías de la victimización primaria. Y, así, se consideran todos aquellos efectos negativos que puede sufrir el menor por la exposición a una situación de victimización sexual. Tradicionalmente se han dividido las repercusiones psicopatológicas asociadas al ASI en dos grupos: consecuencias a corto plazo (en los dos años siguientes a la experiencia de victimización) y consecuencias a largo plazo. Se han detectado -apunta la doctrina-, desajustes en las funciones fisiológicas, en el área cognitiva, emocional, comportamental y relacional de los menores, dependiendo de su etapa evolutiva».

${ }^{9}$ Gómez Colomer introduce en la victimización terciaria los daños ocasionados al infractor. En mi opinión, las consecuencias negativas que la comisión del delito pueda tener para el autor del mismo no deben calificarse como victimización terciaria, porque los daños que puedan producirse se derivan de su actuación antijurídica. Este tipo de victimización es el que más debate doctrinal ha generado en cuanto a su contenido. Gómez Colomer, J.L., Estatuto Jurídico de la Víctima..., cit., pp. 230-231. Véase también Morillas Fernández, D.L., "La victimización penitenciaria», en Revista Internacional de Doctrina y Jurisprudencia, n. ${ }^{\circ}$ 14, 2016.

${ }_{10}$ Adoptada por el Parlamento Europeo y del Consejo el 25 de octubre de 2012. Esta directiva establece normas mínimas sobre los derechos, el apoyo y la protección de las víctimas de delitos, y sustituye la Decisión marco 2001/220/JAI del Consejo. 
convierte en víctima del sistema judicial ${ }^{11}$. Lo habitual es que la victimización secundaria no pueda acreditarse, pues es consecuencia de un trato personal entre el sujeto pasivo del delito y los funcionarios de la administración de justicia o de la policía. Sin embargo, a continuación analizaré brevemente algunos ejemplos de victimización secundaria que podemos encontrar en las resoluciones judiciales.

1. ${ }^{\circ}$ "El caso de la mujer de vida licenciosa» ${ }^{12}$. La sentencia de la Audiencia Provincial de Pontevedra, de 27 de febrero de 1989, absuelve a los procesados por un delito de violación al no apreciar la concurrencia de violencia o intimidación. En la citada sentencia se valoran circunstancias personales de la víctima, como la "vida licenciosa y desordenada» que mantiene, porque se encontraba «sola en una discoteca a altas horas de la madrugada después de haber ingerido bebidas alcohólicas». Asimismo, se cuestiona que la víctima viajase en el «vehículo de unos desconocidos sin la menor oposición», para argumentar la ausencia de violencia o intimidación ${ }^{13}$.

2. El caso de la mujer que se embriaga en compañía de un hombre ${ }^{14}$. A pesar de que puede parecer que estos recelos hacia la víctima quedaron en el pasado siglo, lo cierto es que la sentencia de la Audiencia Provincial de Toledo 29/2010, de 2 de julio, es otro ejemplo de victimización secundaria. Esta resolución cita la sentencia del TS de 3 de diciembre de 1979 que establecía que «si una mujer se embriaga en compañía de un hombre, acepta, en cierto modo, las consecuencias de sus actos, pero que, a pesar de ello, no siempre su embriaguez ha de ser apreciada como prueba de su consentimiento». No sólo impresiona la referencia a la citada sentencia, sino también las manifestaciones que se realizan acerca de que la víctima no se sorprenda de que estaban a solas o las alusiones a que la víctima estaba acostumbrada a ingerir bebidas alcohólicas ${ }^{15}$.

$3 .^{\circ}$ El caso de la joven que se inició en las relaciones sexuales a los 16 años $^{16}$. La argumentación de la sentencia de la Audiencia Provincial de Navarra 38/2018,

11 Morillas Fernández, D.L., Patró Hernández, R.M. y Aguilar Cárceles, M.M., Victimología: un estudio sobre la victima y los procesos de victimización, Dykinson, Madrid, 2014, pp. 115-117.

12 Éste es el título que Landrove Díaz elige para analizar la sentencia de 27 de febrero de 1989, de la Audiencia Provincial de Pontevedra, y que, como él mismo reconoce, recuerda a una fórmula de la literatura policiaca. LANdrove Díaz, G., «La víctima y el juez», en Victimología: VIII Cursos de Verano en San Sebastián, Universidad del País Vasco, 1990, pp. 189-191.

13 Ibidem.

${ }^{14}$ El título de este supuesto sigue la fórmula literaria policíaca escogida en LANDrove Diaz, G., «La víctima y...», cit.

${ }_{15}$ Sentencia de la Audiencia Provincial de Toledo 29/2010, de 2 de julio: «Paula estaba acostumbrada a tomar alcohol, tal vez no en grandes cantidades, pero tampoco era abstemia, y aceptó, incluso antes de ir al piso de Pedro, a tomar caipiriñas».

${ }^{16}$ Aquí también he recurrido a la fórmula literaria policíaca escogida en LANDrove Diaz, G., «La víctima y...», cit. 
de 20 de marzo, gira en torno a la existencia o no de consentimiento por parte de la víctima. No obstante, la polémica no ha tenido su origen en el fallo, sino en el voto particular emitido por uno de los magistrados. Uno de los argumentos del magistrado para mantener su tesis acerca de la existencia de consentimiento es la iniciación de la joven en las relaciones sexuales a los 16 ańos, de modo que entiende el magistrado que la víctima tenía la madurez necesaria para mantener el tipo de relación sexual que decida ${ }^{17}$.

Este sinsentido de los daños que sufre la víctima como consecuencia del funcionamiento de la administración de justicia plantea la duda sobre si la solución a este problema podría venir de la mano de los denominados -desde mi punto de vista, erróneamente ${ }^{18}$ - jueces robot. Sin embargo, además de por lo obvio, pues parece que, como ha señalado Bueno de Mata, debe trazarse una línea roja con el fin de evitar la sustitución del juez por sistemas de inteligencia artificial ${ }^{19}$, debe recordarse que los algoritmos no están exentos de los prejuicios de la sociedad ${ }^{20}$.

Las víctimas de delitos de carácter sexual son especialmente vulnerables a sufrir victimización secundaria no sólo por la naturaleza del hecho delictivo, sino también porque lo habitual en este tipo de delitos es que el único medio de prueba sea la testifical de la víctima. La Sala $2 .{ }^{a}$ del TS ha establecido que el tribunal sentenciador deberá prestar especial atención al testimonio de la víctima y comprobar que no existan razones objetivas que cuestionen su credibilidad. Pues bien, esta cir-

17 Voto particular a la sentencia de la Audiencia Provincial de Navarra 38/2018, de 20 de marzo: «Finalmente, a mi juicio, no puede establecerse como a priori que una joven con edad más cercana a los 19 que a los 18 años e iniciada en las relaciones sexuales a los 16, no esté dotada de suficiente madurez personal como para decidir, con la necesaria autonomía, las relaciones sexuales que quiera mantener, por personalísimas razones que solo le incumben a ella, mucho menos en una sociedad como la actual en la que los individuos, con independencia de su sexo, han alcanzado de hecho un considerable grado de libertad para autodeterminarse sexualmente» (énfasis en cursiva añadido).

${ }^{18} \mathrm{La}$ expresión juez robot hace que pensemos en robot humanoides como los protagonistas de las películas Robocop, Blade Runner o Chappie, también nos recuerda al robot Sophia, creado por el estadounidense David Hanson. Véase la noticia publicada en el periódico El Pais en este enlace: https://bit.ly/3rH4MnP (último acceso: 12 de marzo de 2021). Sin embargo, cuando se hace referencia a los jueces robots en realidad no veremos un robot con forma humanoide y con toga; al contrario, se trata de programas informáticos instalados en un dispositivo electrónico, normalmente un ordenador.

19 Bueno de Mata, F., «Macrodatos, inteligencia artificial...», cit., p. 18.

${ }^{20}$ Borges Blázquez, R., «El sesgo de la máquina en la toma de decisiones en el proceso penal», en IUS ET SCIENTIA: Revista electrónica de Derecho y Ciencia, n. ${ }^{\circ}$ 2, 2020 p. 69, advierte que "predecir el futuro mirando al pasado conlleva el riesgo de que en el futuro se sigan repitiendo los mismos estereotipos de género que vamos superando como sociedad. Debemos ser prudentes no solo en fase de aplicación de la IA, sino ir un paso más allá y preguntarnos quién hay detrás de la máquina, cómo se ha hecho el algoritmo, a quién beneficia y a quién perjudica-consciente o inconscientemente- porque puede acabar por controlar el pensamiento jurídico global». Véase también el artículo publicado en el periódico El Diario titulado "Sesgos de género en los algoritmos: un círculo perverso de discriminación en línea y en la vida». Puede consultarse en https://bit.ly/3etK3A4 (último acceso: 12 de marzo de 2021). 
cunstancia se acentúa más en las declaraciones de víctimas menores de edad, debido a su falta de madurez para afrontar este tipo de situaciones ${ }^{21}$. Por este motivo, la normativa europea se ha preocupado por evitar este riesgo de victimización con especial referencia a las víctimas vulnerables.

\subsection{LA CRECIENTE PREOCUPACIÓN POR EL RIESGO DE VICTIMIZACIÓN SECUNDARIA}

La preocupación europea por la protección de la víctima en el proceso penal se consolida con la Recomendación (85)11, de 28 de junio de 1985, sobre la posición de la víctima en el marco del Derecho penal y del Derecho procesal ${ }^{22}$, y la Decisión Marco 2001/220/JAI, de 15 de marzo de 2001, relativa al estatuto de la víctima en el proceso penal ${ }^{23}$.

A pesar de que estos instrumentos no provocaron la aprobación en España de un estatuto jurídico de la víctima del delito, fomentaron la elaboración de normas que, aunque parcialmente, conformaban un marco normativo garante de los derechos de determinadas víctimas. A modo de ejemplo cabe citar los siguientes textos legales: la Ley Orgánica 19/1994, de 23 de diciembre, de protección a testigos y peritos en causas criminales; la Ley 35/1995, de 11 de diciembre, de ayudas y asistencia a las víctimas de delitos violentos y contra la libertad sexual; la Ley Orgánica 1/1996, de 15 de enero, de protección jurídica del menor; la Ley Orgánica 1/2004, de 28 de diciembre, de medidas de protección integral contra la violencia de género; y la Ley 29/2011, de 22 de septiembre, de reconocimiento y protección integral a las víctimas del terrorismo.

En el año 2009 la Comisión Europea emitió un informe en el que se destaca que ningún Estado miembro había aprobado una única norma reguladora de los derechos de las víctimas ${ }^{24}$. Por este motivo se dictó la Directiva 2012/29/UE para otorgar carácter obligatorio a las disposiciones de la Decisión marco 2001/220/JAI, así como para mejorar la protección de las víctimas en los estados de la Unión. Precisamente este interés por mejorar la defensa de las víctimas supuso que la Directiva

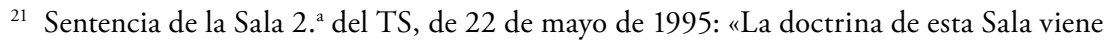
acogiendo el valor probatorio del testimonio de la víctima del hecho como apto para desvirtuar la inicial presunción de inocencia que a todo acusado protege, sobre todo en delitos de agresión sexual que, de ordinario, tan solo son presenciados por las propias víctimas y teniendo en cuenta que, no aceptar esos testimonios alentaría, como ha recogido la jurisprudencia constitucional, un impunismo inaceptable y, de otra parte, que ya han pasado los tiempos en que se pudiera admitir la validez del principio "testis unus, testis nullus", exponente de una rigidez probatoria bien contrapuesta a la ausencia de prueba tasada que informa el sistema probatorio del proceso penal español».

${ }^{22}$ Adoptada por el Comité de Ministros del Consejo de Europa.

${ }^{23}$ Acordada por el Consejo de la Unión Europea.

${ }^{24}$ Informe COM (2009) de la Comisión de conformidad con el artículo 18 de la Decisión marco del Consejo, de 15 de marzo de 2001, relativa al estatuto de la víctima en el proceso penal (2001/220/JAI), emitido en Bruselas el día 20 de abril de 2009. 
2012/29/UE regulase de forma más amplia la victimización secundaria, a diferencia de las breves alusiones que se hacían en la Decisión 2001/220/JAI ${ }^{25}$.

La LEVD, que transpone la Directiva 2012/29/UE, traslada a España las preocupaciones europeas por evitar la victimización secundaria y, entre otras medidas, manifiesta la necesidad de reducir el número de declaraciones y reconocimientos médicos de las víctimas en general ${ }^{26}$. Sin embargo, esta aspiración, plasmada en el preámbulo de la Ley, sólo se materializa en el articulado de la norma con referencia a las declaraciones de las víctimas menores de edad y con discapacidad necesitadas de especial atención.

Por lo que se refiere al APLECrim 2020, se prohíbe la victimización secundaria en su artículo 103, rotulado "prohibición de la victimización secundaria», con el siguiente tenor literal:

1. Todas las autoridades que intervengan en el proceso penal adoptarán las medidas precisas para evitar que la víctima se vea sometida a situaciones que puedan causarle un sufrimiento innecesario o desproporcionado.

Igualmente velarán para que se reciba declaración a las víctimas sin dilaciones indebidas. La declaración de las víctimas y su reconocimiento médico únicamente se realizará cuando sea necesario a los fines de la investigación. No se repetirá su práctica salvo que resulte imprescindible a estos mismos fines.

2. La victima será tratada con pleno respeto a su dignidad en toda diligencia policial o actuación procesal que se realice. Recibirá un trato digno, habilitándose dependencias adecuadas al efecto y permitiendo que permanezca en ellas junto a su representante o persona que la acompañe.

En particular, las dependencias de las fiscalias y de los tribunales tendrán espacios de espera especialmente habilitados para acoger a las víctimas. En el acto del juicio oral se reservará un lugar especifico a la víctima y, en su caso, a su representante o persona que la acompañe.

25 Considerando 5 de la Decisión marco: «Es importante concebir y tratar las necesidades de la víctima de forma integrada y articulada, evitando soluciones parciales o incoherentes que puedan acarrear una victimación secundaria» (énfasis en cursiva añadido). Artículo 15 de la Decisión marco: "Los Estados miembros propiciarán la creación gradual, en el marco de las actuaciones en general y especialmente en los lugares en los que puede incoarse el proceso penal, de las condiciones necesarias para tratar de prevenir la victimación secundaria o evitar que la víctima se vea sometida a tensiones innecesarias. Para ello velarán en particular por que se dé una acogida correcta a las víctimas en un primer momento y por que se creen en dichos lugares condiciones adecuadas a la situación de la víctima" (énfasis en cursiva ańadido). A pesar de que en la traducción se ha elegido el término victimación -que no figura en el Diccionario de la Real Academia Espańola- la referencia se entiende hecha a la victimización secundaria.

26 Apartado vir del Preámbulo de la LEVD: «Para evitar la victimización secundaria en particular, se trata de obtener la declaración de la víctima sin demora tras la denuncia, reducir el número de declaraciones y reconocimientos médicos al mínimo necesario, y garantizar a la víctima su derecho a hacerse acompañar, no ya solo del representante procesal, sino de otra persona de su elección, salvo resolución motivada». 
Esto supone una novedad en relación con la actual LECrim, que, a pesar de que contiene algunas normas que tienen como finalidad evitar el riesgo de victimización secundaria ${ }^{27}$, no se hace referencia en ningún momento a este término. Ya en los Anteproyectos de Ley de Enjuiciamiento Criminal de los años 2011 y 2013 se establecía la prohibición de victimización secundaria, pero el nuevo APLECrim 2020 incluye algunas medidas adicionales que se resaltan en cursiva en la transcripción del artículo ut supra.

El día 25 de junio de 2021 entró en vigor la LOPIIA, que tiene como finalidad cumplir con el requerimiento realizado por el Comité de Derechos del Niño para que en Espańa se aprobara una ley integral sobre la violencia contra los niños y nińas ${ }^{28}$. Asimismo, la citada ley se inspira en los objetivos y metas de desarrollo sostenible fijados en la Agenda 2030, concretamente, en la meta 16.2: «Poner fin al maltrato, la explotación, la trata y todas las formas de violencia y tortura contra los niños ${ }^{29}$.

Tal y como se expone a continuación, el riesgo de sufrir victimización secundaria se incrementa en relación con las víctimas menores de edad, por lo que los funcionarios de la administración de justicia, los agentes de la policía y cualquier otro profesional que participe en el proceso penal deberán prestar especial atención a estas víctimas.

\subsection{LA VICTIMIZACIÓN SECUNDARIA DE LOS MENORES}

Hasta este momento me he referido al riesgo de victimización que fija la atención en el hecho delictivo; sin embargo, en este epígrafe me voy a centrar en el estudio de vulnerabilidad de la víctima, concretamente de las víctimas menores de edad $^{30}$. Landrove Díaz define a las víctimas especialmente vulnerables como aquéllas que «en función de circunstancias de muy diversa naturaleza, ofrecen una predisposición victimógena específica» y distingue dos factores de vulnerabilidad: personales

${ }^{27}$ La disposición final primera de la LEVD introduce modificaciones en la Ley de Enjuiciamiento Criminal (en adelante LECrim) para transponer la Directiva 2012/29/UE. Lo anterior supone que la redacción de algunos artículos de la LECrim esté inspirada en prevenir la victimización secundaria. Por ejemplo, los artículos 433, 448, 544 quinquies o 681 LECrim.

${ }^{28}$ Párrafo $100^{\circ}$ del apartado I del Preámbulo de la LOPIIA: «[...] el Comité de Derechos del Niño, con ocasión del examen de la situación de los derechos de la infancia en España en 2018, reiteró a nuestro país la necesidad de la aprobación de una ley integral sobre la violencia contra los nińos y nińas, que debía resultar análoga en su alcance normativo a la aprobada en el marco de la violencia de género».

${ }^{29}$ Esta meta se fija dentro del objetivo de desarrollo sostenible 16, que persigue como fin «Promover sociedades justas, pacíficas e inclusivas».

30 Siguiendo a Gómez Colomer, que entendía que «si se contempla desde el punto de vista del hecho, se habla de riesgo de victimización; si se contempla desde el punto de vista de sus efectos se habla de vulnerabilidad de la víctima». Gómez Colomer, J.L., Estatuto Jurídico de la Victima..., cit., p. 230 . 
y sociales ${ }^{31}$. Como factores personales puede citarse la edad o el estado psíquico del sujeto pasivo y como factores sociales la posición económica o el lugar de residencia.

La especial vulnerabilidad de las víctimas menores se reconoce, entre otras normas, en la Directiva 2011/36/ UE ${ }^{32}$, en la que se afirma que «los menores son más vulnerables que los adultos». Como ha señalado Magro Servet la vulnerabilidad de los menores a sufrir una segunda victimización se agrava porque no tienen la madurez suficiente para enfrentarse a la condición de víctima de un delito ni a una posterior confrontación con el autor del hecho delictivo ${ }^{33}$. Esta vulnerabilidad de los menores es todavía mayor cuando han sido víctimas de un delito contra la libertad e indemnidad sexuales. Así se ha reconocido por la jurisprudencia de la Sala 2. ${ }^{a}$ del TS, que ha declarado la especial vulnerabilidad de los menores víctimas de delitos de carácter sexual con especial referencia a los menores de corta edad ${ }^{34}$.

Esta especial vulnerabilidad de los menores víctimas de delitos ha generado una preocupación a nivel internacional y europeo por salvaguardar el interés del menor $^{35}$, que se trasladó a la LECrim con la aprobación de la Ley Orgánica 8/2006, de 4 de diciembre, por la que se modifica la Ley Orgánica 5/2000, de 12 de enero, reguladora de la responsabilidad penal de los menores. A pesar de que no parece la norma adecuada para reformar la LECrim, la disposición adicional primera de la Ley Orgánica 8/2006 modificó el artículo 433 LECrim otorgando al juez de instrucción la posibilidad de acordar la grabación de la declaración prestada por el menor en fase de instrucción.

${ }^{31}$ Landrove Díaz, G., Victimología, Tirant lo Blanch, Valencia, 1990, p. 42.

32 Dictada por el Parlamento Europeo y del Consejo de 5 abril de 2011, relativa a la prevención y lucha contra la trata de seres humanos y a la protección de las víctimas y por la que se sustituye la Decisión marco 2002/629/JAI del Consejo.

33 Magro Servet, V., «La victimización secundaria de los menores en el proceso penal», en Diario La Ley, n. ${ }^{\circ}$ 6282, 2005.

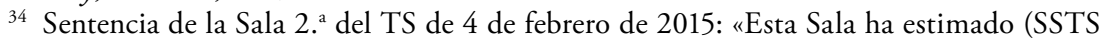
96/2009 de 10 de marzo, 743/2010, de 17 de junio , 593/2012, de 17 de julio y 19/2013, de 9 de enero, entre otras) que la previsión de imposibilidad de practicar una prueba testifical en el juicio oral, exigible para justificar la práctica anticipada de la prueba durante la instrucción, incluye los supuestos de menores victimas de delitos sexuales, con el fin de evitar los riesgos de victimización secundaria, especialmente importantes en menores de muy corta edad, cuando sea previsible que dicha comparecencia pueda ocasionar dańos psicológicos a los menores» (énfasis en cursiva añadido).

35 A modo de ejemplo pueden citarse las siguientes normas: la Convención sobre los Derechos del Niño, de 20 de noviembre de 1989; la Decisión marco 2001/220/JAI; la Directiva 2011/92/ UE del Parlamento Europeo y del Consejo de 13 de diciembre de 2011, relativa a la lucha contra los abusos sexuales y la explotación sexual de los menores y la pornografía infantil y por la que se sustituye la Decisión marco 2004/68/JAI del Consejo; y la Directiva 2012/29/UE. Asimismo, la protección de los menores frente al maltrato, la explotación, la trata y cualquier otra forma de violencia constituye una de las metas del $16 .^{\circ}$ Objetivo de Desarrollo Sostenible fijado en la Agenda 2030. El Gobierno de España hace referencia a un dato preocupante en relación con esta meta: «la cifra de niños entre 0 y 13 años víctimas de malos tratos en el ámbito familiar ha pasado de 13,53\% en 2010 a 26,16 en 2016». Puede consultarse en https://bit.ly/3cVG64H (último acceso 22 de marzo de 2021). 
A continuación, se analizarán las reformas operadas por la LEVD y LOPIIA en la regulación de la prueba testifical anticipada de las víctimas menores de edad, así como la nueva regulación propuesta en el APLECrim 2020.

\section{LA EXPLORACIÓN DE LOS MENORES EN LA FASE DE INSTRUCCIÓN}

Como ha señalado Serrano Masip, una de las situaciones que pueden causar al menor un grave perjuicio es su declaración en condición de víctima o testigo del hecho delictivo, dado que el relato de los hechos que ha padecido o presenciado puede provocar un proceso de victimización secundaria ${ }^{36}$. Actualmente, en el proceso penal español se obliga al juez a grabar la declaración de los menores-víctimas o testigos- practicada en fase de instrucción y se permite que éstas sean reproducidas en el juicio oral para que adquieran pleno valor probatorio. Sin embargo, como explicaré en líneas posteriores, la validez de esta declaración testifical está sujeta a una serie de requisitos y, además, debe apuntarse desde este momento que esta anticipación de la prueba es una excepción a la regla general de que los medios de prueba deben practicarse en el acto del juicio oral ${ }^{37}$.

\subsection{Contexto normativo}

La Decisión marco 2001/220/JAI establece que los Estados miembros propiciarán las condiciones necesarias para evitar el riesgo de "victimación" secundaria. Así, se regula en el artículo 8 de la referida Decisión que los Estados miembros deberán acordar las medidas necesarias para que las víctimas no sufran más daños como consecuencia de la práctica de la declaración testifical.

Esta normativa se transpone en España como consecuencia de la Sentencia de la Gran Sala del Tribunal de Justicia, de 16 de junio de 2005 (C-105/03, caso Pupino). La citada sentencia resuelve una petición de decisión prejudicial planteada por el juez de instrucción del Tribunal de Florencia (Italia) de acuerdo con el art. 35 del Tratado de la Unión Europea. La cuestión prejudicial tiene por objeto que la Gran Sala del Tribunal de Justicia se pronuncie sobre la interpretación de los artículos 2, 3 y 8 de la Decisión marco 2001/220/JAI. La duda interpretativa surge en relación con el carácter vinculante de los citados artículos, pues como sabemos las

36 Serrano Masip, M., «Una justicia europea adaptada al menor: exploración de menores víctimas o testigos en la fase preliminar del proceso penal», en InDret, 2013, p. 4.

37 Sentencia de la Sala 2. ${ }^{a}$ del TS de 19 de marzo de 2021: «En nuestro ordenamiento procesal, como recientemente ha recordado una vez más esta Sala en su sentencia 129/2007 de 24 de febrero, por regla general los medios de prueba con validez e idoneidad para desvirtuar la presunción de inocencia son los que se practican en el Juicio Oral bajo los principios de inmediación ante el mismo Tribunal que ha de juzgar; de contradicción entre las partes del proceso; y de publicidad». 
decisiones marco no tienen efecto directo ${ }^{38}$. La Gran Sala concluye que el órgano jurisdiccional debe interpretar el derecho nacional de acuerdo con las disposiciones de la decisión marco, siempre que no se vulneren los principios generales del derecho del estado miembro ${ }^{39}$. Así, los arts. 2,3 y 8 de la Decisión marco 2001/220/JAI imponen al juez nacional la obligación de utilizar los medios necesarios para proteger a las víctimas especialmente vulnerables.

Parece que el legislador -siguiendo esta exigencia supranacional- decidió modificar el artículo $433 \mathrm{LECrim}^{40}$ y reguló la posibilidad de grabar las declaraciones de los menores en fase de instrucción. Esta reforma proporciona al juez de instrucción una herramienta para proteger el interés del menor pues, si el juez decide acordar la grabación de la declaración, ésta podrá ser reproducida en el acto del juicio oral para que despliegue efectos probatorios sólo, eso sí, cuando el riesgo de victimización secundaria o las singulares condiciones personales del menor lo aconsejen. Por lo tanto, se abre la puerta a la realización de un acto de anticipación de prueba para salvaguardar el interés del menor, de manera que éste no tenga que volver a declarar en fase de juicio oral.

Posteriormente, con la entrada en vigor de la LEVD se modificó nuevamente el artículo 433 LECrim y, entre otras novedades, se impuso al juez la obligación de grabar la declaración de las víctimas menores o personas con la capacidad modificada judicialmente ${ }^{41}$. Además, con ocasión de la aprobación de la LEVD se

38 Artículo 34 UE, apartado 2, en la versión resultante del Tratado de Ámsterdam, que forma parte del título vi del Tratado de la Unión Europea: «b) adoptar decisiones marco para la aproximación de las disposiciones legales y reglamentarias de los Estados miembros. Las decisiones marco obligarán a los Estados miembros en cuanto al resultado que deba conseguirse, dejando, sin embargo, a las autoridades nacionales la elección de la forma y de los medios. No tendrán efecto directo» (énfasis en cursiva añadido).

39 «El órgano jurisdiccional nacional está obligado a tomar en consideración todas las normas del Derecho nacional y a interpretarlas, en todo lo posible, a la luz de la letra y de la finalidad de dicha Decisión marco».

40 Reforma introducida por la Ley Orgánica 8/2006, de 4 de diciembre por la que se modifica la Ley Orgánica 5/2000, de 12 de enero, reguladora de la responsabilidad penal de los menores.

41 Artículo 433 LECrim tras la LEVD: "Al presentarse a declarar, los testigos entregarán al secretario la copia de la cédula de citación. Los testigos mayores de edad penal prestarán juramento o promesa de decir todo lo que supieren respecto a lo que les fuere preguntado, estando el Juez obligado a informarles, en un lenguaje claro y comprensible, de la obligación que tienen de ser veraces y de la posibilidad de incurrir en un delito de falso testimonio en causa criminal. Los testigos que, de acuerdo con lo dispuesto en el Estatuto de la Víctima del Delito, tengan la condición de víctimas del delito, podrán hacerse acompañar por su representante legal y por una persona de su elección durante la práctica de estas diligencias, salvo que en este último caso, motivadamente, se resuelva lo contrario por el Juez de Instrucción para garantizar el correcto desarrollo de la misma. En el caso de los testigos menores de edad o personas con la capacidad judicialmente modificada, el Juez de Instrucción podrá acordar, cuando a la vista de la falta de madurez de la víctima resulte necesario para evitar causarles graves perjuicios, que se les tome declaración mediante la intervención de expertos y con intervención del Ministerio Fiscal. Con esta finalidad, podrá acordarse también que las preguntas se trasladen a la víctima directamente por los expertos o, incluso, excluir o limitar la presencia de las partes en el lugar de la exploración de la víctima. En estos casos, el Juez dispondrá lo necesario para 
reformó el artículo 730 LECrim para permitir la reproducción de las declaraciones de los menores en el acto del juicio oral, aunque esta modificación no supone una novedad, pues la jurisprudencia del TS ya había reconocido esta facultad al tribunal. Aunque habría sido deseable que la aprobación del Estatuto de la víctima solucionara los problemas planteados en torno a la anticipación de la prueba testifical de los menores, lo cierto es que todavía quedaban cuestiones pendientes, como la necesidad de reforma de los arts. 777.2 y 797.2 LECrim $^{42}$.

La LOPIIA ha modificado recientemente la regulación de la declaración testifical de los menores como prueba preconstituida. Así, esta ley suprime el párrafo cuarto del art. $433^{43}$ y el párrafo tercero del artículo 448 de la LECrim $^{44}$. Además, la disposición final primera de la LOPIIA introduce tres preceptos que tienen gran relevancia en la regulación del objeto de este trabajo. En primer lugar, se incorpora el artículo 449 bis LECrim, que regula la declaración de los testigos como la prueba preconstituida en los casos legalmente previstos y, además, se establece que deberá garantizarse el principio de contradicción durante la práctica de la declara-

facilitar a las partes la posibilidad de trasladar preguntas o de pedir aclaraciones a la víctima, siempre que ello resulte posible. El Juez ordenará la grabación de la declaración por medios audiovisuales». La cursiva añadida resalta las reformas que más interesan en este artículo.

42 Serrano Masip, M., «La incorporación al proceso penal español...», cit. p. 540. Esta autora entiende que para otorgar a la exploración de los menores la categoría de prueba anticipada «deberían haberse modificado los arts. 777.2 y 797.2 LECrim e incluir la minoría de edad, o una determinada franja de edad, en los presupuestos habilitadores de la práctica de prueba anticipada basándose en la imposibilidad objetiva de volver a testifical el menor en el juicio oral».

${ }^{43}$ Este precepto queda con el siguiente contenido: «Al presentarse a declarar, los testigos entregarán al secretario la copia de la cédula de citación. Los testigos mayores de edad penal prestarán juramento o promesa de decir todo lo que supieren respecto a lo que les fuere preguntado, estando el Juez obligado a informarles, en un lenguaje claro y comprensible, de la obligación que tienen de ser veraces y de la posibilidad de incurrir en un delito de falso testimonio en causa criminal. Los testigos que, de acuerdo con lo dispuesto en el Estatuto de la Víctima del Delito, tengan la condición de víctimas del delito, podrán hacerse acompañar por su representante legal y por una persona de su elección durante la práctica de estas diligencias, salvo que en este último caso, motivadamente, se resuelva lo contrario por el Juez de Instrucción para garantizar el correcto desarrollo de la misma. El Juez ordenará la grabación de la declaración por medios audiovisuales».

${ }^{44}$ Este artículo queda redactado como sigue: «Si el testigo manifestare, al hacerle la prevención referida en el artículo 446, la imposibilidad de concurrir por haber de ausentarse del territorio nacional, y también en el caso en que hubiere motivo racionalmente bastante para temer su muerte o incapacidad física o intelectual antes de la apertura del juicio oral, el Juez instructor mandará practicar inmediatamente la declaración, asegurando en todo caso la posibilidad de contradicción de las partes. Para ello, el Secretario judicial hará saber al reo que nombre abogado en el término de veinticuatro horas, si aún no lo tuviere, o de lo contrario, que se le nombrará de oficio, para que le aconseje en el acto de recibir la declaración del testigo. Transcurrido dicho término, el Juez recibirá juramento y volverá a examinar a éste, a presencia del procesado y de su abogado defensor y a presencia, asimismo, del Fiscal y del querellante, si quisieren asistir al acto, permitiendo a éstos hacerle cuantas repreguntas tengan por conveniente, excepto las que el Juez desestime como manifiestamente impertinentes. Por el Secretario judicial se consignarán las contestaciones a estas preguntas, y esta diligencia será firmada por todos los asistentes». 
ción ${ }^{45}$. En segundo lugar, se introduce el artículo 449 ter LECrim, que centra su atención en la declaración de las personas menores de catorce años o personas con discapacidad necesitadas de especial protección cuando intervengan como testigos en procedimientos judiciales que tengan por objeto el enjuiciamiento de un «delito de homicidio, lesiones, contra la libertad, contra la integridad moral, trata de seres humanos, contra la libertad e indemnidad sexuales, contra la intimidad, contra las relaciones familiares, relativos al ejercicio de derechos fundamentales y libertades públicas, de organizaciones y grupos criminales y terroristas y de terrorismo». Se establece en este precepto la obligación de la autoridad judicial de acordar en todo caso la práctica preconstituida de la declaración del menor o persona necesitada de especial protección. La práctica de la declaración podrá realizarse por medio de equipos psicosociales que sirvan como apoyo al órgano jurisdiccional; en este caso las preguntas propuestas por las partes serán trasladadas por este equipo de apoyo al menor, una vez que la autoridad judicial haya valorado la pertinencia de éstas. En el último párrafo del artículo 449 ter LECrim se dispone que su contenido también se aplicará en el enjuiciamiento de delitos leves ${ }^{46}$. En tercer lugar, se añade un artículo 703 bis LECrim, que regula la introducción de la grabación de la declaración en el acto del juicio oral ${ }^{47}$.

\subsection{LA DEClARACIÓN DE LOS MENORES EN FASE DE INSTRUCCIÓN: ¿UN ACTO DE PRUEBA ANTICIPADA O PRECONSTITUIDA?}

La jurisprudencia del TS ha establecido como regla general que «los medios de prueba con validez e idoneidad para desvirtuar la presunción de inocencia son los que se practican en el Juicio Oral bajo los principios de inmediación ante el mismo Tribunal que ha de juzgar; de contradicción entre las partes del proceso; y de publicidad ${ }^{48}$. Sin embargo, en ocasiones, la naturaleza irrepetible de los hechos

45 Véase el artículo 449 bis LECrim.

46 Véase el artículo 449 ter LECrim.

47 Véase el artículo 703 bis LECrim.

48 La sentencia de la Sala 2. ${ }^{\text {, }}$, de 10 de marzo 2009, es la primera resolución del TS que aplica la doctrina europea del caso Pupino y declara la validez de la anticipación de la declaración de los menores testigos o víctimas. Resulta cuando menos curioso que en este caso la grabación de la declaración de la menor fue propuesta por un inspector jefe de la brigada provincial de policía judicial que consultó por teléfono al juez de instrucción la posibilidad de realizar una «prueba preconstituida» para que la menor sólo testificase una vez. Parece que esta petición fue trasladada al juez de instrucción por la insistencia de los padres de la menor que -aconsejados por una psicóloga- pretendían evitar que el proceso penal causase todavía más daños a la menor. Artículo 741 LECrim. «El Tribunal, apreciando según su conciencia las pruebas practicadas en el juicio, las razones expuestas por la acusación y la defensa y lo manifestado por los mismos procesados, dictará sentencia dentro del término fijado en esta Ley. Siempre que el Tribunal haga uso del libre arbitrio que para la calificación del delito o para la imposición de la pena le otorga el Código Penal, deberá consignar si ha tomado en consideración los elementos de juicio que el precepto aplicable de aquél obligue a tener en cuenta» (énfasis en cursiva añadido). 
o la imposibilidad de ser trasladados al momento del juicio oral obligan al juez de instrucción -o incluso al Ministerio Fiscal o a la policía judicial- a llevar a cabo el aseguramiento de la prueba: (I) practicando el medio de prueba bajo la inmediación del juez de instrucción (prueba anticipada); (II) asegurando las fuentes de prueba que serán trasladadas al órgano de enjuiciamiento (prueba preconstituida) ${ }^{49}$.

En la Sentencia de la Sala 2. ${ }^{a}$ del TS, de 10 de marzo de 2009, se definen -en mi opinión erróneamente- los actos de prueba anticipada y preconstituida. En cuanto a la prueba anticipada, el TS entiende que la única diferencia entre ésta y la prueba practicada en el acto del juicio oral es la fase del proceso en que se realiza. Por lo tanto, la Sala 2. ${ }^{a}$ del TS ha definido la prueba anticipada como aquélla que se desarrolla en la fase de instrucción, pero ante el órgano de enjuiciamiento y con pleno respeto a los principios propios del juicio oral. Por el contrario, la prueba preconstituida se define como aquélla que se practica ante el juez de instrucción y, por tanto, supone un «sacrificio de la inmediación». Esta diferencia hace que el TS clasifique la grabación de la declaración de los menores en fase de instrucción como "prueba preconstituida" o "prueba anticipada en sentido impropio" ${ }^{50}$.

En mi opinión, siguiendo el profesor Gimeno Sendra, la diferencia entre la prueba preconstituida y la anticipada no se deriva de su realización por el órgano juzgador o de instrucción. Gimeno Sendra define ambos actos de aseguramiento de prueba como "auténticos actos de prueba, pero practicados por el Juez de Instrucción o excepcionalmente, en el caso de la prueba preconstituda por la policía judicial o el Ministerio Fiscal, y custodiados bajo la fe pública del Letrado de la Administración de Justicia». Para el citado autor la diferencia radica en el medio de prueba utilizado y en la posibilidad de que se realice, además de por el juez de instrucción, por el Ministerio Fiscal o la policía judicial. Así, entiende que los medios de prueba utilizados en la prueba anticipada son la testifical y la pericial, mientras que en la prueba preconstituida es la documental pública ${ }^{51}$.

Por todo lo expuesto, en este trabajo me referiré a la declaración de los menores en fase de instrucción como prueba anticipada, dado que los actos de anti-

${ }^{49}$ Gimeno Sendra, V., Derecho procesal penal, Castillo de Luna, Madrid, 2018, p. 322. Artículo 448 LECrim: «Si el testigo manifestare, al hacerle la prevención referida en el artículo 446, la imposibilidad de concurrir por haber de ausentarse del territorio nacional, y también en el caso en que hubiere motivo racionalmente bastante para temer su muerte o incapacidad física o intelectual antes de la apertura del juicio oral, el Juez instructor mandará practicar inmediatamente la declaración, asegurando en todo caso la posibilidad de contradicción de las partes [...]». La cursiva añadida pretende fijar la atención del lector en la referencia al juez de instrucción como encargado de realizar la prueba anticipada.

${ }^{50}$ La doctrina ha acogido la calificación dada por el TS. Véase, por ejemplo, BLANCO García, A.I., «El nuevo régimen de la declaración de testigos del Estatuto de la Víctima del delito: reforma del artículo 433 de la LECrim», en El proceso penal. Cuestiones fundamentales, Tirant lo Blanch, Valencia, 2017; Magro Servet, V., «Necesidad de la práctica de la prueba preconstituida con menores de edad en el Juzgado de Instrucción en los delitos contra la libertad sexual», en Diario La Ley, n. ${ }^{\circ}$ 6972, 2008.

51 Gimeno Sendra, V., Derecho procesal..., cit., p. 322. 
cipación de prueba se caracterizan por la realización del medio de prueba -como sucede con la grabación de la exploración de los menores en fase de instrucción-, a diferencia de la prueba preconstituida, que supone el aseguramiento de la fuente de prueba $^{52}$. Así, a pesar de que la anticipación de la declaración de los menores no se debe a la irrepetibilidad del hecho, entiendo que se trata de una imposibilidad objetiva impuesta por el legislador para proteger el interés del menor y evitar el riesgo de victimización secundaria ${ }^{53}$.

\subsection{El PRinCipio de CONTRAdicCión y la CÁMARA GESELL}

El principio de contradicción es «el fundamento del derecho de defensa» ${ }^{54}$. El Tribunal Constitucional (en adelante TC) ha declarado que las pruebas aptas para vincular a los órganos jurisdiccionales penales son las practicadas en el acto del juicio oral ante el juzgado o tribunal que dictará sentencia y bajo los principios de contradicción e inmediación ${ }^{55}$. La anterior afirmación ha sido matizada por el mismo tribunal en el sentido de que las diligencias sumariales que se han desarrollado cumpliendo con las garantías establecidas en la Constitución y la LECrim podrán valorarse por el órgano de enjuiciamiento siempre que puedan ser sometidas a contradicción en el acto de la vista ${ }^{56}$. Por lo tanto, se admite la validez de los actos de prueba anticipada y preconstituida, pues el TC ha manifestado que debe hacerse valer «la seriedad de lo actuado por los órganos encargados de la represión penal», máxime en un sistema que ampara la necesidad de protección de los bienes jurídicos y los derechos de los ciudadanos frente a posibles abusos ${ }^{57}$.

La jurisprudencia del TS ha declarado que la regla general debe ser la declaración de los menores en el acto del juicio oral ${ }^{58}$. Pero ha establecido una serie de

52 Ibidem. Gimeno Sendra señala que «[...] el aseguramiento de la prueba es una actividad del Juez de Instrucción que comprende dos cometidos concretos, bien la práctica del acto de prueba, en cuyo caso nos encontramos ante un supuesto de prueba instructora anticipada, bien la guarda o custodia de ambas fuentes de prueba a través de actos de prueba preconstituida».

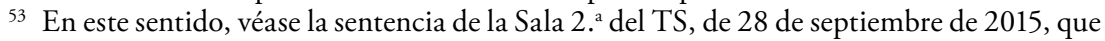
equipara la prueba testifical anticipada de un testigo que no podrá acudir al juicio oral con la anticipación de la declaración de los menores por la existencia de un riesgo de victimización.

54 Gimeno Sendra, V., Constitución y proceso, Tecnos, Madrid, 1998, p. 88.

55 Véase en este sentido SSTC 217/1989, de 21 de diciembre; 161/1990, de 19 de octubre, 303/1993, de 25 de octubre; 12/2002, de 28 de enero; y 280/2005 de 7 de noviembre. Además, el artículo 449 bis LECrim establece que «la autoridad judicial garantizará el principio de contradicción en la práctica de la declaración» (énfasis en cursiva añadido).

${ }^{56}$ En este sentido, SSTC 10/1992, de 16 de enero; y 187/2003, de 27 de octubre.

57 STC 56/2010, de 4 de abril: «Un sistema que pondere adecuadamente tanto la necesidad social de protección de bienes jurídicos esenciales, como el haz de garantías frente a posibles abusos de los ciudadanos, con independencia de su posición, ha de estar en condiciones de hacer valer la seriedad de lo actuado por los órganos encargados de la represión penal; siempre que lo actuado lo haya sido con pleno respeto a aquellas garantías».

58 Sentencia de la Sala 2. ${ }^{\text {a }}$ del TS, de 14 de octubre de 2014. 
presupuestos para que la grabación de la declaración del menor en fase de instrucción tenga valor probatorio: (I) la existencia de riesgo para la salud psíquica de los menores, que deberá estar acreditada, por ejemplo, por un informe psicológico; (II) la ponderación de la edad y madurez del menor; (III) la imposibilidad de adoptar otras medidas que eviten la victimización secundaria; (Iv) la motivación por el juez o magistrado de la necesidad de anticipar la prueba testifical; (v) la reproducción de la grabación de la declaración del menor en el acto del juicio oral ${ }^{59}$. Estos presupuestos, junto con la presencia del juez de instrucción, el Ministerio Fiscal y el letrado del investigado en la declaración prestada, permiten que no pueda apreciarse vulneración del derecho a un proceso con todas las garantías ${ }^{60}$.

Tras la entrada en vigor de la LOPIIA deberá acordarse la declaración testifical de los menores de catorce ańos y personas con discapacidad necesitadas de especial protección en los delitos «de homicidio, lesiones, contra la libertad, contra la integridad moral, trata de seres humanos, contra la libertad e indemnidad sexuales, contra la intimidad, contra las relaciones familiares, relativos al ejercicio de derechos fundamentales y libertades públicas, de organizaciones y grupos criminales y terroristas y de terrorismo" ${ }^{61}$.

La excepcionalidad de la declaración de los menores como prueba anticipada se debe a que el principio de contradicción sólo puede garantizarse plenamente en el juicio oral; por lo tanto, sólo se admite la limitación de la contradicción para proteger el interés superior del menor cuando existan razones fundadas de la existencia de un riesgo de victimización secundaria ${ }^{62}$.

Como ha señalado Moreno Catena, para que exista una contradicción procesal efectiva es necesario que la defensa pueda no sólo proponer y practicar los medios de prueba pertinentes para su defensa, sino también que intervenga en el desarrollo de la prueba para desacreditar la fiabilidad del testigo o poner de manifiesto contradicciones en su testimonio ${ }^{63}$. En las declaraciones sumariales de los menores la contradicción se garantiza en dos ocasiones: (I) en la fase de instrucción, pues las partes podrán plantear al menor -por medio del perito psicológico- las preguntas

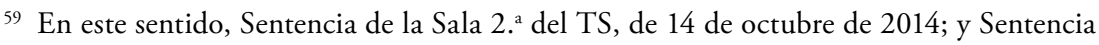

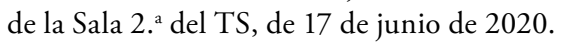

${ }^{60}$ Sentencia de la Sala 2. ${ }^{\text {a }}$ del TS, de 10 de marzo de 2009: «En definitiva en este caso la prueba preconstituida se hizo a presencia del Juez de Instrucción, asistido del Secretario Judicial, y con la presencia del Ministerio Fiscal y del letrado del imputado, en la fase instructora del procedimiento abreviado, quedando por ello cumplida la exigencia del principio de contradicción establecida por el art. 772.2 de la LECr».

${ }^{61}$ Artículo 449 ter LECrim introducido por la LOPIIA, que entró en vigor el 26 de junio de 2021.

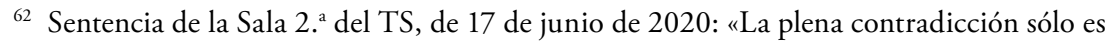
posible en el juicio oral, pues sólo en ese momento se dispone de la hipótesis acusatoria formalizada y se conoce el contenido de los elementos investigativos empleados para construirla, así como el listado de los medios de prueba propuestos para verificarla».

${ }^{63}$ Moreno Catena, V.M., «La protección de los testigos y peritos en el proceso penal español», en Revista penal, n. ${ }^{\circ}$ 4, 1999, p. 65. 
que el juez estime pertinentes; (II) en la fase del juicio oral con la reproducción de la declaración del menor las partes podrán debatir la verosimilitud del testimonio del menor ${ }^{64}$. Una de las herramientas utilizadas para garantizar que tanto el juez como las partes puedan presenciar la declaración de los menores y plantear al menor las preguntas que consideren es la denominada cámara Gesell. Esta cámara, también denominada de observación, permite que los menores declaren en una sala, mientras que las partes y el juez están situados en una sala contigua separada por un espejo que les permite observar al menor y al mismo tiempo impide que el menor se percate de su presencia ${ }^{65}$.

Aunque algunos juzgados y tribunales españoles ya cuentan con unas instalaciones que cumplen con las condiciones de la cámara Gesell ${ }^{66}$, lo cierto es que destinar dos salas de un juzgado o tribunal -que habitualmente no disponen de instalaciones suficientes- puede suponer un problema para implementar el uso de esta técnica. Tal y como apuntaba al comienzo de este trabajo, los medios tecnológicos de grabación de imagen y sonido pueden servir de gran ayuda para proteger el interés del menor. El uso de equipos de grabación de imagen y sonido facilita a los juzgados y tribunales la toma de declaración a través de un sistema de cámara de observación, pues el uso de una cámara web en la sala en la que está situado el menor y un ordenador en cualquier otra sala del juzgado -que no tiene por qué situarse de forma contigua a la sala donde se encuentra el menor-permitirá que las partes y el juez presencien en tiempo real la declaración del menor.

La pregunta que se plantea a continuación es la siguiente: ¿cómo trasladarán las partes y el juez las preguntas al psicólogo? Pues bien, la tecnología ofrece también una solución a este problema. El uso de un auricular inalámbrico por el psicólogo será el medio para que el juez trasmita al psicólogo las preguntas que tanto él mismo como las partes quieran plantear al menor, así se garantiza también que el juez valore previamente la procedencia de las cuestiones propuestas por las partes.

La grabación de la prueba anticipada será reproducida en el acto del juicio oral, de modo que se someta al debate de las partes en presencia del tribunal sentenciador y se garantice el principio de inmediación y contradicción ${ }^{67}$. Parece que

${ }^{64}$ Cubillo López, I.J., La protección de los testigos en el proceso penal, Aranzadi, Navarra, 2009, pp. 212-213.

65 Sempere Faus, S., «La grabación audiovisual de la declaración del menor de edad: la prueba preconstituida y la eficacia de la cámara Gesell en la reducción de la victimización secundaria», en Revista General de Derecho procesal, n. ${ }^{\circ} 48,2019$, p. 38.

${ }^{66}$ Por ejemplo, la Ciudad de la Justicia de Las Palmas de Gran Canaria (https://bit.ly/2OYcrA7); los juzgados de Arrecife en Lanzarote (https://bit.ly/38XBfie); o los juzgados de Móstoles, en Madrid (https://bit.ly/3r1U1v3). Último acceso a los enlaces: 22 de marzo de 2021. En este sentido, Sempere Faus, S., «La grabación audiovisual de la declaración del menor..., cit.

${ }_{67}$ Cubillo López, I.J., La protección de los testigos..., cit., p. 225, en Calderón CuaDRADO, M.P., La encrucijada de una justicia penal tecnológicamente avanzada. Sobre la grabación de las vistas, los recursos y la garantía de la inmediación, La Ley, Madrid, 2011, p. 131, la autora -en relación con la reproducción del medio de prueba en fase de recurso- entiende que no se trata de «un verdadero juicio inmediato", pues la actividad probatoria no se repite en presencia del órgano que conoce 
- como ha señalado el TS - no debe existir una confrontación entre el principio de contradicción y el derecho de defensa del acusado con la protección de los menores frente al riesgo de victimización secundaria ${ }^{68}$.

\subsection{La VAlideZ De LA PRUEba ANTICIPADA PARA DESVIRTUAR EL DERECHO A LA PRESUNCIÓN DE INOCENCIA}

Gimeno Sendra acogía de forma efusiva la consagración del derecho a la presunción de inocencia en la Constitución Española de 1978, pues la situación anterior a esta norma fundamental otorgaba al imputado una «presunción de culpabilidad, de la cual había de desprenderse en el momento del juicio oral» ${ }^{69}$. El derecho fundamental a la presunción de inocencia está presente en todas las fases del proceso penal; sin embargo, en el acto de juicio oral adquiere especial importancia, pues las partes acusadoras deben proponer la práctica de medios de prueba suficientes para desvirtuar la presunción de inocencia del acusado.

El TC ha declarado que el derecho a la presunción de inocencia «se configura en tanto que regla de juicio y desde la perspectiva constitucional, como el derecho a no ser condenado sin pruebas de cargo válidas, lo que implica que exista una mínima actividad probatoria, realizada con las garantías necesarias, referida a todos los elementos esenciales del delito y que de la misma quepa inferir razonablemente los hechos y la participación del acusado en ellos» ${ }^{70}$. Las declaraciones de los menores en fase de instrucción suscitan dos cuestiones en relación con el derecho a la presunción de inocencia: (I) la testifical de la víctima como única prueba de cargo; (II) la práctica de la prueba en la fase de instrucción.

del recurso. Así, entiende que la reproducción de la grabación podría comportar «una inmediación virtual». Lo mismo sucede en la reproducción de la prueba testifical anticipada, pues el órgano de enjuiciamiento puede presenciar de forma mediata la práctica de la prueba, pero no podrá realizar las preguntas que estime necesarias al testigo-víctima.

${ }^{68}$ Véase la sentencia de la Sala 2. ${ }^{2}$ del TS, de 26 de noviembre de 2019, en Alonso Rimo, A., «Medidas de protección de los intereses de las víctimas: su fundamentación desde un punto de vista penal», en Estudios de Victimología. Actas del I Congreso español de victimología, Tirant lo Blanch, Valencia, 2005, p. 53, el autor afirma que «una comprensión del Derecho -que es, según creo, la que resulta más respetuosa con nuestro modelo de Estado constitucional- en virtud de la cual aquél debe limitarse a "ordenar la convivencia externa de los ciudadanos del modo menos gravoso posible para sus derechos y libertades", no ha de resultar problemático afirmar -haciendo una interpretación de dicha concepción kantiana del Derecho en clave integradora de la víctima- que deben respetarse también tales exigencias (es, decir, esos mismos derechos y libertades) en relación asimismo con la víctima». Por lo tanto, los derechos del autor del delito y la víctima deben alcanzar un equilibrio no sólo en el derecho procesal, sino también como señala Alonso Rimo en el derecho penal (énfasis en cursiva añadido).

${ }^{69}$ Gimeno Sendra, V., Constitución y..., cit., p. 109.

70 Véase, STC 123/2006, de 24 de abril. 
(I) En cuanto al testimonio de la víctima como única prueba de cargo -como ya he dicho en páginas anteriores ${ }^{71}-$, el TS ha establecido que puede valorarse como prueba de cargo suficiente, siempre que el tribunal no aprecie razones que resten credibilidad al testimonio de la víctima. Para la determinación de la verosimilitud de la declaración de la víctima el TS ha establecido los siguientes criterios orientativos: (I) inexistencia de enemistad, resentimiento, ánimo de venganza, enfrentamiento o cualquier interés ajeno a la finalidad del proceso; (II) existencia de datos de carácter objetivo que corroboren la versión de la víctima; y (III) persistencia en la incriminación. Respecto a este último criterio, en la Sentencia de la Sala 2. ${ }^{a}$ del TS, de 13 de noviembre de 2003 , se señala que el acusado debe tener la oportunidad de evidenciar las contradicciones o ambigüedades de la declaración de la víctima.

(II) Esta última exigencia guarda estrecha relación con la práctica de la prueba en la fase de instrucción. Para garantizar el derecho a la presunción de inocencia no sólo debe existir un testimonio verosímil, sino que además debe permitirse a la defensa del acusado poner en duda dicha verosimilitud. A pesar de que la STC 31/1981, de 28 de julio, precisó que las pruebas que debe valorar el órgano enjuiciador son las practicadas en el acto del juicio oral, la prueba anticipada, como es sabido, es una excepción a esta regla general. La doctrina del TS ha establecido los siguientes requisitos para que la prueba testifical anticipada consistente en la declaración del menor sea una prueba de cargo suficiente para desvirtuar el derecho a la presunción de inocencia: (I) la imposibilidad de comparecencia del menor en el juicio oral, que, como hemos visto, se acredita por el informe pericial que ponga de manifiesto el riesgo de victimización; (II) la declaración debe prestarse ante el juez de instrucción; (III) el principio de contradicción debe respetarse con la presencia de la defensa; (Iv) la grabación de la declaración debe ser reproducida en el acto de juicio oral ${ }^{72}$.

Por lo tanto, la protección del interés superior del menor permite que la prueba testifical anticipada - practicada conforme a las exigencias que ha establecido la jurisprudencia del TS- se constituya como prueba de cargo suficiente para desvirtuar el derecho a la presunción de inocencia.

\subsection{LA REgUlaCión DE LA DEClARACIÓN DE LAS VÍCTIMAS MENORES DE EDAD EN EL APLECRIM 2020}

Como ya he apuntado, la LOPIIA ha reformado la regulación de la prueba testifical anticipada cuando las víctimas son menores de 14 años o personas necesitadas de especial protección; no obstante, el APLECrim 2020 también propone

71 V. supra, 1.1.

72 La Sentencia de la Sala 2. ${ }^{a}$ del TS, de 28 de septiembre de 2015, fija estos criterios en relación con la prueba testifical anticipada de un testigo que se prevé no podrá acudir a declarar al acto del juicio oral, pero la Sala 2. ${ }^{a}$ declara que serán de aplicación también a los supuestos en que la anticipación se realice por la existencia de un riesgo de victimización secundaria. 
una regulación novedosa de la declaración de los menores en la fase de instrucción y su posterior reproducción en el acto del juicio oral. Tras la exigencia del Comité de Derechos del Niño en el año 2018 para aprobar una ley integral sobre violencia contra niños y niñas, parece que el legislador aprovechó la LOPIIA para modificar e introducir algunos preceptos con respecto a la regulación de la declaración anticipada de los menores. Las reformas introducidas por la LOPIIA ya han sido analizadas, por lo que este apartado se centrará en el análisis de la propuesta de regulación del APLECrim 2020, pues si este anteproyecto se convierte en Ley la principal consecuencia será una nueva modificación de la prueba testifical anticipada como instrumento para evitar la victimización secundaria de los menores.

Así, en el capítulo v del APLECrim 2020, rotulado «el estatuto de la víctima en el proceso penal», se otorga la condición de víctima en situación de especial vulnerabilidad a aquélla que por su edad, discapacidad o enfermedad no puede «someterse directamente al examen contradictorio de las partes» ${ }^{73}$. En este mismo capítulo se establece la prohibición de victimización secundaria y se dispone que la declaración de las víctimas debe llevarse a cabo sin dilación y, en la medida de lo posible, una única vez ${ }^{74}$.

Tal y como ha señalado Montesinos García, el proceso de victimización secundaria como consecuencia de la relación de la víctima con la administración de justicia es tan evidente que no sólo se ha acuñado esta expresión para referirla ${ }^{75}$, sino que además el APLECrim 2020 impone a todas las autoridades que intervengan en el proceso penal la adopción de medidas para prevenir el riesgo de victimización secundaria.

En relación con la declaración de los menores de edad o personas con discapacidad, el legislador establece una serie de especialidades en los arts. 600 a 602 del APLECrim 2020. Así, la declaración testifical de los menores -o personas con la capacidad modificada judicialmente- se realizará de forma reservada con la presencia de un perito experto en psicología "del testimonio»" ${ }^{76}$. El juez podrá acordar que la declaración se practique sin la presencia inmediata del Ministerio Fiscal ni de las partes, pero deberá garantizarse que puedan presenciarla de forma mediata.

73 Artículo 102 del APLECrim 2020: «Tienen en todo caso esta condición las víctimas que por razón de su edad, enfermedad o discapacidad no puedan someterse directamente al examen contradictorio de las partes».

${ }^{74}$ Artículo 103.1 párrafo segundo del APLECrim 2020: «Igualmente velarán para que se reciba declaración a las víctimas sin dilaciones indebidas. La declaración de las víctimas y su reconocimiento médico únicamente se realizará cuando sea Anteproyecto de Ley de Enjuiciamiento Criminal necesario a los fines de la investigación. No se repetirá su práctica salvo que resulte imprescindible a estos mismos fines».

${ }^{75}$ Montesinos García, A., «La lectura o reproducción de las declaraciones sumariales de los menores en el juicio oral", en El proceso penal. Cuestiones fundamentales, Tirant lo Blanch, Valencia, 2017, p. 239.

${ }^{76}$ El cumplimiento de la exigencia de la participación de un perito psicólogo del testimonio dependerá de la disponibilidad del juzgado, así que puede que en la práctica participe en la declaración un psicólogo sin dicha especialidad. 
La presencia mediata del juez y las partes acusadoras podrá tener lugar por medio de las siguientes técnicas: (I); la declaración del menor en una sala que permita a las partes y al juez observar lo que sucede a través de un cristal efecto espejo (cámara Gesell); o (II) la reproducción de imagen y sonido en tiempo real en otra sala del juzgado o tribunal. Esta presencia "mediata» permite que el menor no sienta la presión del MF o las partes y garantiza el principio de contradicción, pues las partes pueden plantear al juez las preguntas que estimen oportunas para que éste las transmita al perito psicólogo.

El artículo 600 del APLECrim 2020 establece que la declaración del menor será siempre grabada para que, si la edad del menor o circunstancias personales del testigo lo aconsejan, pueda reproducirse tal grabación en el acto del juicio oral. Además, añade que podrá reproducirse también la grabación de la declaración en el acto del juicio oral cuando por el tiempo transcurrido se presuma que la «calidad informativa del testimonio" se ha visto mermada.

La protección del interés del menor en el APLECrim 2020 se cierra con la regulación de algunas particularidades para aquellos supuestos en que la víctima menor de edad finalmente deba declarar en el acto del juicio oral: (I) la presencia de representante legal del menor o persona con discapacidad; (II) cuando el menor tenga menos de 16 años se evitará la confrontación visual con el acusado; (III) cuando sea posible, el menor prestará declaración sin estar presente en la sala de vistas; (Iv) el interrogatorio se realizará por el presidente del tribunal, que trasladará las preguntas de las partes ${ }^{77}$.

\section{CONCLUSIONES}

La grabación de la declaración de los menores en la fase de instrucción es una medida eficaz para reducir el riesgo de victimización secundaria, pues así se permite que ésta pueda reproducirse en el acto del juicio oral para que adquiera pleno valor probatorio. En mi opinión, esta declaración debe clasificarse como un acto de prueba anticipada, puesto que en la fase de instrucción se ha practicado el

77 Artículo 672 del APLECrim 2020: «Cuando los testigos menores de edad y las personas con discapacidad en situación de vulnerabilidad hayan de prestar declaración en el juicio oral, será de aplicación el régimen establecido para la declaración de testigos con las siguientes salvedades: a) La declaración se prestará con la asistencia del representante legal del menor o de quien integre la institución de apoyo de la persona con discapacidad, conforme a lo establecido en los artículos 469 y 470 de esta ley. b) La declaración de los testigos menores de dieciséis años siempre se llevará a cabo evitando la confrontación visual con el acusado. c) Cuando las condiciones de la persona que haya de declarar lo requieran, la declaración se realizará utilizando las tecnologías de la comunicación que permitan que el testigo preste declaración en dependencias judiciales, sin estar presente en la sala de vistas. d) El testigo será interrogado únicamente por el presidente del tribunal, pudiendo las partes solicitar que realice las preguntas adicionales que consideren necesarias. No obstante, el presidente permitirá que las partes realicen las preguntas directamente si de ello no se deriva perjuicio alguno para el testigo». 
medio de prueba, a diferencia de los actos de prueba preconstituida, en los que el juez de instrucción se limita a asegurar la fuente de prueba. La otra cuestión que plantea dudas en relación con la clasificación como prueba anticipada de la exploración sumarial del menor es la inexistencia de irrepetibilidad del hecho; no obstante, debe concluirse que se trata de una imposibilidad objetiva impuesta por el legislador para proteger el interés del menor y, en consecuencia, de la sociedad.

En cuanto al interés de la sociedad, debe señalarse que el hecho de que las relaciones con la administración de justicia puedan causar perjuicios a las víctimas parece contrario a la idea de justicia que GUASP desdobla en dos facetas: la satisfacción y el perfeccionamiento ${ }^{78}$. Pues bien, en mi opinión, el legislador debe proporcionar a las autoridades que participan en el proceso penal los instrumentos necesarios para reducir el riesgo de victimización secundaria. Parece que éste es el objetivo de la introducción de la prohibición de la victimización secundaria en el APLECrim, así como de la regulación más detallada de las declaraciones de las víctimas menores de edad. No obstante, tras la entrada en vigor de la LOPIIA, parece que la normativa española ha cumplido con las exigencias europeas en relación con la protección del interés superior del menor y está más cerca de lograr la referida satisfacción social.

Recibido: marzo de 2021; ACEPTAdo: abril de 2021

${ }^{78}$ Guasp, J., Derecho, Madrid, 1971, pp. 327-328 


\section{BIBLIOGRAFÍA}

Alonso Rimo, A., «Medidas de protección de los intereses de las víctimas: su fundamentación desde un punto de vista penal», en Estudios de Victimología. Actas del I Congreso español de victimología, Tirant lo Blanch, Valencia, 2005.

Barona Vilar, A., "Cuarta revolución industrial (4.0) o ciberindustria en el proceso penal: revolución digital, inteligencia artificial y el camino hacia la robotización de la justicia», en Revista jurídica digital UANDES, n. ${ }^{\circ} 1,2019$.

Borges Blázquez, R., «El sesgo de la máquina en la toma de decisiones en el proceso penal», en IUS ET SCIENTIA: Revista electrónica de Derecho y Ciencia, n. ${ }^{\circ}$ 2, 2020.

Bueno de Mata, F., «Macrodatos, inteligencia artificial y proceso: luces y sombras», en Revista General de Derecho Procesal, n. ${ }^{\circ}$ 51, 2020.

Blanco García, A.I., «El nuevo régimen de la declaración de testigos del Estatuto de la Víctima del delito: reforma del artículo 433 de la LECrim», en El proceso penal. Cuestiones fundamentales, Tirant lo Blanch, Valencia, 2017.

Calderón Cuadrado, M.P., La encrucijada de una justicia penal tecnológicamente avanzada. Sobre la grabación de las vistas, los recursos y la garantía de la inmediación, La Ley, Madrid, 2011.

Cubillo López, I.J., La protección de los testigos en el proceso penal, Aranzadi, Navarra, 2009.

Gimeno Sendra, V., Constitución y proceso, Tecnos, Madrid, 1998.

Gimeno Sendra, V., Derecho procesal penal, Castillo de Luna, Madrid, 2018.

Gómez Colomer, J.L., Estatuto Jurídico de la Victima del delito. La posición jurídica de la víctima de delito ante la justicia penal. Un análisis basado en el Derecho comparado y en las grandes reformas españolas que se avecinan, Aranzadi, Navarra, 2014.

Guasp, J., Derecho, Madrid, 1971.

Landrove Díaz, G., Victimología, Tirant lo Blanch, Valencia, 1990.

Landrove Díaz, G., "La víctima y el juez», en Victimología: VIII Cursos de Verano en San Sebastián, Universidad del País Vasco, 1990.

Magro Servet, V., «Necesidad de la práctica de la prueba preconstituida con menores de edad en el Juzgado de Instrucción en los delitos contra la libertad sexual», en Diario La Ley, n. ${ }^{\circ} 6972,2008$.

Magro Servet, V., «La victimización secundaria de los menores en el proceso penal», en Diario La Ley, n. ${ }^{\circ}$ 6282, 2005.

Montesinos García, A., «La lectura o reproducción de las declaraciones sumariales de los menores en el juicio oral», en El proceso penal. Cuestiones fundamentales, Tirant lo Blanch, Valencia, 2017.

Moreno Catena, V.M., «La protección de los testigos y peritos en el proceso penal español», en Revista penal, n. ${ }^{\circ}$ 4, 1999.

Morillas Fernández, D.L., "La victimización penitenciaria», en Revista Internacional de Doctrina y Jurisprudencia, n. ${ }^{\circ}$ 14, 2016.

Morillas Fernández, D.L., Patró Hernández, R.M. y Aguilar Cárceles, M.M., Victimologia: un estudio sobre la victima y los procesos de victimización, Dykinson, Madrid, 2014. 
Sempere Faus, S., «La grabación audiovisual de la declaración del menor de edad: la prueba preconstituida y la eficacia de la cámara Gesell en la reducción de la victimización secundaria», en Revista General de Derecho procesal, n. ${ }^{\circ} 48,2019$.

Serrano Masip, M., «La incorporación al proceso penal español de la normativa UE sobre el interrogatorio o la exploración de la víctima menor de edad», en Delitos contra la libertad e indemnidad sexual de los menores, Aranzadi, Navarra, 2015.

Serrano Masip, M., "Una justicia europea adaptada al menor: exploración de menores víctimas o testigos en la fase preliminar del proceso penal», en InDret, 2013. 



\title{
LA RESPONSABILIDAD DE LAS PLATAFORMAS DE ECONO- MÍA COLABORATIVA A LA LUZ DE LA LEY 34/2002 DE SERVICIOS DE LA SOCIEDAD DE LA INFORMACIÓN
}

\author{
Nora Rodríguez García \\ Profesora ayudante de Derecho civil \\ Universidad de La Laguna
}

\section{RESUMEN}

Las plataformas de economía colaborativa juegan hoy un papel fundamental en el desarrollo de las relaciones comerciales digitales, y con el nacimiento de este modelo de intercambio se generan una serie de cuestiones jurídicas que el legislador nacional e internacional ha preferido abordar de manera cautelosa. Se estudia en este trabajo el debate en torno a la responsabilidad de los intermediarios a través del análisis de la Ley de Servicios de la Sociedad de la Información y la dicotomía entre el intermediario digital y el proveedor de servicios, analizando las dificultades existentes para su distinción y graduación de su régimen de responsabilidad. Con la vista en la propuesta de Reglamento de Servicios Digitales, la inexistencia de una legislación internacional vigente que abarque esta casuística implica que se deba resolver mediante normas de Derecho Internacional Privado para subsumirse en la legislación interna de cada país, aunque existen unos regímenes "generales» de responsabilidad contractual y extracontractual, los cuales serán objeto de estudio de este artículo.

Palabras Clave: economía colaborativa, responsabilidad civil, intermediarios digitales, proveedores de servicios.

\section{LIABILITY OF THE COLLABORATIVE ECONOMY PLATFORMS IN THE LIGHT OF LAW 34/2002 ON INFORMATION SOCIETY SERVICES}

\section{Abstract}

Collaborative economy platforms now play a fundamental role in the development of digital commercial relations and with the birth of this model of exchange, a series of legal questions have arisen that national and international legislators have preferred to approach cautiously. This paper examines the debate surrounding the liability of intermediaries through an analysis of the Law on Information Society Services and the dichotomy between the digital intermediary and the service provider, analysing the difficulties that exist in distinguishing between them and graduating their liability regime. With a view to the proposed Digital Services Regulation, the lack of current international legislation covering this casuistry means that it must be resolved by means of Private International Law rules to be subsumed in the domestic legislation of each country, although there are some "general" regimes of contractual and non-contractual liability, which will be the subject of study in this article. KEYWORDs: collaborative economy, liability, digital intermediaries, service providers. 
Las plataformas de economía colaborativa juegan hoy un papel fundamental en el desarrollo de las relaciones comerciales digitales, especialmente en lo que respecta al nexo en que las partes intervinientes son particulares o peers. El surgimiento de este modelo de intercambio plantea una serie de cuestiones jurídicas que tanto los legisladores nacionales como los internacionales han preferido abordar de manera cautelosa. Estamos ante un modelo de mercado muy reciente y fuertemente marcado por el nacimiento de internet en los ańos noventa del pasado siglo, pero con un desarrollo y crecimiento exponencial, lo cual hace muy difícil que se recoja adecuada y satisfactoriamente en la legislación actual. Ello es lo que explica que, a día de hoy, en España, la única normativa aplicable consiste en directivas de la UE transpuestas a las leyes españolas, pues tampoco contamos todavía con una legislación internacional aprobada que aborde este nuevo sistema en su conjunto.

La sentencia del TJUE de 13 de mayo de $2014^{1}$ sobre el derecho al olvido ha reabierto el debate en torno a la responsabilidad de los intermediarios, ya que la inexistencia de una legislación internacional que abarque la casuística que se viene produciendo implica que se deba resolver mediante normas de Derecho Internacional Privado para subsumirse en la legislación interna de cada país, aunque existen unos regímenes "generales» de responsabilidad contractual y extracontractual, de los que nos ocuparemos a lo largo del trabajo. En general, se tiene la idea de que esta solución sabe a poco, sobre todo debido al carácter internacional intrínseco de la economía colaborativa y a su desarrollo a través de internet. La globalización y la apertura del espacio digital, que rompe con las barreras geográficas y políticas, forman parte, pues, de su naturaleza, y se hace necesario darle soluciones jurídicas particularizadas.

En este trabajo se analiza un aspecto muy concreto de este fenómeno: la responsabilidad de las plataformas de economía colaborativa en el caso español cuando actúan, bien como intermediaria digital, o bien como proveedor del servicio; es decir, presuponiendo que las normas de conflicto nos hayan llevado a la designación de la legislación española como ley aplicable.

En primer lugar, haremos una breve introducción a la economía colaborativa, en la que esbozaremos los principales aspectos del tema que nos ocupa. Así, explicaremos los principios y elementos básicos que la conforman y su funcionamiento, para poder entender la responsabilidad de los intermediarios que la constituyen.

En segundo lugar, desarrollaremos el marco normativo analizando y explicando brevemente las directivas internacionales que se han dictado sobre la materia, así como su transposición a la legislación española. Con ello queremos conocer y diferenciar los regímenes existentes con respecto a la responsabilidad de las plataformas.

En tercer lugar, entrando propiamente en la materia, abordaremos las bases constitutivas y rasgos diferenciales de los dos tipos de plataformas digitales: la intermediaria digital y la proveedora de servicios.

En cuarto lugar, debido a que la implicación de ambas en el control de sus actividades influirá directamente en el tipo o grado de responsabilidad que, en caso

\footnotetext{
${ }^{1}$ Sentencia de 13 de mayo de 2014, C131/12, ECLI:EU:C:2014:317.
} 
de producir algún perjuicio, acarreará, centraremos el análisis en los artículos 13 a 17 de la LSSI. Debemos señalar que no nos centraremos en el tipo de ilícito cometido, como, por ejemplo, el derecho de libertad de expresión, el derecho de autor, el derecho al honor y la intimidad, etc., sino que estudiaremos los regímenes por los que se deberá regir su responsabilidad. No debemos olvidar que, una vez que se cometa el ilícito, deberemos atender también a las normas sectoriales existentes. Es por ello por lo que solo nos centraremos en el momento previo, es decir, en la situación en la que se estudia si un acto en una determinada plataforma genera responsabilidad para la misma.

Finalmente, en quinto lugar, expondremos algunas conclusiones extraídas del análisis de la materia objeto de estudio.

\section{INTRODUCCIÓN A LA ECONOMÍA COLABORATIVA}

La economía colaborativa es uno de los fenómenos jurídico-sociales más importantes de los últimos tiempos ${ }^{2}$. Se presenta como un nuevo modelo de prestación de servicios o bienes en el que se prioriza el acceso, que no la propiedad, sobre bienes o servicios y, de esta manera, el motor y el objeto principal de la economía colaborativa es compartir, intercambiar, distribuir, alquilar, etc. ${ }^{3}$. La cantidad de oferta y demanda a la que acceden las plataformas de economía colaborativa, debido al hecho de que al cambiar al intermediario tradicional por el intermediario digital se eliminan las barreras geográficas y se reducen los costes de transacción, hace que autores como Domenech $(2015)^{4}$ resalten que la crisis económica que se inicia en 2008 haya incentivado el florecimiento de la economía colaborativa, teniendo en cuenta que resulta muy atractivo para un ciudadano medio acceder a bienes y servicios de los que había quedado privado precisamente a consecuencia de esta crisis.

Para situar la materia, me valdré de la definición de economía colaborativa propuesta en la Comunicación de la Comisión al Parlamento Europeo titulada «Una Agenda Europea para la economía colaborativa» $(2016)^{5}$, que, a pesar de no ser de

2 En general, se considera que Rachel Botsman es la líder del movimiento, pues fue la que puso de relieve y en el punto de mira la importancia de la economía colaborativa en su obra What's mine is yours (Harper Collins, 2010).

${ }^{3}$ La Comisión Nacional de los Mercados y la Competencia (en adelante CNMC) la define en sus "Conclusiones preliminares sobre los nuevos modelos de prestación de servicios y la economía colaborativa» como el "fenómeno que se caracteriza como el mejor aprovechamiento de los recursos infrautilizados, mediante la puesta a disposición de los usuarios de las plataformas recursos, bienes o servicios». Disponible en https://docs.google.com/document/d/1n65MjUaTmRLuZCqTIlqyWvobVqreR-iAzsz1mhxy2y0/edit.

${ }^{4}$ Doménech Pascual, G. «La regulación de la economía colaborativa (El caso «Uber contra el taxi») Ceflegal». Revista práctica de Derecho, 2015, vol. 175-176, 61-104.

5 Comunicación de la Comisión al Parlamento Europeo, al Consejo, al Comité Económico y Social Europeo y al Comité de las Regiones: «Una Agenda Europea para la economía colabo- 
rabiosa actualidad, constituye uno de los primeros documentos europeos que realizan un esfuerzo de comprensión de este fenómeno. Así pues, a los efectos de lo que nos interesa en este trabajo, nos serviremos de la definición que se recoge en Una Agenda Europea (p. 3):

el término economía colaborativa se refiere a modelos de negocio en los que se facilitan actividades mediante plataformas colaborativas que crean un mercado abierto para el uso temporal de mercancías o servicios ofrecidos a menudo por particulares. La economía colaborativa implica a tres categorías de agentes i) prestadores de servicios que comparten activos, recursos, tiempo y/o competencias - pueden ser particulares que ofrecen servicios de manera ocasional («pares») o prestadores de servicios que actúan a título profesional ("prestadores de servicios profesionales»); II) usuarios de dichos servicios; III) intermediarios que -a través de una plataforma en línea- conectan a los prestadores con los usuarios y facilitan las transacciones entre ellos ("plataformas colaborativas»).

El nacimiento de la economía colaborativa pone, pues, sobre el plano jurídico una serie de nuevos e importantes retos: la redefinición de conceptos, deberes y obligaciones contraídos a través de canales no tradicionales, relaciones jurídicas generadas de forma atípica que hasta ahora el derecho no había tenido que regular, ya que no desarrollaban un papel subsumible en la normativa existente o, al menos, no habían generado controversia en cuanto a la resolución de conflictos. Todo ello nos lleva a una cuestión clave: ¿es necesaria la creación de nuevas normas jurídicas que cubran la casuística generada por la economía colaborativa? $\mathrm{O}$, por el contrario, ¿permite la regulación actual nacional e internacional dar respuesta a las situaciones controvertidas que esta nueva forma de acceder a la contratación genera?

Además, surgen nuevas figuras, como las plataformas de economía colaborativa, pilar básico de este fenómeno y a través de las cuales se realizan todas las transacciones que pueden ser consideradas de consumo colaborativo. Es una herramienta sin la cual no estaríamos dentro de este tipo de negocio jurídico. Estas son un instrumento tecnológico y digital que pone en contacto la oferta y la demanda, es decir, a los usuarios. $\mathrm{Y}$ en este contexto se pueden comportar de dos maneras, como intermediarios digitales y como proveedores de servicios. En esta contribución se analiza el primer caso, es decir, la responsabilidad de los intermediarios, cuya actividad fundamental es poner en contacto a los prestadores de servicios que desarrollen una actividad profesional o no profesional en el plano online con los usuarios que demanden el mismo.

Las relaciones jurídicas en la economía colaborativa tienen una estructura triangular, pues se dan relaciones simultáneas entre los tres tipos de agentes intervinientes: la PLATAFORMA (intermediario digital), el PRESTADOR DE SERVICIOS (profesional o particular que oferta un servicio a los usuarios que lo demanden: podrá ser

rativa». Publicado en el Registro de documentos de la Comisión el 2 de junio de 2016. Documento COM (2016)356/F1. En adelante, Una Agenda Europea. 
tanto la propia plataforma como el agente externo que hace uso de ella para desarrollar su actividad profesional) y el USUARIO (entendiendo como tal tanto el consumidor usuario del servicio como el profesional usuario de la plataforma). Es por ello por lo que determinar la responsabilidad de los intermediarios digitales es una tarea ardua, ya que, en esta encrucijada, estos muchas veces no actuarán solo como intermediarios, sino también como prestadores de servicios.

El problema principal que enfrenta la economía colaborativa es la inseguridad jurídica que se produce por la falta de conocimiento para aplicar los marcos jurídicos existentes; ello no significa que se desconozca lo permitido y lo prohibido, sino que una vez que se produce una lesión de derechos, un menoscabo de derechos, no resulta claro a dónde tenemos que acudir para subsanarlo. Tal y como señala la Comunicación en Una Agenda Europea, anteriormente citada, uno de los principales efectos de la economía colaborativa es que se desdibujan los límites establecidos entre pares como consumidor y proveedor, trabajador por cuenta propia y trabajador por cuenta ajena, etc. Este tipo de cuestiones son tratadas en las legislaciones propias de cada país y su diferencia cada vez es menos clara; de esta manera, los derechos y obligaciones de cada una de las partes varían, se transforman y se adaptan al caso concreto.

\section{MARCO NORMATIVO}

En este apartado nos ocuparemos del marco normativo que incide directamente o indirectamente con la responsabilidad. Lo haremos haciendo un repaso de la normativa nacional o internacional que se ha de tener en cuenta a la hora de establecer el régimen de responsabilidad por el que se regirán las plataformas. Para analizar el marco normativo existente se han de tener en cuenta las normas de Derecho Internacional Privado que determinarán la competencia judicial internacional y la ley aplicable. Sin embargo, el supuesto sobre el que se trabaja es que efectivamente conocerá de esta incidencia la normativa española ${ }^{6}$. Por otro lado, dejaremos de lado la normativa específica relativa al tipo de ilícito cometido y analizaremos las normativas que se pronuncian acerca de la responsabilidad de las plataformas.

Ante un sistema en el que se ha de atender caso por caso, ya que dependiendo de los factores que intervengan se abrirá la posibilidad de aplicar unas leyes u otras, lo lógico es abordar su estudio por orden cronológico; de este modo, se podrá comprobar si las distintas problemáticas que suscitaban las primeras legislaciones publicadas han ido siendo subsanadas a lo largo del tiempo ${ }^{7}$.

${ }^{6}$ Se ha de poner de relieve que, tratando el supuesto de hecho desde el inicio, en primer lugar deberíamos acudir al Reglamento Roma I, Reglamento (CE) n. ${ }^{\circ}$ 593/2008 del Parlamento Europeo y del Consejo, de 17 de junio de 2008, sobre la ley aplicable a las obligaciones contractuales, o al Reglamento Roma II, Reglamento (CE) n. ${ }^{\circ}$ 864/2007 del Parlamento Europeo y del Consejo de 11 de julio de 2007, relativo a la ley aplicable a las obligaciones extracontractuales.

7 En este punto es necesario reiterar la corta vida de este fenómeno, por lo que en el transcurso de este breve espacio de tiempo, no es común que se haya publicado normativa que supere e 
2.1. La Directiva 2000/31/CE del Parlamento Europeo y del Consejo, de 8 DE JUNIO DE 2000, Y SU INCORPORACIÓN AL ORDENAMIENTO JURÍDICO ESPAÑOL por la Ley 34/2002 de Servicios de la Sociedad de la Información y de Comercio Electrónico

Todo comienza con la Directiva 2000/31/CE del Parlamento Europeo y del Consejo, de 8 de junio de 2000, relativa a determinados aspectos jurídicos de los Servicios de la Sociedad de la Información, en particular el comercio electrónico en el mercado interior (Directiva sobre el comercio electrónico, en adelante DCE). Propuesta por la Comisión y en virtud del Tratado constitutivo de la Unión Europea, el Parlamento Europeo adopta esta Directiva, reforzando así la idea de la existencia de un único mercado interior europeo sin fronteras ni barreras y garantizando la libre circulación de los servicios de la sociedad de la información en los Estados Miembros. Esta directiva, posteriormente transpuesta por la Ley 34/2002 de Servicios de la Sociedad de la Información y de Comercio Electrónico, se configura como necesaria y susceptible de ser superada en nivel de protección por los Estados Miembros y ha servido para definir nuevos conceptos antes no regulados: servicios de la sociedad de información, prestador de servicios, prestador de servicios definido, destinatario, comunicación, etc.; y también para establecer los principios y requisitos básicos por los que se ha de regir un agente o prestador de servicios para desarrollar su actividad y fomentar la idea de desarrollo del mercado interior.

Antes de analizar en profundidad la Ley 34/2002 de Servicios de la Sociedad de la Información y de Comercio Electrónico (en adelante LSSI), debemos evidenciar que, tal y como señala Montero Pascual $(2017)^{8}$, el iter legislativo con respecto a la conceptualización de SERVICIO DE LA SOCIEDAD DE LA INFORMACIÓN COMO categoría jurídica comienza con la Directiva 98/48/CE 9 , que, a su vez, modifica la Directiva 98/34/CE ${ }^{10}$, calificándolo en su artículo 2 como «todo servicio prestado normalmente a cambio de una remuneración, a distancia, por vía electrónica y a petición individual de un destinatario de servicios. A efectos de la presente definición, se entenderá por "a distancia", un servicio prestado sin que las partes estén presentes simultáneamente; "por vía electrónica", un servicio enviado desde la fuente y recibido por el destinatario mediante equipos electrónicos de tratamiento (incluida la compresión digital) y de almacenamiento de datos y que se transmite, canaliza y recibe enteramente por hilos, radio, medios ópticos o cualquier otro medio electro-

introduzca cambios reales como consecuencia de la problemática existente.

${ }^{8}$ Montero Pascual, J.J. La regulación de la economía colaborativa: Airbnb, BlaBlaCar, Uber y otras plataformas. Tirant lo Blanch, Valencia. 2017.

9 Directiva 98/48/CE del Parlamento Europeo y del Consejo de 20 de julio de 1998, que modifica la Directiva 98/34/CE, por la que se establece un procedimiento de información en materia de las normas y reglamentaciones técnicas, DOCE L 217/18, de 5.8.1998.

${ }_{10}$ Directiva 98/34/CE del Parlamento Europeo y del Consejo, de 22 de junio de 1998, por la que se establece un procedimiento de información en materia de las normas y reglamentaciones técnicas, DOCE 204/37, de 21.7.1998. 
magnético; y por "a petición individual de un destinatario de servicios", un servicio prestado mediante transmisión de datos a petición individual».

La LSSI en su exposición de motivos establece que «se acoge, en la Ley, un concepto amplio de "servicios de la sociedad de la información", que engloba, además de la contratación de bienes y servicios por vía electrónica, el suministro de información por dicho medio (como el que efectúan los periódicos o revistas que pueden encontrarse en la red), las actividades de intermediación relativas a la provisión de acceso a la red, a la transmisión de datos por redes de telecomunicaciones, a la realización de copia temporal de las páginas de Internet solicitadas por los usuarios, al alojamiento en los propios servidores de información, servicios o aplicaciones facilitados por otros o a la provisión de instrumentos de búsqueda o de enlaces a otros sitios de Internet, así como cualquier otro servicio que se preste a petición individual de los usuarios (descarga de archivos de vídeo o audio...), siempre que represente una actividad económica para el prestador». En relación con esto, debemos considerar lo seńalado por Rodríguez de las Heras Ballell (2011), que entiende que se comprenden dentro de esta Ley los servicios no remunerados ${ }^{11}$, siempre que constituyan una actividad económica para el prestador, lo que nos permite un mayor rango de aplicación de la misma ${ }^{12}$. Así, el objetivo de la Ley es claramente la regulación del régimen jurídico de los servicios de la sociedad de la información y la contratación electrónica. Lo que interesa para el análisis de esta Ley es el régimen de responsabilidad que se establece en los artículos 13-17, instituyendo en la misma cinco tipos de prestadores de servicio, subsumibles en cada uno de los artículos, que guían el régimen por el que se han de regir. De esta manera, distingue entre:

a) Responsabilidad de los prestadores de los servicios de la sociedad de la información.

b) Responsabilidad de los operadores de redes y proveedores de acceso.

c) Responsabilidad de los prestadores de servicios que realizan copia temporal de los datos solicitados por los usuarios.

d) Responsabilidad de los prestadores de servicios de alojamiento o almacenamiento de datos.

e) Responsabilidad de los prestadores de servicios que faciliten enlaces a contenidos o instrumentos de búsqueda.

Esta Ley no establece cuál es el régimen por el que se debe regir la responsabilidad de las plataformas, sino cuáles son las exenciones a la responsabilidad.

${ }^{11}$ El prisma de esta afirmación reside en que no ha de ser el destinatario del mismo (el consumidor) el que abone el precio del servicio aun obteniéndolo, como puede ser en el caso de la publicidad y comunicaciones comerciales: no es un servicio remunerado por el consumidor y constituye parte de la actividad económica de la plataforma.

12 Rodríguez de las Heras Ballell, T., «Régimen jurídico de los acuerdos clickwrap y browsewrap». Revista Iberoamericana de Derecho de Autor, 2011-año v, (9), 82-113. 


\subsection{Directiva 2011/83/UE del Parlamento Europeo y del Consejo, de 25 de OCTUBRE DE 2011, SOBRE LOS DERECHOS DE LOS CONSUMIDORES}

Por último, nos encontramos ante la Directiva 2011/83/UE del Parlamento Europeo y del Consejo, de 25 de octubre de 2011, sobre los derechos de los consumidores. El problema que presenta la aplicación de esta directiva a la materia es el ámbito mismo de aplicación de la directiva especifica, que solo será aplicable a los contratos celebrados entre un comerciante y un consumidor; sin embargo, esto no se refleja de manera acertada en la naturaleza de las plataformas de economía colaborativa, ya que pueden ser $\mathrm{C} 2 \mathrm{C} / \mathrm{P} 2 \mathrm{P}, \mathrm{B} 2 \mathrm{~B}$ o $\mathrm{B} 2 \mathrm{C}$ (como vemos, solo aplicaría en el último caso):

a) $\mathrm{C} 2 \mathrm{C} / \mathrm{P} 2 \mathrm{P}$ (consumer to consumer/peer to peer): entre particulares que ejercen de manera puntual el ofrecimiento de servicios a la sociedad de la información.

b) B2B (business to business): entre comerciantes.

c) B2C (business to consumer): entre comerciantes y consumidores.

Aunque por su naturaleza las plataformas de la economía colaborativa están destinadas a tener un modelo $\mathrm{C} 2 \mathrm{C}$, es inevitable que en determinadas plataformas o aplicaciones ${ }^{13}$ exista una tendencia que incluye cada vez más sujetos profesionales o semiprofesionales de la materia ${ }^{14}$, lo que la convierte en una plataforma en la que también se pueden dar relaciones B2C. De manera generalizada, en las plataformas coexisten relaciones $\mathrm{C} 2 \mathrm{C}$ y $\mathrm{B} 2 \mathrm{C}$ sin que haya especial fricción, aunque una de las cuestiones más debatidas acerca de la responsabilidad es si la plataforma debiera distinguir entre profesionales y no profesionales. Recordemos que en la Comunicación de la Comisión Una Agenda Europea se indica que en la legislación de la Unión Europea no se establece expresamente cuándo, en qué momento y bajo qué circunstancias un peer se convierte en un prestador de servicios profesional. En este caso, se ha de estar a los umbrales que establece la legislación interna de cada país.

Como solución a ello, esta Directiva incorpora en su considerando 13 que «un Estado Miembro podrá mantener o introducir normas de Derecho interno que correspondan a las disposiciones de la presente Directiva o a algunas de las disposiciones de la misma respecto de contratos que queden fuera del ámbito de aplicación

${ }_{13}$ Se entiende aquí por aplicaciones lo que recoge el Diccionario de la lengua española de la RAE en la acepción cuarta de la definición de esta palabra: «Inform. Programa preparado para una utilización específica, como el pago de nóminas, el tratamiento de textos, etc.». Disponible en https:// dle.rae.es/aplicación?m=form.

${ }^{14}$ Un ejemplo de ello es la plataforma Airbnb, destinada al alquiler (por días, semanas o meses) de una vivienda que, generalmente, constituye la segunda residencia de los propietarios o bien otra de sus propiedades; en teoría, Airbnb está destinada a consumidores (que, por tanto, no ejercen actividad profesional), quienes establecen una relación que les facilita liberarse de las cargas que puede generar la propiedad y les permite aprovechar bienes que están infrautilizados; en la práctica, cada vez más agentes de la propiedad o inmobiliarios usan esta aplicación para ejercer su actividad profesional. 
de la presente Directiva», entendiendo que los derechos que afectan a los consumidores de los servicios de la sociedad de la información deberán quedar sujetos a esta Directiva, a pesar de no encontrarse en su ámbito de aplicación. Se trata de una Directiva que incorpora derechos para los consumidores de importancia vital, tal y como el derecho de información y desistimiento en los contratos celebrados a distancia o fuera del establecimiento, ámbito en el que se desarrolla la actividad principal de los prestadores de servicios de la sociedad de la información.

Una vez expuesto brevemente el marco jurídico existente hasta ahora, se observan dos aspectos: uno, que la normativa que lo regula no es reciente; y dos, que el crecimiento exponencial de la tecnología (factor determinante de este fenómeno) hace que los presupuestos que se contemplaban hace quince años y que eran susceptibles de regulación han quedado desfasados. Actualmente, y cada vez más, las plataformas de economía colaborativa se comportan tanto como intermediarios como como prestadores de servicios. El hecho de que la normativa existente solo regule la responsabilidad de los intermediarios deriva en que no exista una respuesta homogénea en cuanto a la responsabilidad total. En el momento en el que se introdujo la LSSI, la actividad principal de las plataformas era como intermediarios digitales; tenemos que pensar en herramientas como Google y en la inexistencia de negocios tales como Facebook o Airbnb, que son ejemplos de economía colaborativa recientes y de mayor amplitud, en los que podemos observar cómo sus actividades exceden del comportamiento de intermediario digital puro y pasan a prestar un servicio de la sociedad de la información. Es por ello por lo que, superados actualmente los presupuestos por los cuales se dictaron estas normativas, se hace necesaria una revisión de las mismas.

2.3. Directiva (UE) 2019/770 del Parlamento Europeo y del Consejo, de 20 DE MAYO DE 2019, RELATIVA A DETERMINADOS ASPECTOS DE LOS CONTRATOS DE SUMINISTRO DE CONTENIDOS Y SERVICIOS DIGITALES

De reciente adopción, y aportando mayor luz sobre la materia, la Directiva (UE) 2019/770 del Parlamento Europeo y del Consejo, de 20 de mayo de 2019, relativa a determinados aspectos de los contratos de suministro de contenidos y servicios digitales ${ }^{15}$, introduce en su considerando 18 una nueva vía por la cual los Estados Miembros disponen de la libertad de calificar a los prestadores de servicios como empresarios cuando estos no actúen en «calidad de socio contractual directo del consumidor", pudiendo entonces ser responsables por la no conformidad del suministro de contenidos o servicios digitales a los consumidores, quedando sujetos a

${ }_{15}$ El corpus de esta Directiva contiene, tal y como expresa su artículo 1, «normativa relativa a la conformidad de los contenidos o servicios digitales en el contrato, las medidas correctoras en caso de falta de conformidad o incumplimiento del suministro y las modalidades para exigirlas, y la modificación de los contenidos o servicios digitales». 
la «Responsabilidad del empresario» determinada en el artículo 11 de la Directiva, así como los artículos 12-16 relativos a la carga de la prueba, medidas correctoras por incumplimiento, medidas correctoras por falta de conformidad y ejercicio del derecho a la resolución del contrato, respectivamente. Se establece así una vía de resolución y régimen de responsabilidad que permite una observancia del problema sin la delimitación del caso por caso, previo a la atención de las normativas sectoriales, debido a que el grado de armonización de esta Directiva es pleno, reforzando la seguridad jurídica para consumidores y empresarios.

\subsection{La propuesta de Reglamento de Servicios Digitales (Digital Services Act)}

Por último, y enfocando la vista hacia el futuro, no podemos dejar de mencionar la propuesta de Reglamento de Servicios Digitales (Digital Services Act, en adelante DSA) publicada el 15 de diciembre de $2020^{16}$ por la Comisión Europea, perteneciente al paquete de medidas que tomó forma a raíz de la estrategia Shaping Europe's Digital Future ${ }^{17}$. Esta propuesta de Reglamento tiene como objetivo crear un espacio digital que goce de mayor seguridad jurídica, protegiendo los derechos fundamentales de los usuarios de servicios digitales. En la misma, se contempla una nueva batería de derechos y obligaciones para los proveedores de servicios de intermediación, los proveedores de servicios relativos al alojamiento de datos, las plataformas online y las plataformas online de gran tamaño ${ }^{18}$. De esta manera, la DSA se propone mejorar significativamente los mecanismos de eliminación de contenido ilegal para la efectiva protección de los derechos fundamentales de los usuarios, incluyendo el derecho a la libertad de expresión, a través de siete medidas: a) establecimiento de mecanismos de detección de contenido, servicios o bienes ilícitos por parte de los usuarios o los trusted flaggers (alertadores fiables) ${ }^{19}$, b) nuevas obligaciones sobre trazabilidad de los usuarios comerciales para ayudar a la detección de posibles vendedores de productos ilegales, c) nuevas garantías para los usuarios ${ }^{20}$,

16 Disponible para su consulta en https://eur-lex.europa.eu/legal-content/es/TXT/?qi$\mathrm{d}=1608117147218 \&$ uri $=$ COM\%3A2020\%3A825\%3AFIN.

${ }^{17}$ Esta estrategia se basa en cuatro pilares fundamentales: tecnología al servicio de la sociedad, un entorno de competencia digital económica justa, una sociedad digital sostenible, democrática y abierta y la concepción de Europa como actor digital mundial.

${ }_{18}$ El considerando 54 de la propuesta establece que las plataformas de muy gran tamaño entrańan un riesgo para la sociedad una vez que el número de destinatarios de una plataforma asciende a un porcentaje importante de la población de la Unión que se fija en el 10\% de la población de la Unión, umbral que se deberá mantener actualizado.

19 Nueva figura que introduce la DSA, que permite que una entidad habilitada como tal pueda informar de manera prioritaria a la plataforma sobre el contenido ilícito que la misma aloja, transmite, facilita, etc.

${ }^{20}$ Como, por ejemplo, la posibilidad de impugnar decisiones de moderación de contenidos de las plataformas. 
d) medidas adicionales de transparencia para las plataformas digitales ${ }^{21}$, e) obligaciones para las plataformas muy grandes para evitar abusos en sus sistemas, $\mathrm{f}$ ) acceso por parte de investigadores a datos claves de estas plataformas muy grandes para analizar la evolución de los riesgos online y g) una nueva estructura de supervisión de las plataformas muy grandes adecuada a la actual complejidad del ciberespacio ${ }^{22}$.

\section{LAS PLATAFORMAS DE ECONOMÍA COLABORATIVA. DICOTOMÍA ENTRE EL INTERMEDIARIO DIGITAL Y EL PROVEEDOR DE SERVICIOS}

Las plataformas de economía colaborativa tienen una función que ha sido determinada; nos valemos de nuevo de la definición que establece la Comunicación de la Comisión Una Agenda Europea, que las define como entes que proporcionan un «servicio prestado normalmente a cambio de una remuneración, a distancia, por vía electrónica y a petición individual de un prestatario de servicios, ofrecen un servicio de la sociedad de información ${ }^{23}$. La estructura tripartita de relaciones entre las partes intervinientes, a la que hemos hecho referencia más arriba, hace que conceptos básicos del derecho, como pueden ser consumidor, profesional, proveedor, prestador de servicios, etc., se actualicen, alteren y evolucionen, ya que, como se ha reiterado, sus características principales han ido cambiando. Del mismo modo en que las figuras del profesional y el consumidor se han ido confundiendo, lo cual ha derivado en un nuevo concepto y nueva figura, el prosumer ${ }^{24}$, las figuras de interme-

${ }^{21}$ Contempladas en la propuesta en su Capítulo III, "Obligaciones de diligencia debida para crear un entorno en línea transparente y seguro", estas medidas adicionales hacen referencia a un amplio rango de actuaciones que comprenden desde la emisión de informes por parte de las plataformas digitales de intermediación que contengan información sobre cualquier actividad de moderación de contenidos (incluyendo número de órdenes recibidas por autoridades de los Estados, número de avisos, actividad de moderación realizada por iniciativa propia y número de reclamaciones recibidas), mecanismos de notificación y acción para prestadores de servicios de alojamiento de datos, hasta el envío de una exposición de motivos al destinatario del servicio cuando se retiren elementos de información o se inhabilite el acceso a la misma, entre otros.

${ }^{22}$ Gracias a la creación de un Consejo Europeo de Servicios Digitales.

${ }^{23}$ Definición extraída del art. 2 a) de la Directiva 2000/31/CE.

${ }^{24}$ Concepto que surge para aquellos particulares que actúan como profesionales en un determinado negocio jurídico; por ejemplo, el particular que alquila periódicamente su vivienda a terceros puede ser considerado un prosumer, ya que tiene una cierta experiencia en el tipo de negocio, y además se beneficia de él. No constituye su medio de vida, pero sí le aporta una retribución. Se trata de un particular que está más próximo a nuestro concepto de consumidor que al de profesional. Las cargas, responsabilidades y obligaciones de un profesional, a las que se añade la necesidad de observancia de la legislación que le atańe, resultarían arduas para un peer, que no desempeña esta labor en términos de actividad profesional. Para ahondar sobre este término se recomienda la lectura de Sánchez Carrero, J. y Contreras Pulido, P., «De cara al prosumidor: producción y consumo empoderando a la ciudadanía 3.0». ICONO 14, vol. 10, n. ${ }^{\circ} 3,62-84$. 2012; JARNE Muñoz, P.: «El prosumidor como figura clave en el desarrollo del Derecho de consumo derivado del mercado 
diario digital y proveedor de servicios han terminado fundiéndose, aunque aún no existe un término que lo conceptualice. Pero lo que es cierto es que muchas veces, y cada vez más, estamos ante plataformas (es decir, el instrumento mediante el cual se relacionan las partes) que pueden actuar tanto como intermediario como como prestador de un servicio. E identificar cada situación es de vital importancia para la determinación de la responsabilidad civil de las plataformas, ya que se aplicarían normas distintas para determinarla.

Por tanto, ¿qué sucede cuando una plataforma actúa como un simple intermediario?: aplicamos la LSSI. ¿Qué sucede cuando actúa como un prestador de servicios?: aplicamos las normas estatales sobre responsabilidad contractual y extracontractual, atendiendo a las posibles normas sectoriales que puedan existir (como en el mercado del transporte o del alojamiento vacacional, por ejemplo). Pero ¿qué sucede cuando actúa como ambas?: en este caso, deberemos estudiar cuál es el nivel de implicación de la plataforma (sea prestadora o intermediaria) en el control de los contenidos que aloja, transmite, reproduce, guarda o redirecciona.

Hasta aquí, la definición de un intermediario digital o plataforma de economía colaborativa no parece presentar mayor complejidad; sin embargo, cuando dichas plataformas comienzan a ofrecer el servicio subyacente, es decir, aquel que los prestadores de servicios (ya sean $\mathrm{C} 2 \mathrm{C}$ o $\mathrm{B} 2 \mathrm{C}$ ) proporcionan, la responsabilidad de las mismas se verá incrementada y será difícil de atribuir. Con los presupuestos que contempla la Ley podemos determinarla claramente cuando actúan como una y como otra, pero, cuando están a caballo entre ambas actividades, deberemos atender a otro tipo de consideraciones, de las que nos ocuparemos a continuación.

Existen tres sistemas generales de régimen de responsabilidad ${ }^{25} \mathrm{y}$ dentro de ellos se podrán subsumir los casos diferenciados de intermediarios digitales y prestadores de servicios:

A. Exención absoluta de responsabilidad: se da inmunidad prácticamente absoluta sobre el contenido recabado en las plataformas, siempre que no intervenga sobre el mismo y siempre que, cuando reciba orden de eliminarlo, colabore con la autoridad competente (régimen presente en Chile, Estados Unidos, etc.).

B. Responsabilidad objetiva: se requiere a los intermediarios que monitoreen activamente el contenido de las plataformas, ya que de lo contrario se podrán enfrentar a acciones legales (régimen presente en China).

C. 'Safe harbors' o puertos seguros: los intermediarios serán eximidos de toda responsabilidad siempre que cumplan con los requisitos de notificación y retirada. La notificación y retirada se produce cuando los usuarios alertan a

digital». Revista CESCO de Derecho de Consumo, n. ${ }^{\circ}$ 19/2016, 41-51,2012; y Jarne Muñoz, P. Economía colaborativa y plataformas digitales. Editorial Reus, Madrid, 2020.

25 Tomado de Article 19: «Los intermediarios del Internet: Dilema de responsabilidad -sesión de preguntas y respuestas». Agosto de 2013. Disponible en https://www.article19.org/es/ resources/internet-intermediaries-dilemma-liability-q/. 
la plataforma de la existencia de un contenido presuntamente ilegal, y en caso de que no eliminen el contenido de la plataforma podrán estar sujetos a responsabilidad (régimen presente en Singapur, Ghana, Uganda y la UE).

Pese a que la LSSI habla de cuatro tipos de «agentes» de la sociedad de la información, realmente estos agentes solo hacen referencia a cuatro tipos de intermediarios digitales: operadores de redes y proveedores de acceso; aquellos que realizan copia temporal de los datos solicitados por los usuarios; prestadores de servicios de alojamiento o almacenamiento de datos; y aquellos que facilitan enlaces a contenidos o instrumentos de búsqueda. De la letra de la Ley no se desprende con claridad si se trata de intermediarios digitales puros (aquellos que no prestan el servicio subyacente) o si se trata de prestadores de servicios puros (aquellos que sí lo prestan) hasta que habla del régimen de exoneración de la responsabilidad; es ahí cuando nos damos cuenta de que en el art. 13 de la LSSI se hace referencia a los prestadores de servicios (que no intermediarios digitales) y solo para dejar claro que se regirán por las normativas nacionales en términos de responsabilidad; mientras que para los intermediarios digitales detalla lo que antes denominábamos exoneración de la responsabilidad.

\section{LA RESPONSABILIDAD DE LOS INTERMEDIARIOS DIGITALES Y DE LOS PROVEEDORES DE SERVICIOS}

Para dilucidar la responsabilidad de los intermediarios digitales nos basaremos en la LSSI, ya que esta es la que establece el régimen de responsabilidad, o más precisamente, el régimen de exención de responsabilidad de los intermediarios digitales.

\subsection{Algunas notas previas}

Con respecto a los intermediarios digitales, partimos de la base de la exención absoluta, aunque para que se puedan "activar» estas exoneraciones siempre se debe cumplir con los presupuestos que se contemplan. La LSSI no contiene ninguna norma que afecte directamente a la responsabilidad civil de los proveedores de información: solo se ocupa de los prestadores intermediarios, es decir, de aquellos que no crean la información, sino que se limitan a permitir el acceso o difusión de la misma, diferencia clave que permite la delimitación de la responsabilidad. En el momento en el que la plataforma es creadora del contenido que se difunde o publica, siguiendo las reglas establecidas hasta ahora, será responsable de la ilegalidad del contenido que dicha información contenga. Sin embargo, tal y como apunta Cavanillas Múgica $(2007)^{26}$, que no se nombre en la LSSI a los proveedores de infor-

26 Cavanillas Múgica, Santiago, «La responsabilidad de los proveedores de información en la Ley 34/2002, de Servicios de la Sociedad de la Información y de Comercio Electrónico», en Responsabilidades de los proveedores de información en internet, 2007, pp. 1-39. 
mación en cuanto a la responsabilidad directa que puedan generar no significa que la responsabilidad de estos prestadores no pueda verse afectada indirectamente por la LSSI dada la existencia de lo que denomina como "casos problemáticos»" Para estos casos intermedios, estudia la relación entre la iniciativa del destinatario del servicio, la incorporación de la información mediante enlaces directos, el alojamiento de dichos datos recopilados por el prestador, la pasividad técnica del prestador y los datos proporcionados por el destinatario del servicio. Así mismo, en la obra Grimalt Servera $(2007)^{28}$ analiza otro posible "caso problemático» como es la prensa digital en relación con los servicios de intermediación y la afección indirecta la LSSI con respecto a la Ley 14/1966, de Prensa e Imprenta, con las complicaciones que surgen de la determinación del servicio de prensa digital como servicio de la sociedad de la información.

\subsection{LA RESPONSABILIDAD EN LA LSSI}

Como intermediarios digitales entendemos los operadores de redes y proveedores de acceso, los prestadores de servicios que realizan copia temporal de los datos solicitados por los usuarios, los prestadores de servicios de alojamiento o almacenamiento de datos y los prestadores de servicios que faciliten enlaces a contenidos o instrumentos de búsqueda. Así, los artículos 13-17 de la LSSI contemplan lo siguiente en cuanto a la responsabilidad:

1. Prestadores de servicios de acceso a la Red: dirigido a «operadores de redes de telecomunicaciones y proveedores de acceso a una red de telecomunicaciones que presten un servicio de intermediación que consista en transmitir por una red de telecomunicaciones datos facilitados por el destinatario del servicio o facilitar el acceso a esta. No serán responsables por la información transmitida salvo que ellos mismos hayan originado la transmisión, modificado los datos o seleccionado estos a los destinatarios de dichos datos». Por lo tanto, no serán responsables por el contenido que alojen pero sí tienen un deber de colaboración para/con las autoridades competentes cuando se les requiera interrumpir un servicio o retirar un contenido de la web.

2. Prestadores de servicio de copia temporal: «prestadores de un servicio de intermediación que transmitan por una red de telecomunicaciones datos facilitados por el destinatario del servicio y, con la única finalidad de hacer mucho más

27 Hace referencia a «terceros que hacen llegar una información, por vía electrónica o no, para que la aloje», «autor de una página web que coloca en la misma información tomada de otra fuente, con autorización o no y con cita o no de la fuente empleada" y "prestador de un servicio de foto o blog que se reserva expresamente el ejercicio de una función censora de contenidos ilícitos o incorrectos o que suspende la publicación de mensajes de terceros hasta que han pasado dicho filtro».

${ }^{28}$ Grimalt Servera, Pedro, «La responsabilidad de los proveedores de información en Internet y la Ley 14/1966, de Prensa e Imprenta», en la misma obra, pp. 41-81. 
eficaz su transmisión, almacenan una copia temporal» (memoria tampón o caching); no serán responsables del contenido de esos datos ni de la reproducción temporal siempre que se cumplan las siguientes condiciones, que transcribimos a continuación:

a) No modifican la información.

b) Permiten el acceso a ella solo a los destinatarios que cumplan las condiciones impuestas a tal fin, por el destinatario cuya información se solicita.

c) Respetan las normas generalmente aceptadas y aplicadas por el sector para la actualización de la información.

d) No interfieren en la utilización lícita de la tecnología generalmente aceptada y empleada por el sector, con el fin de obtener datos sobre la utilización de la información.

e) Retiran la información que hayan almacenado o hacen imposible el acceso a ella, en cuanto tengan conocimiento efectivo de:

1. ${ }^{\circ}$ Que ha sido retirada del lugar de la red en que se encontraba inicialmente,

2. ${ }^{\circ}$ que se ha imposibilitado el acceso a ella, o

$3 .^{\circ}$ que un tribunal u órgano administrativo competente ha ordenado retirarla o impedir que se acceda a ella.

3. Prestadores de servicio de alojamiento de datos: prestadores de un servicio de intermediación consistente en albergar datos proporcionados por el destinatario de ese servicio. En este caso, la letra de la Ley no especifica mucho más, por lo que nos encontramos ante la problemática encrucijada de definir exactamente qué es. La misma hace referencia a las actividades de housing y hosting, que las practica cualquier espacio en que se permita a usuarios distintos del administrador incorporar contenidos (por ejemplo: en los foros online se puede publicar una opinión y también facilitar el acceso a archivos). En este caso tampoco serán responsables por la información almacenada a petición del destinatario, siempre que, por una parte, no tengan conocimiento efectivo de que la actividad o la información almacenada es ilícita o de que lesiona bienes o derechos de un tercero susceptibles de indemnización; y, por otra, que si lo tienen, actúen con diligencia para retirar los datos o hacer imposible el acceso a ellos.

Como se observa, de nuevo se establece una presunción de «conocimiento efectivo" condicionada por los siguientes aspectos: a) Un órgano competente debe haber declarado la ilicitud de los datos, ordenado su retirada o que se imposibilite el acceso a los mismos, o se hubiera declarado la existencia de la lesión de bienes o derechos de un tercero susceptibles de indemnización; y b) Que el prestador conociera la correspondiente resolución, sin perjuicio de los procedimientos de detección y retirada de contenidos que los prestadores apliquen en virtud de acuerdos voluntarios y de otros medios de conocimiento efectivo que pudieran establecerse. 
Arroyo $(2020)^{29}$ propone una matización en el análisis y aplicación de la exención de responsabilidad en el caso de los prestadores de servicios de alojamiento de datos, abandonando la clasificación de los mismos según su rol activo o pasivo y reemplazando la misma por la apreciación del «grado de control», «desempeño de funciones editoriales» o "conocimiento efectivo», de los que hablaremos más adelante.

4. Prestadores de enlaces e instrumentos de búsqueda: «facilitan enlaces a otros contenidos o incluyen en los suyos directorios o instrumentos de búsqueda de contenidos». Al contrario que en los casos anteriores, en este punto el legislador español se desvió de lo dispuesto en la directiva comunitaria, que contemplaba la no responsabilidad de este tipo de prestadores de servicios, a la espera de un informe para analizar la necesidad de presentar responsabilidad de los proveedores de hipervínculos e instrumentos de localización. El legislador español, en vez de esperar al informe, utiliza el mismo método que en los artículos anteriores y exime de todo tipo de responsabilidad, siempre que estos «no tengan conocimiento efectivo de la actividad o la información a la que remiten o recomiendan es ilícita, o que pueden lesionar bienes o derechos de un tercero susceptibles de indemnización». Como conocimiento efectivo entiende «la existencia de una resolución de un órgano competente declarando, bien la ilicitud de los datos, ordenando su retirada o que se imposibilite el acceso a los mismos, bien la existencia de la lesión y, en segundo lugar, que el prestador de los servicios conozca esa resolución».

El principal escollo que presenta la aplicación de estos preceptos es la determinación del "conocimiento efectivo", pues no existe una homogeneidad de criterios para resolver si efectivamente se cumple este requisito o no de manera efectiva. En todos los casos analizados, un presupuesto objetivo de esta exención es que haya sido decretada por un órgano o autoridad competente, además de «otros medios de conocimiento efectivo que pudieran establecerse»; sin embargo, esto resulta contradictorio con el principio de notificación y retirada, ya que los propios usuarios podrían haber advertido del contenido ilícito o lesivo presente en la plataforma y esta obviarlo debido a que no proviene de una autoridad competente. En la propuesta de DSA elaborada por la Comisión Europea, se contempla la regulación del estatus de los alertadores fiables o trusted flaggers para que, evitando las posibles situaciones de abuso y menoscabo de derechos fundamentales como la libertad de expresión o el propio derecho a la información, las empresas de gran tamaño ${ }^{30}$ prioricen la retirada de contenido ilícito o el acceso al mismo a través de estas entidades habilitadas, sin perjuicio de las posibles notificaciones que puedan recibir por

29 Arroyo Amayuelas, E., «La responsabilidad de los intermediarios en internet: ¿Puertos seguros a prueba de futuro?». Cuadernos de Derecho Transnacional, 2020, n. . 1, pp. 808-837.

30 Se entienden por estas aquellas con un alcance del $10 \%$ de los 450 millones de usuarios que se estiman en Europa. 
parte de los usuarios individuales que así lo detecten ${ }^{31}$. Cabe la posibilidad de que se den situaciones en las que la plataforma conocía de manera efectiva la presencia de contenido ilícito y obvia su obligación de retirarlo, ya que sigue amparada en las exenciones de responsabilidad al no ser notificada por una autoridad competente, a la espera de una mayor aclaración por parte de la DSA. Al respecto de la LSSI, Peguera Ponch (2007) ${ }^{32}$ llama la atención sobre el hecho de que la jurisprudencia tampoco ha sido uniforme en la interpretación de estos artículos (art. 13-17), que varían desde una interpretación restrictiva (exigiendo la notificación por medio de resolución judicial o administrativa de la existencia de contenido ilícito) a una más amplia (entendiendo que el conocimiento efectivo de contenido ilícito se puede obtener por otros medios $\left.{ }^{33}\right)$.

Juliá-Barceló $(1998)^{34}$, anticipándose con su publicación a la estrategia que se propone actualmente con la DSA, se pronuncia acerca de la falta de regulación del sistema de notificación y retirada, y señala que es necesaria la «creación de un cuerpo especial, cuya composición habría de ser cuidadosamente elegida, encargado de recibir todas las notificaciones y decidir en qué casos debe actuar el proveedor de servicios», concepto que casa con el anteriormente denominado como trusted flaggers. De esta manera, «se tendría al intermediario por notificado, quedando obligado a retirar o bloquear el acceso al material presuntamente ilícito"; sin embargo, el texto actual de la propuesta DSA se aleja de esta imposición para todos los intermediarios digitales, entendiendo que esto puede ser dificultoso (y oneroso) para el intermediario digital medio (que no de gran tamaño), añadiendo una obligación adicional a cumplimentar para poder acogerse a los safe harbors, acreditando que disponen o colaboran con un cuerpo especial para el estudio de las notificaciones por hechos ilícitos.

31 Teniendo en cuenta que se puede dar el caso de repetidas notificaciones injustificadas producidas por usuarios que notifiquen contenidos lícitos de forma abusiva, afectando a los derechos de libertad de expresión o información de otros usuarios.

32 Peguera Ponch, M., (2007): «Sólo sé que no sé nada (efectivamente)»: la apreciación del conocimiento efectivo y otros problemas en la aplicación judicial de la LSSI. Monográfico del «III Congreso Internet, Derecho y Política (IDP). Nuevas perspectivas». Revista de Internet, politica $y$ derecho n. ${ }^{\circ}$ 5. 2007, pp. 2-18.

${ }^{33}$ Parecería que se produce aquí una alteración de la carga de la prueba; sin embargo, atendiendo a la Directiva (UE) 2019/770, relativa a determinados aspectos de los contratos de suministro de contenidos y servicios digitales, su considerando 59 nos indica que «si bien corresponde al consumidor aportar pruebas de que los contenidos o servicios digitales no son conformes, el consumidor no ha de tener que demostrar que la falta de conformidad existía en el momento del suministro de los contenidos o servicios digitales o, en caso de suministro continuo, durante la vigencia del contrato. En su lugar, debe ser el empresario quien demuestre la conformidad de los contenidos o servicios digitales en ese momento o durante ese periodo».

34 Juliá-Barceló, R., «Liability of online intermediaries: An european perspective». European Intellectual Property Review, 1998-Issue 12, pp. 1-9. 
Vistos los presupuestos que determina la Ley, Peguera Ponch $(2001)^{35}$ advierte que en esta directiva se establecen dos supuestos de exención: uno de carácter objetivo, para las actividades de transmisión de datos y provisión de acceso a una red de comunicaciones, ya que solo es necesaria la no modificación de los contenidos; y uno de carácter subjetivo, en el caso de almacenamiento y alojamiento de datos, ya que en estos casos el agente debe cumplir con una cierta diligencia en la prestación del servicio.

Queda manifiesto que la Ley solo se refiere al primero de los agentes, es decir, solo contempla a aquellos sujetos de la sociedad de la información que hayan intervenido como meros intermediarios en el tratamiento de los datos que almacenan y de los servicios que proporcionan. Por tanto, su función es únicamente poner en contacto a los consumidores y/o profesionales para que se produzca la oferta y la demanda, trabajando en un sistema en el que se permite a los interesados realizar las actividades de intercambio de bienes o servicios, ya sean C2C o B2C. El art. 13 de la LSSI hace referencia a los prestadores de servicios, pero solo para dejar claro que estos estarán sujetos a la responsabilidad civil, penal y administrativa establecida con carácter general en el ordenamiento jurídico, sin perjuicio de lo dispuesto en esta Ley. Así, en este caso, el régimen de responsabilidad o las exenciones de la misma no se aplicarán con la misma facilidad que para los meros intermediarios, en el caso de aquellas plataformas que actúen como ambos. Así, se hace necesaria la observación del caso concreto, analizando el hecho que ha desencadenado una posible responsabilidad por parte de la plataforma, y el papel que la misma haya tomado.

\subsection{LA GRAdUACión DE LA RESPONSABILIDAd EN BASE AL CONTROL DE LA PLATA- FORMA}

La Comunicación a la Comisión Una Agenda Europea ofrece una manera de distinguir entre los prestadores de servicios y los intermediarios digitales, y sin embargo la Ley no expone de manera precisa cuándo se trata de uno y cuándo de otro. Esta clara separación pone al descubierto a su vez a aquellas plataformas que comparten rasgos de ambas figuras. Así, en Una Agenda Europea, se fijan tres criterios para determinar el nivel de control de las plataformas:

a. Con respecto al precio: ¿la plataforma fija/no fija el precio final que deben pagar los usuarios por el servicio?

b. Con respecto a las condiciones contractuales: ¿establece términos y condiciones contractuales que determinarán la relación contractual entre el prestador de servicios y el usuario?

35 Peguera Ponch, M., Mensajes y mensajeros en internet: La responsabilidad civil de los proveedores de servicios intermediarios. 2001. 
c. Con respecto a la propiedad de activos clave: :posee activos para prestar el servicio subyacente?; ¿puede prestar el servicio sin necesidad de la actividad de los prestadores de servicio?

Cuando hacemos referencia a un proveedor de servicios nos referimos a un intermediario digital que ha comenzado a ofrecer el servicio subyacente presente en la plataforma. Como vemos, el criterio sobre el que se basa la diferenciación es la instrumentalidad de la propia plataforma.

En este sentido, la Sentencia de 10 de diciembre de 2019, Airbnb Ireland UC, C-390/18, EU:C:2019:1112, dictada por el Tribunal de Justicia de la Unión Europea (de ahora en adelante TJUE), versa, entre otros, sobre el carácter disociable o indisociable de la actividad principal (puesta en contacto de la oferta y la demanda) con respecto a la actividad secundaria (posible prestación del servicio subyacente, en este caso el alojamiento) y, por tanto, el papel de la plataforma hacia la intermediación o la prestación de servicios. Así, la sentencia falla sobre una cuestión prejudicial elevada por el Gobierno francés para la interpretación del artículo 3 de la DCE, relativo a determinados aspectos jurídicos de los servicios de la sociedad de la información en relación con el comercio electrónico en el mercado interior a raíz de una denuncia inicial por la cual se demanda a Airbnb Ireland por haber ejercido desde abril de 2012 hasta enero de 2017 una actividad de intermediación y gestión de inmuebles sin estar en posesión de la acreditación necesaria estipulada en la legislación francesa (tarjeta profesional de agente inmobiliario). El TJUE, para dilucidar sobre la interpretación del mencionado artículo 3 y su aplicabilidad al caso concreto, considera finalmente que Airbnb Ireland es un prestador de servicios de la sociedad de la información y que su actividad es la intermediación entre la oferta y la demanda; citando la propia sentencia: «ese servicio de intermediación es disociable de la transacción inmobiliaria propiamente dicha en la medida en que no solo tiene por objeto la realización inmediata de una prestación de alojamiento", sino también "proporcionar un instrumento que facilite la conclusión de contratos en futuras transacciones». Esta afirmación se basa sobre las siguientes premisas: la actividad de intermediación no es indispensable para llevar a cabo la actividad de prestación del servicio de alojamiento, es disociable de la transacción inmobiliaria objeto del contrato y no ejerce una influencia decisiva sobre las condiciones en las que se ha de desarrollar el servicio de alojamiento ${ }^{36}$, argumentos esgrimidos por la parte demandante para constatar que Airbnb Ireland presta «servicios adicionales característicos de la actividad de intermediación en las transacciones mobiliarias».

Como se observa, estos tres criterios a que aludíamos más arriba inciden de manera directa en el régimen de responsabilidad de las plataformas. La línea divisoria estará en si ejercen una actividad puramente auxiliar o si bien prestan el servicio que

${ }^{36} \mathrm{Si}$ bien es cierto que pone a disposición de los arrendadores de alojamientos servicio de fotografía, plantilla donde pueden definir el contenido del contrato de alojamiento, seguro de responsabilidad civil y garantía por daños, todos ellos de carácter opcional. 
pone en contacto a los usuarios (prestadores de servicio o no). Por lo tanto, cuanto mayor control ejerzan sobre los bienes o servicios que se transmitan a través de la propia plataforma, mayor análisis en cuanto a la graduación de la responsabilidad y posible conocimiento de la ilicitud de sus contenidos generarán. A este respecto, es muy interesante el planteamiento de Rodríguez de las Heras Ballell $(2010)^{37}$, pues supone un cambio en el método de aproximación al problema: en vez de determinar como ilícita una conducta ya realizada, plantea qué acciones pueden llevar a cabo las plataformas para paliar, atenuar o evitar los posibles riesgos derivados del contenido transmitido, alojado, enlazado, etc. Esta autora ofrece cinco estrategias:

1. «Informar al usuario del tipo de servicio que se presta y de las condiciones de prestación.

2. Implantar sistemas de detección y retirada y sistemas de reposición de contenidos retirados o bloqueados.

3. Recurrir preferentemente al uso de enlaces ordinarios.

4. Incluir en un lugar visible y de fácil acceso la política de supervisión y de retirada de los contenidos, aplicable muy especialmente a los casos de foros y chats moderados.

5. Incluir cláusulas razonables de limitación o exoneración de responsabilidad o, en todo caso, de advertencia a los usuarios de las limitaciones propias del servicio (warning terms)».

Todo lo señalado hasta ahora pone de relieve que son necesarios más criterios para poder diferenciar estos dos tipos de agentes intervinientes, ya que el régimen de responsabilidad puede ir desde una exoneración absoluta hasta una pena o multa de consideración, con el añadido de la complejidad que presenta para su tipificación las situaciones en las que un intermediario comienza a proveer del servicio subyacente.

\section{ALGUNAS CONCLUSIONES}

Las plataformas de economía colaborativa implican el nacimiento de un nuevo modelo de mercado nacido a raíz del desarrollo de las nuevas tecnologías de la información y la comunicación, la emergencia de la sociedad de la información y la crisis económica mundial de la última década. Nacida en una época que exigía solidaridad y empatía, la economía colaborativa se presentó como una necesidad de la sociedad para poder aliviar las cargas de las transacciones económicas cotidianas, lo que no excluye que se haya generado un negocio económico de grandes dimensiones que han aprovechado los profesionales del sector en cada caso.

37 Rodríguez de las Heras Ballell, T., «Responsabilidad jurídica de los marcos electrónicos». ICEX eMarketServices. 2010. Disponible en http://www.emarketservices.es/icex/cma/contentTypes/common/records/mostrarDocument o/?doc=4327620. 
Resulta prácticamente imposible para la legislación europea y nacional establecer un régimen de responsabilidad delimitado en el que se pueda subsumir toda la casuística. Es por ello por lo que la Directiva 2000/31/CE y su posterior transposición a la legislación española con la Ley 34/2002 solo se ocupa de las plataformas que actúan como intermediarias puras, ya que tienen unas actividades delimitadas que se han podido distinguir y regularizar. Ello ha dado como resultado que las plataformas que actúan como prestadoras de servicios queden al amparo de la legislación interna de cada país, ya que su casuística es mucho más variada y las actividades que realizan pueden ser de cualquier índole, siempre que exista oferta y demanda.

La LSSI se configuró como una ley que pretendía dar seguridad jurídica al nacimiento de las plataformas electrónicas y las posibles actividades que llevaban a cabo las mismas; sin embargo, a la fecha de publicación de dicha ley, debemos tener en cuenta que no existían plataformas tales como Youtube, Twitter, TikTok, Facebook, etc., plataformas que cambiaron el mercado digital existente en el momento, con respecto a tal y como lo conocemos ahora. Así, define nuevos conceptos, diferencia entre agentes de la sociedad de la información, establece exoneraciones de la responsabilidad, etc. Actualmente la seguridad jurídica que proporcionó ha desaparecido, ya que, al regular tan ambiguamente los preceptos de responsabilidad, no se entiende bien cuáles son los presupuestos para determinarla.

Actualmente la LSSI queda, en cierto sentido, incompleta y ambigua, el cambio del paradigma digital y su crecimiento exponencial plantean situaciones no contempladas en la ley, aunque no debemos dejar de lado que la DCE y su transposición a través de la LSSI han permitido el florecimiento y transformación de los servicios digitales de finales del pasado siglo. En este sentido se pronuncia la Comisión Europea con su comunicación sobre Online Platforms and the Digital Single Market Opportunities and Challenges for Europe ${ }^{38}$ sobre garantizar la conducta responsable de las plataformas en línea.

Aun así, la LSSI no contempla la responsabilidad de los proveedores de servicios, sino solo de los intermediarios que proporcionan la plataforma para el desarrollo de los mismos. El régimen de responsabilidad contractual y extracontractual español es aplicable siempre que no se den las excepciones que la LSSI considera para la exención de la responsabilidad.

Es necesario que el legislador se pronuncie a la hora de establecer criterios para determinar cuándo estamos ante un mero intermediario digital y cuándo estamos ante un real proveedor de servicios. Dejarlo al arbitrio de la legislación interna de cada país puede derivar en una desigualdad importante, pese a estar en el marco común de la Unión Europea. Se producen y se producirán situaciones de abuso de derecho, ya que en determinados territorios será más beneficioso ser un prestador

38 Comunicación de la Comisión al Parlamento Europeo, al Consejo, al Comité Económico y Social Europeo y al Comité de las Regiones: «Las plataformas en línea y el mercado único digital: Retos y oportunidades para Europa». Publicado en el Registro de documentos de la Comisión el 25 de mayo de 2016. Documento $\operatorname{COM}(2016) 288$ final. 
de servicios que en otros, o bien la justicia será más benevolente con la comisión de un ilícito digital en unos países que en otros, y así sucesivamente.

Con respecto a la determinación de la responsabilidad de los proveedores de servicios, entendiendo por tal el intermediario que proporciona el servicio subyacente, la pasividad se revela como un elemento clave para la determinación de la responsabilidad de las plataformas. Así, cuanto más intervenga la plataforma en la regulación de elementos esenciales del contrato, más sujeta estará al régimen de responsabilidad contractual y extracontractual estatal; de la misma manera, cuanto menos intervenga, más difícil será determinar la responsabilidad de la misma.

Recibido: enero de 2021; ACEPTADo: febrero de 2021 


\title{
LA EDUCACIÓN CÍVICO-TRIBUTARIA: \\ UNA ASIGNATURA PENDIENTE Y UN INSTRUMENTO NECESARIO CONTRA EL FRAUDE FISCAL*
}

\author{
Sergio Siverio Luis \\ Profesor ayudante de Derecho Constitucional \\ Universidad de La Laguna
}

\section{RESUMEN}

La educación cívico-tributaria es un instrumento imprescindible para combatir el fraude fiscal, señalado por Sainz de Bujanda como el más potente que existe para acabar con esta lacra. Ello tendría como resultado la eliminación de desconfianzas entre el contribuyente y la Administración, con el fortalecimiento del Estado social y democrático de Derecho. Sin embargo, la implantación de esta pretendida educación fiscal es una asignatura pendiente para Espańa, pues aún no se ha conseguido desarrollar adecuadamente. De esta forma, la educación tributaria se convierte en una necesidad imperiosa para eliminar el fraude fiscal, pues facilitaría el cumplimiento voluntario de las obligaciones fiscales y contribuiría al mantenimiento de un sistema tributario justo, como establece la Constitución.

Palabras Clave: fraude fiscal, educación cívico-tributaria, contribuyente, Administración Tributaria, justicia.

\author{
CIVIC TAX EDUCATION: \\ A FORGOTTEN SUBJECT AND NECESSARY TOOL \\ AGAINST TAX FRAUD
}

\section{Abstract}

Civic tax education is a necessary step in the process of addressing and thusly reducing tax fraud. According to Sainz de Bujanda, it is in fact the most powerful instrument to bring an end not only to tax evasion and fraud but also to the mistrust between taxpayers and the Administration. However, in Spain introducing civic tax education has been a forgotten subject. Thereby, civic tax education becomes a fundamental pillar in improving our country and eradicating tax fraud, by gaining the voluntary compliance to tax obligations. This would contribute to maintaining a fair tax system, as established in the Constitution. KeYwORds: tax fraud, civic tax education, taxpayers, Tax Administration, justice. 


\section{INTRODUCCIÓN}

La participación de la ciudadanía en el esfuerzo común de financiar el gasto público ha estado presente en todos los textos del constitucionalismo español. En el artículo 8 de la Constitución de 1812 se establecía que «está obligado todo español sin distinción alguna a contribuir en proporción de sus haberes para los gastos del Estado", de donde arranca la consagración constitucional del deber que incumbe a todos y todas de ser partícipes en el sostenimiento del gasto público, y que encuentra su último hito, por el momento, en el artículo 31.1 de la Constitución de 1978: «todos contribuirán al sostenimiento de los gastos públicos de acuerdo con su capacidad económica mediante un sistema tributario justo inspirado en los principios de igualdad y progresividad que, en ningún caso, tendrá alcance confiscatorio».

Lo que late en esos preceptos constitucionales es el deber de contribuir, el deber que incumbe a la ciudadanía en su conjunto de participar con sus ingresos en la financiación del gasto público, siendo el tributo el instrumento a través del cual se realiza efectivamente tal deber. De la pluralidad de perspectivas desde las que puede ser analizado el deber de contribuir, en el presente trabajo ponemos el foco en su relación con la educación cívico-tributaria, a fin de explicar cómo en un Estado social y democrático de Derecho, prestaciones patrimoniales que son impuestas coactivamente al ciudadano ha de procurarse que sean cumplidas por éste espontáneamente, desde su convicción de que, más allá de cumplir con un deber que le viene impuesto por la Ley, está realizando el principio de solidaridad, que despliega una fuerza motriz a lo largo de nuestra Constitución, como elemento consustancial al ideal de justicia.

$\mathrm{Al}$ abordar la educación cívico-tributaria, una primera reflexión se impone: no se pretende en estas páginas realizar un análisis de cómo y de qué manera el ordenamiento jurídico establece que deban ser cumplidas las obligaciones y los deberes que, a cargo de los ciudadanos, establecen las normas tributarias; nuestra exposición arranca del concepto de educación tributaria tal como lo construyó a partir de 1966 el profesor Sainz de Bujanda, situándolo en el plano de la «personalidad considerada en bloque, y no al comportamiento de los individuos considerados tan solo como sujetos pasivos de obligaciones o deberes nacidos a su cargo por imperativos de ciertos preceptos del ordenamiento positivo»" La educación tributaria, como precisaba el maestro, es parte de la educación, del proceso educativo que, como destacara García Hoz, busca "una modificación del hombre» que signifique «de alguna manera, un mejoramiento, un desenvolvimiento de las posibilida-

* Este trabajo, que obtuvo el Premio de Estudios Jurídicos Don Felipe González Vicén (2019), forma parte del proyecto de $\mathrm{I}+\mathrm{D}+\mathrm{i}$ denominado «Vulnerabilidad, precariedad y brechas sociales. ¿Hacia una redefinición de los derechos fundamentales?» (PID2020-114718RB-I00), financiado por el Ministerio de Ciencia e Innovación del Gobierno de España. Se ha tratado de mantener, en lo posible, el texto original del trabajo premiado.

${ }^{1}$ Sainz de Bujanda, F., Hacienda y Derecho, Volumen 5. ${ }^{\circ}$; Instituto de Estudios Políticos, Madrid, 1967, p. 84. 
des del ser o un acercamiento del hombre a lo que constituye su propia finalidad. La idea de perfección se encuentra, en suma, en la base del proceso educativo ${ }^{2}$. Si la educación cívico-tributaria persigue la transformación de la ciudadanía, la cuestión radica en dilucidar cuándo deba entenderse que el contribuyente está educado tributariamente, lo que nos sitúa en el plano del perfeccionamiento ético-político del ciudadano en el ámbito tributario.

Ese perfeccionamiento no es predicable en términos absolutos, sino que habrá que analizarlo en sede de un ordenamiento jurídico tributario concreto y desde la perspectiva de los valores y principios constitucionales a los que tal ordenamiento se vincula. En otras palabras: la educación cívico-tributaria es, ha de estar, al servicio del Estado social, tal y como lo proclama y estructura nuestra Constitución.

\section{EL ESTADO SOCIAL COMO ESTADO FISCAL}

En lo que se refiere al artículo 1 de la Constitución, conforme al cual «Espańa se constituye en un Estado social y democrático de Derecho, que propugna como valores superiores de su ordenamiento jurídico la libertad, la justicia, la igualdad y el pluralismo político», ha señalado el profesor Rodríguez Bereijo que no contiene una simple calificación retórica de España como tal Estado social y democrático de Derecho, sino que integra un auténtico principio constitucional que vincula a los poderes públicos. Entiende que el Estado social debe tomar la forma de un Estado fiscal, en el sentido de que las potestades tributarias y de gasto público permiten aportar los elementos necesarios para la consecución de un orden social más justo, en tanto que las políticas que integran el Estado social implican un gasto, cuya financiación demanda recursos financieros que la propia Constitución quiere que preferentemente sean aportados por los propios ciudadanos cumpliendo con el deber de contribuir ${ }^{3}$.

Dada la limitación de recursos, la realización del Estado social dependerá de lo financieramente posible, sin que de ello se pueda derivar, como el propio Rodríguez Bereijo destaca, que se pueda limitar un derecho social constitucionalmente reconocido por una alusión abstracta a una situación de crisis económica. La cláusula constitucional de un Estado social y democrático de Derecho es un concepto abierto a múltiples interpretaciones según las diversas opciones políticas, pero no significa que esté vacío de contenido, pues está garantizado por los valores superiores del ordenamiento jurídico, en su sentido material ${ }^{4}$. Buen ejemplo de ello es lo que expresa la exposición de motivos de la Ley territorial 4/2012, de 25 de junio, de

2 García Hoz, V., Principios de pedagogía sistemática, Rialp, Madrid, 1963, p. 17 (cit. por Sainz de Bujanda, F., op. cit., pp. 99).

3 Rodríguez Bereijo, A., La Constitución fiscal de España, Centro de Estudios Políticos y Constitucionales, Madrid, 2015, pp. 46-47.

${ }^{4}$ Rodríguez Bereijo, A., La Constitución..., op. cit., pp. 48-54. 
medidas administrativas y fiscales ${ }^{5}$; cuando explica las razones para aprobar, en un contexto de profunda crisis económica y financiera, una serie de medidas fiscales a aplicar en la Comunidad Autónoma de Canarias:

Somos los ciudadanos los que hemos sido convocados para realizar conjuntamente el esfuerzo solidario para una mayor contribución al sostenimiento de los gastos públicos, garantizando así con nuestros impuestos el mantenimiento de los servicios públicos esenciales. La reducción de las otras fuentes de financiación, especialmente la reducción impuesta en la participación por la Comunidad Autónoma de Canarias en los ingresos del Estado, aboca a adoptar medidas de incremento de la carga fiscal, pues la alternativa a ello sería el desmantelamiento del núcleo esencial del Estado de bienestar.

En relación con la materia tributaria, Rodríguez Bereijo destaca que toda la Hacienda y el proceso de aplicación de los tributos tienen como fundamento el deber general de contribuir de todas las personas al sostenimiento del gasto público, establecido en el artículo 31 de la Constitución. En una valoración conjunta de los preceptos de nuestra Carta Magna, podemos decir que la Hacienda Pública es, además, un instrumento para la redistribución de la renta y la riqueza para conseguir un orden social más justo e igualitario. Por tanto, la función de los tributos pasa, no solo por la financiación de los servicios públicos o la administración, sino que entronca con la redistribución de la riqueza, pudiendo, en cierto modo, entenderse el Derecho Tributario como un conjunto normativo que afecta, preferentemente, a quien tiene mayor capacidad económica; mientras que el Derecho del gasto público pasaría a ser el conjunto normativo relativo, preferentemente, a quienes menor capacidad económica ostentan ${ }^{6}$. En definitiva, a lo que queremos llegar es a lo que finalmente expresa Rodríguez Bereijo después de desarrollar su teoría acerca del Estado fiscal al destacar como función del Derecho Financiero «no tanto (aunque contenga normas de este tipo) prevenir o reprimir comportamientos desviantes o impedir conflictos o facilitar su arreglo una vez surgidos, como la de repartir los recursos disponibles para influir en las condiciones de vida de la sociedad; estimular, incentivar y promocionar los comportamientos de individuos y grupos sociales considerados económica y socialmente ventajosos»?

Esta cita nos invita a reflexionar brevemente sobre la finalidad del Derecho, una cuestión que debería plantearse cualquier persona que sea o aspire a ser jurista. Federico de Castro dejó escrito que las normas jurídicas no eran fines en sí mismos, sino medios para alcanzar otros fines, teniendo en cuenta que el fin último del Derecho es servir al bien común, reflejando el ideal de Justicia y practicando el ideal de

与 BOE núm. 166, de 12 de julio de 2012.

${ }^{6}$ Rodríguez Bereijo, A., La Constitución..., op. cit., pp. 55-58.

7 Rodríguez Bereijo, A., La Constitución..., op. cit., p. 58. La cursiva es nuestra. 
vida contenido en las normas ${ }^{8}$. Por tanto, nos decía Federico de Castro, autor de obligada lectura para entender la Ciencia Jurídica, que el Derecho no solo debía contener una ordenación jurídica general, sino que debía incorporar un deber de conciencia, insistiendo, pues, desde su posición iusnaturalista, en que se debe moralizar el Derecho ${ }^{9}$; una idea que hemos pretendido plasmar en el presente trabajo, cuando insistimos en que el Derecho Tributario debe tener en cuenta la responsabilidad moral o conciencia fiscal del contribuyente. Federico de Castro sintetiza esta crucial idea expresando lo siguiente: «De modo que el Derecho, y consiguientemente la vida social, quede basado no en la pretendida seguridad resultante de unas reglas mecánicas y abstractas, sino en la seguridad que nace de una conducta moral normal, procurada y amparada por el aparato coactivo del Estado ${ }^{10}$. En este mismo sentido, Sainz de Bujanda comenta que

Efectivamente, el ordenamiento jurídico tributario -como cualquier otra parcela del Derecho- no puede limitarse a ser un espejo en el que se refleje, cuidadosamente articulada, la imagen de un grupo social. Existen, por supuesto, unos condicionamientos sociales del mundo jurídico, pero éste se proyecta hacia arriba, apunta hacia unos ideales que inspiran su misión configuradora de la vida social. Sin ese empuje ascensional, el Derecho quedaría aprisionado en el mundo del ser; perdería, en definitiva, su perfil normativo y su fundamentación axiológica. En definitiva, dejaría de ser Derecho ${ }^{11}$.

A la vista de lo expuesto y entrando ya en la materia del presente trabajo, podemos afirmar que una persona está educada tributariamente cuando tenga interiorizado como valor ético que, desde su posición económica y social ventajosa, ha de participar activamente en el reparto de los recursos disponibles; y diríamos más: que rechace cualquier forma de fraude fiscal. El profesor Sainz de Bujanda vinculó su construcción sobre una teoría de la educación tributaria con el fraude, pues en su artículo "Aspectos de la educación tributaria en España»" ${ }^{12}$ dando por hecho que el fraude fiscal alcanzaba por aquel entonces en nuestro país proporciones considerables, se planteaba si la vía educativa podría ser un instrumento eficaz para luchar contra esta lacra, combatiendo la dialéctica que en más de una ocasión parecía existir entre la percepción por los contribuyentes de un «Estado-ladrón» o "Fisco-usurpador", y la que tendría la Administración Tributaria acerca del ciudadano como un «contribuyente-defraudador». Pasan los años y quizás esa dialéctica a la que se refería Sainz de Bujanda siga presente cuando en la conocida como Declaración de Granada, de 18 de mayo de 2018, se denuncia que «parece que el afán recaudatorio se ha convertido en el único objetivo del comportamiento de los órganos tributarios,

8 De Castro y Bravo, F., Compendio de Derecho Civil, Instituto de Estudios Políticos, Madrid, 1966 (obra original publicada en 1949), pp. 16-17.

9 De Castro y Bravo, F., op. cit., p. 17.

10 De Castro y Bravo, F., op. cit., p. 17.

11 Sainz de Bujanda, F., op. cit., p. 245.

12 Sainz de Bujanda, F., op. cit., pp. 149-318. 
con olvido de los derechos y garantías individuales. Lo que debe ser una función pública que tiene como fin hacer efectiva la tributación de todos de acuerdo con la Constitución y las leyes, se lleva a cabo atendiendo de manera preferente a normas reglamentarias e instrucciones internas que, más veces de las deseables, solo están pensadas para allegar más recursos al Erario público, pero no necesariamente para hacerlo de forma más justa $»^{13}$.

Como en la propia Declaración se dice, países como los centroeuropeos tienen «una ciudadanía convencida de que el cumplimiento de las obligaciones tributarias constituye la mejor arma para alcanzar los objetivos sociales y políticos que debe perseguir una sociedad avanzada, además de constituir la mejor defensa frente a políticas populistas ${ }^{14}$; lo que reiteradamente se ha expresado con frase feliz como se es ciudadano porque se es contribuyente y ambas condiciones personales son indisociables. En nuestra opinión, que nuestra ciudadanía no tenga ese convencimiento viene dado, en gran medida, por la perniciosa tendencia de los discursos políticos a huir de los tributos, en tanto que los gobiernos y las oposiciones se marcan como objetivo la reducción o supresión de éstos, convirtiendo en fin lo que no es sino un instrumento: el objetivo no puede ser reducir o aumentar los tributos, pues la decisión previa es qué nivel y calidad de gasto público se pretende, para a continuación decidir cómo se va a financiar y si es posible alcanzar la correspondiente suma de recursos.

Ése es, entendemos, el quid de la educación tributaria: trasladar a la ciudadanía la unidad inescindible del fenómeno financiero, es decir, que se ingresa para gastar; como la realización de políticas públicas comporta necesariamente un gasto, es preciso obtener los recursos dinerarios para cubrirlo; recursos que se obtienen exigiendo de los ciudadanos que cumplan con su deber de contribuir. De este modo, reducir la intensidad de tal deber comporta necesariamente una menor capacidad de financiación y, por tanto, una correlativa reducción de la intensidad y/o calidad del gasto público; la alternativa a ello es que la huida del tributo venga acompañada de una atracción fatal por los ingresos derivados de la emisión de Deuda pública, con las consecuencias que de ello se derivan.

A la dialéctica descrita por Sainz de Bujanda entre el Estado ladrón o Fisco usurpador y el ciudadano defraudador, ha entrado en juego, en mi opinión, un nuevo papel del Estado como denostador de lo tributario.

13 Rodríguez Bereijo, A., Martín Delgado, J.A., Martín Queralt, J., Tejerizo, J.M., Pérez-Royo, F., Cortés, M., et al., «Declaración de Granada», Revista Española de Derecho Financiero (17-34), n. ${ }^{\circ} 179,2018$, pp. 20-21.

14 Rodríguez Bereijo, A., Martín Delgado, J.A., Martín Queralt, J., Tejerizo, J.M., Pérez-Royo, F., Cortés, M., et al., op. cit., p. 19. 


\section{LA DIALÉCTICA ENTRE LA PRESUNCIÓN DEL ESTADO LADRÓN VS. LA DEL CONTRIBUYENTE DEFRAUDADOR}

Recurriendo a los mecanismos de lo que podría denominarse como psicologismo tributario, el profesor Sainz de Bujanda explicó la problemática relativa a la lucha contra el fraude fiscal situando en el centro de su exposición la dialéctica que se suscitaba entre dos presunciones: la del Estado ladrón o Fisco usurpador, por una parte; y la del contribuyente defraudador, por otra.

Lo primero que hemos de precisar es que Sainz de Bujanda no utiliza el término presunción en un sentido técnico jurídico estricto, sino que, con el mismo, se refería a los estados de opinión, basados en más de una ocasión en meros prejuicios, que incidían decisivamente sobre los comportamientos de los contribuyentes y la Administración Tributaria. Con esas expresiones se refería Sainz de Bujanda a lo que en algunos textos legislativos de aquella época -1966- se invocaba como la «idiosincrasia» del pueblo español, y que, para algunos ciudadanos, servía como cobertura moral con la que justificar el incumplimiento de sus obligaciones fiscales, al mismo tiempo que se diseñaba un modelo de sistema tributario y de gestión del mismo adaptado a la desconfianza que los contribuyentes merecían de la Administración. Esa dialéctica a lo único que conducía era a una degradación de la pedagogía tributaria, pues al mantener esos prejuicios una vigencia secular en el seno de la sociedad y no combatirlos adecuadamente, se mantendría el problema del fraude fiscal en el tiempo "si la Administración no se decide a poner en ello un sincero y decidido empeño $»^{15}$.

\subsection{La PRESUnCión del FisCo USURPADOR O DEL ESTADO LADRÓN}

En primer lugar, Sainz de Bujanda aborda el pensamiento que tenía -tieneuna parte de la ciudadanía acerca del Estado, al considerar que la Hacienda no administra lo suficientemente bien el dinero público que recauda de la ciudadanía a través de los tributos, en tanto que destina buena parte de los ingresos tributarios a gastos que merecen la calificación de improductivos, pues no tienen como fin alcanzar el interés general. Incluso, ese grupo de ciudadanos destaca la falta de honestidad por parte del Estado en la gestión de los recursos públicos ${ }^{16}$.

De esta forma, al presumir algunos contribuyentes que el Estado malgasta el dinero público que detrae de sus economías, encuentran una justificación para incumplir sus obligaciones tributarias; justifican, por tanto, el fraude fiscal en su desconfianza en el Estado para gestionar con responsabilidad los recursos de la colectividad. Al fin y a la postre, presumen que la Hacienda Pública usurpa su dinero para utilizarlo, no en beneficio de la colectividad, como debería, sino,

\footnotetext{
15 Sainz de Bujanda, F., op. cit.; p. 197.
}

16 Sainz de Bujanda, F., op. cit., p. 125. 
todo lo contrario, en cuestiones que no reportan en el bien común y, como consecuencia de ello, se consideran legitimados para no cumplir con sus obligaciones para con el Fisco.

Sainz de Bujanda considera que esta presunción de desconfianza de los contribuyentes en el Estado es una constante que no deja de tener manifestaciones a lo largo de nuestra historia, como lo demuestra la actitud que adoptan algunos sectores de la sociedad ante las propuestas en materia tributaria. Así, la ciudadanía rechaza que sus decisiones económicas sean gravadas para obtener recursos públicos, al entender que existe una desigualdad en la distribución de la carga impositiva, que no cumple con la exigencia de progresividad. Por otro lado, también pone su atención en la inadecuada gestión de los ingresos tributarios, por un lado, señalando los excesos en el gasto por parte del Estado para poner en marcha servicios que se estiman como innecesarios o que podrían ser prestados a menores costes o, por otro, denunciando, desde las concretas posiciones ideológicas, que se utilicen esos recursos para apuntalar y reforzar los privilegios de ciertos sectores, que, en la actualidad, cobran especial relevancia cuando se identifican con los de la clase política.

Todo ello manifiesta, según Sainz de Bujanda, unos efectos profundamente nocivos, entre los que sobre todo destaca, no solo el incumplimiento de las obligaciones tributarias por parte de los contribuyentes o, lo que es lo mismo, el fraude fiscal, sino, lo que es más grave, la falta de confianza de éstos en el Estado como ente que tiene como principal objetivo la gestión responsable de los recursos de la colectividad, a través de la actividad financiera, con vistas a satisfacer el interés general. Se rompe así, en cierta medida, el contrato social en virtud del cual los individuos confían en el Estado para satisfacer sus necesidades colectivas sobre las individuales ${ }^{17}$, a través del pago de los tributos, en los términos previstos en la legislación vigente.

Ante la existencia en la sociedad de esos estados de opinión sobre la actuación del Estado en el ámbito de lo financiero, Sainz de Bujanda considera que lo fundamental no es combatir el fraude fiscal a través de medidas represivas, sino que procede analizar los motivos por los que la ciudadanía incide en tales conductas defraudadoras, siendo uno de tales motivos la presunción a la que nos venimos refiriendo de que el Estado no gestiona bien lo público, por lo que es conveniente combatir estas generalizaciones para generar un cambio de actitud en la población y acabar así con el fraude fiscal. Retomaremos este punto en las soluciones propuestas para erradicar el mecanismo de las presunciones.

Al mismo tiempo que Sainz de Bujanda considera que estas generalizaciones de un sector de la población son rotundamente falsas, aconseja al Estado alejarse de ciertas actividades que alimentan este supuesto prejuicio tan dańino para el Estado de Derecho. Dicho de otro modo, expresa literalmente que «el método educativo por excelencia es la probidad en el manejo del producto fiscal $»^{18}$, lo que

17 Bravo Cucci, J., Derecho Tributario. Reflexiones; Jurista editores, Perú, 2018, p. 28.

18 Sainz de Bujanda, F., op. cit., p. 126. 
coloquialmente se conoce como predicar con el ejemplo, y se refiere concretamente a evitar actividades para favorecer económicamente a determinados grupos o entidades, en lugar de a la colectividad.

\subsection{LA PRESUNCIÓN DEL CONTRIBUYENTE DEFRAUDADOR}

Hemos hablado de una dialéctica, por lo que el mecanismo de las presunciones en el ámbito tributario no se agota con la que acabamos de señalar, sino que a ella se suma la presunción inversa, en virtud de la cual la Administración entiende que el contribuyente es, por norma, un defraudador, es decir, que no cumple con sus obligaciones tributarias. Es lo que algunos autores han venido denominando el principio de la incredulidad sistemática respecto de la veracidad de lo que declaran los contribuyentes y que se utiliza por la Administración como un elemento esencial en el que fundamentar sus medidas represivas para luchar contra el fraude fiscal ${ }^{19}$.

Al presumir la Administración que los ciudadanos defraudan, ineludiblemente, una cierta cantidad de dinero que, por ley, debiera ingresarse en cumplimiento de sus obligaciones tributarias, en el proceso de elaboración de las normas reguladoras de los tributos se aprueban normativas cuyo fundamento está en compensar ese nivel de fraude que se presume, mediante reglas ciertamente injustas, pues no encuentran su fundamento en la realización efectiva de los principios constitucionales tributarios, sino en lograr un nivel de recaudación dado, amortizando, vía normativa, el efecto del fraude. En este sentido, podemos señalar como ejemplos la decisión de elevar las bases imponibles y/o los tipos de gravamen, con el fin de obtener la recaudación esperada en caso de no existir ese supuesto nivel de fraude.

Si nos preguntamos por la intensidad en que cada una de las presunciones que entran en dialéctica despliega sus efectos, Sainz de Bujanda se inclina por dar mayor peso a la del ciudadano defraudador, hasta el punto de que la misma ha quedado recogida expresamente en textos positivos en más de una ocasión. Cabe señalar al respecto la Ley de 26 de diciembre de 1957, por la que se formalizó una de las grandes reformas de nuestro sistema tributario ${ }^{20}$, en la que, al asumir el legislador la presunción del contribuyente defraudador, se instauró, como fórmula de lucha contra el fraude, el régimen de convenios y evaluaciones globales sobre cuotas y bases, mediante cálculos que, en determinados casos, se llevarían a cabo a través de decisiones tomadas por un Jurado tributario, al margen de la propia estructura del tributo, sin que apenas quedase posibilidad para probar lo contario por parte del contribuyente, pues tales Jurados tomaban sus decisiones en conciencia, cuestión que poco los apartaba de los Tribunales de honor.

19 Sainz de Bujanda, F., op. cit., p. 129.

${ }^{20}$ Ley de 26 de diciembre de 1957, por la que se aprueban los Presupuestos Generales del Estado para el bienio 1958-1959, y reformas tributarias (BOE núm. 323, de 27 de diciembre de 1957). 
Pues bien, esta presunción, al igual que la del Estado ladrón o Fisco usurpador, ocasiona efectos profundamente nocivos para la educación tributaria y el valor de solidaridad que debe fundamentarla; a mayor abundamiento, incorporar a nuestra legislación la presunción del ciudadano defraudador como eje matriz de la misma lleva, paradójicamente, al efecto contrario al pretendido, pues el ciudadano, a la vista de decisiones normativas que alteran el adecuado juego de los principios tributarios, se siente legitimado para incorporar por su parte la distorsión en la declaración de sus datos fiscales. Dicho de otro modo: si los contribuyentes, incluso los cumplidores, toman conciencia de que la Administración, para obtener una determinada recaudación, presupone un nivel de fraude en sus declaraciones, aquéllos reducirán la cuantía de las mismas, por lo que se incurrirá en lo que precisamente se pretendía evitar: la mentira fiscal, el fraude fiscal. La vacuna acaba convirtiéndose en el veneno que corroe a nuestro sistema tributario. Se trata, por tanto, de un ciclo sin fin de recíprocas desconfianzas, que, en lugar de frenar, dan aliento a las conductas defraudadoras, provocadas por la falta de educación cívico-tributaria.

\subsection{VISIÓN GLOBAL SINTETIZADORA DE LAS PRESUNCIONES}

Antes de abordar las soluciones planteadas para resolver el problema expuesto, parece adecuado que tengamos una visión global que sintetice el mecanismo de las presunciones sobre los comportamientos y actitudes de contribuyentes y Administración, respectivamente. Sainz de Bujanda resume a la perfección lo que he tratado de explicar con estas certeras palabras:

El contribuyente, de una parte, oculta la riqueza imponible, porque presume que el Fisco no reparte equitativamente la carga fiscal o no emplea con justicia las sumas que obtiene, y, de otra parte, la Hacienda concede escaso valor -tanto en el terreno normativo, como en la aplicación práctica- a las declaraciones y a los datos que el contribuyente le procura, porque presume que éste defrauda. En la medida en que ambas presunciones se dilatan y vigorizan, decrece la educación tributaria, hasta casi desaparecer cuando aquéllas se generalizan, esto es, cuando los supuestos en los que no operan son tan escasos que su intervención puede reputarse nula o insignificante a la hora de caracterizar un sistema tributario o unos hábitos fiscales ${ }^{21}$.

En la línea marcada por Sainz de Bujanda, podemos comprobar a partir del esquema de la página siguiente (ilustración 1), de elaboración propia, cómo funciona la dialéctica de las presunciones que ya explicó a mediados del siglo pasado el hacedor de la teoría a partir de la cual hoy realizamos la presente investigación:

${ }^{21}$ Sainz de Bujanda, F., op. cit., p. 196. La cursiva es nuestra. 


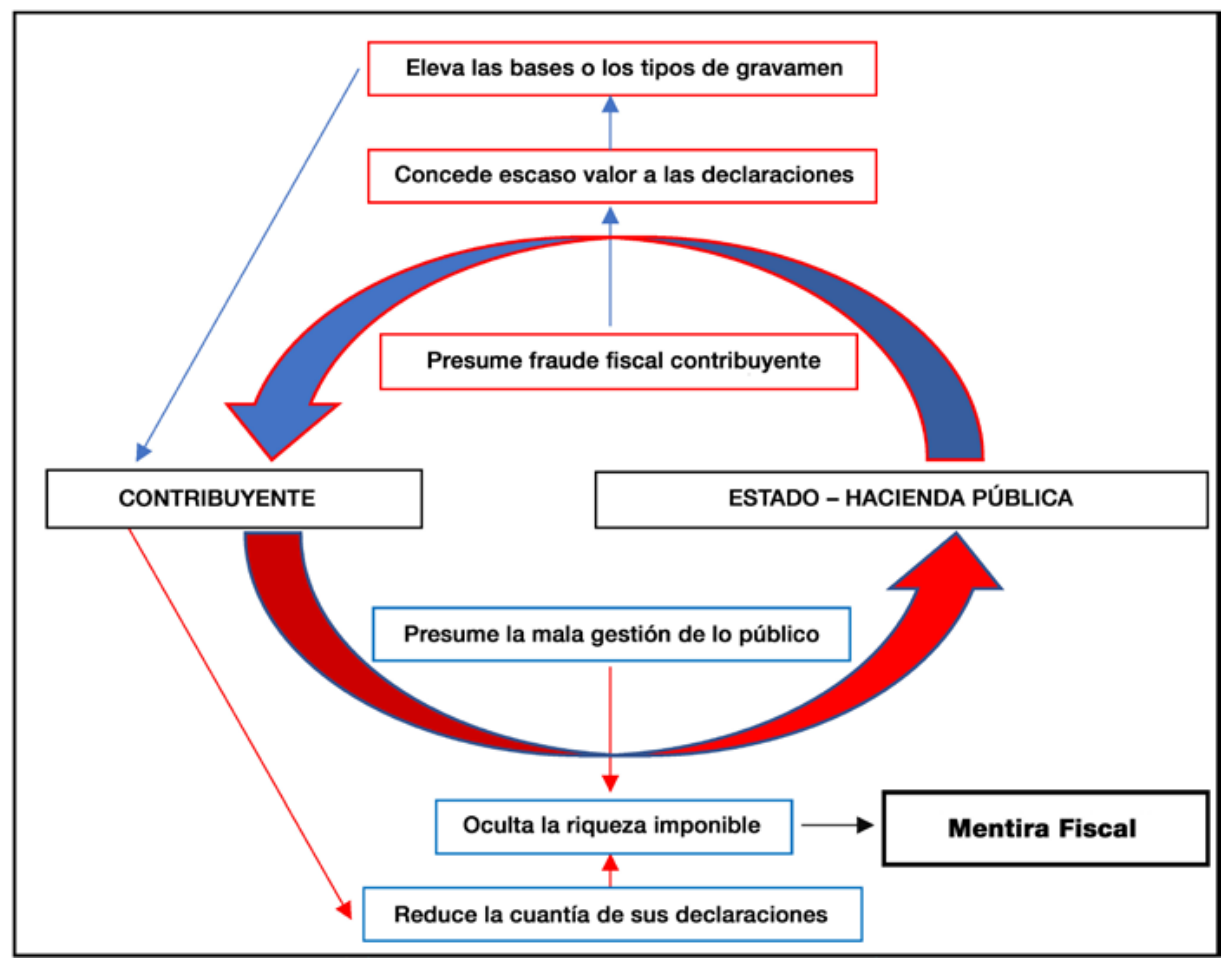

Ilustración 1. Esquema del mecanismo de las presunciones de Sainz de Bujanda. Fuente: elaboración propia.

\subsection{REMEDIOS PROPUESTOS PARA RESOLVER ESTE PROBLEMA DESDE LA EDUCACIÓN} TRIBUTARIA Y SUS PREVISIBLES RESULTADOS

Tras estudiar detalladamente los efectos de las presunciones del Estado ladrón o Fisco usurpador y del ciudadano defraudador en lo que respecta a la aplicación del sistema tributario y, por extensión, en la elaboración de la normativa tributaria, Sainz de Bujanda pasó a centrar su atención en la exposición de algunas medidas que pudieran ser utilizadas para erradicar tales presunciones y los nocivos efectos que las mismas generaban. En todos estos posibles remedios encontramos una línea de pensamiento que los cohesionan, ya que todos ellos quedan al servicio de profundizar en la educación tributaria, por lo que el profesor pone sobre la mesa los resultados que pueden derivarse de la introducción de una educación tributaria de signo social en España.

En primer lugar, para acabar con la presunción del Estado ladrón o del Fisco usurpador, Sainz de Bujanda propone trabajar en dos vías diferentes: el fortalecimiento de la justicia distributiva en la imposición y el refuerzo de la institución 
presupuestaria. Parece lógico que, si la ciudadanía desconfía de la Administración porque entiende que hay un reparto injusto y desigual de la carga impositiva, la tarea del legislativo ha de centrar sus esfuerzos en mejorar la justicia en la imposición.

En este sentido, la ciudadanía ha asumido que, por lo general, contribuye en demasía a las arcas públicas a través de sus ingresos tributarios, pues, en tanto que desconoce la comparación entre su contribución y la del resto de ciudadanos, presume lo que escuchamos de forma cotidiana con expresiones como la de «los ricos no pagan». Lejos de entrar a valorar si esta opinión generalizada es o no correcta, lo cual debería ser objeto de un análisis exhaustivo más propio de la Ciencia de la Hacienda Pública, lo cierto es que más allá de los slogans resulta imprescindible la realización de estudios por parte de la Universidad o del Instituto de Estudios Fiscales, en los que se acredite de forma fehaciente la contribución de la ciudadanía por tramos de renta, integrando la carga tributaria total -impuestos directos e indirectos-; y centrándose en los contribuyentes personas físicas, sin mezclar a éstos con la contribución de las sociedades -que es una contribución medial, pues, en definitiva, la renta es en última instancia del socio y no de la sociedad-. Así, resultaría más provechoso en cuanto a la educación tributaria de los contribuyentes que, en lugar de colocar en el centro del debate público las decisiones políticas sobre la dicotomía de subir o bajar los impuestos, se explicase de forma clara y concisa a la ciudadanía, por ejemplo, el concepto y funcionamiento de los impuestos sobre el consumo, y de la operativa del sistema de retenciones a cuenta y su efecto «a devolver» en la correspondiente autoliquidación del Impuesto sobre la Renta de las Personas Físicas.

En concreto, Sainz de Bujanda se detiene en los mecanismos que nos permitirían reforzar la visión de la ciudadanía en el Presupuesto como institución, remedio en el que nos centraremos especialmente por su importancia capital para la disciplina jurídica sobre la que versa este trabajo. Según el profesor, para acabar con la presunción del Estado ladrón o Fisco usurpador, debe reforzarse la institución presupuestaria, a través de la transparencia y la publicidad, mediante la información, de forma clara y sencilla a la ciudadanía, de los ingresos obtenidos y los gastos efectuados, así como la afectación de los ingresos a destinos que vengan previamente determinados de forma específica en el Presupuesto, sobre todo si estos ingresos tributarios se producen como consecuencia de la prestación de servicios públicos ${ }^{22}$.

Como sabemos, el Presupuesto ${ }^{23}$ es, antes que nada, una norma jurídica, por cuanto podemos definirlo, según Rodríguez Bereijo, como «el acto legislativo mediante el cual se autoriza el montante máximo de los gastos que el Gobierno puede realizar durante un período de tiempo determinado en las atenciones que detalladamente se especifican y se prevén los ingresos necesarios para cubrirlos» ${ }^{24}$. De esta forma, Rodríguez Bereijo expresaba que el Presupuesto del Estado abarca el ciclo

22 Sainz de Bujanda, F., op. cit., pp. 217-223.

23 Escribimos Presupuesto así, con mayúsculas, siguiendo a los autores que citamos en estas líneas, por estarnos refiriendo al Presupuesto del Estado como institución jurídica.

${ }^{24}$ Rodríguez Bereijo, A., El Presupuesto del Estado, Tecnos, Madrid, 1970, p. 19. La cursiva es nuestra. 
financiero completo, desde la detracción de riqueza de las economías privadas para convertirla en ingresos públicos, con el fin de cubrir los gastos propios de las necesidades colectivas, hasta la transformación de dichos ingresos en servicios públicos ${ }^{25}$; una idea que pone el foco en la unión inexorable existente entre el ingreso y el gasto.

Sin embargo, también debemos decir que el Presupuesto, además de una norma jurídica, es un documento informativo, en tanto que en el mismo se refleja el programa de actuación que el legislativo marca al ejecutivo para un ejercicio determinado, de suerte que el contribuyente ha de ser capaz de derivar del mismo las acciones que el ejecutivo ha de realizar; y es, en este sentido, a lo que se refiere Sainz de Bujanda cuando destaca que debemos profundizar en la publicidad del Presupuesto para que la ciudadanía tenga suficiente información acerca del destino de los gastos públicos, en aras de la eliminación de la presunción del Estado ladrón o Fisco usurpador. Rodríguez Bereijo entiende también que una estructura presupuestaria debe responder, entre otras, a la exigencia de ofrecer el cuadro más exacto posible de los ingresos y gastos públicos a realizar durante el ejercicio presupuestario, con un grado suficiente de especificación, con el fin de que los contribuyentes conozcan la distribución de los impuestos que inciden sobre sus economías ${ }^{26}$; ingresos públicos que deben servir para la satisfacción de necesidades públicas a través del gasto.

Por otro lado, Sainz de Bujanda aclaraba a este respecto que «es ineludible no confundir la propaganda con la información $\aleph^{27}$, teniendo en cuenta que la primera no ayuda en nada a la ingente tarea que tenemos por delante para erradicar la dialéctica de las presunciones, mediante la educación cívico-tributaria. Es a lo que también se refiere Ferreiro cuando critica el recurso frecuente en el ámbito fiscal a "normas propaganda», es decir, normas vacías de un contenido jurídico que no incorporan innovaciones en el ordenamiento que las haga realmente necesarias, sino que pretenden fundamentalmente "la propaganda política de la acción del Gobierno", lo cual complica la sencillez del sistema tributario, teniendo en cuenta que éstas no añaden nada al contenido de la ley, sino, más bien al contrario, la complican y la convierten en ininteligible para la ciudadanía ${ }^{28}$. Un ejemplo de ello, en el ámbito que nos ocupa en estas líneas, es una campaña impulsada en 2019 por la Consejería de Economía y Hacienda del Gobierno de Canarias, titulada literalmente «Bajamos los impuestos", que tenía como objetivo difundir información sobre las ventajas fiscales para los contribuyentes introducidas en los Presupuestos Generales de la Comunidad Autónoma ${ }^{29}$. No entraremos a valorar los objetivos de las medidas fiscales que

25 Rodríguez Bereijo, A., El Presupuesto..., op. cit. p. 15.

${ }^{26}$ Rodríguez Bereijo, A., El Presupuesto..., op. cit., pp. 23-38.

27 Sainz de Bujanda, F., op. cit., p. 133.

${ }^{28}$ Ferreiro Lapatza, J.J., Ensayos sobre metodología y técnica juridica en el Derecho Financiero y Tributario, Marcial Pons, Madrid, 1998, pp. 36-37.

${ }_{29}$ Toda la información sobre la campaña acerca de la rebaja fiscal está disponible en https:// bit.ly/2oQgTzV. 
pretende difundir esta campaña ${ }^{30}$, los cuales, según la misma, pasan por la recuperación económica de las familias y la redistribución de la riqueza, a través de una serie de exenciones en el Impuesto General Indirecto Canario (IGIC) y de deducciones en la cuota íntegra del Impuesto sobre la Renta de las Personas Físicas (IRPF); pero resulta cuando menos llamativo que todo cuanto pretende transmitir el Gobierno a la ciudadanía con respecto a los presupuestos (con la importancia que trae consigo, como ya hemos destacado, esta institución) es que se van a bajar los impuestos, con un lema que parece más propio de una publicidad bancaria que de un ejecutivo autonómico ("con las nuevas ventajas fiscales, tú sales ganando»), en lugar de informar con claridad a los ciudadanos a través del Presupuesto acerca de los servicios y bienes públicos que se van a suministrar, esto es, de las políticas que ha de ejecutar el Gobierno por mandato del Parlamento expresado en la Ley de Presupuestos, es decir, en qué se van a emplear los recursos públicos obtenidos a través de los tributos pagados por los contribuyentes; un método educativo que, como ya comentamos, es una de las recomendaciones que propone Sainz de Bujanda como remedio a los problemas a los que nos hemos referido, para potenciar la conciencia tributaria.

Esta actitud de los partidos políticos -y, creemos que podemos afirmar, sin excepción alguna- hacia lo tributario, proponiendo respecto de los mismos reducciones sucesivas, y presentando ante los ciudadanos como un éxito cualquier rebaja fiscal, es el peor servicio que pueda prestarse a los objetivos de una pedagogía tributaria, pues sucesivas medidas legislativas únicamente orientadas a satisfacer las exigencias del marketing, tomadas en más de una ocasión a demanda de grupos de presión, desdibujan lo que es la lógica interna que debe presidir un conjunto de tributos merecedor de la calificación de sistema tributario. En la situación que describimos lo que encontramos es lo que la ciencia política explica como la sustitución del político de oferta-aquél que es capaz de diseñar una propuesta de configuración de la sociedad-por el político de demanda-que, carente de proyecto, se limita a recibir lo que la sociedad quiere y responderle dándole satisfacción-; cuando desaparecen

${ }^{30}$ Aunque sí que debemos alertar sobre los peligrosos efectos que tendría para nuestros servicios públicos la decisión de proceder a una bajada de impuestos, lo cual finalmente no beneficiaría a la población. No debemos olvidar que la Consejería de Hacienda realiza una labor instrumental en la estructura orgánica del Gobierno de Canarias, pues su objetivo no es otro que el de recaudar los recursos suficientes para financiar los servicios públicos, que serán ejecutados por el resto de consejerías del ejecutivo autonómico (en una actividad finalista). En este sentido, el Gobierno, para optar por bajar los impuestos, debe informar a la ciudadanía sobre dos cuestiones previas: o bien ha logrado que los servicios públicos se presten a un menor coste, necesitando menos recursos para la prestación de los mismos; o bien va a reducir la cobertura y calidad de los servicios públicos, al dotarlos de una menor financiación, ante la falta de recaudación que supone dejar de percibir ingresos tributarios a causa de la bajada de los impuestos (también podría informar, en su caso, de que ha obtenido ingresos por otras vías distintas de la preferente para la financiación de los gastos públicos). Resulta como mínimo cuestionable que, con la situación en la que se encuentra actualmente nuestra Comunidad Autónoma con respecto a los servicios públicos (listas de espera en la sanidad, recortes en educación y dependencia...), sea conveniente la bajada de los impuestos, pero resulta aún más preocupante que el Gobierno no haya explicado los motivos (más allá de los meramente propagandísticos), en la línea de los comentados, que le llevan a tomar esta decisión. 
las propuestas de configuración de la sociedad, lo que desaparecen son los ideales éticos y de justicia. Una vez más, Sainz de Bujanda supo describir la situación en la que hoy nos encontramos:

Sólo en la medida en que esos ideales éticos y de justicia estén presentes en la tarea legislativa, actuará ésta como instrumento de educación tributaria, y esa misión habrá de cumplirla aún a costa de inevitables choques y enfrentamientos con aquellos sectores sociales que más llamados estén al sacrificio, para que el mejoramiento de la vida colectiva llegue a producirse. A la inversa, en la medida en que la legislación renuncie a ejercer su función configuradora del contorno social, y busque tan sólo en éste la línea de menor resistencia, su papel será negativo en el proceso de la educación tributaria. Dado que entonces la propia normativa vendrá a consolidar toda clase de egoísmos y de corruptelas ${ }^{31}$.

Es por esto por lo que a la dialéctica que planteaba el profesor entre el Estado ladrón y el contribuyente defraudador, entendemos que en los momentos actuales hay que sumar la realidad de un Estado denostador de lo tributario, que no implícitamente, sino de manera expresa y clara, ha adoptado una posición beligerante contra lo tributario. Con tal posición, los poderes públicos -y los partidos políticos, ya estén en la oposición o en responsabilidades de Gobierno- lo que han hecho es sembrar la simiente que ha ido germinando en una actitud cada vez más reacia por la ciudadanía hacia los tributos.

A los remedios planteados por Sainz de Bujanda para acabar con la presunción Estado ladrón, entiendo que cabría sumar, con respecto al presupuesto, específicamente en el ámbito municipal, dada su complejidad en niveles territoriales superiores, el impulso de medidas como la participación ciudadana en la toma de decisiones sobre el destino de los gastos públicos con iniciativas, por ejemplo, como la de los presupuestos participativos, que no solo fomentarían la publicidad, sino también la corresponsabilidad de la ciudadanía, en la gestión de los recursos públicos ${ }^{32}$. En el sentido expuesto, el artículo 17 de la Ley 7/2015, de 1 de abril, de los municipios de Canarias ${ }^{33}$, plantea como uno de los medios para el ejercicio de la participación ciudadana en los Ayuntamientos de Canarias los presupuestos participativos (Art. 17.1, letra L, de la Ley), para que, a través de las Juntas de Distrito, Consejos de barrio o sector, Consejos de participación ciudadana o asociaciones vecinales, la ciudadanía pueda «formular programas de necesidades vecinales valorados económicamente que, una vez aceptados por el órgano correspondiente de los citados, serán elevados al Área de Gobierno competente en materia de hacienda para su consideración y, en su caso, integración en el presupuesto general de la corporación».

31 Sainz de Bujanda, F., op. cit., pp. 245-246.

32 Calvo Vérgez, J., La experiencia de los presupuestos participativos en los entes locales; Colección Fiscalidad Dykinson, Madrid, 2011, pp. 81-83.

${ }^{33}$ BOC núm. 70, de 14 de abril de 2015; BOE núm. 101, de 28 de abril de 2015. 
Por otro lado, la extirpación definitiva de la presunción, en este caso, del contribuyente defraudador, imprescindible para implementar y mejorar la educación tributaria, debería pasar, según Sainz de Bujanda, por el reconocimiento de la personalidad moral del contribuyente ${ }^{34}$. Ello exige que el Estado cambie su actitud de desconfianza hacia el ciudadano y, en lugar de mostrar una incredulidad sistemática respecto de lo declarado por los contribuyentes, opte por una «sistemática certidumbre de la veracidad" acerca de sus declaraciones. Es decir, pasar de la presunción contribuyente defraudador a la presunción contribuyente fiel cumplidor de la ley tributaria. Y, a pesar de que considera que esta presunción está mucho más cercana a la realidad que la primera, entiende que debemos poner el foco de forma ineludible en la educación tributaria (y no únicamente en los mecanismos sancionadores) para combatir el fraude fiscal ${ }^{35}$; una cuestión a la que nos referiremos posteriormente al abordar el recurso cada vez más frecuente de la Administración Tributaria a la hora de facilitar el cumplimiento voluntario de los contribuyentes de sus obligaciones tributarias.

Por último, después de plantear éste y otros problemas que perjudican a nuestro sistema tributario (como los peligros del psicologismo fiscal o la escasa política de información tributaria), cuya solución pasa ineludiblemente por el fomento de la educación tributaria, Sainz de Bujanda recoge los principales resultados que, a su juicio, traería consigo para el conjunto de la sociedad el logro de un mejor nivel educativo de los contribuyentes, los cuales esbozaré brevemente a continuación:

a) Justicia y racionalidad del sistema tributario. Un contribuyente tributariamente educado cumpliría con sus obligaciones tributarias, siempre que sean planteadas como idóneas para los fines de justicia y eficacia propios de los tributos. Para lograr la racionalidad del sistema tributario hay que poner el énfasis en los principios de solidaridad y de responsabilidad moral.

b) Simplificación de la Administración financiera. La racionalidad del sistema favorecerá la simplificación de la Administración que lo aplica, que centrará su atención en el perfeccionamiento de las figuras tributarias y no en la persecución del contribuyente, cuya oposición al Fisco se reducirá.

c) Reducción de la conflictividad tributaria. El fin de las desconfianzas entre contribuyentes y Administración Tributaria disminuirá los conflictos jurídicos, logrando que los procesos tributarios tengan un alcance estrictamente interpretativo ${ }^{36}$.

${ }^{34}$ Nos genera ciertas dudas la referencia que hace Sainz de Bujanda a la personalidad moral del contribuyente, pues consideramos que, en realidad, se refiere, como ya lo hace en otras ocasiones, a su responsabilidad moral, haciendo alusión a una consideración de la ética de los contribuyentes como uno de los presupuestos de la educación tributaria. No obstante, hemos preferido mantener lo expresado literalmente por el autor, con los matices que hacemos constar en esta nota.

35 Sainz de Bujanda, F., op. cit., pp. 223-228.

36 Sainz de Bujanda, F., op. cit., pp. 137-141. 
No cabe dar por concluida esta primera parte del análisis de la construcción del profesor Sainz de Bujanda sobre la educación tributaria sin exponer lo que él considera que supone ser un contribuyente educado. Esa cualidad del contribuyente no solo tiene que ver con el cumplimiento de las obligaciones tributarias, sino también con la resistencia u oposición a las actitudes injustas por parte de la Administración Tributaria; añadiríamos por nuestra parte que esa doble perspectiva de la cualidad de educado es la que se corresponde con un contribuyente que, antes que tal, es ciudadano:

El contribuyente, en suma, sólo estará bien educado si, además de cumplir las obligaciones y deberes que el ordenamiento le impone, está dispuesto a velar para que los órganos administrativos actúen con arreglo a Derecho, atajando, con los pertinentes remedios jurídicos, cualquier aplicación arbitraria del tributo. En términos pedagógicos, diríamos, pues, que el contribuyente no está sólo facultado, sino obligado, a exigir que la Administración se comporte con corrección jurídica. El incumplimiento de esta obligación es tan grave-tal vez más grave-que el fraude del tributo ${ }^{37}$.

Se trata, por tanto, como bien expresa el profesor, de una cuestión bidireccional: el Estado debe poner en marcha los mecanismos educativos para que las personas puedan ser contribuyentes tributariamente educados, pero el resultado de esta estrategia no solo debe generar el respetuoso cumplimiento de las obligaciones fiscales por parte del pueblo, sino también la enérgica oposición de éste a cualquier posible vulneración por parte de la Administración de los principios que construyen lo que nuestra Carta Magna denomina sistema tributario justo.

Esta premisa entronca directamente con la concepción dogmática del tributo en relación con la categoría jurídica de la obligación que tan acertadamente introdujo en nuestro país Sainz de Bujanda. El tributo no es, como defendía Otto Mayer en el siglo XIX, una simple relación de poder, en la que el individuo está vinculado al Estado por una situación jurídica de sujeción general, en virtud de la cual quedaba sujeto a obedecer y cumplir las pretensiones de la Administración financiera, por una cuestión de supremacía. Cuando decimos que el contribuyente no solo tiene la posibilidad de cumplir sus obligaciones, sino la obligación de resistir ante las injusticias, estamos diciendo, como bien nos explica Nawiasky ${ }^{38}$, que el contribuyente (acreedor tributario) está en un plano de igualdad con la Administración (deudor tributario), pues ambos quedan sujetos de igual manera en cuanto a sus derechos y obligaciones al Derecho, sus posiciones jurídicas derivan de las normas del ordenamiento jurídico; de tal forma que es falso que el Estado esté en una posición superior al deudor, pues debe ajustarse a la estricta aplicación de las normas jurídicas que, como ya hemos dicho, vinculan igualmente al ciudadano y a la Administración.

37 Sainz de Bujanda, F., op. cit., p. 155. La cursiva es nuestra.

${ }^{38}$ Nawiasky, H., Cuestiones Fundamentales de Derecho Tributario (Juan Ramallo, trad.), Instituto de Estudios Fiscales, Madrid, 1982 (obra original publicada en 1926), pp. 52-54. 
Al fin y al cabo, volviendo a lo que exponía Sainz de Bujanda, la educación no significa únicamente enseñar a obedecer, sino a tener pensamiento crítico, a reflexionar y a dudar. Significa enseñar a cumplir, sí, pero también a resistir con todos los medios admitidos en Derecho ante las injusticias. Dicho de otro modo, en palabras de Sainz de Bujanda: «Despertar y avivar la conciencia, en vez de adormecerla, es el gran método educativo ${ }^{39}$.

\section{LA VIGENCIA DE LOS PLANTEAMIENTOS DE SAINZ DE BUJANDA}

Cuando tantas veces se califica a propuestas o iniciativas como «modernas», y tal es el caso de las campañas dirigidas a la educación cívico-tributaria, es necesario destacar, como se hace en la Declaración de Granada, el esfuerzo intelectual que a lo largo de los años 50 y 60 del siglo pasado hicieron juristas de la talla del profesor Sainz de Bujanda para elaborar un arsenal de conceptos que trascienden al momento histórico-político en el que se elaboraron, pues lo fueron sobre los sólidos cimientos de lo que es la dogmática jurídica y el conocimiento pleno e integral del Derecho. La construcción de Sainz de Bujanda sobre la educación cívico-tributaria -y esta afirmación es válida con carácter general para el conjunto de su obra- mantiene actualmente plena vigencia, porque se construyó sobre la decidida apuesta por el imperio de la Ley, poniendo el eje estructurante de su pensamiento en una constante preocupación por el anhelo de la justicia y por los principios propios de un Estado de Derecho. Sainz de Bujanda no se contentaba con realizar un mero análisis del Derecho positivo del momento, sino que construyó las bases del Derecho Financiero, como veremos después, sobre los cimientos de un Estado de Derecho, pensando en los países europeos del entorno, ante las carencias evidentes que tenía España en esa época ${ }^{40}$. Es ésta una cuestión que felizmente se ha destacado en la Declaración de Granada:

Los autores de los años 50 y 60 crearon un Derecho financiero constitucional, propio de un Estado de Derecho, esto es, desarrollaron su actividad «como si» (y es necesario resaltar las comillas) en España existiera entonces un régimen democrático [...]. Por ello, la incorporación de los principios y reglas esenciales del ordenamiento financiero a la Constitución de 1978 se realizó sin apenas discusión parlamenta-

39 Sainz de Bujanda, F., op. cit., p. 120.

${ }^{40}$ No debemos olvidar que Helsen también escribió su gran obra durante los tiempos oscuros de la Alemania nazi, dando cumplida respuesta al estructurar su explicación del tributo sobre las bases del Estado de Derecho. Ello nos demuestra que hay intelectuales que son capaces de elevarse a su tiempo, construyendo teorías que van más allá de lo establecido en un determinado periodo y que, por este motivo, tienen la capacidad de que se mantengan sus construcciones teóricas a lo largo de la historia, como demostramos en este trabajo con las enseñanzas de Sainz de Bujanda. 
ria, ya que el andamiaje conceptual sobre la que se asienta estaba construido, y no fue necesaria otra tarea que trasladarlo materialmente al texto constitucional ${ }^{41}$.

En suma, en el presente apartado nos planteamos si realmente el mecanismo de las presunciones Estado ladrón y contribuyente defraudador sigue estando de actualidad en España, demostrando su vigencia secular. Pues bien, parece claro que, si finalmente concluimos que la dialéctica de las presunciones sigue vigente en la sociedad española del siglo xxI, será un signo evidente que apunte a la urgente necesidad de incorporar ineludiblemente la educación cívico-tributaria en España, por las nocivas consecuencias que está inoculando en la concepción misma de nuestro sistema tributario.

\subsection{El Legado de Sainz de Bujanda}

Los estudios de Sainz de Bujanda sobre la educación tributaria incorporados a su obra Hacienda y Derecho quizás no hayan recibido la misma atención que la doctrina ha dedicado a otras partes de su obra, lo que no quita valor a la brillantez de su análisis sobre esta cuestión. En mi opinión, tales estudios son un hito más, y no de menor entidad, de lo que por muchos es hoy considerado el legado de Sainz de Bujanda, como ha acuñado el profesor Clavijo, en un artículo cuyo título he tomado para rotular el presente apartado, en el que afirmaba con rotundidad su opinión sobre la obra del maestro: «Si cuando él vivía sus tesis eran un punto de referencia obligado para cualquier tributarista, hoy me parece que lo son más ${ }^{42}$. Destaca el profesor Clavijo lo que considera como las cuatro tesis fundamentales que constituyen el legado de Sainz de Bujanda en Derecho Tributario y que debemos continuar difundiendo; a saber: la obligación tributaria como eje dogmático de esta disciplina, el concepto instrumental del procedimiento tributario, la distinción entre Derecho Tributario material y formal y, por último, la existencia de un conglomerado de potestades en el Derecho Tributario.

Considero que el legado de Sainz de Bujanda es tan abundante y valioso que es tarea ardua acotarlo definitivamente, pues, de entre sus ideas, algunas tienen, sin duda, una vigencia indefinida en el tiempo; otras, incluso, cobran especial sentido precisamente por el paso del tiempo. Una de ellas, sin duda, es la que introdujo en los dos capítulos que vehiculan y han inspirado el presente trabajo, sobre la educación tributaria en España.

Sainz de Bujanda, alejándose del momento político que le tocó vivir, tuvo, como otros tantos, la grandeza intelectual de apartarse de lo que, con terminología

${ }^{41}$ Rodríguez Bereijo, A., Martín Delgado, J.A., Martín Queralt, J., Tejerizo, J.M., Pérez-Royo, F., Cortés, M., et al., op. cit., p. 18.

${ }^{42}$ Clavijo, F., «El legado de Sainz de Bujanda en Derecho Tributario», en Fernando Sainz de Bujanda Fundador de los estudios de Derecho Financiero y Tributario (147-156). Servicio de publicaciones. Facultad de Derecho Universidad Complutense de Madrid, Madrid, 2003, p. 147. 
actual, podríamos llamar politicamente correcto para sustentar su construcción teórica sobre los principios democráticos del Estado de Derecho recogidos en las Constituciones de los países de nuestro entorno ${ }^{43}$. Esto queda claro en la severa crítica que dispensa a la Ley de 26 de diciembre de 1957, en la que identificaba el máximo exponente de la presunción del contribuyente defraudador en nuestros textos positivos. No en vano, como recordaba el profesor García Añoveros, don Fernando Sainz de Bujanda fue parte del bando republicano tras el golpe de Estado y la Guerra Civil, para posteriormente adquirir la condición de Letrado de las Cortes ya en la dictadura franquista ${ }^{44}$; pero, tras una lectura detenida de su obra, es más que evidente que su pensamiento y valores no concordaban con el momento político en el que la construyó, teniendo, como hemos comentado, la capacidad de elevarse para construir una dogmática del Derecho Financiero, sobre los cimientos del Estado de Derecho.

La vigencia de los planteamientos del maestro es innegable. Específicamente centrados en su demanda para la incorporación de forma decidida de la educación tributaria en nuestro país, a la vista de los numerosos problemas que aquejaban -aquejan- a nuestro sistema, pretendemos señalar en el apartado siguiente algunos indicios que demuestran que las presunciones Estado ladrón y contribuyente defraudador se han perpetuado en el tiempo, lo cual nos hace llegar a la conclusión de que el mecanismo de las presunciones, al que hemos venido refiriéndonos en apartados precedentes, está más vigente que nunca en la España del siglo XXI, precisamente por la ausencia de una apuesta convencida por parte del Estado para erradicarla. Y, como hemos apuntado, en la actualidad a esa dialéctica se ha sumado en nuestra opinión el nuevo rol del Estado -y de buena parte de la clase política-como agente denostador de lo tributario.

\subsection{LA PELIGROSA DiALÉCTICA DE LAS PRESUNCIONES EN LA ESPAÑA DEL SigLO XXI}

Con respecto a la presunción Estado ladrón o Fisco usurpador, una investigación del Instituto de Estudios Fiscales sobre las opiniones y actitudes fiscales de los contribuyentes ha puesto de manifiesto que un $30 \%$ de la población justificaría el fraude fiscal (ilustración 2); de los cuales un 22\% lo haría por circunstancias de la vida personal o empresarial; y, lo que es más preocupante, un $8 \%$ lo haría porque entiende que el fraude es una cuestión consustancial a los impuestos y que es una forma de equilibrarlos, un problema estructural del sistema impositivo español. En cuanto a las causas del fraude fiscal, un 31,7\% considera que los que más defraudan están impunes; un 25,8\% que existe falta de hon radez y conciencia cívica; un 14,9\% que la lucha contra el fraude fiscal no es eficaz; un $14,4 \%$ que los actuales impues-

43 Cazorla Prieto, L.M. (introd.), Hacienda y Derecho (fragmentos), Centro de Estudios Políticos y Constitucionales, Madrid, 2015, pp. 18-20.

44 Añoveros, J., "Un jurista: Fernando Sainz de Bujanda», en Fernando Sainz de Bujanda Fundador de los estudios de Derecho Financiero y Tributario (177-187). Servicio de publicaciones. Facultad de Derecho Universidad Complutense de Madrid, Madrid, 2003, p. 178. 


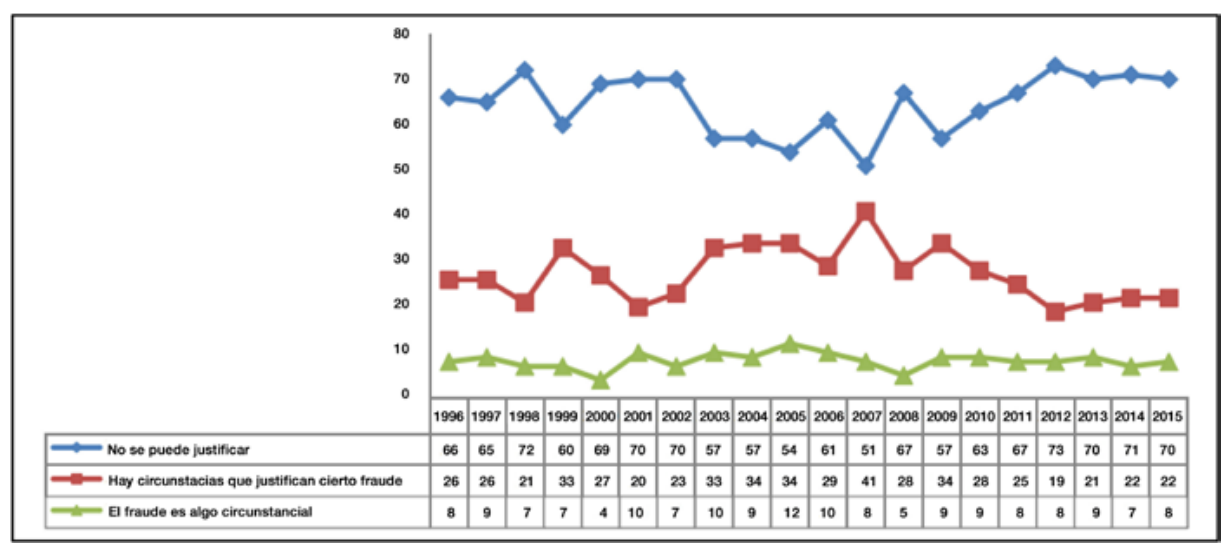

Ilustración 2. Evolución de las opiniones justificativas del fraude fiscal (1995-2015).

Fuente: Opiniones y actitudes fiscales de los españoles en 2015,

Instituto de Estudios Fiscales (IEF), p. 42.

tos son excesivos; un $6,5 \%$ que a veces hace falta trampear para salir adelante; $y$ un $5,6 \%$ que los servicios y prestaciones no se adecúan a lo que se paga ${ }^{45}$.

En el análisis del fraude fiscal desde la educación cívico-tributaria, no puede dejarse de lado la doble perspectiva que presenta, como ya hemos indicado, el fenómeno financiero de las Administraciones públicas: el ingreso y el gasto. Como muy bien destacó el profesor Rodríguez Bereijo, la unidad esencial del fenómeno financiero supone la unión inescindible entre el ingreso y el gasto público, la cual viene dada por un criterio teleológico: se ingresa para gastar ${ }^{46}$, lo que explica que la Constitución no solo se ocupe de los principios rectores de la justicia en el ingreso público, sino que también lo haga respecto del gasto, estableciendo en el artículo 31.2 que «el gasto público realizará una asignación equitativa de los recursos públicos, y su programación y ejecución responderán a los criterios de eficiencia y economía». A esa unidad teleológica entre ingreso y gasto poco ayuda que anide entre la población de modo generalizado la percepción de un Estado ladrón o Fisco usurpador, siendo responsabilidad de los poderes públicos, como destacara Sainz de Bujanda, erradicar tal percepción, lo que se logrará administrando con honestidad y probidad los recursos tributarios que se hayan obtenido de la colectividad.

Con vistas a una administración de tal carácter de los recursos tributarios, es menester, como ya hemos indicado, evitar aquellos gastos que se realizan para dar

45 El estudio a que hago referencia del Instituto de Estudios Fiscales (2016, pp. 29-42) se denomina Opiniones y actitudes fiscales de los españoles en 2015, y se encuentra disponible en https:// bit.ly/2Nr50hP.

${ }^{46}$ Rodríguez Bereijo, A., Introducción al estudio del Derecho Financiero, Instituto de Estudios Fiscales, Madrid, 1976, p. 72. 
un beneficio no fundado en criterios de justicia distributiva a determinados grupos de personas, y no a la colectividad en general -tal sería el caso, por ejemplo, de las remuneraciones a personal en términos que no se corresponden con los habituales del mercado o, en su grado máximo, cuando sus cuantías no se basan en módulos legales ni en limitaciones previamente establecidas-; o incluso, los que suponen la entrega total del producto de los impuestos, mediante el traspaso de fondos a determinadas personas o entidades vía subvenciones, cuya concesión responde más a la labor de grupos de presión que a la necesidad de atender ciertas necesidades colectivas, lo cual hace surgir una vigorosa oposición del contribuyente, por la falta de cumplimento de los principios que estructuran la gestión del Presupuesto del Estado ${ }^{47}$.

No en vano, el barómetro publicado por el Centro de Investigaciones Sociológicas (CIS), de julio de 2018, ha evidenciado que el segundo mayor problema de España, según los ciudadanos, es la corrupción y el fraude (38,5\%), al mismo tiempo que es considerado como el quinto que más les afecta $(11,2 \%)^{48}$, lo cual pone de manifiesto, a la vista también de los diferentes y numerosos casos de corrupción, prueba de una cuestionable gestión de lo público, que el Estado tampoco ha predicado con el ejemplo para generar confianza en la ciudadanía y eliminar de raíz la presunción Estado ladrón o Fisco usurpador. También resulta preocupante la cantidad de dinero de los Presupuestos Generales del Estado que se emplea para el pago de los intereses de la Deuda pública adquirida durante los años de la crisis económica y financiera, que el pasado año alcanzaría previsiblemente la cifra de 250000 millones de euros, un $25 \%$ del PIB $^{49}$, lo cual evidenciaría la renuncia por parte del Estado a hacer efectivo el mandato presente en el citado artículo 31 de nuestra

47 Sainz de Bujanda, F., op. cit., p. 127. Si bien Sainz de Bujanda no especifica concretamente a qué gastos públicos se refiere cuando habla de esta gestión inadecuada de los recursos públicos, podemos intuir que piensa en ciertas decisiones del Estado que, lejos de cumplir el mandato constitucional de proteger el interés general, se limitan a favorecer los intereses de un sector determinado. Así, podemos ver numerosos ejemplos de normas jurídicas que, bajo la generación en la sociedad de la ilusión de que se pretende proteger cuestiones que parecen propias del interés general, como puede ser el medioambiente, introducen ventajas fiscales que en realidad pretenden beneficiar, por ejemplo, a un determinado sector económico o grupo empresarial; una práctica que no solo es cuestionable desde un punto de vista jurídico y ético, sino que, aun peor, genera un clima de desconfianza de la ciudadanía hacia el Estado en cuanto a la gestión de lo público, que alienta con más fuerza que nunca la presunción Estado ladrón. Un ejemplo de ello puede ser la introducción en las leyes de presupuestos de la Comunidad Autónoma de Canarias de los ańos 2004 a 2008 del tipo reducido del 2\% a la importación y entrega de vehículos híbridos, que supuso un incentivo fiscal para la comercialización de estos vehículos llamados «ecológicos», con consecuencias económicas muy positivas para los sectores que los introdujeron en el mercado canario en este periodo, lo cual debe ser analizado con atención para detectar si dicha medida benefició en especial a algún grupo o empresa determinada, poniendo a los productos de la misma en ventaja competitiva y reduciendo sus precios vía reducir la carga tributaria para modelos concretos y ofertados por aquel entonces por un único importador.

48 Datos obtenidos del Centro de Investigaciones Sociológicas (CIS) (julio de 2018, pp. 3-4), Estudio n. ${ }^{\circ}$ 3219, disponible en https://bit.ly/2INVEbl.

49 Dato extraído del artículo del diario ElMundo titulado «Los intereses de la deuda cuestan ya 250000 millones a España desde el inicio de la crisis», a partir de la Ejecución Presupuestaria de la Intervención General del Estado, publicado el 3 de abril de 2017. Disponible en https://bit.ly/2nU2Jyj. 
Constitución, en el sentido de que el instrumento normal, ordinario y preferente de financiación del gasto público ha de ser el tributo y no otras vías, como la Deuda pública; una cuestión que, como veremos, ha sido profundamente criticada por la doctrina tributaria más afamada ${ }^{50}$.

No pretendemos justificar de ninguna manera el fraude fiscal con estas pruebas de cuestionable gestión de lo colectivo por parte del Estado, pero sí pretendemos llamar la atención de lo que expresaba Sainz de Bujanda y que volvemos a reproducir aquí: «el método educativo por excelencia es la probidad en el manejo del producto fiscal $\aleph^{51}$. En palabras de Durán-Sindreu Buxadé: «Es obvio que una política de educación tributaria sin un comportamiento ético de la Administración es y será ineficiente $\rangle^{52}$. En suma, no podemos pedirle a la ciudadanía que cumpla con sus obligaciones fiscales si, mientras tanto, es testigo de las sospechas de prácticas de corrupción y gestión ineficaz en el seno de la Administración Pública.

En cuanto a la presunción contribuyente defraudador, si bien podemos decir que está mucho más oculta, no cabe duda de que sigue existiendo, como se demuestra, aunque sea de manera vedada, en la incredulidad sistemática de la Administración Tributaria sobre las declaraciones de los ciudadanos como contribuyentes.

La Asociación Española de Asesores Fiscales (AEDAF) elaboró un documento de trabajo, en el año 2013, denominado «Malos tiempos para la seguridad jurídica de los contribuyentes", en el que denunciaba que, con las normas tributarias de urgencia producidas por el Gobierno (se refería, concretamente, a la Ley $7 / 2012$, de prevención y lucha contra el fraude ${ }^{53}$ ), con el único objetivo de aumentar la recaudación, la Administración Tributaria estaba tratando al contribuyente como un defraudador potencial. Criticaba, además, que el ciudadano se encontraba en una situación de indefensión a la hora de confrontar o resolver los conflictos generados con la Administración y concluía afirmando que, si bien era plenamente consciente del fraude fiscal existente en España y de la necesidad de combatirlo, éste no podía servir como excusa para la pérdida de derechos y garantías por parte

50 Como sabemos, durante los ańos de la crisis económica, ante la falta de ingresos para sostener los gastos públicos para el mantenimiento de los servicios públicos, el Estado recurrió sobre todo a la suscripción de deuda pública, en lugar de acudir a los tributos, la vía que nuestra Constitución marca, y así lo ha entendido también la mayoría de la doctrina, como preferente para el sostenimiento del gasto público. En este hecho, que puede parecer irrelevante, podemos detectar, como ya hemos dicho, el miedo de los políticos a la hora de recurrir a la subida de impuestos en situaciones como la descrita, por las desastrosas consecuencias que tendría esta decisión desde un punto de vista electoral, sin tener en cuenta los efectos, para nada desdeñables, de acudir al endeudamiento del Estado; una cuestión que, finalmente, acabará recayendo en los contribuyentes, no solo actuales, sino también futuros. Se demuestra, pues, la paradoja del Estado denostador de lo tributario.

${ }^{51}$ Véase cit. 18.

52 Durán-Sindreu Buxadé, A., «Fraude Fiscal y Educación Tributaria en España», Revista Derecho \& Sociedad (207-214), n. ${ }^{\circ}$ 43, 2014, p. 213.

${ }^{53}$ Ley $7 / 2012$, de 29 de octubre, de modificación de la normativa tributaria y presupuestaria y de adecuación de la normativa financiera para la intensificación de las actuaciones en la prevención y lucha contra el fraude (BOE núm. 261, de 30 de octubre de 2012). 
de los contribuyentes ${ }^{54}$. Además, son numerosas las denuncias públicas que realizan diversos organismos, con el fin de evidenciar la actitud desconfiada de la Administración para con los contribuyentes, como, por ejemplo, la que realizó en el año 2015 Pilar Otero, presidenta del Colegio de Gestores Administrativos de Galicia y, en la actualidad, vicepresidenta segunda del Consejo General de Gestores Administrativos de España, que en una entrevista al diario La Opinión de A Coruña sentenció que «Al ciudadano se le considera un defraudador en potencia y se obliga a demostrar su inocencia $\$ 5$.

En paralelo y, curiosamente, coincidiendo con la realización del presente trabajo, un grupo de más de treinta catedráticos de Derecho Financiero, entre los que cabe citar a Álvaro Rodríguez Bereijo, José María Martín Delgado, Juan Martín Queralt, José Manuel Tejerizo, Fernando Pérez-Royo o Matías Cortés, entre otros, han hecho pública una declaración que mucho tiene que ver con la materia que venimos tratando. La -como han titulado sus firmantes-Declaración de Granada denuncia que los esfuerzos de la Administración Tributaria para luchar contra el fraude fiscal no justifican en ningún caso la preterición de los principios de justicia tributaria, así como también destaca que «el afán recaudatorio se ha convertido en el único objetivo del comportamiento de los órganos tributarios, con olvido de los derechos y garantías individuales ${ }^{56}$. Como una sumaria muestra de ello, los firmantes de la citada Declaración ponen de manifiesto numerosos ejemplos -algunos de ellos analizados en el presente trabajo, como los peligros del endeudamiento público o el empleo del gasto público para satisfacer intereses individuales y no necesidades colectivas- que evidencian la quiebra de los principios de legalidad, de igualdad, de seguridad jurídica, de solidaridad y de justicia financiera en la actuación de las Administraciones Públicas. Específicamente en este apartado del trabajo, en el que tratamos de evidenciar la pervivencia de la presunción contribuyente defraudador por parte del Fisco, conviene destacar un fragmento literal de esta Declaración, en el marco de la quiebra del principio de legalidad, que sirva para ratificar definitivamente nuestros planteamientos, poniendo el foco en la autoridad académica de quienes la refrendan:

... frente al principio que garantiza la presunción de inocencia, parece haberse dado cálida acogida en las dependencias administrativas a la presunción de culpabilidad. El problema es muy grave, y se acentúa cuando, como sucede actualmente, el Legislador ha convertido al contribuyente en una especie de administrador vicario, lo que le obliga a cumplir con unas obligaciones materiales y unos deberes formales que originariamente deben ser propios de la Administración Tributaria.

${ }^{4}$ El artículo a que hago referencia es autoría de la Asociación Española de Asesores Fiscales (AEDAF) y se denomina Malos tiempos para la seguridad jurídica de los contribuyentes, $17 \mathrm{de}$ junio 2013. Disponible en https://bit.ly/2NXmcsw.

55 Fragmento extraído de la entrevista a Pilar Otero en La Opinión de A Coruña publicada el 21 de junio de 2015. Disponible en https://bit.ly/2wVyfiN.

56 Véase cit. 13. 
En esta situación, el contribuyente solo siente la cercanía de la Administración cuando se ve sancionado por haber cumplido mal, a juicio de ésta, con las obligaciones y los deberes a que está llamado. Hemos llegado asi a una Administración que solo realiza funciones de control y castigo ${ }^{57}$.

Sin duda, como destaca también la Declaración de Granada, debemos seguir luchando para acabar con el fraude fiscal, que tiene unas consecuencias desastrosas tanto para nuestra sociedad como para nuestra economía, pero eso no debe pasar, en ningún caso, por presumir que los contribuyentes son, en general, defraudadores. Hay contribuyentes que defraudan incumpliendo sus obligaciones fiscales, pero, sin duda, hay muchísimos más contribuyentes que pagan sus impuestos con la responsabilidad moral que debería caracterizar a todo ciudadano de cualquier Estado democrático que se precie. En esta línea, volvemos a reproducir la enseñanza de Sainz de Bujanda, que debería regir la actuación de las Administraciones Públicas, más allá de su afán recaudatorio o de sus funciones coercitivas: «La educación tributaria aparece como el más potente y eficaz instrumento de lucha contra el fraude. Un contribuyente educado es un contribuyente que no defrauda ${ }^{58}$.

\section{LA NECESIDAD DE UNA EDUCACIÓN CÍVICO-TRIBUTARIA DE SIGNO SOCIAL}

Hasta ahora hemos realizado un análisis acerca de algunos de los problemas educativos de nuestro país en relación con el fenómeno tributario, a través del pensamiento de Sainz de Bujanda; hemos tratado de constatar que su dialéctica de las presunciones sigue vigente en la Espańa del siglo xxi y hemos concluido que la solución pasa por la implantación decidida de la educación cívico-tributaria en la sociedad española. En el presente apartado, consideramos que es imprescindible ahondar en el tema central de este trabajo, para fundamentar por qué es tan necesaria la tantas veces reclamada educación cívico-tributaria, analizando la problemática de nuestro sistema tributario en relación con la técnica legislativa, la lucha contra el fraude fiscal o los programas de cumplimiento voluntario, entre otras cuestiones, como parte de una estrategia general de pedagogía fiscal para la ciudadanía.

57 Rodríguez Bereijo, A., Martín Delgado, J.A., Martín Queralt, J., Tejerizo, J.M., Pérez-Royo, F., Cortés, M., et al., op. cit., p. 24.

58 Sainz de Bujanda, F., op. cit., p. 105. 


\subsection{LA MEJORA DE LA TÉCNICA LEGISLATIVA PARA LA PRACTICABILIDAD DE LAS NORMAS TRIBUTARIAS}

Antes de abordar las bondades que ofrece la educación cívico-tributaria para acabar definitivamente con el fraude fiscal, resulta fundamental que hagamos referencia a un problema que también podemos encontrar en el marco del Derecho Tributario y que es crucial mejorar para lograr los fines de justicia fiscal; nos referimos, concretamente, a la técnica legislativa, es decir, la forma de elaboración y redacción de las normas jurídicas en materia tributaria y sus efectos en relación con la ciudadanía que es destinataria de éstas.

En primer lugar, debemos tener claro que el Derecho Financiero, tanto en el ámbito del Derecho de los gastos públicos como en el del Derecho de los ingresos públicos, es una disciplina compleja. Ello es así debido a la gran cantidad de conceptos jurídicos que maneja la disciplina, además de su estrecha relación con otras disciplinas científicas (no solo jurídicas, sino también económicas) que se deben controlar para su comprensión integral. De hecho, el profesor Sainz de Bujanda advierte que uno de los principales peligros a los que se enfrenta el jurista a la hora de defender los valores que encarna nuestro ordenamiento jurídico es la preeminencia de la técnica en el ámbito de la Hacienda Pública. «El daño surge cuando con la técnica se pretende sustituir al Derecho. La técnica es ineludible en la vida financiera moderna, pero su desarrollo y perfeccionamiento no pueden producirse en modo alguno a expensas de los valores jurídicos $\rangle^{59}$.

Es necesario tomar conciencia de la presencia, en numerosas normas jurídicas de la parte especial del Derecho Tributario, de un glosario jurídico tributario que acompaña a la norma y que hace prácticamente imposible de comprender e interpretar la misma por parte de la ciudadanía que está obligada a cumplirla ${ }^{60}$, motivo por el cual no nos debería extrañar la aparición de una gran cantidad de asesorías fiscales (que no encontramos en otras disciplinas jurídicas) para desentrañar el contenido de las normas y así poder aplicarlas, máxime en un contexto en el que el contribuyente debe aplicar la norma por sí mismo, en el marco de los sistemas de autoliquidación. De esta forma, se establece una excepción a lo establecido en el artículo 12 de la Ley General Tributaria ${ }^{61}$, puesto que primará en la interpretación de las normas el sentido jurídico (y no el usual) de los términos normativos.

A este aspecto que estamos abordando se refiere también de forma bastante explícita la Declaración de Granada, a la que ya nos hemos referido, en el ámbito de la quiebra del principio de legalidad en que incurre la Administración Tributaria, cuando expresa que

59 Sainz de Bujanda, F., op. cit., p. 29.

${ }^{60}$ Podemos encontrar numerosos ejemplos de esta cuestión en las reformas más recientes de la normativa tributaria, por ejemplo, en el ámbito de los delitos fiscales o la prescripción tributaria.

${ }^{61}$ Ley 58/2003, de 17 de diciembre, General Tributaria (BOE núm. 302, de 18 de diciembre de 2003). 
... el legislador usa en demasiadas ocasiones expresiones difícilmente comprensibles, permanentes remisiones normativas y otras fórmulas similares que hacen poco menos que imposible no ya la interpretación de los textos legales o reglamentarios, sino su propia comprensión, incluso por parte de los especialistas en la materia. De ello se deriva una ulterior consecuencia indeseable, y es que convierte a la DGT en una especie de oráculo que viene a explicar a todos (Administración, contribuyentes y Tribunales) la verdad revelada contenida en la norma objeto de interpretación ${ }^{62}$.

En el estudio del principio de transparencia en materia de la imposición, Fritz Neumark se refiere a la ininteligibilidad y oscuridad de las normas jurídico-tributarias, demandando la reducción de las reglamentaciones especiales, a través de la simplificación fiscal. Asimismo, critica que existe un elevado número de impuestos con una naturaleza muy compleja, solo entendible para un número ínfimo de contribuyentes, debido a la difícil formulación de las normas y a la existencia de formularios de las declaraciones tributarias muy extensos y prácticamente incomprensibles ${ }^{63}$. Y finalmente, Neumark concluye que «Una repulsa incondicional merecen [...] las violaciones del postulado de transparencia que se manifiestan en disposiciones jurídicas oscuras (imprecisas) que favorezcan la arbitrariedad de la Administración oly el fraude fiscal de los contribuyentes" ${ }^{64}$.

Esta cuestión entronca directamente con otra a la que se ha prestado muy poco interés por parte de los juristas, que se han centrado más en cuestiones de naturaleza formal de las normas jurídicas, y no de los condicionantes de la realidad social para su ejecución ${ }^{65}$ : nos referimos a la llamada practicabilidad de las normas tributarias, que ha sido definido por Neumark como:

El postulado de que se configure la Política Fiscal, en sus principios generales y en sus particularidades, de manera que sus medidas y los objetivos que con ellas se persiguen satisfagan la comprensión intelectual y las tendencias políticas del contribuyente medio (tipico), por una parte, y las atribuciones institucionales y materiales de los órganos de exacción, recaudación y control, por otra, resultando así eficazmente aplicables y practicables ${ }^{66}$.

Por tanto, debemos rescatar un paso previo y complementario en la implantación de la educación cívico-tributaria en nuestras sociedades: la mejora de la técnica legislativa, para acabar con los aspectos oscuros o ininteligibles de los textos normativos, con el fin de facilitar la practicabilidad de las normas tributarias y, en

${ }^{62}$ Rodríguez Bereijo, A., Martín Delgado, J.A., Martín Queralt, J., Tejerizo, J.M., Pérez-Royo, F., Cortés, M., et al., op. cit., p. 23. Cuando menciona la DGT se refiere a la Dirección General de Tributos.

${ }^{63}$ Neumark, F., Principios de la Imposición, Instituto de Estudios Fiscales Ministerio de Hacienda, Madrid, 1974, pp. 416-420.

${ }^{64}$ Neumark, F., op. cit., p. 423. La cursiva es nuestra.

${ }^{65}$ Génova Galván, A., «La practicabilidad de las normas tributarias», Revista de Hacienda Canaria, n.o 42, 2016, pp. 93-105.

${ }^{66}$ Neumark, F., op. cit., p. 424. La cursiva es nuestra. 
suma, para evitar la arbitrariedad de la Administración y el fraude fiscal de los contribuyentes. En conclusión, no solo la ciudadanía debe acercarse al Derecho, sino que el Derecho debe ajustarse lo más posible, bajo el principio de transparencia en la imposición, a la ciudadanía que tiene el deber de cumplirlo e incluso aplicar por sí misma, a través de la autoliquidación de las obligaciones tributarias.

Del mismo modo, complementariamente, y con esto entroncamos con el siguiente apartado, el Estado tiene el deber de educar a la ciudadanía para la comprensión de los propios conceptos tributarios utilizados habitualmente en las normas jurídicas. Ello lo explica muy bien, de nuevo, el profesor Sainz de Bujanda al comentar que "Cuanto más amplio sea el núcleo de personas que en el seno de la sociedad posean conocimientos rigurosos de Derecho financiero, más difícil será que la vida tributaria discurra por cauces irregulares» ${ }^{67}$.

\subsection{LA LUCHA CONTRA EL FRAUDE FISCAL: ¿COERCIÓN O EDUCACIÓN?}

Antes de comenzar su estudio acerca de la educación tributaria en España, Sainz de Bujanda se plantea dos posibles vías para luchar contra el fraude: la vía educativa y la vía positiva. Entiende que, si lo que queremos es combatir el fraude a la par que elevar la responsabilidad moral del contribuyente, debemos usar métodos pedagógicos, escogiendo la primera vía. Si, de lo contrario, lo que pretendemos es únicamente que la falta de ética tributaria no provoque un déficit de recaudación, sin ánimo de mejorar al contribuyente, debemos acudir a procedimientos técnicos o psicológicos decantándonos por la vía positiva ${ }^{68}$. Bajo su visión, en España prevalece la segunda, pero expresa que "La educación tributaria y la lucha contra el fraude son tareas que el Estado ha de cumplir simultáneamente, con el apoyo de conocimientos que la Psicología le brinda sobre el modo de ser del contribuyente medio, y con el aliento que la Ética y la Política le procuren para definir las metas ideales a las que ambas misiones han de dirigirse» ${ }^{69}$.

Por tanto, podemos decir que no se trata de elegir entre educar al contribuyente o perseguirlo para que cumpla; ambas actividades no son excluyentes entre sí y el Estado debe complementarlas para poder lograr un mayor grado de cumplimiento fiscal, a la vez que mejora la responsabilidad moral del contribuyente (en este sentido, en el próximo apartado analizaremos el enfoque del palo y la zanahoria). Dicho de otro modo y siguiendo a Sainz de Bujanda: si empleamos todos los recursos de la lucha contra el fraude en vencer al contribuyente mediante métodos coercitivos, en lugar de a persuadirle a través de un cambio de actitud con respecto

${ }^{67}$ Sainz de Bujanda, F., op. cit., pp. 135-136. En este punto, cuando Sainz de Bujanda se refiere a que la vida tributaria transcurra por cauces regulares, entendemos que hace alusión a este deber, tanto por parte de la Administración Tributaria, evitando la arbitrariedad en sus decisiones y actos, como por parte del contribuyente, evitando el fraude fiscal.

68 Sainz de Bujanda, F., op. cit., pp. 153.

69 Sainz de Bujanda, F., op. cit., p. 229. La cursiva es nuestra. 
al cumplimiento de sus obligaciones tributarias, no nos debe extrañar que éste no colabore y que prefiera eludir o contrarrestar las pretensiones del Fisco con las técnicas que considere oportunas ${ }^{70}$.

Durán-Sindreu Buxadé entiende que es necesario un replanteamiento de la política educativa en materia fiscal, así como también destaca que no es de gran ayuda la «tozudez de la Administración en vivir al margen de la realidad convencida de que la vía adecuada para atajar el fraude es la coercitiva», la cual lo único que genera es desconfianza por parte de los contribuyentes, que, como hemos señalado, tampoco conocen el complejo sistema tributario y que, al no comprenderlo, consideran que pagan muchos impuestos y que los instrumentos de lucha contra el fraude fiscal son insuficientes ${ }^{71}$.

$\mathrm{Al}$ referirse Pont Mestres al procedimiento inspector, considera que la educación tributaria debe ser un valor instrumental del imperio de la Ley, que sería el objetivo principal en el desarrollo de esta actividad. Expresaba el entonces catedrático de Hacienda Pública y Derecho Tributario de la Universidad Central de Barcelona que la Administración Tributaria debe procurar la comprensión del ciudadano del complejo sistema tributario, pero siendo tratado, no como un potencial defraudador, sino como una persona normal que realiza actividades por las que debe pagar tributos, en una relación basada en la colaboración y comprensión recíproca, poniendo el foco, pues, en la responsabilidad moral del contribuyente, a través de la educación ${ }^{72}$. A ello nos referiremos más adelante, cuando hagamos referencia a algunas experiencias que se han implantado, por ejemplo, en la Comunidad Foral de Navarra, donde cada vez con más intensidad la Administración Tributaria ha pasado de basar su actuación en la represión y fiscalización a la puesta en marcha de mecanismos a través de los cuales se incentiva al contribuyente a cumplir voluntaria y espontáneamente sus obligaciones tributarias, mediante la puesta en marcha en sus planes de lucha contra el fraude fiscal de programas específicos dedicados a la educación cívico-tributaria.

Por contra, Martínez Álvarez y Miquel Burgos destacan que el fin primordial de la lucha contra el fraude fiscal es el aumento de la recaudación como paso previo a la redistribución y la sostenibilidad del Estado de Bienestar. Consideran que el primer paso en esa lucha pasa por incrementar las sanciones de los defraudadores y, al mismo tiempo, realizar un mayor número de inspecciones fiscales; ya en un segundo plano, se refieren a la sensibilización fiscal de los contribuyentes para indicar que es necesaria una nueva estrategia comunicativa por parte de la Agencia Tributaria $^{73}$. Este planteamiento, al mismo tiempo que valora la educación fiscal para combatir el fraude fiscal, la coloca en una posición secundaria, pues ambos

70 Sainz de Bujanda, F., op. cit., p. 231.

71 Durán-Sindreu Buxadé, A., op. cit., pp. 213-214.

72 Pont Mestres, M., Estudios sobre temas tributarios actuales, Universidad de Barcelona, Barcelona, 1985, pp. 421-423.

73 Martínez Álvarez, J.A. y Miquel Burgos, A.B., «Instrumentos clave en la lucha contra el fraude fiscal: la importancia de la educación fiscal», Crónica Tributaria, n. ${ }^{\circ} 146,2013$, pp. 179-192. 
autores entienden que el objetivo primordial de la Administración -como critica la citada Declaración de Granada - es la recaudación y no la mejora de la cualidad de los ciudadanos como contribuyentes, haciendo especial hincapié en su responsabilidad moral o en su conciencia fiscal; renunciando pues a esa mejora cualitativa, centran la lucha en medidas coercitivas para después limitar la educación fiscal a un simple cambio en la estrategia comunicativa, como si - una vez más- de una cuestión de marketing se tratara, en lugar de a un proceso de formación continua de la ciudadanía, especialmente de la población más joven, con el fin de que se corresponsabilice en la gestión de los recursos públicos, conozca el destino de sus tributos y cumpla con sus obligaciones tributarias.

En definitiva, considero, en la línea de Sainz de Bujanda, que la herramienta más importante para luchar contra el fraude fiscal es la educación cívico-tributaria o educación fiscal; las medidas coercitivas son, sin duda, necesarias para castigar a quienes defraudan gravemente al Fisco, incumpliendo normas jurídicas obligatorias, pero esas medidas no van a prevenir el fraude futuro; a lo sumo, simplemente harán que se recupere una parte del dinero efectivamente defraudado, para aumentar la recaudación. La lucha contra el fraude fiscal debe consistir en un conjunto de acciones multidisciplinares y transversales que pongan el foco en la conciencia fiscal del contribuyente, en la profundización de su responsabilidad moral para el cumplimiento de su obligación de contribuir al sostenimiento de los gastos públicos, pero no como una mera estrategia comunicativa, sino como una apuesta decidida y continuada en el tiempo, dotada de recursos suficientes y, sobre todo, basada en la convicción de que podemos mejorar como sociedad mediante la vía educativa, para que la ciudadanía pague sus tributos con conciencia de que ello reportará una mejora de la calidad de los servicios públicos, del Estado de Bienestar que nos hemos dado y, sobre todo, la redistribución de la riqueza.

Para terminar este apartado, quisiera reproducir una importante cita del profesor Sainz de Bujanda:

Sólo un Estado que educa, al tiempo que exige, puede, en definitiva, hacer soportable la carga tributaria a la colectividad. Para un contribuyente educado, el tributo es un noble y honroso sacrificio; para un contribuyente sin educar, es una expoliación abusiva ${ }^{74}$.

\subsection{LOS PROGRAMAS DE CUMPLIMIENTO TRIBUTARIO VOLUNTARIO Y COOPERATIVO EN} LA LUCHA CONTRA EL FRAUDE FISCAL

Una vez que nos hemos inclinado en el sentido de que la posición del Estado en la lucha para acabar con el fraude fiscal pasa fundamentalmente por la educación (y no tanto por la coacción), no podemos pasar por alto una cuestión que está

74 Sainz de Bujanda, F., op. cit., p. 231. 
teniendo especial relevancia en los sistemas tributarios de España y el mundo: los programas de cumplimiento tributario voluntario y cooperativo; una nueva vertiente promovida por la Organización para la Cooperación y el Desarrollo Económico (en adelante OCDE), que se está poniendo en marcha cada vez con mayor frecuencia en numerosos Estados.

Simbólicamente, podríamos analizar estos nuevos programas de cumplimiento, mediante el enfoque del palo y la zanahoria, que debiera regir la actuación de la Administración para adaptarse al tipo de contribuyente. Como explica Soto Bernabéu, la zanahoria quedaría representada por los incentivos propuestos en los programas de cumplimento voluntario, que pueden consistir en reducciones de la deuda o intereses de demora; por su parte, el palo simbolizaría las medidas coercitivas o punitivas a las que no debe renunciar la Administración, tanto con una finalidad disuasoria como sancionadora, ante los posibles incumplimientos del contribuyente ${ }^{75}$. Este enfoque está presente, de alguna manera, en la visión de Sainz de Bujanda que hemos tratado de dilucidar en este trabajo, en el sentido de que la vía educativa y la positiva son, a su modo de ver, complementarias para la lucha contra el fraude fiscal.

En cualquier caso, debemos tener en cuenta que, como nos dice Soto Bernabéu, «no existe un único tipo de contribuyente» ${ }^{76}$; existen múltiples circunstancias que inciden en el cumplimiento o no de sus obligaciones tributarias, por lo que debemos analizar los motivos que incitan a una parte de la ciudadanía a incumplir sus obligaciones para con el Fisco, algunas de las cuales ya hemos recogido en este trabajo, como la falta de confianza en el sistema, la complejidad de la normativa, la visión de que el sistema es injusto, cuestiones morales o éticas, el papel del Estado como denostador de lo tributario, etc.

Así, el cumplimiento voluntario por parte de los contribuyentes, no solo debe ser el objetivo de cualquier Administración Tributaria que se precie, sino también la mejor herramienta para recaudar los ingresos tributarios al menor coste posi$\mathrm{ble}^{77}$. Un contribuyente puede cumplir sus obligaciones en el periodo voluntario o de forma extemporánea, pero debemos considerar que el cumplimiento es voluntario cuando la Administración no ha ejercitado ninguna potestad para exigir el pago de las deudas tributarias, lo cual comporta no incurrir en costes administrativos ${ }^{78}$.

75 Soto Bernabéu, L., «Los programas de cumplimiento voluntario como medidas de estímulo al cumplimiento extemporáneo de las obligaciones tributarias», Nueva Fiscalidad (195-213), n. ${ }^{\circ} 1,2018$, p. 197. Este enfoque descansa, según la autora, en lo que Ayres y Braithwaite han calificado como responsive regulation, mediante una filosofía quid pro quo. Cfr. Ayres, I. y Braithwaite, J.: Responsive regulation, New York: Oxford University Press, Inc., 1992, pp. 4-7.

76 Soto Bernabéu, L., op. cit., p. 199.

77 Soto Bernabéu, L., op. cit., p. 198.

${ }^{78}$ El único coste que ese cumplimiento extemporáneo comporta es de naturaleza financiera, que queda cubierto suficientemente mediante el interés de demora; por su parte, con respecto a los recargos en este periodo, la finalidad que persiguen no es de carácter represivo sino, precisamente, incentivar el cumplimiento espontáneo por el contribuyente, aunque sea fuera de plazo, como exponemos en el texto. 
De esta forma, la OCDE ha promovido la creación de programas de cumplimiento voluntario, que pueden ser generales o especiales. En nuestra legislación, podemos encontrar un ejemplo de programa de cumplimiento voluntario general en el artículo 27 de la Ley General Tributaria, en lo relativo al régimen de los recargos por declaración extemporánea sin requerimiento previo por la Administración, con la oportunidad permanente para que el contribuyente incumplidor regularice voluntariamente su situación, como un estímulo al cumplimiento voluntario; en cuanto a los programas especiales, han sido -y siguen siendo-objeto de polémica, como la última regulación de la declaración tributaria especial (más conocida coloquialmente como amnistía fiscal), a través del Real Decreto-Ley 12/2012, de 30 de marzo ${ }^{79}$, declarado inconstitucional por Sentencia del Tribunal Constitucional de 8 de junio de 2017.

Soto Bernabéu concluye, siguiendo la doctrina tributaria más afamada, que los programas de cumplimiento voluntario son la herramienta más apropiada para la consecución de dos objetivos: por un lado, el aumento de la recaudación de un modo más rápido y a un menor coste; $\mathrm{y}$, por otro, la mejora del cumplimiento espontáneo por parte de los contribuyentes de sus obligaciones tributarias ${ }^{80}$. Han sido numerosos los Estados que han puesto en marcha en todo el mundo programas de cumplimiento voluntario (Argentina, Bélgica, Brasil, Italia, Portugal, El Salvador, Guatemala, Turquía, etc.), pero, concretamente dentro de España, debemos destacar a la Comunidad Foral de Navarra, que ha impulsado en sus Planes de Lucha contra el Fraude Fiscal una serie de medidas en las que se incentiva el cumplimiento voluntario por parte del contribuyente, con el convencimiento de que «si se persigue conseguir que los contribuyentes cumplan de la manera más completa y puntual con sus obligaciones tributarias, la Administración ha de desplegar cuantas medidas pueda para que ese cumplimiento se realice de la manera más cómoda posible» ${ }^{81}$; lo cual demuestra que han ido calando en la Administración navarra las ideas de Sainz de Bujanda, en el sentido de que el comportamiento del Fisco para con los contribuyentes fuera menos coercitivo y más pedagógico, facilitando así el cumplimiento espontáneo de sus obligaciones tributarias; una nueva tendencia que debe estar presente en las estrategias implementadas por la Administración Tributaria, para prevenir y luchar contra el fraude fiscal.

Algunos ejemplos de las medidas incorporadas por parte de la Comunidad Foral de Navarra para fomentar el cumplimiento voluntario de los contribuyentes los podemos encontrar en uno de los apartados del Plan de Lucha contra el Fraude Fiscal 2016-2019, en el que se hace alusión a la notificación electrónica, la modificación de la potestad de representación tributaria, la potenciación del cumplimiento

79 Real Decreto-Ley 12/2012, de 30 de marzo, por el que se introducen diversas medidas tributarias y administrativas dirigidas a la reducción del déficit público (BOE núm. 78, de 31 de marzo de 2012).

${ }^{80}$ Soto Bernabéu, L., op. cit., p. 210.

${ }^{81}$ Frase extraída del Plan de Lucha contra el Fraude Fiscal 2016-2019 del Gobierno de Navarra, en su página 32. Disponible en https://bit.ly/2Qb4xix. 
de obligaciones por vía telemática, la simplificación de las obligaciones tributarias, la organización de los medios adecuados para la atención al público, entre otras.

Por otro lado, también se ha formado, bajo recomendaciones de la OCDE, un nuevo modelo de cumplimiento tributario cooperativo, en virtud del cual se postula que se debe crear una relación institucional cooperativa entre la Administración Tributaria y los contribuyentes, asumida voluntariamente por ambos bajo la confianza mutua, el diálogo, la transparencia y la búsqueda del entendimiento a través de la reciprocidad, con lo que se pretende la aplicación correcta de las leyes fiscales, para una determinación correcta de la cuantía del impuesto, mediante el respeto de los derechos de todas las partes ${ }^{82}$. Este nuevo modelo de relación entre la Administración y la ciudadanía, implantada en numerosos Estados (Irlanda, Países Bajos, Estados Unidos, Australia, entre otros), aspira a lograr el mayor índice posible de cumplimiento voluntario por parte de los contribuyentes. Calderón Carrero y Quintas Seara sintetizan a la perfección el objetivo de esta novedosa relación cooperativa: «viene a configurarse como una relación que favorece la colaboración frente a la confrontación, y se encuentra anclada más en la confianza mutua que en una dinámica relacional legal que pivota sobre un modelo de sujeción fiscal del contribuyente basado en las obligaciones legalmente establecidas» ${ }^{83}$.

Podríamos desarrollar extensamente este apartado en relación con los programas de cumplimiento tributario voluntario y cooperativo, pero únicamente era nuestro interés mostrar una tendencia actual, a nivel internacional, fundamentada en la confianza mutua entre la Administración Tributaria y los contribuyentes, que solo puede tener sentido, de una forma o de otra, mediante la implantación de una educación cívico-tributaria de signo social, que favorecerá la eficacia de estos novedosos programas puestos en marcha, como hemos visto, dentro y fuera de España.

\subsection{LA EDUCACIÓN CÍVICO-TRIBUTARIA EN EL MARCO DE UNA EDUCACIÓN EN VA- LORES DEMOCRÁTICOS}

El filósofo y sociólogo francés Edgar Morin, al reflexionar sobre la educación del futuro en un libro realizado en colaboración con la UNESCO, planteó que debíamos enseñar la democracia y el civismo, entre otras cosas porque la democracia supone al mismo tiempo la autolimitación del poder estatal con la consiguiente separación de poderes, la garantía de los derechos individuales y la protección de la vida privada. Criticaba Morin los procesos en los que se marginaba a la ciudadanía de las decisiones políticas, para ser sustituida por expertos técnicos, por lo que los ciudadanos se ven usurpados de los problemas fundamentales de la sociedad; concluyendo que todos estos factores producían el debilitamiento del civismo, la evasión

82 Calderón Carrero, J.M. y Quintas Seara, A., Cumplimiento tributario cooperativo y Buena gobernanza fiscal en la era BEPS, Editorial Aranzadi, Navarra, 2015, pp. 64-65.

${ }^{83}$ Calderón Carrero, J.M. y Quintas Seara, A., op. cit., p. 68. La cursiva es nuestra. 
y la búsqueda del refugio en la vida privada, debilitando, en suma, la democracia ${ }^{84}$. Sin duda, esto que comentaba el sociólogo en el marco de los retos educativos del vigente siglo XxI tiene mucho que ver con la educación cívico tributaria, tal y como la entendemos.

Decía Ortega y Gasset que «El problema de los españoles es un problema educativo; pero éste, a su vez, es un problema de ciencias superiores, de alta cultura ${ }^{85}$. Un reciente estudio de la Universidad Estatal de Sonora (México) ha demostrado la correlación existente entre cultura y educación tributaria, lo cual evidencia que, a pesar del endurecimiento de las sanciones legales impuestas a los defraudadores, los contribuyentes no se han concienciado de sus obligaciones tributarias, ni siquiera en los niveles de educación superior, una cuestión a la que no ayuda la complejidad de las leyes en materia fiscal, por lo que se propone la puesta en marcha de forma urgente de programas de educación fiscal para generar cultura tributaria ${ }^{86}$.

Durán-Sindreu Buxadé ha puesto de manifiesto, en el artículo a que hemos hecho referencia con anterioridad, la necesidad de implantar una educación cívico-tributaria diferente a la planteada hasta ahora: debe estar basada en principios cívicos, éticos y morales, teniendo en cuenta el pago de los impuestos como una obligación ética de la ciudadanía. En este sentido, expresa que "es imprescindible una educación basada en el deber cívico de contribuir entendido como valor, y no como obligación, y su más profunda razón de ser: la justa redistribución de la riqueza como un exponente de la solidaridad ${ }^{87}$.

No cabe duda de que el artículo 31 de nuestra Carta Magna es claro al expresar que todos tenemos el deber de contribuir al sostenimiento de los gastos públicos y que la categoría de obligación es, como ya nos dice el profesor Clavijo, en tanto que uno de los denominados legados de Sainz de Bujanda, el eje dogmático del Derecho Tributario ${ }^{88}$. Sin embargo, considero que en el marco de la educación cívico-tributaria se debe hacer hincapié también en la responsabilidad moral del contribuyente o conciencia fiscal, poniendo el foco en su deber cívico de contribuir al sostenimiento de los gastos públicos, mediante el pago de los tributos. Debemos señalar igualmente que es elemental que la ciudadanía comprenda el sistema tributario desde el valor de justicia redistributiva y de solidaridad que lo fundamenta; valores de la democracia, que deben ser fomentados, a través de los métodos educativos y pedagógicos.

${ }^{84}$ Morin, E., Los siete saberes necesarios para la educación del futuro, Paidós Studio, Barcelona, 2000, pp. 131-138.

85 Ortega y Gasset, J., "La pedagogía social como problema político», en Obras Completas, vol. I, Rev. Occ., Madrid, 1946, p. 84.

${ }^{86}$ Mendoza Shaw, F., Palomino Cano, R., Robles Encinas, J.E. y Ramírez GuarDADO, S.R., "Correlación entre cultura tributaria y educación tributaria universitaria: caso Universidad Estatal de Sonora", Revista Global de Negocios, vol. 4, n. . 1, 2016, pp. 61-76.

87 Durán-Sindreu Buxadé, A., op. cit., p. 213.

${ }^{88}$ Clavijo, F., "El legado de Sainz de Bujanda en Derecho Tributario», en Fernando Sainz de Bujanda Fundador de los estudios de Derecho Financiero y Tributario (147-156). Servicio de publicaciones. Facultad de Derecho Universidad Complutense de Madrid, Madrid, 2003, p. 148. 
La educación cívico-tributaria debe pivotar en el marco de una educación en valores democráticos, donde la ciudadanía entienda que vivir en democracia y disfrutar de los servicios públicos, como la educación o la sanidad, tiene un coste, que debe ser asumido por la colectividad, a través de un sistema impositivo justo. Si la ciudadanía toma conciencia de su condición de contribuyentes con cultura y educación tributaria, cumplirá con sus obligaciones fiscales, porque sabe que reportaría en su propio beneficio como ciudadano, pero también, como hemos comentado, impedirá o se resistirá ante cualquier ejercicio arbitrario del Derecho por parte del Estado.

En suma, no se debe fomentar la educación cívico-tributaria para que el ciudadano pague sus tributos adormecido, sino para despertar su conciencia fiscal en el marco de una educación en valores. En este sentido, Sainz de Bujanda expresaba que

No puede razonablemente postularse que los sujetos paguen los impuestos insensiblemente, como en un sueño, adormecidos por no sabemos qué engaños o ilusiones. Esa anestesia fiscal que se predica es un veneno corrosivo que destruye las raíces de los ideales tributarios. Frente a ella alzamos la voz en defensa de un robustecimiento incesante de la conciencia tributaria ${ }^{89}$.

\section{EL FRACASO EN LA IMPLANTACIÓN DE LA EDUCACIÓN CÍVICO-TRIBUTARIA EN ESPAÑA}

En el año 2003 se crea en España el Programa de Educación Cívico-Tributaria (en adelante, PECT), dependiente de la Agencia Estatal de Administración Tributaria (en adelante, AEAT), fruto de diversos estudios demoscópicos sobre el fraude fiscal realizados por el Instituto de Estudios Fiscales (en adelante, IEF), en los que se demostraba que un $73 \%$ de la población consideraba que la educación cívico-tributaria en la etapa escolar podía influir positivamente en el cumplimiento fiscal en el futuro ${ }^{90}$. El trabajo del PECT desde entonces se ha centrado fundamentalmente en realizar diversas jornadas de puertas abiertas en las delegaciones de la Agencia Tributaria y en la creación de un portal web específico sobre la educación cívico-tributaria destinado a estudiantado y profesorado ${ }^{91}$, así como el ofrecimiento de diversas charlas y formaciones específicas a los diversos sectores de la comunidad educativa. Todo ello cuenta con unas valoraciones profundamente positivas por parte del personal técnico responsable del PECT, teniendo en cuenta que los resultados solo se podrán ver a largo plazo y también los retos de continuidad del programa, como la extensión a más niveles educativos, la intensificación de la formación del

89 Sainz de Bujanda, F., op. cit., pp. 119-120. La cursiva es nuestra.

${ }_{90}$ El dato a que hago referencia fue extraído del documento de trabajo del Instituto de Estudios Fiscales (IEF) que lleva por título Opiniones y actitudes fiscales de los contribuyentes en 2004, publicado en el año 2005, p. 59. Disponible en https://bit.ly/2QeD4fK.

${ }_{91}$ Disponible en https://bit.ly/1gc11NN. 
profesorado y la renovación del material didáctico ${ }^{92}$. En cuanto al impacto en el año 2009, el PECT había alcanzado la cifra de 166589 alumnos y 13084 profesores $^{93}$.

Sin embargo, sin menospreciar el trabajo desarrollado en el marco del PECT, parece haber un vacío existencial, desde el año 2009 hasta la actualidad, en la evaluación del impacto y los resultados que el programa ofrece, para poder analizar si los retos enunciados para la continuidad del programa se han implantado efectivamente. De hecho, la socióloga y colaboradora del IEF Ruiz de Zauzu ha manifestado que el programa se encuentra congelado por la falta de apoyo institucional y de financiación para poner en marcha las importantes aspiraciones del PECT; según expresa, solo se realizan acciones dispersas en algunas provincias gracias a la labor desinteresada de los formadores ${ }^{94}$. Lo que sí parece evidente, a la vista de lo planteado, es que el programa ha fracasado en su compromiso de continuidad; que las acciones desarrolladas se demuestran a todas luces insuficientes; que falta llegar a muchos sectores de la población de una forma transversal y de forma continuada en el tiempo; así como que los recursos didácticos que ofrece el PECT están completamente desfasados (una prueba de ello es el portal web del programa), lo cual requiere una actualización integral, que permita el acercamiento de la población, especialmente de la más joven, en aras de la consecución de los importantes objetivos del PECT.

Por otro lado, en el año 2006 se crea en España, siguiendo recomendaciones del Consejo de Europa, la Educación para la Ciudadanía, una asignatura obligatoria en la Educación Primaria y Secundaria, cuyos objetivos fundamentales pasan por «favorecer el desarrollo de personas libres e íntegras a través de la consolidación de la autoestima, la dignidad personal, la libertad y la responsabilidad y la formación de futuros ciudadanos con criterio propio, respetuosos, participativos y solidarios, que conozcan sus derechos, asuman sus deberes y desarrollen hábitos cívicos para que puedan ejercer la ciudadanía de forma eficaz y responsable»"

Esta asignatura incorporaba a su currículo académico material didáctico relativo al Derecho Tributario, con apartados específicos relativos a los impuestos y la contribución de los ciudadanos, en un bloque formativo sobre las sociedades democráticas del siglo xxi. Como muestra de ello, un libro de esta asignatura para alumnado de Educación Secundaria Obligatoria (ESO) abordaba en una de sus unidades el concepto de Hacienda Pública, la relación entre el pago de los tributos y el disfrute de los servicios públicos, los principios fundamentales del sistema tributario, el concepto de impuesto y sus tipos, así como las repercusiones del fraude

${ }_{92}$ Estos datos son extraídos del documento de trabajo del Instituto de Estudios Fiscales (IEF) denominado La experiencia educativa de la Administración Tributaria Española, publicado en el año 2009. Disponible en https://bit.ly/2hVtQHz.

${ }_{93}$ Según el estudio más reciente encontrado, citado en la nota anterior.

94 Ruiz de ZAuzu, M.G., "Medidas sociales para combatir el fraude fiscal en España», Fundación Alternativas, 2014, p. 29. Disponible en https://bit.ly/2eB0XuW.

95 Real Decreto 1631/2006, de 29 de diciembre, por el que se establecen las enseñanzas mínimas correspondientes a la Educación Secundaria Obligatoria (BOE núm. 5, de 5 de enero de 2007). 
fiscal y la economía sumergida, entre otras cuestiones; con contenido teórico y práctico $^{96}$. Se procedía a incorporar, de esta forma, la educación cívico-tributaria en el marco educativo general, fomentando, al fin y al cabo, la conciencia fiscal de los contribuyentes del futuro. Sin embargo, fruto de la polémica que se generó sobre su presunto contenido ideológico, la asignatura fue eliminada con la Ley Orgánica $8 / 2013$, de 9 de diciembre, para la mejora de la calidad educativa (LOMCE) ${ }^{97}$, sin que hasta la fecha se haya sabido implantar una alternativa para seguir promoviendo la educación cívico-democrática y en Derechos Humanos, tal como recomienda el Consejo de Europa ${ }^{98}$.

No obstante, tras la eliminación de la asignatura de Educación para la Ciudadanía, se procedió a incorporar progresivamente cuestiones relativas a la educación financiera en los centros educativos, introducidas desde la Educación Primaria al currículo de otras asignaturas como Ciencias Sociales o Economía, con contenidos como el dinero, el ahorro, la empleabilidad y el espíritu emprendedor, así como las actividades y funciones de las empresas, entre otros asuntos ${ }^{99}$. De hecho, el Informe español PISA 2012 sobre competencia financiera, elaborado por el Instituto Nacional de Evaluación Educativa (INEE), dependiente del Ministerio de Educación del Gobierno de España, cita la educación cívico-tributaria en una sola ocasión en el marco del análisis de Educación para la Ciudadanía; y, sin embargo, expresa sobre la educación financiera que «la evolución de la sociedad española y su economía hace ver que ha aumentado la necesidad de formar a jóvenes y adultos en educación financiera», para después hacer referencia a la implantación de esta materia en primaria y secundaria, a través de las asignaturas de Ciencias Sociales y Economía ${ }^{100}$.

En este sentido, han sido muchas las voces críticas que han salido al paso de la incorporación de estos contenidos en el sistema educativo, a la vista del aparente abandono de la educación cívico-tributaria o fiscal en nuestro país. Una de ellas ha sido la de Rodríguez Márquez, profesor titular de Derecho Financiero y Tributario de la Universidad Complutense de Madrid y director de estudios del IEF, que mostraba su sorpresa ante el éxito de la incorporación de la educación financiera en la enseñanza (la cual sí considera necesaria) y manifiesta que no se está priorizando

96 Pérez Carrasco, J., Díaz Otero, C. y Díaz Fleitas, J.M., Jóvenes Ciudadan@s, Educación para la ciudadanía y los derechos humanos, Pearson Alhambra, Madrid, 2008, pp. 47 y 68-69.

${ }^{97} B O E$ núm. 295, de 10 de diciembre de 2013.

${ }^{98}$ Lo cual supone, según algunos autores, un grave retroceso en muchos sentidos para nuestro sistema educativo, en el que ha quedado excluida y olvidada la educación cívico-tributaria. Cfr. Muñoz Ramírez, A.: "¿Qué ha sido de Educación para la Ciudadanía con el Partido Popular?», Foro de Educación, 14 (20), Salamanca, 2016, pp. 105-128. Disponible en el siguiente enlace web: http://dx.doi.org/10.14516/fde.2016.014.020.007.

${ }_{99}$ Real Decreto 126/2014, de 28 de febrero, por el que se establece el currículo básico de la Educación Primaria (BOE núm. 52, de 1 de marzo de 2014).

${ }^{100}$ Extraído del Informe español PISA 2012 sobre competencia financiera, Instituto Nacional de Evaluación Educativa (INEE), Ministerio de Educación Gobierno de España (p. 14). Versión preliminar disponible en https://bit.ly/2wY8HkQ. 
bien en este asunto, a la par que destaca la importancia de la educación fiscal, no solo para la Agencia Tributaria, sino para el conjunto de la sociedad y el resto de poderes públicos ${ }^{101}$. Más intensas han sido las críticas de Rodolfo Rieznik, economista y vocal de la Junta Directiva de Economistas Sin Fronteras, que expresó su total rechazo a la implantación de la educación financiera en las aulas e hizo una reivindicación de una mayor educación y responsabilidad fiscal y tributaria, en detrimento de las finanzas, alertando de la sucesiva desaparición de la educación fiscal, que ya hemos analizado ${ }^{102}$. También, desde la Plataforma por la Justicia Fiscal, se alertaba recientemente sobre los efectos del desmantelamiento de la educación cívico-tributaria en los currículos de enseñanza, exigiendo la recuperación de las iniciativas del PECT y, sobre todo, la inclusión en el Pacto de Estado por la Educación del compromiso para dar cabida a la educación fiscal en los centros educativos, pues destacan que su objetivo primordial «es transmitir valores y actitudes favorables a la responsabilidad fiscal y contrarios a las conductas defraudadoras»; cuestiones que se están perdiendo ante un alarmante déficit de conciencia fiscal ${ }^{103}$.

En suma, resulta más que acreditado que el Estado se ha olvidado de la educación cívico-tributaria que intentó implantar a través del PECT y que, por tanto, ha fracasado en su misión de fomentar la conciencia fiscal de los contribuyentes para, así, conseguir un mayor grado de cumplimiento fiscal. La falta de apoyo institucional y de recursos económicos ha terminado por desterrar la educación cívico tributaria de la enseñanza en los centros educativos españoles. A la vista de lo planteado, parece que el Estado tiene otras prioridades que no pasan por mejorar la educación fiscal de los contribuyentes, lo cual coadyuvaría también a eliminar de raíz las presunciones vigentes del Estado ladrón y contribuyente defraudador, que, lógicamente, se perpetuarán en el tiempo hasta que la Administración se decida a poner en marcha iniciativas estables y continuas de educación fiscal; las incorpore decididamente al currículo de enseñanza de la educación primaria y secundaria; así como, y esto es muy importante, las dote de los recursos y apoyo institucional suficientes para que se mantengan en el tiempo. Esto no es óbice para que se mantenga una educación sobre ciertas materias financieras; sin embargo, lo que no es asumible en el marco del Estado social como Estado fiscal es la erradicación de los contenidos tributarios de los planes de estudios de quienes, ineludiblemente, mañana serán contribuyentes.

Los problemas del país relativos a la educación fiscal siguen vigentes, porque no se ha hecho lo suficiente para acabar con ellos, con la implantación decidida de

101 Artículo de opinión de Jesús Rodríguez Márquez en el diario digital Cinco Días, bajo el título «Es tiempo de educación fiscal», publicado el 28 de octubre de 2016. Disponible en https:// bit.ly/2wXE7aW.

${ }^{102}$ Artículo de opinión de Rodolfo Rieznik en eldiario.es, bajo el título «Educación financiera o educación fiscal y tributaria», publicado el 9 de junio de 2017. Disponible en https://bit.ly/2MgPJvG.

103 Artículo de opinión de José Manzanarez Núnez, miembro de la Plataforma por la Justicia Fiscal, en el diario digital infolibre, bajo el título «Educación fiscal contra pobreza y desigualdad», publicado el 29 de septiembre de 2017. Disponible en https://bit.ly/2xTetol. 
la educación cívico-tributaria, que sigue siendo, como reza el título de este trabajo, una asignatura pendiente, lo cual, sumado al nuevo rol del Estado como denostador de lo tributario, provoca un crecimiento incesante del fraude fiscal.

\section{ALGUNAS PROPUESTAS DE BUENAS PRÁCTICAS EN ESPAÑA Y EN EL MUNDO}

En el presente apartado trataremos de esbozar algunos ejemplos de dentro y fuera de España, donde se han desarrollado iniciativas que nos pueden servir de referencia para implantar-recuperar-a nivel estatal un programa de educación cívico-tributaria que, atendiendo a la realidad concreta de nuestro país, logre ser eficaz en la lucha contra el fraude fiscal. Estas propuestas deben sumarse a los diversos remedios planteados por Sainz de Bujanda, así como otros destacados en este trabajo, para acabar con la pervivencia del mecanismo de las presunciones y el papel del Estado como denostador de lo tributario.

En este sentido, la OCDE ha publicado un libro que pretende ser una guía sobre educación tributaria en el mundo y que recoge las innovadoras estrategias de veintiocho países alrededor de todo el planeta en el marco de la educación fiscal. Se plantean, en concreto, las propuestas de buenas prácticas en este ámbito de países como Bangladesh, Bután, Brasil, Burundi, Chile, Colombia, Costa Rica, El Salvador, Estonia, Guatemala, Jamaica, Kenia, Corea, El Líbano, Malasia, Mauricio, México, Mozambique, Nigeria, Perú, Ruanda, Senegal, Singapur, Sudáfrica, Turquía, Uruguay o Zambia ${ }^{104}$. En la sinopsis del libro se recoge expresamente el convencimiento de que «La Educación Cívico-Tributaria no es sólo una estrategia para recaudar más ingresos ni se centra exclusivamente en explicar por qué han de pagarse los impuestos, más bien intenta fortalecer actitudes de compromiso con el bien e interés general enfatizando el valor social del impuesto y su nexo con el gasto público» ${ }^{105}$.

Resulta profundamente instructiva la lectura de las diferentes propuestas que estos países han desarrollado en sus sociedades, con el fin de implantar decididamente una educación fiscal eficaz. A continuación, desarrollaremos algunos programas aun activos de determinados Estados que, por su proximidad cultural con España, podrían servirnos de ejemplo para su traslación adaptada a nuestro país:

a) Programa de Educación Fiscal del Servicio de Impuestos Internos de Chile ${ }^{106}$. Puesto en marcha en el año 2006, el programa desarrollado en Chile para el fomento

${ }^{104} \mathrm{OECD} /$ The International and Ibero-American Foundation for Administration and Public Policies (FIIAPP), Fomentando la cultura tributaria, el cumplimiento fiscal y la ciudadanía. Guia sobre educación tributaria en el mundo, OECD Publishing, París, 2015. Disponible completo en http://dx.doi.org/10.1787/9789264222786-es.

${ }^{105}$ OECD, op. cit., p. 13.

106 OCED, op. cit., pp. 55-62. 
de la educación fiscal se ha concretado en las siguientes tareas: un portal web educativo, una obra de teatro representada en todo el país, artículos promocionales en revistas especializadas, entrega de material didáctico en las aulas, series en la televisión nacional chilena, visitas a colegios y charlas de los funcionarios, incorporación del programa a los planes de estudios de los centros de enseñanza secundaria y superior e inclusión de un módulo de educación cívico-tributaria en la formación de los nuevos funcionarios, entre otras medidas. Especial importancia reviste el Programa de Educación Fiscal en línea (SIIEduca y Planeta SII), dirigido a docentes, padres, tutores, alumnado y comunidad en general (con diferente tratamiento en el propio portal web), para aprender sobre la materia tributaria de una forma didáctica; resulta imprescindible destacar que ambos portales web se han actualizado recientemente, para facilitar la inclusión de las redes sociales y otras tecnologías de la información en el proceso de aprendizaje, con unos resultados profundamente positivos ${ }^{107}$.

b) Programa Nacional de Educación Fiscal del Servicio de Administración Tributaria de México ${ }^{108}$. En el año 1997 nace este programa en México, que concibe la participación ciudadana como un elemento fundamental de la educación fiscal y que ha desarrollado, entre otras, las siguientes acciones: diseño de asignaturas específicas sobre fiscalidad en educación superior, inclusión de contenidos fiscales en material escolar gratuito, creación del personaje Fiscalito para formar con diversión al alumnado de educación primaria, conferencias y visitas guiadas, exposiciones y ferias culturales y la creación de un centro recreativo para jóvenes llamado Kidzania, la ciudad de los impuestos. La implantación de una asignatura específica sobre formación e información tributaria en más de medio centenar de Universidades mexicanas, así como en la educación a distancia, ha tenido especial importancia en el desarrollo de este programa, que aún tiene muchos retos por delante ${ }^{109}$.

c) Programa de Educación Fiscal de la Dirección General Impositiva de Uruguay ${ }^{110}$. Impulsado en el año 2003, la acción más novedosa propuesta por el mismo versa sobre los videojuegos sobre educación tributaria: consiste en dotar a cada niño del país de un ordenador portátil (Plan Ceibal) para utilizar en el aula de los centros de educación primaria, con diversos videojuegos sobre educación cívico-tributaria, donde se abordan temas como los derechos y obligaciones, la sociedad, el Estado y la cultura fiscal; cabe destacar que han tenido un amplio alcance en el país ${ }^{111}$. Asimismo, se puso en marcha

107 Más información en http://www.sii.cl/destacados/sii_educa/.
108 OCED: op. cit., pp. 137-143.
109 Más información en https://www.sat.gob.mx/home.
110 OCED: op. cit., pp. 199-205.
111 Destacamos esta iniciativa para contraponerla a la reciente polémica que se ha generado en torno a la decisión de la Consejería de Educación del Gobierno de Canarias a la hora de introducir en los centros educativos los llamados eSports, con videojuegos deportivos competitivos (más 
un portal web en el que la población más joven podría encontrar no solo los videojuegos, sino también información relativa al ámbito tributario ${ }^{112}$.

d) Programa de Educación Civico-Tributaria Dirección General de Tributación de Costa Rica ${ }^{113}$. Creado en el año 2010, ha iniciado acciones muy interesantes en esta materia, como la semana de cultura fiscal en el calendario escolar, los cursos de formación para docentes de primaria, secundaria, personal de la administración y cursos básicos de fiscalidad para estudiantes de contabilidad, entre otras. La propuesta más interesante de este programa es la Sala de Juegos Un tributo a mi pais, un espacio específico en el Museo del@s Niñ@s, situado en la capital de Costa Rica, donde se da cabida a más de una docena de juegos interactivos en materia fiscal, que ha tenido un impacto de casi 100000 personas entre 2010 y 2013, con el reto de poder implantar una sala de juegos como esta en cada escuela del país ${ }^{114}$.

No cabe duda, a la vista de lo expuesto en este apartado sobre buenas prácticas, que tenemos mucho margen en España para mejorar nuestro - congeladoPrograma de Educación Cívico-Tributaria: se requieren políticas más estables, actualizadas e innovadoras, que pongan el foco en la conciencia fiscal del contribuyente. Es más que probable que Espańa pueda encontrar a lo largo de estas páginas novedosas iniciativas, puestas en marcha por Estados en vias de desarrollo que, con compromiso institucional y político, han logrado sustentar en el tiempo programas de educación tributaria, donde se pone el foco en la conciencia fiscal de los contribuyentes, como recomendamos en este trabajo de investigación.

Sin embargo, a decir verdad, también podemos encontrar en España algunas iniciativas que nos demuestran que, con compromiso institucional y político, se puede intentar implantar la educación cívico-tributaria o educación fiscal. A modo de ejemplo, podemos exponer las siguientes:

a) Planes de Lucha contra el Fraude Fiscal de la Comunidad Foral de Navarra. Como ya comentamos en el apartado anterior, podemos considerar que la Comunidad Foral de Navarra ha introducido elementos en sus políticas que nos permiten calificarlas como ejemplares, pues ha recogido la obligación por parte del Gobierno de Navarra de elaborar y presentar ante el Parlamento un plan o estrategia cuatrienal de lucha contra el fraude fiscal, a través de la disposición Adicional 6. ${ }^{a}$ de la Ley Foral 14/2013, de 17 de abril, de Medidas contra el fraude fiscal ${ }^{115}$. En este Plan de lucha contra el fraude fiscal (en

info en https://bit.ly/2Nw62JE). Tal vez el Gobierno de Canarias podría aprender de esta iniciativa puesta en marcha en Uruguay para educar a la población más joven en el ámbito fiscal, a través de los videojuegos, en lugar de esta iniciativa.

${ }_{112}$ Más información en http://www.dgi.gub.uy/educa.

113 OCED: op. cit., pp. 69-74.

114 Más información en http://educa.hacienda.go.cr:8080/costarica_prod/.

115 BON núm. 80, de 29 de abril de 2013. 
adelante, PLCFF), que ya se venía realizando desde el año 2008 y que se ha promulgado en tres ocasiones, con versiones distintas (2008-2012, 20142017 y 2016-2019) $)^{116}$, es habitual incorporar, además de los programas de cumplimento voluntario a los que ya nos hemos referido, un apartado específico sobre educación cívico-tributaria o educación fiscal, por considerarlo «uno de los instrumentos que mayor utilidad puede ofrecer para prevenir el fraude fiscal». Dicho apartado introduce también medidas específicas encaminadas a la introducción de la misma en la sociedad, a través de la educación en valores y la formación e información a la ciudadanía, como pueden ser -en el PLCFF 2016-2019- la introducción en los planes educativos de materias relacionadas con la administración presupuestaria y tributaria, la mejora de la percepción por el público del esfuerzo tributario o la mejora en la producción y difusión de las estadísticas tributarias, entre otras.

b) Contenidos de educación tributaria y conciencia fiscal en los centros de enseñanza del País Vasco. También podemos referirnos a otra iniciativa, esta vez dirigida a los centros educativos, que nace del Departamento de Educación del Gobierno Vasco, a raíz de una sugerencia del Departamento de Hacienda y Finanzas en el marco de las políticas contra el fraude. Esta medida consiste en la incorporación desde el curso 2015-2016 al currículo de las asignaturas de Valores Sociales y Cívicos en Primaria y Valores Éticos en Secundaria, de contenidos relativos a la educación tributaria y a la conciencia fiscal, en los que se explicaría la importancia de los impuestos para el mantenimiento de los servicios públicos y el Estado de Bienestar ${ }^{117}$. Esta experiencia nos demuestra que es fundamental incluir, como ya hemos visto en las propuestas de buenas prácticas de otros países, en el marco de los centros educativos programas de educación cívico-tributaria, para sensibilizar a la población más joven sobre estos asuntos, con especial énfasis en su conciencia fiscal.

En cuanto a la Comunidad Autónoma de Canarias, no tenemos material ni datos suficientes que nos permitan pensar que, como en el País Vasco o Navarra, se haya implantado algún programa específico -más allá de medidas puntuales o meras estrategias comunicativas - relativo a la educación cívico-tributaria de forma análoga al PECT impulsado por la Agencia Estatal de Administración Tributaria, por lo que podemos considerar, como reza el título del presente trabajo, que, por ahora, es una asignatura pendiente también para nuestra Comunidad Autónoma. Ante esta realidad, esperamos, por el bien de nuestro sistema tributario, que esto sea así por poco tiempo, pues resulta ciertamente recomendable, especialmente en nuestra Comunidad Autónoma, en la que contamos con un sistema fiscal especial

116 Podemos encontrar el más reciente de ellos, el Plan de lucha contra el fraude fiscal 20162019, aún vigente y sobre el que nos basamos para exponer esta propuesta de buenas prácticas, en el siguiente enlace web: https://bit.ly/2Qb4xix.

117 Noticia publicada en la agencia Europa Press el 16 de agosto de 2015. Disponible en el siguiente enlace: https://bit.ly/2wXLb7s. 
y particular respecto al resto del Estado, la implantación de una estrategia de educación cívico-tributaria específica para la ciudadanía canaria.

Sin duda, podríamos señalar más propuestas de buenas prácticas de otros territorios de dentro y fuera de España sobre la implantación de la educación cívico-tributaria en sus sociedades, lo cual nos ocuparía extensas páginas, pero únicamente pretendíamos hacer constar en este trabajo un catálogo de algunas propuestas que evidenciarían que disponemos a nuestro alcance de los recursos y las referencias suficientes para acometer la urgente y necesaria implantación de la educación cívico-tributaria en nuestro país para acabar, entre otras cosas, con la dialéctica de las presunciones o la posición del Estado como agente denostador de lo tributario, y que, si aún no hemos emprendido con éxito dicha tarea, es por la falta de -en palabras de Sainz de Bujanda- «un sincero y decidido empeño» por parte del Estado.

\section{CONCLUSIONES}

A la vista de lo que hemos planteado a lo largo de esta investigación podemos afirmar que la educación cívico-tributaria es, como reza el título de este trabajo, por un lado, una asignatura pendiente $y$, por otro, un instrumento imprescindible en la lucha contra el fraude fiscal.

Es una asignatura pendiente porque, a pesar de que la Administración Tributaria ha intentado implantar un Programa de Educación Cívico-Tributaria, éste ha tenido escasos resultados, debido a la falta de compromiso y apoyo financiero e institucional. En consecuencia, los problemas que aquejaban a nuestro sistema tributario en la década de los sesenta del siglo pasado, y que tan lúcidamente destacó el profesor Sainz de Bujanda, siguen vigentes en la España del siglo xxi, lo cual se demuestra con la pervivencia, entre otras cuestiones, de la dialéctica de las presunciones Estado ladrón o Fisco usurpador y contribuyente defraudador, prejuicios que inciden sobre los comportamientos sociales y generan un clima de desconfianza entre los contribuyentes y la Administración Tributaria, que provoca un aumento imparable de la mentira y la injusticia fiscales. Ha quedado más que patente, como ya nos advirtió el profesor, que éste y el resto de los problemas que aquejan a la educación tributaria en España seguirán estando vigentes indefinidamente hasta que el Estado demuestre con decisiones políticas su sincero compromiso de acabar con ellos, a través de la educación cívico-tributaria de la población.

Con el paso del tiempo hemos detectado, además del mecanismo de las presunciones que destacara Sainz de Bujanda hace más de medio siglo, una nueva actitud por parte del Estado que no resulta para nada favorecedora de la educación cívico-tributaria: la que he denominado paradoja del Estado denostador de lo tributario; expresión con la que, entiendo, cabe referirse a que cada vez con más frecuencia los discursos políticos - casi sin excepción- reniegan de la razón de ser de los tributos como un instrumento de justicia social, mostrando una peligrosa tendencia a rechazar su empleo preferente para financiar el gasto público, como ha establecido el legislador constitucional. Si el Estado denuesta lo tributario, rehúye de la materia impositiva y únicamente se refiere a esta cuestión en el marco de cam- 
pañas de marketing relativas al alivio fiscal de los contribuyentes, no debe extrañarnos el aumento incesante del fraude fiscal en nuestro país. En suma, una actitud denostadora de lo tributario por parte del Estado fomenta las conductas defraudadoras de la ciudadanía.

La educación cívico-tributaria se presenta también como un instrumento necesario, más aún, imprescindible, para la lucha contra el fraude fiscal; Sainz de Bujanda nos decía incluso que, de entre todos los posibles, es el más potente y eficaz. La finalidad más imperiosa a la hora de combatir el fraude de los contribuyentes en el cumplimiento de sus obligaciones tributarias no debería pasar exclusivamente por obtener la recaudación que éstos pretenden defraudar, sino por intensificar la conciencia fiscal o responsabilidad moral de los contribuyentes, facilitando así una mejora de éstos a través precisamente de la educación cívico-tributaria. Es por ello por lo que los métodos coercitivos languidecen y resultan ineficaces en la lucha contra el fraude fiscal, lo cual demuestra la necesidad de que la Administración opte por incentivar, como ya se está haciendo en algunas Comunidades Autónomas, el cumplimiento voluntario de las obligaciones tributarias por parte de los contribuyentes, creando una relación institucional cooperativa, tal como recomienda la OCDE. Además, debemos aclarar que la educación cívico-tributaria no solo revertiría en el cumplimiento de los contribuyentes de sus obligaciones fiscales, sino que también provocaría el rechazo y la resistencia consciente de éstos ante posibles actitudes injustas por parte de la Administración; siendo ambas cuestiones las que nos convertirían en una mejor sociedad.

Dicho esto, una vez que hemos concluido que es crucial -y un deber del Estado-para la colectividad la implantación de políticas encaminadas a la mejora de la educación cívico tributaria de la sociedad, debemos determinar cuál es el modelo para ello, para lo que contamos con un enorme catálogo de numerosas propuestas de dentro y fuera de España, que han puesto en marcha con éxito la educación cívico-tributaria en sus sociedades, poniendo especial énfasis en la población más joven, a través de los centros educativos, así como experiencias novedosas, como los programas de cumplimiento tributario voluntario y cooperativo. No nos corresponde a nosotros determinar cómo se debería implantar esta pretendida educación fiscal, pero sí alertar de que determinadas actitudes y decisiones de los Gobiernos - de dudosa legalidad- dificultan dicha imperiosa tarea, como pueden ser la confusión de la propaganda con la información, la existencia de normas jurídicas oscuras, imprecisas e ininteligibles o la cuestionable gestión de los recursos públicos por parte de la Administración, con un déficit notable de honestidad.

Por último, pero no menos importante, es imprescindible destacar que la introducción decidida de la educación cívico-tributaria en nuestra sociedad reportaría la mejora del principio de justicia -y solidaridad- que, no solo irradia sobre nuestro sistema tributario, sino que también es, según nuestra Carta Magna, un valor superior de nuestro ordenamiento jurídico.

Y, precisamente en este sentido, volvemos a sostener como función del jurista la defensa, sin sostener posición neutral alguna, de los valores que encarna el Derecho; una enseñanza que Sainz de Bujanda nos legó y que, sobre todo en estos tiempos, debemos seguir protegiendo como un símbolo que evidencia también los 
beneficios de una educación fiscal, capaz de convertir nuestra sociedad en una más libre, más igualitaria, más justa y más plural.

ReCIBIDO: agosto de 2020; ACEPTADO: noviembre de 2020 



\section{CRÓNICA}

Crónica de nuestros maestros y compañeros. Curso 2019-2020

A mis compañeros de Claustro

Alberto Génova Galván

Profesor titular de Derecho Financiero y Tributario. Universidad de La Laguna

En el ya lejano siglo XIII los intelectuales de las ciudades se iban reuniendo en la corporación, gremio o universidad de los maestros y los estudiantes; lo relevante no era el lugar en que se reunieran, tampoco su regulación jurídica, sino la propia reunión de personas que se sentían vinculadas por el común deseo de la búsqueda y transmisión del saber. Tengo para mí que en este siglo Xxi lo que sigue dando carta de naturaleza a las universidades es el Claustro de profesores y alumnos, $\mathrm{y}$ al igual que en los orígenes de la Universidad, es esencial en nuestra Facultad de Derecho no tanto la institución, sino la corporación, manteniendo plena vigencia el viejo aforismo universitas non moritur.

En efecto, universitas non moritur; pero ha de entenderse bien que lo que no muere no es la universidad, sino la asociación, que es como ha de entenderse aquí universitas. Nada es nuevo bajo el sol, pues ya en Roma los clásicos supieron distinguir la colectividad de los elementos que la componen sentando las bases de lo que con el tiempo serían las personas jurídicas; pero lo que ahora nos interesa es llamar la atención sobre el lema universitas non moritur. La fórmula canónica Dignitas non moritur, glosada por Bernardo de Parma como «la dignidad nunca perece (Dignitas nunquam perit) mientras que los individuos mueren todos los días», se tomó, coincidiendo temporalmente con la formación de las primeras universidades, para legitimar la institución monárquica, de suerte que se llega a proclamar Imperium Semper est.

Ernst Kantorowicz, un profesor universitario que en 1938 escapó de la Alemania nazi al haberse negado a firmar un juramento de lealtad al nazismo; acogido en los Estados Unidos, renunció a su plaza de profesor en Berkeley por negarse a firmar un juramento de lealtad para identificar a los simpatizantes del Partido Comunista; trasladándose a Princeton, donde en su Institute for Advanced Study encontraría la calma para escribir su obra magna. The King's Two Bodies. A Study in Medieval Political Theology, es un libro de consistentes 500 páginas del que existe versión castellana publicada en 2012 por Akal, en el que Kantorowicz sitúa en la Edad Media la cuestión atinente a los «Dos cuerpos del rey»: el cuerpo espiritual y el cuerpo natural, explicando cómo se fue desarrollando una «teología política» en la que el cuerpo natural del rey, con sus atributos físicos, muestra su finitud padeciendo y muriendo, igualándose en ello con todos los seres humanos. La mortalidad del monarca poco se compadecía con el pretendido origen divino de la monarquía. La solución la dio la canónica Dignitas non moritur que sirvió para

DOI: https://doi.org/10.25145/j.anfade.2021.38.08

Anales de la Facultad de Derecho, 38; septiembre 2021, pp. 199-203; ISSN: e-2530-8319 
sostener el segundo cuerpo del rey: el espiritual, que trasciende lo terrenal y nos lo presenta como símbolo de su desempeño como monarca, un símbolo que permitirá conciliar la mortalidad del rey con el derecho divino a gobernar que corresponde a la monarquía («por la gracia de Dios»). La combinación de los dos cuerpos a los que se refiere Kantorowicz fundamenta y legitima la continuidad de la monarquía incluso con la muerte del monarca, idea que es la que explica el significado del lema «El rey ha muerto. Larga vida al rey».

Una línea de pensamiento similar llevó al armazón como asociación de la universidad de los maestros y estudiantes, como corporación caracterizada por su continuidad en el tiempo, dando nueva grafía a la original fórmula canónica, que ahora pasaría a ser universitas non moritur. Una universidad integrada por profesores y alumnos mutables y por edificios perecederos, que permanecía en el tiempo porque además era una entidad inmaterial e invariable, al modo en que los glosadores hablaban de "un conjunto o colección de una pluralidad de personas en un cuerpo».

Hoy nuestra Facultad de Derecho es un non moritur, pero no por la solidez de sus muros de hormigón armado, sino por lo único que en ella es trascendente: las personas, y no sólo las que en el momento en que se dan a la estampa estos Anales nos reunimos entre esos muros, sino que nos sentimos vinculados a la larga nómina de profesores y alumnos que desde su creación se han integrado en la Corporación de la que somos miembros, y cuando nos sea leve la tierra ya otros nombres estarán incluidos en el rol de nuestra Facultad. Ellos y nosotros sólo somos piezas en la inevitable sucesión física forzada por el tiempo y a través de la mediación del tiempo. Tenemos ahí la dialéctica entre la finitud y la infinitud del hombre en conjuntada armonía, somos finitos porque formamos parte de la infinitud, y hemos tenido la fortuna de desarrollar laboralmente nuestra finitud formando parte de una corporación de maestros y discípulos; cuando ya nuestra tumba no tenga quien la recuerde, seguiremos en la infinitud de esa corporación. En palabras de Inocencio IV, la universidad era una persona intelectual que no puede morir, y no una persona real; una persona caracterizada por la sucesión de sus miembros, proyectándose en el pasado y en el futuro.

\footnotetext{
¿Qué otra enseñanza encierran estos versos de nuestro himno?

"Nuestra vida es corta,

En breve se acaba.

Viene la muerte velozmente,

Nos arrastra cruelmente,

No respeta a nadie»
}

El propio himno nos libera de la muerte, que para nosotros tampoco es el final, al cantar a continuación:

Viva la Universidad, vivan los profesores.

Vivan todos y cada uno

de sus miembros,

resplandezcan siempre. 
En la inevitable sucesión física a la que me he referido, a lo largo del curso académico 2019-2020 compañeros de nuestro Claustro han fallecido y otros han pasado a la situación administrativa de jubilados. Todos ellos viven en cada uno de nosotros y en la Corporación pareciendo oportuno que quienes fuimos discípulos suyos y compañeros reseñemos la figura de nuestros colegas. Compañeros que en su momento pasaron a formar parte de nuestro Claustro renovando, como hemos ido haciendo cada uno de nosotros, los motivos que llevaron a que aparecieran las universidades medievales: «el deseo innato -escribe Ponz Piedrafita en Reflexiones sobre el quehacer universitario - del hombre de aprender, de buscar la verdad y, a la vez, de hacer a los demás partícipes de los conocimientos adquiridos; y junto a esto, del espíritu de cooperación, de su tendencia a asociarse, en este caso para compartir los saberes particulares y alcanzar, al menos con cierta aproximación, el saber universal, entonces todavía asequible. A este fin constituyen comunidades de maestros y discípulos en las que se cultivan las diversas Ciencias de la época, se contrastan las ideas y se transmiten de unos a otros; comunidades que procuran proveerse de notable autonomía e independencia, muchas veces también territorial».

Hemos transitado compartiendo con nuestros compañeros el centro de cultivo de la ciencia del Derecho asumiendo la doctrina aristotélica de la eternidad del mundo, y dando relieve al cuerpo místico de la Facultad, no otra cosa es la Corporación a la que me vengo refiriendo. Esa comunidad de maestros y discípulos es la Universidad, más allá de su caracterización jurídico-administrativa; es decir, una Corporación caracterizada por su continuidad en el tiempo.

Valga lo anterior para expresar mi convencimiento en que nuestra Facultad de Derecho va más allá de la dependencia administrativa incrustada en la organización de la Universidad de La Laguna -reducida ahora a la sigla ULL-. No es fácil atisbar ese más allá cuando estamos en la espesura del enrevesado armazón burocrático del que la Universidad se ha ido dotando en los últimos veinte años, y como los de la propia casa no se bastan para enredar un poco más ese armazón, suman a la tarea alianzas con entes como ANECA. Esa espesura burocrática parece habernos abocado a poner en primer lugar la Facultad como institución; todo queda en segundo plano para atender lo que antes era accesorio y que ahora se nos presenta como nuevo bálsamo de Fierabrás que resolverá todos los problemas de la Universidad; todo se solventa en sedes electrónicas, instancias normalizadas para todo lo divino y lo humano, en sucesivas convocatorias de reuniones - con sus preparatorias-, en rendición de memorias, todo ello regado con una abundante dosis de correos electrónicos. El monstruo que entre todos hemos creado se despreocupa de qué docencia se imparte en el Aula 02.7 el lunes a las diez, por poner por caso; sí se interesa algo por la investigación, pero no porque la valore en sí misma, sino para ensanchar su presencia en los rankings. Y cada cierto tiempo alimentan al monstruo burocrático creando nuevos cargos «académicos», alentando al abandono de la tiza; y lo malo es que los nombrados parece que se sienten obligados «a hacer cosas» y se ponen a la tarea de inventar nuevo pienso burocrático.

Y hablando del monstruo burocrático, volvamos a la Corporación: ¿cómo se gestiona la sucesión física en la misma? 
Ese nefando reforzamiento de la vis institucional de nuestra Facultad se está llevando buena parte de las mejores energías de nuestros jóvenes profesores, a quienes el modelo pomposamente llamado de Bolonia -y que, en mi opinión, no va más allá de haber incrustado en la Universidad la burocratización de la enseñanza y el aprendizaje propio de la LOGSE- aboca a la velocidad y la urgencia. Hago votos para que regrese el imperio de la Corporación que tan intensamente pude vivir en mis primeros años en esta Facultad, cuando a mis 22 ańos formaba Claustro con los profesores D. Felipe González Vicén, D. José María Hernández-Rubio Cisneros, D. Juan Miquel González de Audícana, D. José Juan Ferreiro Lapatza, D. Antonio Martín Pérez, D. Leopoldo de la Rosa Olivera, D. Rodolfo Soto Vázquez, D. Manuel Morón Palomino, D. Eladio Arroyo Lara, D. Antonio Pérez Voituriez, D. . Sonsoles Mazorra Manrique de Lara, D. Ángel Torío López, D. Alberto Guanche Marrero, y los ahora glosados D. ${ }^{a}$ María del Carmen Sevilla González, D. Francisco Clavijo Hernández, D. ${ }^{a}$ María Victoria Sansón Rodríguez, D. José María Sainz-Ezquerra Foces y D. ${ }^{a}$ María Luisa Zamora Rodríguez, además del ya citado Dr. Morón. Todos -además de quienes no cito por falta de espacio, aunque no puedo dejar de hacerlo con mi compañero en la etapa de doctorandos, el profesor D. Guillermo Núñez Pérez- siempre tuvieron el tiempo que les solicité, y me centraron en mi formación y carrera académica; todos ellos dejan huella indeleble en mi pensamiento, y no sólo en el jurídico, y aprovecho estás páginas para expresar mi respeto y afecto hacia ellos.

Hacer votos porque regrese el imperio de la Corporación es como desear que mis jóvenes colegas -en realidad, ya todos lo son- puedan disfrutar de aquella Facultad de Derecho de la Universidad de La Laguna que el profesor Sainz de Bujanda supo describir como un lugar a modo de «la escuela de Rabindranath Tagore, en Bolpur, una 'morada de paz', un lugar remansado en el que encontrar tiempo para leer, para pensar, para dialogar y para escribir». ¿Cuánto esfuerzo y talento se dilapida burocratizando a nuestros profesores en lugar de incitarlos a la vida universitaria de ese leer, pensar, dialogar y escribir? Entiéndaseme bien: nuestros profesores ejercen esa vida universitaria $-y$, en más de una ocasión, con una formación que sanamente envidio-, pero lo hacen con más sacrificios que los que se nos imponían a «los antiguos», pues el marco regulatorio vigente los obliga a dedicar tiempo a lo burocrático -tiempo que siempre será excesivo- para formar sus curriculum con vistas a futuras oposiciones.

La Dirección de los Anales de la Facultad, ahora en las buenas manos del Dr. D. Andrés González Sanfiel, ha tenido el acierto de, en esa especie de cuerpo místico que formamos quienes compartimos Claustro, situarnos en el punto medio entre la aeternitas y el tempus al que aludía santo Tomás y aprovechar la instantaneidad de los Anales para dejar constancia en ellos de quienes, por una u otra razón, causaron baja en nuestra Corporación en el curso 2019-2020. Quienes fuimos convocados por nuestro director para redactar las semblanzas, y quienes las leemos, estamos dando testimonio del tiempo que cada uno de nosotros pasó con quienes fueron maestros y compañeros de Claustro. De todos ellos aprendimos de la Ciencia que cultivamos; con todos ellos compartimos tiempo para dialogar y dedicamos tiempo a reflexionar sobre nuestras conversaciones. Convivimos en un tiempo en el que cuando esos ingredientes cuajaban, entonces sí y sólo entonces, escribía- 
mos espoleados por el afán de saber y transmitir; eran tiempos felices en los que no teníamos que preocuparnos por ver en qué casilla encuadraba el artículo con vistas a futuros concursos.

Todos ellos nos devolvieron su conocimiento convencidos, como afirmaba Aristóteles, de que el conocimiento es lo único que no pierde valor al compartirlo. De esa generosidad hicieron su bandera, sabedores de que la única razón de ser del profesor universitario es adquirir y ayudar a formar conocimiento y, al mismo tiempo, compartirlo. Huyeron de pecar del individualismo que reflejaba Hegel: «cada uno es un fin para sí mismo y los demás no son nada para él»; no aspiraron a ser importantes, simplemente pensaron en ser útiles. Rindieron homenaje pleno a la máxima kantiana de "atrévete a pensar», e hicieron lo propio respecto de la llamada de atención de Horacio: «atrévete a saber». Lo demás es burocracia, tarea impropia de profesores, en la que se entierran horas que dedicadas al conocimiento hubieran sido más eficientes para la sociedad. Es esta, evidentemente, una reflexión personal que en modo alguno refleja necesariamente la opinión de mis ahora colegas de redacción de las glosas.

Si algo unió a los compañeros de quienes acompañamos breves reseñas es que, con Ortega y Gasset, localizaron la misión de la Universidad en la formación «de profesionales que aparte de su especial profesión, sean capaces de vivir e influir vitalmente según la altura de los tiempos».

Rilke, un poeta alemán, dijo que "hace falta una vida para escribir un verso»; nuestros compañeros no sólo han escrito -lo han hecho con abundancia y excelencia-, sino que también supieron leer y comprender los versos de nuestro Calderón de la Barca: «Y así, de modestia llenos, a los más viejos verás tratando de ser lo más y de aparentar lo menos». Ojalá su ejemplo nos sirva a nosotros para hacer lo propio, permaneciendo sus cuerpos espirituales en nuestro Claustro y que, cuando nos llegue la jubilación, hayamos sido dignos sucesores suyos en la cadena corporativa de la que todos somos importantes eslabones. 



\section{PROF. DR. FRANCISCO F. CLAVIJO HERNÁNDEZ \\ Catedrático de Derecho Financiero y Tributario}

Francisco Clavijo es un universitario cabal, dedicado por más de cuarenta años a su vocación de profesor de Derecho Financiero y Tributario y, más precisamente, en su querida Universidad de La Laguna, a cuya Facultad de Derecho se incorporó en 1974, tras haberse licenciado en ese mismo año en la Universidad de Granada.

El profesor Clavijo nació en Las Palmas de Gran Canaria, el 22 de abril de 1952. Se licenció en Derecho por la Universidad de Granada en 1974, doctorándose por la Universidad de La Laguna el 4 de octubre de 1976, obteniendo el Premio Extraordinario. Por Orden Ministerial de 27 de agosto de 1976, accedió por oposición a profesor adjunto numerario de Derecho Financiero y Tributario; y por Resolución del Rectorado de la Universidad de La Laguna de 14 de mayo de 1986, fue nombrado catedrático de Universidad de Derecho Financiero y Tributario.

En octubre de 1976 obtenía Clavijo su doctorado con Premio Extraordinario con la tesis doctoral El Impuesto sobre las Rentas del Capital; para en noviembre de 1977 ya ser nombrado, por virtud de concurso oposición, profesor adjunto de Derecho Financiero y Tributario.

A partir de ese inicio, el curriculum del profesor Clavijo recoge lo que ha dado a la estampa a través de sus libros y artículos; sin embargo, lo que queremos destacar en estas líneas es su perfil universitario.

Francisco Clavijo es, en mi opinión, paradigma del universitario generoso, que, habiendo renunciado a buena parte de los reconocimientos que su formación le hubiera deparado, encontró su lugar en la Universidad, contemplándola no sólo como el lugar del que haya de salir la tecnología que tanto nos aporta para nuestra vida material, sino que siempre ha centrado su atención en considerar su aula como el lugar idóneo donde considerar el futuro como algo que se prepara en el presente, formando a personas. Sus sólidos valores y principios le han llevado a poner en el altar de su dedicación universitaria a los alumnos, a quienes les ha inculcado, formado, responsabilizado, hecho partícipes, facilitado, complementado y orientado en su formación jurídica, por supuesto, pero también como personas.

Ha mantenido inquebrantable su sentido de lo que la Universidad ha de ser: claustro en el que han de ser los pilares esenciales educar, formar y sembrar inquietudes y valores; aunque en más de una ocasión haya de enfrentarse a un entorno en el que parece que a lo único que se da importancia es a una especialización profesional vacía de todo contenido valorativo. Y en ese enfrentamiento Clavijo siempre sale 
victorioso, porque para él en la Universidad sólo tiene cabida el saber culto; alcanzar ese saber es lo que explica que la Universidad merezca protección, porque es la institución social que asume el liderazgo en el desarrollo científico y técnico y porque, además, desde su irrupción en la historia, ha sido el instrumento de renovación y perfeccionamiento de la vida social desde el punto de vista de los valores humanos naturales. Nunca se dejó deslumbrar por el pragmatismo, y se ha mantenido fiel a los fines de la Universidad, rechazando de plano el saber que sólo persigue fines prácticos y que, como él dice, no pasa de ser un saber vulgar.

Somos muchos quienes en la Facultad de Derecho de la Universidad de La Laguna reconocemos en el profesor Clavijo una de las señas que han de adornar al universitario; nos referimos a su generosidad, pues para él el conocimiento no es algo que reserve para su erudición y hacer gala de la misma, sino que lo pone diariamente al servicio de sus alumnos y de quienes hemos compartido Claustro tanto en la Facultad de Derecho como en la de Económicas. Ha tenido claro a lo largo de su carrera académica que en la educación no se encierra la mera transmisión de un cuerpo inerte de conocimientos de una generación a otra, sino que se trata de un proceso en el que se incrustan la recepción, el crecimiento y el legado del saber de un grupo humano a sus sucesores. Como bien decía santo Tomás, «enseñar es dar vida a la ciencia en otro, ayudándolo a servirse de su razón natural», concluyendo en que "lo que hace el maestro es poca cosa, lo que hace hacer lo es todo». Clavijo se ajusta a estas máximas, convencido de que sólo compartiendo ese conocimiento y reflexionando con los demás podía alcanzar lo que para él siempre ha sido enseña: el conocimiento culto del Derecho.

Si algo caracteriza al profesor Clavijo es su convicción de que antes que cualquier adjetivo, el Derecho es, pura y simplemente, Derecho, lo que no es poca cosa. Se nos presenta ahí nuestro compañero como el más rendido conservador entre nosotros de las enseñanzas de su venerado profesor González Vicén, quien, junto a Xabier Zubiri, han modelado buena parte de su formación jurídica y personal. Creo en acertar al decir que su pasión ha sido buscar el camino para llegar a saber qué es Derecho, y en ese camino siempre ha buscado la guía en las palabras de don Felipe González Vicén.

Fue en don Felipe donde, precisamente, encontró Clavijo la clave que le ayudó a comprender y explicar una institución a la que ha dedicado buena parte de sus esfuerzos: el Régimen Económico Fiscal de Canarias. El exhaustivo estudio de los antecedentes históricos y de la evolución del REF le permitieron ser pionero en la explicación dogmática de las notas o rasgos estructurales que, por su carácter estable y constante, han definido y definen el REF de Canarias, rasgos que dedujo a través de los principios que históricamente lo han configurado y por medio de los cuales se ha conformado la conciencia jurídica sobre su propio contenido y naturaleza. A partir de ahí, llegó a la explicación jurídica del REF como institución, como un ente cerrado que puede considerarse in se y per se porque posee individualidad propia y que, como tal institución, es un concepto histórico por su vinculación esencial a una estructura histórica, caracterizado por su permanencia, lo que no obsta a que mude la regulación legal de sus elementos sin que ello implique la pérdida de su identidad. 
La segunda pasión en su labor investigadora la encuentra Clavijo en el Derecho tributario formal. En las ocasiones en que ha tomado la pluma para enfrentarse con los problemas que suscita nuestra disciplina en el ámbito procedimental, da buenas razones a quienes rechazan calificar a este sector como adjetivo. Sitúa la comprobación en el tradicionalmente denominado «procedimiento de liquidación tributaria», conectándola con la norma tributaria material y con las potestades para la aplicación de la misma, como hicieran Sainz de Bujanda, Albiñana García-Quintana y Palao Taboada, entre otros. Con ese proceder llega a tres importantes resultados: en primer lugar, identifica y deslinda entre sí las actividades de comprobación y de liquidación tributarias; en segundo lugar, descubre la estructura lógica interna de la actividad comprobadora; y, finalmente, esclarece las dudas que se han suscitado acerca de la naturaleza de la estimación indirecta.

Francisco Clavijo es, sin duda, de los profesores de la disciplina que han prestado más atención al estudio de la relación contabilidad-Derecho tributario. No en vano, la determinación en estimación directa de las bases imponibles requiere manejar eficazmente enormes volúmenes de datos y documentos que sólo la contabilidad puede suministrar y mucho ha reflexionado acerca de la compatibilidad inexcusable de las normas tributarias con la exigencia de la imagen fiel que se ha de predicar de las cuentas anuales. En los estudios que ha dedicado al Impuesto sobre Sociedades queda plasmada su convicción de que es imposible entender cabalmente este Impuesto si no se tienen en cuenta las implicaciones que en las normas tributarias tienen las normas contables. En el curso de Derecho Tributario, parte especial, en el que participó junto a los profesores Ferreiro, Martín Queralt, Pérez Royo y Tejerizo López, explicó con sumo detalle las implicaciones contables en el Impuesto sobre Sociedades, trasladando para el profano en contabilidad el juego de los ajustes tributarios en el resultado neto contable a fin de determinar la base imponible.

El profesor Clavijo fue feliz en su despacho universitario; sin embargo, no se ha refugiado en la comodidad de las aulas universitarias, sino que, en cuantas ocasiones se le reclamó, dio el paso al frente y asumió responsabilidades extraacadémicas. A diferencia de muchos, nunca ha ocupado un puesto Francisco Clavijo, sino que los ha servido, pues en los que se le designó siempre fue más allá del estricto cumplimiento de sus deberes, nunca se limitó a dejar pasar el tiempo. En este sentido, fue nombrado, el 13 de abril de 1981, magistrado suplente de la Audiencia Provincial de Santa Cruz de Tenerife. Posteriormente, por Acuerdo de 26 de octubre de 1989 de la Comisión Permanente del Consejo General del Poder Judicial, fue nombrado magistrado suplente del Tribunal Superior de Justicia de Canarias y reelegido en todos los ańos judiciales hasta el 2000, habiendo quedado adscrito durante ellos a la Sala de lo Contencioso- Administrativo del Tribunal Superior de Justicia (sede Santa Cruz de Tenerife). El 20 de julio de 2007 fue nombrado director general de Tributos del Gobierno de Canarias, puesto que desempeńó hasta el 4 de agosto de 2011.

Ha sido miembro de la Comisión nombrada por la Secretaría de Estado de Hacienda (Resolución de 30 de junio de 2000) para el análisis de los problemas de la aplicación de la Reserva para Inversiones en Canarias. Por Resolución de 1 de octubre de 2002 fue designado miembro de la Comisión nombrada por la Secretaría de Estado de Hacienda para el estudio del borrador del anteproyecto 
de la nueva Ley General Tributaria. Asimismo, ha sido vocal del Consejo para la Defensa del Contribuyente (Orden de 6 de noviembre de 2001). En la actualidad es presidente del Tribunal Económico-Administrativo del Ayuntamiento de Santa Cruz de Tenerife.

En el ámbito universitario, ha desempeñado las siguientes tareas: desde el 24 de enero de 1986 al 13 de febrero de 1987 fue secretario general de la Universidad de La Laguna. Desde el 13 de febrero de 1987 al 20 de febrero de 1989 fue decano de la Facultad de Derecho de la Universidad de La Laguna. Fue director del Departamento de Derecho Público y Privado especial y Derecho de la Empresa, cargo para el que fue elegido en febrero de 2016.

$\mathrm{Ha}$ recibido diversos premios y distinciones, de entre los que citamos la Encomienda de Isabel la Católica, que le fue concedida el 15 de enero de 2004. En 1999, el Colegio Oficial de Titulados Mercantiles y Empresariales de Santa Cruz de Tenerife le distinguió con el Premio Andrés Pérez Faraudo.

Ha participado en Congresos científicos, presentando comunicaciones y ponencias, de entre las que destacamos la Ponencia nacional al tema II («Los puertos, Zonas y Depósitos francos») que presentó en agosto de 1979 en las IX Jornadas Latino-Americanas de Derecho Tributario celebradas en Asunción (Paraguay). En mayo de 1984 presentó una Comunicación en las Jornadas de la Dirección General de lo Contencioso del Estado sobre las Haciendas Locales, mientras que en octubre de 1993 presentó una Comunicación al XX Congreso Nacional de la Asociación Española de Asesores Fiscales, celebrado en el Puerto de la Cruz (Tenerife).

Alberto Génova Galván

Profesor titular de Derecho Financiero y Tributario

\section{PROF. ${ }^{a}$ DR. ${ }^{a}$ MARÍA DEL CARMEN SEVILLA GONZÁLEZ \\ Catedrática de Historia del Derecho y de las Instituciones}

En septiembre de 2020, acabados los exámenes del curso, y por cumplir la edad correspondiente, se ha jubilado la profesora María del Carmen Sevilla González, catedrática de Historia del Derecho y de las Instituciones. Se ha jubilado en su Universidad, la Universidad de La Laguna, en la que ha permanecido, primero como estudiante, después como profesora, la mayor parte de su vida. Y se ha jubilado en una universidad de esas de las que Georges Steiner dijo: «las universidades son, desde su instauración en Bolonia, Salerno, o el París medieval, bestias frágiles, aunque tenaces». Universidad, fragilidad y tenacidad, en las sabias palabras de Steiner.

Si algo debe ser destacado de forma primordial de la vida universitaria de la profesora Sevilla es su condición de pionera en su sentido de persona que inicia la exploración de nuevas tierras o persona que da los primeros pasos en alguna actividad humana, en las definiciones que ofrece al respecto el Diccionario de la Real Academia Española. Y es que no puede negarse que haya sido la pionera en muchas sendas abiertas en la Universidad de La Laguna o que haya ido por delante en los más 
variados campos durante su larga vinculación con la misma. Y es que la profesora Sevilla fue la primera mujer contratada en la Facultad de Derecho, fue la primera lagunera de nacimiento en obtener el doctorado en Derecho en la Universidad de La Laguna, la primera lagunera de nacimiento en ser profesora titular y catedrática de la Facultad de Derecho, la primera mujer en ser directora de un departamento de disciplinas jurídicas, la primera mujer en ocupar el Decanato de la Facultad de Derecho y la primera mujer en pronunciar la lección magistral, en nombre de la Facultad de Derecho, en una ceremonia de apertura del curso académico. No cabe duda de que en su trayectoria académica ha sido precursora.

Otras dos notas deben ser puestas de relieve del extenso quehacer universitario de la profesora Sevilla: su constancia en la labor docente, que ha ejercido siempre desde su ya lejana incorporación al claustro de la Facultad de Derecho a comienzos de la década de los años setenta, teniendo siempre a su cargo grupos de alumnos, tanto en la asignatura de Historia del Derecho Español de licenciatura del Plan de Estudios de 1953, como en el triste y municipal sistema de asignaturas cuatrimestrales de los nuevos tiempos universitarios; y la intensidad de su labor investigadora que se ha manifestado en todo momento, desde su tesis doctoral sobre el Cabildo de Tenerife durante el siglo xviII, defendida en 1982, hasta la todavía inacabada producción científica manifestada en diversos libros, innumerables artículos de revista o participación en publicaciones colectivas sobre los más variados, y muchas veces complicados, temas de nuestro pasado histórico jurídico, pero especialmente en relación con la historia institucional española y europea. En esta labor investigadora debe ser destacada tanto la vinculación intensa al excelente magisterio del profesor Escudero, que ha servido de guía intelectual cercana y eficaz, como la concesión del Premio Nacional de Historia que obtuvo la obra colectiva sobre la monarquía en España, dirigida precisamente por el profesor Escudero y en la que participó la profesora Sevilla.

Una vez jubilada, sigue su vinculación con la Facultad a través de sus discípulos y de su interés por una materia como es la Historia del Derecho y de las Instituciones, que nos ha prometido, y ahí está cumpliendo su promesa, no abandonar.

Aurelio B. Santana Rodríguez Profesor contratado doctor

\section{PROF. ${ }^{a}$ DR. ${ }^{a}$ MARÍA VICTORIA SANSÓN RODRÍGUEZ Catedrática de Derecho Romano}

La vida laboral de M. ${ }^{a}$ Victoria Sansón Rodríguez ha tenido dos nortes: la enseñanza del Derecho Romano y la Universidad de La Laguna. Discípula de Juan Miquel, uno de los grandes romanistas españoles, captó lo esencial de su enseñanza para mantener la llama de la investigación en el Derecho Romano y posteriormente en el Derecho Comparado desde su incorporación a la Academia tras la finalización de sus estudios en 1979 . 
Su labor profesional como catedrática de Derecho Romano ha estado dedicada a esta materia tanto con sus publicaciones de repercusión nacional e internacional, como puede ser su monografía La transmisión de la propiedad, como a través de su participación en congresos nacionales e internacionales y miembro en diversos proyectos de investigación, lo que conlleva un estudio y actualización constante en las materias de aquéllos, como puede ser «La Tradición Romanística ante las grandes reformas del Derecho de comparaventa», de la Universitat Rovira i Virgili del Ministerio de Ciencia en Innovación, en el cual continúa trabajando tras su jubilación. Su respeto, admiración, colaboración y amistad con el profesor Antonio Fernández de Buján, quien ha sido colaborador incansable del área, especialmente tras la repentina pérdida del profesor Miquel, han dado un vuelco al área de Derecho Romano de nuestra Facultad.

El compromiso con nuestra universidad se ha reflejado asimismo en el desempeño de cargos de gestión, no siempre gratos pero imprescindibles para el desenvolvimiento de la Institución; así los ha ejercido tanto en la Facultad como en la Universidad en general: directora del Departamento de Disciplinas Jurídicas Básicas, directora del Secretariado del Vicerrectorado de Postgrado y nuevos Estudios de la ULL entre otros, lo que demuestra su compromiso, decisión y lealtad con nuestra Institución.

Junto con el profesor Miquel, impulsó el Seminario de Derecho comparado (ahora Seminario de Derecho comparado "Juan Miquel»), que tiene una trayectoria de XXII ediciones en nuestra Facultad y que sigue su prestigioso recorrido de la mano de la profesora Sánchez Jordán.

Su labor docente e investigadora, junto con el compromiso con la gestión, no nos debe hacer olvidar su semblanza como persona: su dedicación a los alumnos, su generosidad con sus discípulos, su entrega a la Universidad, su paciencia y delicadeza en todo momento con su entorno académico, su capacidad de trabajo, su discreción, honradez y amistad. Todas ellas virtudes que describen a una profesora que ha llevado, lleva y llevará la Universidad, la docencia y la investigación del Derecho Romano en sus venas.

María Etelvina de las Casas León

Profesora contratada doctora

\section{PROF.a MARÍA LUISA ZAMORA RODRÍGUEZ \\ Profesora asociada de Derecho Romano}

Si habláramos de María Luisa Zamora Rodríguez, quizás muchos de nosotros no la reconoceríamos, porque ella ha sido siempre Marisa, tanto para sus compañeros como para todas las generaciones de estudiantes que han pasado hasta el año 2019 en el grupo de tarde por nuestra Facultad. Desde que comenzó sus estudios en la Facultad, su interés se centró en el Derecho Romano. Tal es así que el profesor Miquel se dio cuenta de que era la persona idónea junto con su compañera 
y gran amiga de promoción, M. ${ }^{a}$ Victoria Sansón Rodríguez, para formar parte del área de Derecho Romano.

Y por supuesto que no erró en su decisión. Profesora asociada a tiempo parcial, María Luisa Zamora compatibilizó desde la finalización de sus estudios de Derecho hasta el año de su jubilación (también anticipada) su carrera docente en la ULL con la responsabilidad en cargos de gestión de todo tipo en la política canaria, aportando al alumnado no solo sus conocimientos de Derecho Romano, sino también su experiencia profesional. Y a pesar de las responsabilidades políticas que asumió, siempre estuvo pendiente de que los cargos políticos pudieran ser compatibles con la docencia, lo que ya nos indica su interés por la Universidad y nuestra Facultad.

Destacó siempre por su dedicación al alumnado, intentando facilitarles la comprensión de los conceptos jurídicos romanos en todo momento e intentando que fueran conscientes de la importancia del Derecho Romano en la actualidad. $Y$ de igual manera podríamos destacar su amabilidad con el resto del profesorado: siempre que necesitábamos algo de ella, Marisa no dudaba en ayudarnos en todo lo que podía.

María Etelvina de las Casas León Profesora contratada doctora 



\section{PROF. DR. MANUEL MORÓN PALOMINO \\ Catedrático de Derecho Procesal}

Manuel Morón Palomino nació en Sevilla, en el barrio y día de San Lorenzo, el 10 de agosto, si bien no seré yo quien contribuya a desvelar su año de nacimiento, en relación con el cual, y siempre con sonrisa perspicaz, le gustaba guardar la más estricta confidencialidad. Cursó sus estudios correspondientes a la Licenciatura en Derecho en la Universidad de Sevilla (promoción 1944-1949), obteniendo una calificación media de sobresaliente y matrícula de honor. Por lo que se refiere a la etapa de estudios de doctorado, el 4 de febrero de 1957 recibe el grado de doctor en Derecho con Premio Extraordinario.

Ya desde esta primera etapa, se inició en la labor docente en la Facultad de Derecho de la Universidad de Sevilla como profesor ayudante; en un primer momento (curso 1951-1952) en la Cátedra de Derecho Internacional y luego ya en la de Derecho Procesal, con el profesor Faustino Gutiérrez-Alviz Armario, de quien fue el primer discípulo y quien desde ese mismo momento se convirtió en su querido maestro. Pasados unos años, en 1958, mediante concurso oposición, ganó una plaza de profesor adjunto de Derecho Procesal en la misma Universidad de Sevilla. Solo dos años después, en 1960 y también tras la correspondiente oposición, toma posesión de la plaza de catedrático de Derecho Procesal de la Universidad de La Laguna. Salvo el período comprendido entre 1962 y 1967, en que, por concurso de traslado, se incorporó a la Universidad de Granada, Manuel Morón formó parte del claustro de profesores laguneros hasta que alcanzó la edad de su jubilación, si bien todavía, más allá de esta, fue nombrado catedrático emérito de Derecho Procesal de esta Universidad de La Laguna, siendo dicho contrato, previa acreditación de méritos, renovado sucesivamente hasta el año 2010, máximo permitido por la normativa. Todo lo cual arroja el dato de nada menos que cincuenta ańos de dedicación a la docencia, la investigación y los servicios institucionales en la Universidad española, de los cuales, cuarenta y cinco lo han sido en el desempeño de la Cátedra de Derecho Procesal de la Universidad de La Laguna. En definitiva, el Prof. Morón nos brindó la posibilidad de poder disfrutar de la presencia de todo un clásico del Derecho Procesal, a lo cual también contribuyó la fortuna de haber alcanzado tan avanzada edad y no de cualquier manera, sino en un estado de salud física y mental envidiables.

En el seno del área de Derecho Procesal de la ULL, tuvo ocasión de impulsar la investigación en su disciplina, dirigiendo numerosas tesis doctorales, de entre las que, al menos, deben ser destacadas, por un lado, la del Dr. López-Fragoso Álva- 
rez -hoy, como es sabido, catedrático de Derecho Procesal de esta Universidad-, y, por otro lado, la del Dr. Marchena Gómez, actual presidente de la Sala Segunda del Tribunal Supremo.

Por lo que se refiere a su actividad científica, debe citarse en primer lugar su tesis doctoral, realizada bajo el magisterio del Prof. Gutiérrez-Alviz Armario y que versó sobre La nulidad en el proceso civil español. La calidad de este trabajo es tal que, a pesar de datar de 1957, todavía hoy es citado (concretamente, por el Prof. Ramos Méndez) como una obra clave en los más altos foros de debate científico, como ha sido el caso, recientemente, de los Diálogos procesales organizados por la Fundación Manuel Serra Domínguez en formato telemático.

Dos de sus publicaciones merecen una mención especial, y ello ya no solo por su rigor científico, sino también por el cariño que a dichas obras le profesamos en el área de Derecho Procesal de la ULL: me refiero, por un lado, a su Derecho Procesal Civil. Cuestiones fundamentales, publicado en 1993 y que todavía hoy, no obstante la entrada en vigor de la Ley 1/2000, de 7 de enero, de Enjuiciamiento Civil, seguimos recomendando a los estudiantes, dada la gran calidad del trabajo realizado por el Prof. Morón en relación con los conceptos generales de la asignatura, lo cual, no solo constituye un desafío a la célebre máxima de Von Kirchmann, sino que confirma el carácter científico de la obra del Dr. Morón Palomino. Tampoco puedo dejar de referirme, por otro lado, a su monografía La nueva casación civil, que vio la luz en 2001. En ella, el brillante profesor da cuenta de una teoría propia sobre el citado recurso, defendiendo su carácter ordinario, así como la prevalencia del derecho subjetivo del litigante (ius litigatoris) frente a la función nomofiláctica y uniformadora de la jurisprudencia (ius constitutionis) del recurso de casación civil. A pesar del rigor dogmático con el que abordó esta cuestión, Manuel Morón no se detenía en el mero prurito teórico, sino que, antes al contrario, basaba la defensa de su tesis en la experiencia atesorada a lo largo de su dilatada trayectoria de ejercicio profesional como abogado.

Manuel Morón fue un estudioso del Derecho, que disfrutó realizando tal actividad. Mientras le fue posible, no dejó de venir por la biblioteca de la Facultad -cuyo personal lo acogía con gran cariño- para abstraerse durante horas en la lectura de las últimas novedades; y ello tanto en el ámbito académico, como en el de la práctica forense, a través del ejercicio de la abogacía. No puede dejar de citarse en este contexto el despacho que fundó y al que posteriormente se incorporó su gran amigo y compañero, el también exquisito Prof. José María Sainz-Ezquerra Foces, a quien ahora también queda unido por la triste coincidencia de compartir los dos el mismo año de fallecimiento.

Prueba de su compromiso institucional, asumió también responsabilidades de gestión como vicedecano de la Facultad de Derecho de la Universidad de Granada, llegando a ser también decano en la Facultad de Derecho de La Laguna, así como director del Aula de Práctica Jurídica durante varios años.

Fue nombrado miembro del Instituto Español de Derecho Procesal, del Instituto Iberoamericano de Derecho Procesal, designado académico correspondiente de la Real Academia de Jurisprudencia y Legislación. Incluso, en el año 2009, el Ministerio de Justicia le impuso la condecoración de la Cruz de la Orden de San 
Raimundo de Peñafort con distinción de primera clase, como reconocimiento a una carrera dedicada a la justicia.

Pero más allá de los indudables méritos hasta aquí reseñados, no pueden dejar de recordarse en estas líneas aquellos rasgos de su personalidad que más lo identificaban, en particular, el ánimo conciliador, siempre refractario al enfrentamiento, así como su elegancia y aspecto impecables..., al hilo de lo cual a buen seguro que a más de un lector le vendrá al recuerdo de aquella frase que con tanta convicción repetía y, lo más importante, llevaba a la práctica: «la Universidad es magisterio y señorío». Sin perjuicio de ello, Manuel Morón fue siempre un hombre libre e independiente, al cual le gustaba afirmar en contextos distendidos que él no formaba parte de lo que simpáticamente denominaba la ortodoxia procesal, sino de la más estricta heterodoxia, tal y como lo demuestra el hecho, ya referido, de que defendiera la naturaleza ordinaria del recurso de casación.

A pesar de que siempre nos acompańará su recuerdo amable, obvio es decir que lo echaremos de menos, pues con su marcha, inexorablemente, se cierra una etapa.

Alicia González Navarro

Profesora titular de Derecho Procesal

\section{PROF. DR. JOSÉ MARÍA SAINZ-EZQUERRA FOCES \\ Profesor titular de Derecho Romano}

José María Sainz-Ezquerra fue en el más amplio sentido del término un intelectual del Derecho. Pero un intelectual que hizo de la docencia su canon vital, puesto que su extenso conocimiento del Derecho Romano estuvo siempre a disposición de generaciones de estudiantes que recibieron su magisterio como uno de los fundamentos de su formación jurídica.

El profesor Ezquerra fue ante todo un enseñante, que hizo del estudio y la reflexión crítica el norte de su vida profesional, y que trasmitió a sus hijos que se desempeñan como profesionales del Derecho desde la admiración a su figura paterna.

José María Sainz-Ezquerra fue para muchísimos estudiantes laguneros un pórtico de excelencia hacia el mundo del Derecho. En primero de carrera, su exquisita educación y su amabilidad natural hicieron del inicio de los estudios de Derecho un placer compartido para los que recibieron su magisterio.

Conceptos complejos aparecían prístinos y claros, el elaborado hilo de su argumentación hacía que entre las personas que asistían a sus clases lo llamasen carinosamente el «cuentacuentos». Para muchas de estas personas, esos cuentos fueron la base de su formación jurídica y sin duda en su vida profesional dictar una sentencia, elaborar un informe, preparar un alegato o un recurso han manado de esas explicaciones que «engancharon» en el mundo del Derecho.

No es de extrañar este comportamiento en quien tenía como libro de cabecera el Quijote, del que sin duda siempre tomó como guía la caballerosidad, y cuyo despacho se adornaba con las fotografías de Ihering y Savigny, grandes entre los 
grandes del Derecho Romano y que al profesor Saínz-Ezquerra le mantenían siempre en esa perspectiva intelectual que adornó su docencia.

Fruto de sus capacidades fue su obra señera «La regula catoniana» y la «Imposibilidad de convalidación de los actos jurídicos nulos», reconocida a nivel nacional e internacional por su análisis exhaustivo y riguroso del tema y que ha quedado como obra de referencia en la materia.

Maria Etelvina de las Casas León Profesora contratada doctora 


\section{REVISORES}

María Dolores Adam Muñoz (Universidad de Córdoba)

Yésica Álvarez (Universidad de La Laguna)

Fernando Betancort Reyes (Universidad de La Laguna)

Miguel Ángel Boldova Pasamar (Universidad de Zaragoza)

Antonio Cayón Galiardo (Universidad Complutense de Madrid)

María del Pilar Diago Diago (Universidad de Zaragoza)

Lucas Sebastián de Erice Aranda (Universidad de La Laguna)

María José Fernández Pavés (Universidad de Granada)

Gabriel García Cantero (Universidad de Zaragoza)

Pedro González de la Fe (Universidad de Las Palmas de Gran Canaria)

Andrés González Sanfiel (Universidad de La Laguna)

Francisco Lorenzo Hernández González (Universidad de La Laguna)

Ulises Hernández Plasencia (Universidad de La Laguna)

Mar Jimeno Bulnes (Universidad de Burgos)

Arantza Libano Beristain (Universidad Autónoma de Barcelona)

José Luis Linares Pineda (Universidad de Girona)

Ángel Lobo Rodrigo (Universidad de La Laguna)

Cesare Maroli (Universitá di Bologna)

Ruth Martinón Quintero (Universidad de La Laguna)

José María Miquel González (Universidad Autónoma de Madrid)

Cristóbal Molina Navarrete (Universidad de Jaén)

María del Carmen NúŃEz LoZano (Universidad de Huelva)

Lucas Pérez Martín (Universidad de Las Palmas de Gran Canaria)

Javier Plaza Penadés (Universidad de Valencia)

Encarnación Ricart Martí (Universidad Rovira y Virgili de Tarragona)

Gloria Pilar Rojas Rivero (Universidad de La Laguna)

Eloy Ruiloba García (Universidad de Málaga)

Gumersindo Ruiz Bravo de Mansilla (Universidad de Málaga)

Ambrosio Sampere Flores (Universidad de Murcia)

María Elena SÁnchez JordÁn (Universidad de La Laguna)

José Luis SÁnchez-Parodi Pascua (Universidad de La Laguna) 
Aurelio Santana Rodríguez (Universidad de La Laguna)

Dulce María Santana Vega (Universidad de Las Palmas de Gran Canaria)

José María Souvirón Morenilla (Universidad de Málaga)

José Suay Rincón (Universidad de Las Palmas de Gran Canaria)

José Manuel Ventura Ventura (Universidad de La Rioja)

Francisco Villar Rojas (Universidad de La Laguna)

María Zambonino Pulito (Universidad de Cádiz) 
INFORME DEL PROCESO EDITORIAL DE ANALES DE LA FACULTAD DE DERECHO DE LA UNIVERSIDAD DE LA LAGUNA 38, 2021

El equipo de dirección se reunió a finales del mes de junio de 2021 para tomar decisiones sobre el proceso editorial del número 38 de AFDULL.

Estadística:

Núm. de trabajos recibidos: 8 .

Núm. de trabajos aceptados para publicación: 7 (87,5\%).

Media de revisores por trabajo: 2 .

Media de tiempo entre envío y aceptación: 3 meses.

Media de tiempo entre aceptación y publicación: 12 meses.

Los revisores varían en cada número, en atención al tema de los trabajos presentados. 



\section{NORMAS DE SELECCIÓN DE ORIGINALES PARA SU PUBLICACIÓN}

EN LOS ANALES DE LA FACULTAD DE DERECHO DE LA ULL

(Adoptadas por el Consejo de Redacción en su sesión de 9 de abril de 2018; pendientes de ratificación por la Junta de la Facultad de Derecho)

Primera. La revista se publica en formato digital, en un número anual, con dos fascículos semestrales a través de la plataforma de gestión de revistas on line de la Universidad de La Laguna: http://revistas.webs.ull.es/index.php/derecho. Los trabajos que se presenten al proceso de selección para su publicación deberán cumplir las siguientes normas:

a) Plazo y forma de presentación. La revista tiene permanentemente abierta su convocatoria de propuestas de publicación. Las propuestas podrán ser sometidas a consideración por sus autores a través de la plataforma de gestión de revistas on line de la Universidad de La Laguna: http://revistas.webs.ull.es/index.php/derecho.

b) Autores. Solo podrán presentar trabajos en la revista aquellas personas que reúnan la cualidad de tituladas en alguna de las enseñanzas universitarias oficiales de grado, máster y doctorado, o categorías equivalentes. Los autores deberán identificar su categoría académica y/o profesional, así como cuál es la institución a la que pertenecen.

c) Temática. Los trabajos deben ser investigaciones de contenido jurídico.

Excepcionalmente y de manera subsidiaria podrán incluirse trabajos de materias afines si los miembros del Consejo de Redacción asistentes unánimemente así lo consideran.

d) Estructura y formato de los trabajos.

I. Para la sección Artículos: los trabajos no deben exceder de los 60000 caracteres con espacios (unas 20 páginas) y tendrán un título (en español e inglés), como mínimo tres palabras clave (en español e inglés) y un resumen (en español e inglés). No deberá incluirse ni sumario ni bibliografía final. Las propuestas de publicación se presentarán en archivo en formato editable: Word o rtf.

II. Para la sección Comentarios, de legislación y jurisprudencia: los trabajos no deben exceder de los 30000 caracteres con espacios (unas 10 páginas) y tendrán un título (en español e inglés), como mínimo tres palabras clave (en español e inglés) y un resumen (en español e inglés). No deberá incluirse ni sumario ni bibliografía final. Las propuestas de publicación se presentarán en archivo en formato editable: Word o rtf.

III. El formato del texto principal será Times New Roman, a espacio y medio, tamaño de letra 12; y para las notas a pie de página es Times New Roman, a un espacio y con tamaño de letra 10. Las normas para las citas son las siguientes: A) artículos de revistas. Ejemplo: SaAvedra Ruiz, J., «La iniciativa del tribunal en el acto del juicio oral», Cuadernos de Derecho Judicial, n. ${ }^{\circ} 10,1994$, p. 13 y ss. B) libros/monografías. Ejemplo: Ortells Ramos, M., El proceso penalabreviado, Comares, Granada, 1997.

e) Idioma. Los trabajos deberán estar escritos en lengua española, o en alguna lengua extranjera de relevancia en el ámbito jurídico siempre que la revista cuente con revisores que conozcan la lengua extranjera y sean expertos en el área de conocimiento de la propuesta presentada. En todo caso, el título, las palabras clave y el abstract deberán presentarse en espańol e inglés. 
f) Originalidad de los trabajos. Todos deben ser inéditos y no deben estar pendientes de publicación en otra revista o libro.

Segunda. La presentación de un trabajo en la revista Anales de la Facultad de Derecho de la Universidad de La Laguna conlleva el conocimiento y la aceptación de las siguientes normas por parte de los autores:

1. Es condición para la publicación que el autor o autores ceda(n) a la revista, en exclusiva, los derechos de reproducción, así como que consientan su inclusión en bases de datos, catálogos, bibliotecas, índices o servidores que permitan la mayor difusión de las investigaciones. Si se producen peticiones de terceros para reproducir o traducir artículos o partes de los mismos, la decisión corresponderá al Consejo de Redacción.

2. De las opiniones sustentadas en los trabajos firmados responden exclusivamente sus autores. La publicación de los diferentes artículos no implica adhesión ni conformidad de la revista con las opiniones mantenidas por los autores.

Tercera. Se asignará uno o dos evaluadores, preferiblemente externos, por cada uno de los originales presentados, según la materia sobre la que versen los mismos, para que informen en el plazo que se establezca sobre la conveniencia de su publicación. La evaluación será anónima en todo momento, de manera que los autores no conocerán quién evaluó su trabajo ni el evaluador conocerá quién es el autor.

Cunta. Pese a ser la evaluación anónima, en el caso de concurrir causa de abstención en alguno de los miembros propuestos o cuando este lo proponga de manera motivada, se podrá designar a otro/s evaluador/es experto/s en la materia que se evalúa.

Quinta. Cada evaluador rendirá su informe teniendo en cuenta los siguientes criterios: la calidad y rigor de los argumentos presentados; la oportunidad y relevancia del artículo; la creatividad, metodología, propuestas y aportaciones; así como la adecuación a las normas de publicación. Los informes tendrán carácter confidencial y reservado.

Sexta. Una vez transcurrido el plazo para presentar los informes de evaluación, se reunirá el Consejo de Redacción, al que se dará cuenta del punto en el que se encuentra el proceso, llevándose a cabo la valoración del resultado de las evaluaciones. Cuando exista contradicción entre los informes emitidos, el Consejo de Redacción designará a un tercer experto en la materia, para que proceda a una nueva evaluación.

SÉptima. Se trasladará al autor el resultado de la evaluación y, en su caso, las modificaciones sugeridas por los expertos, con la advertencia de que el Consejo de Redacción se reserva el derecho a no publicar el original presentado cuando no se observaren las modificaciones propuestas por los expertos.

Octava. Cuando algún miembro del Consejo de Redacción fuere autor del original presentado deberá ausentarse de las votaciones. 


\section{Servicio de Publicaciones \\ Universidad de La Laguna}

